A Framework for Emergence:

Embracing Ecological Principles in Post-Industrial Landscapes

Sandra Wojtecki

Master of Architecture Thesis

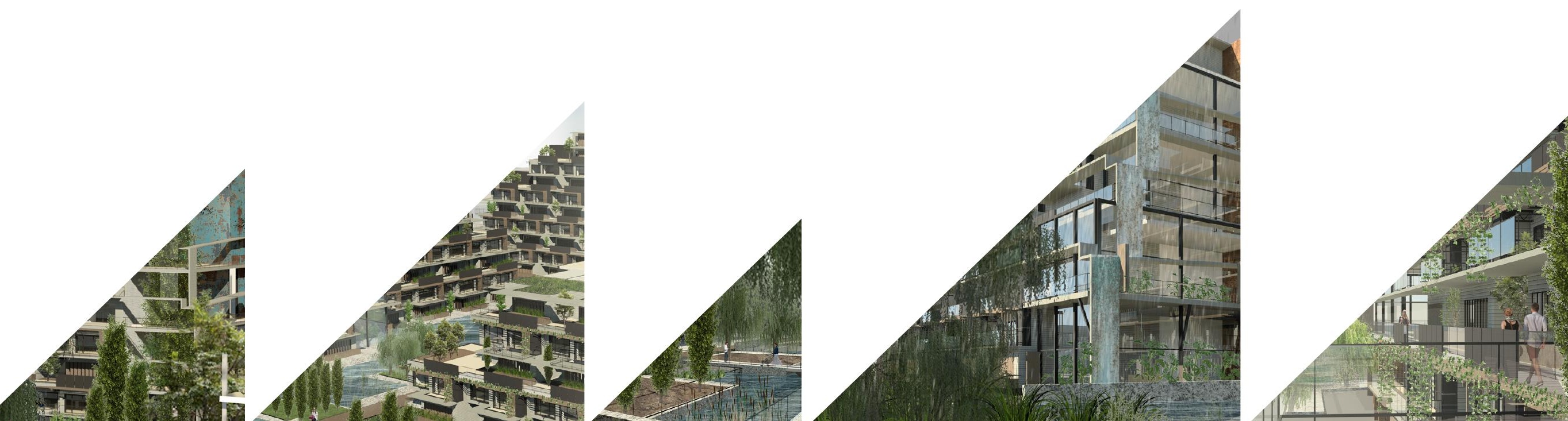



A Framework for Emergence:

Embracing Ecological Principles in Post-Industrial Landscapes

by

Sandra Wojtecki

Bachelor of Architectural Science

Ryerson University, Toronto Ontario, Canada, 2009

A Design Thesis Project

Presented to Ryerson University

In partial fulfillment of the

requirements for the degree of

Master of Architecture

Toronto, Ontario, Canada, 2016

@ Sandra Wojtecki 2016 

Author's Declaration:

I hereby declare that I am the sole author of this thesis. This is a true copy of the thesis, including any required final revisions, as accepted by my examiners.

I authorize Ryerson University to lend this thesis to other institutions or individuals as for the purpose of scholarly research.

I further authorize Ryerson University to reproduce this thesis by photocopying or other means, in total or in part, at the request of other institutions or individuals for the purpose of scholarly research.

I understand that my thesis may be made electronically available to the public. 



\title{
A Framework for Emergence: Embracing Ecological Principles in Post- Industrial Landscapes
}

\author{
Master of Architecture, 2016
}

\author{
Sandra Wojtecki
}

\section{Master of Architecture \\ Ryerson University}

The Anthropocene, a name proposed for our current geologic age, is a phrase that describes how universal conditions on earth are changing by human impact- faster than geological occurrences. The shape of our landscapes, the composition of our soils and bodies of water, and even atmospheric particles are impacted by human activities. We see the dominating mindset most evidently in our urban environments, as the efficiency of roadways guide the shape of the landscape, and the forces of economics shape our skyline. Unlike a biological organism that emerges from the flux and flow of available materials and nutrients, we permanently affix ourselves on the earth and take beyond our resource share. This thesis explores how architecture can respond to the needs of density by reconceptualizing our practical and temporal relationship to nature through embracing the fundamentals of ecological principles, formulating a framework for the built environment in post-industrial landscapes. 



\section{Acknowledgements:}

I would like to thank my supervisor, Dr. Mark Gorgolewski, for his unyielding optimism and inspiration to continually move forward. I always left our meetings encouraged and energized by new ideas, motivated by our shared interests for the work to reflect a greater purpose.

I would like to thank my second reader, Leila Farah, for her tough but necessary critiques that forced me to find an intellectual rigor. I would also like to thank my third reader, Masha Etkind, for her perspective on the bigger picture.

I would like to thank all of my colleagues in the Master of Architecture program for your friendship, as well as for all of the unforgettable experiences we got to share.

Lastly, I would like to dedicate this book to my parents for their support and unconditional love. Thank you for supporting everything that I do, I am forever grateful. 
Authors Declaration

Abstract

\section{Acknowledgements}

Table of Contents

\section{List of Figures}

\subsection{Our Place in Nature}

1.1 The Anthropocene

1.2 Historic Trends of the Human and Nature Divide

1.3 The Reality of Interdependence

1.4 Current Trends in Urbanization and Population Growth

1.5 The Need for Synthesis

\subsection{Defining the Balance: Spatial Ideologies}

2.1 Interrelation

2.11 Ecological Footprinting

2.12 BedZED

2.2 Integration

2.11 Biophilic Cities

2.12 Ken Yeang's Biointegrative Design

2.3 Separation

2.31 The Ecomodernist Manifesto

2.32 Paolo Soleri's Hexahedrons

2.33 Buckminster Fuller's Dymaxion House I

2.3 Conclusions
3.1 Nature-City - WORKac

3.2 The Garden in the Machine - Studio Gang Architects

3.3 60 Richmind Housing Co-operative - Teeple Architects

3.4 Lessons from Singapore

4.0 Opportunities in Post-Industrial

Landscapes

4.1 Overview

4.2 Site

4.3 Site Analysis

\subsection{Intervention 1.0}

5.1 A Framework for Emergence

5.11 Self-Cleanses

5.12 Emerges in a Succession

5.13 Forms to Face the Sun

5.14 Forms to Capture Water

5.15 Builds upon Existing/Local Materials 69

5.16 Expresses Changes through Time

73 
6.0 Intervention 2.0

6.1 Framework Reevaluation 8।

6.11 Site $\quad 83$

6.12 Building Form $\quad 85$

6.13 Daily Time $\quad 89$

6.14 Seasonal Time 93

6.15 Yearly Time and Beyond $\quad 103$

\subsection{Conclusions}

7.1 Conclusion $\quad$ II5

7.2 Design Critiques $\quad 115$

7.3 The Future of Architecture $\quad 116$

Appendix: Supporting Research

Local Density Comparison $\quad$ II8

$\begin{array}{ll}\text { Models } & 119\end{array}$

Research Exploration I2I

$\begin{array}{ll}\text { Pre-design Proposal } & 125\end{array}$ 


\section{List of Figures:}

Fig. 1: North America from space

Source: http://www.dailymail.co.uk/news/article-2170422/Revealed-The-stunning-images-Europe-wastes-energy-polluteslight-Africa-South-America-Asia-darkness.html

Fig. 2: Our Place in Nature: A Timeline Source: Author

Fig. 3: Urbanization trends and projections.

Source: United Nations. (2014). World urbanization prospects : the 2014 revision : highlights. Retrieved from https://esa. un.org/unpd/wup/Publications/Files/WUP2014-Highlights. pdf

Fig. 4: Trends ranging from rural to urban settlements, that propose sweeping changes to existing ways of life. Source: Author

Fig. 5: Ecological Footprint by country per person, 2007 Source: Ecological Footprint Network, WWF Living Planet Report 2014, page 32

Fig. 6: BedZED Eco-Village in the UK

Source: https://en.wikipedia.org/wiki/BedZED

Fig. 7: BedZED's solar panels, wind cowls, and exterior walkway. Source: http://www.zedfactory.com/\#!bedzed/diwjq

Fig. 8: Beginning of ramp that makes a continuous spiral around the building

Source: Author

Fig. 9: "Eco-cell" rainwater collection feature within Solaris Source: Author

Fig. 10: Photo of 3D model of Solaris

Source: Author

Fig. 11: Paolo Soleri's Hexahedron cities
Source: http://luxurycommunism.tumblr.com/image/39118546095

Fig. 12: Buckminster Fuller and a Dymaxion House prototype Source: Fracalossi, Igor. (2013). AD Classics: The Dymaxion House / Buckminster Fuller. ArchDaily. Retrieved from http:// www.archdaily.com/401528/ad-classics-the-dymaxionhouse-buckminster-fuller

Fig. 13: Triangle of Spatial Ideologies Source: Author

Fig. 14: Triangle of Spatial Ideologies - Project placements Source: Author

Fig. 15: Precedents within Triangle of Spatial Ideologies Source: Author

Fig. 16: Collage of low-rise housing types Source: Bergdoll, B. \& Martin, R. (2012). Foreclosed: rehousing the American dream. New York, N.Y: Museum of Modern Art.

Fig. 17: Arial view of Nature-City proposal Source: Bergdoll, B. \& Martin, R. (2012). Foreclosed : rehousing the American dream. New York, N.Y: Museum of Modern Art.

Fig. 18: Collage of various housing typologies Source: Bergdoll, B. \& Martin, R. (2012). Foreclosed : rehousing the American dream. New York, N.Y: Museum of Modern Art.

Fig. 19: Ground floor perspective

Source: Bergdoll, B. \& Martin, R. (2012). Foreclosed : rehousing the American dream. New York, N.Y: Museum of Modern Art.

Fig. 20: Phytoremediation infrastructure

Source: Bergdoll, B. \& Martin, R. (2012). Foreclosed: rehousing the American dream. New York, N.Y: Museum of Modern Art.

Fig. 21: View from railway line

Source: Bergdoll, B. \& Martin, R. (2012). Foreclosed : rehousing the American dream. New York, N.Y: Museum of Modern Art. 
Fig. 22: View from community space

Source: Bergdoll, B. \& Martin, R. (2012). Foreclosed : rehousing

the American dream. New York, N.Y: Museum of Modern Art.

\section{Fig. 23: Community garden}

Source: https://www.canadianarchitect.com/wp-content/

upload

\section{Fig. 24: Open core strategy}

Source: https://www.canadianarchitect.com/wp-content/

upload

Fig. 25: View from street

Source: http://www.archdaily.com/85762/60-richmond-housing-cooperative-teeple-architects

Fig. 26: Section describing nutrient cycle

Source: http://www.archdaily.com/85762/60-richmond-housing-cooperative-teeple-architects

Fig. 27: Exterior community space

Source: http://www.archdaily.com/85762/60-richmond-housing-cooperative-teeple-architects

Fig. 28: The port of Singapore

Source: Author

Fig. 29: Interlace development by OMA

Source: Author

Fig. 30: Highway ecological infrastructure

Source: Author

Fig. 31: Pedestrian walkway

Source: Author

Fig. 32: Sky Habitat by Moshie Safdie

Source: Author

Fig. 33: Facade of Oasia Downtown

Source: Author
Fig. 34: Khoo Teck Puat Hospital

Source: Author

Fig. 35: Hotel Parkroyal by WOHA Architects

Source: Author

Fig. 36: Hotel Parkroyal

Source: Author

Fig. 37: Map of the City of Toronto, 1882

Source: http://oldtorontomaps.blogspot.ca/2013_02_01_archive.html

Fig. 38: West Toronto Railway line, from Queen Street to Dupont Street.

Source: Author

Fig. 39: Project lot with partially demolished industrial

building in tact.

Source: http://www.blogto.com/upload/2009/07/20090714-

tower12.jpg

Fig. 40: Cultural context.

Source: Author

Fig. 41: 3D Site material matrix.

Source: Author

Fig. 42: Site Analysis

Source: Author

Fig. 43: Site plan proposed by Castlepoint Numa

Source: http://castlepointnuma.com/project/perth-sterlingrevitalization/

Fig. 44: Six Principles for a Framework for Emergence

Source: Author

Fig. 45: Project Summary - Construction through occupation

Source: Author 
Fig. 46: Site massing development.

Source: Author

Fig. 47: Site Condition, October 2015

Source: Author

Fig. 48: Example of poplar tree

Source: https://www.thetreecenter.com/tulip-poplar/

Fig. 49: Example of willow tree

Source: https://findingstrengthtostandagain.wordpress.

com/2011/04/26/lessons-from-the-willow-tree/

Fig. 50: Existing Urban Tree Canopy Map

Source: http://gis.w3.uvm.edu/utc/Reports/TreeCanopy_Report_Toronto.pdf

Fig. 51: Diagrammatic Site Plan, Year 0

Source: Author

Fig. 52: Diagrammatic Site Plan, Year 2

Source: Author

Fig. 53: Diagrammatic Site Plan, Year 4

Source: Author

Fig. 54: Diagrammatic Site Plan, Year 6+

Source: Author

Fig. 55: Site Render, Year 0

Source: Author

Fig. 56: Site Render, Year 2

Source: Author

Fig. 57: Site Render, Year 4

Source: Author

Fig. 58: Site Render, Year 6+

Source: Author
Fig. 59: Shadow Studies on Sept. 21st

Source: Author

Fig. 60: Arial view of project proposal

Source: Author

Fig. 61: Balcony Space

Source: Author

Fig. 62: Diagram of thermal buffer zone operation

Source: Author

Fig. 63: Fig. 59: Unit Layouts and One Bedroom + Den Render Source: Author

Fig. 64: Energy Reduction Chart

Source: Author and Matthew Gelowitz, a summary of findings from energy analysis report

Fig. 65: Diagram of surface water flow

Source: Author

Fig. 66: Trellis sunshading devices

Source: Author

Fig. 67: Site plan diagram showing impervious surfaces Source: Author

Fig. 68: Green roof gardens

Source: Author

Fig. 69: Sectional perspective

Source: Author

Fig. 70: Water Reduction Chart

Source: Author and Matthew Gelowitz, a summary of findings from energy analysis report

Fig. 71: Material strategies

Source: Author 
Fig. 72: Material sources

Source: Author

Fig. 73: Thatch screen

Source: Author

Fig. 74: Community hearth

Source: Author

Fig. 75: Material Selection Chart

Source: Author and Matthew Gelowitz

Fig. 76: Building in Winter

Source: Author

Fig. 77: Building in Summer

Source: Author

Fig. 78: Ground Floor Plan

Source: Author

Fig. 79: Third Floor Plan

Source: Author

Fig. 80: Fifth Floor Plan

Source: Author

Fig. 81: Axonometric Wall Section by Matthew Gelowitz Source: Matthew Gelowitz

Fig. 82: Axonometric Wall Section by Matthew Gelowitz Source: Matthew Gelowitz

Fig. 83: A Framework for Emergence redeveloped Source: Author

Fig.84: Conceptual re-development through time Source: Author

Fig.85: Site excavation strategy

Source: Author
Fig.86: Conceptual re-development through time

Source: Author

Fig.87: Revised Arial Perspective

Source: Author

Fig.88: Site Plan

Source: Author

Fig.89: Revised Unit Layouts

Source: Author

Fig.90: Daylight control

Source: Author

Fig.91: Exterior walkway during the day

Source: Author

Fig.92: Exterior walkway at night

Source: Author

Fig.93: Greenhouse interor spring/fall

Source: Author

Fig. 94: Greenhouse interior summer

Source: Author

Fig. 95: Rainfall render

Source: Author

Fig.96: Ground floor commercial spaces, warmer months Source: Author

Fig.97: Ground floor commercial spaces, colder months

Source: Author

\section{Fig. 98: North view}

Source: Author

Fig.99: Variation of facade configurations 
Fig.100: Typical residential / multi-use section Source: Author

Fig. 101: Dry landscape plan / early development Source: Author

Fig. 102: Dry landscape render / early development Source: Author

Fig. 103: Wet landscape plan / late development

Source: Author

Fig. 104: Wet landscape render / late development Source; Author

Fig. 105: View from train

Source; Author

Fig. 106: View southern pathway

Source: Author

Fig.107: Sectional perspective, early built phase Source: Author

Fig.108: Sectional perspective, 5 years in

Source: Author

Fig.109: Sectional perspective, post-apocalypse Source: Author
Appendix Figures:

Fig. 1: Local comparisons

Source: Author

Fig. 2: Material model

Source: Author

Fig. 3: Site model

Source: Author

Fig. 4: Community test size configurations

Source: Author

Fig. 5: Community ecological footprint estimations by commuting distance

Source: Author

Fig. 6: Space taken up per person

Source: Author

Fig. 7: Chart of high and low potential for each community type

Source: Author

Figures 8-21: Arial site view progressions

Source: Author 



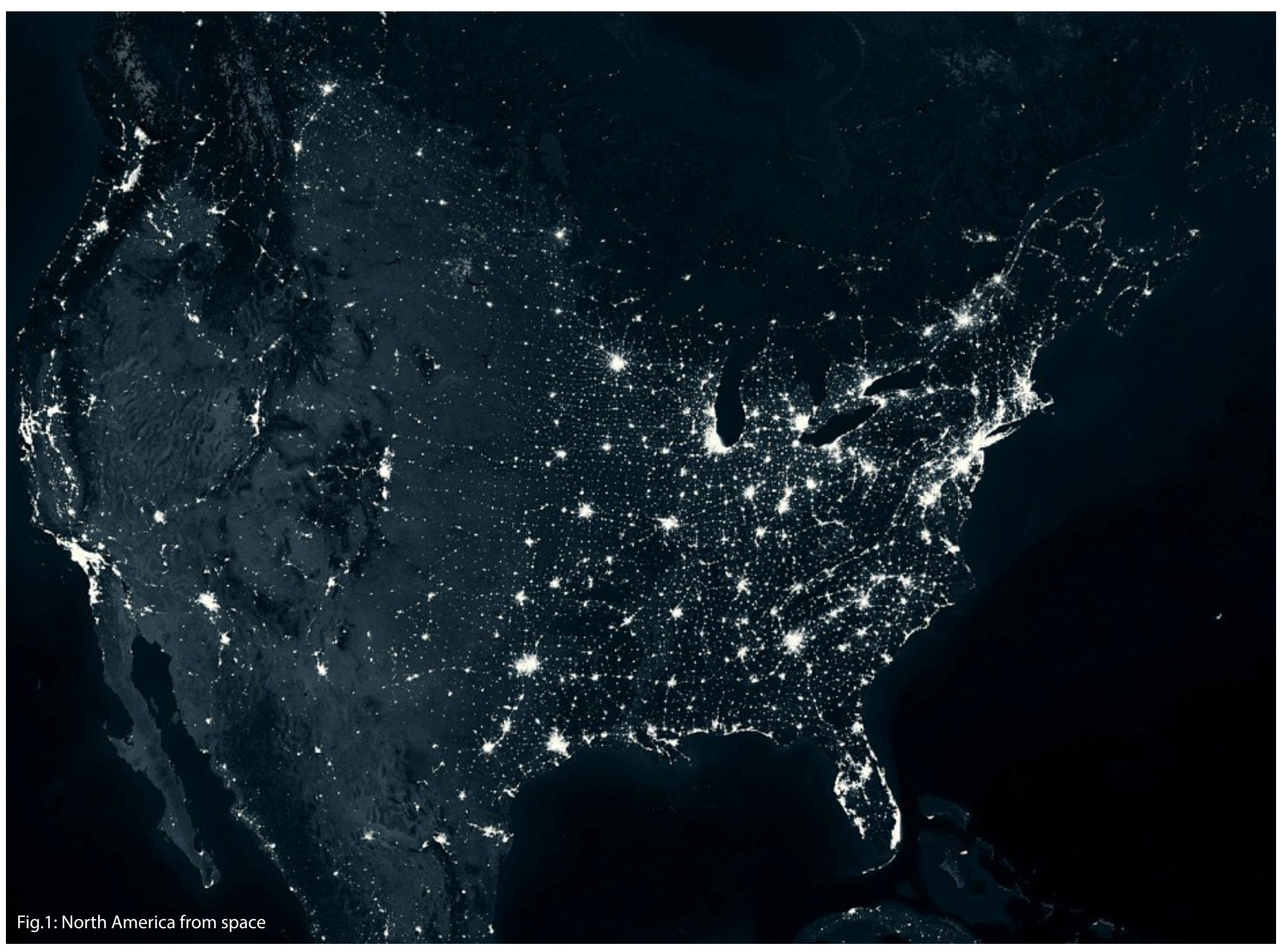




\subsection{Our Place in Nature}

\subsection{The Anthropocene}

The age of the Anthropocene, where humans are taking over the future projection of environmental patterns on our planet, poses one of the most significant moral conundrums faced today by humankind. Is the planet ours to utilize, by any means of extraction or procurement, to fulfill our every desire as long as were alive? Or is everything that we do justifiable, as long as it does not jeopardize the future needs of mankind, regardless of the floral or faunal biodiversity we may be eliminating? Alternatively, should we condemn our lives to the utmost efficiency, minimization, and resourcefulness to protect the planet? Current projections suggest that we have chosen the former, as the alternative has no compelling qualities although many would agree that the protection of our planet is of importance. Our degree of control and independence from the confines of nature in the past has taken on a life of its own, as we steadily speed onward to achieving our personal and collective economic goals, ignorant of our destructive path.

In conjunction, one cannot speak about the rise in environmental depletion and degradation without also acknowledging the phenomenon of globalization. Encompassing all social, economic, political, environmental, cultural, and technical aspects of life, developments in each of these realms has led to the functioning of a planetary society. Issues concerning our environment are no longer confined to any boundaries, but now have implications at the scale of the globe. As we become more united as a global civilization, the need to stay grounded in its literal and metaphorical sense has become ever more pressing. The reality of our interdependence with the earth seems to have gotten lost amidst the complexity.

Realizations of the global scale of our destructive path are relatively new in the spectrum of human civilization. One of the earliest proponents in the environmental discourse within globalization is arguably Rachel Carson and her book Silent Spring, published in 1962. Her focus on the proliferation of pesticides highlighted the devastation that the use of chemicals could cause, explaining their biological ability to harm existing ecosystems and human health. Her book sparked an understanding of the interconnected nature of our biosphere, and began to point out the comprehensive extent of harm that human endeavors can have (Carson, 1962). Another significant mark in the change of perception about the earth was in 1972, when the first photograph of the planet in its entirety was taken from Apollo 17. Given the name "The Blue Marble", the earth was seen for the first time as a singular, finite entity. A sense of preciousness and fragility was recognized on a global scale, cascading the beginnings of a series of nation wide conferences that sought to align goals about the common future of the planet.

Since then, architects have been faced with and continue to be faced with the issue of how to adapt our architectural strategies to these values. For the first time in the spectrum of human evolution, we have an understanding of our dramatic influence in shaping natures course, primarily through the unin- 
tended consequences of our actions.

\subsection{Historic Trends of the Human and} Nature Divide

Throughout history, humanity's reliance on nature has shaped a profound relationship that reflects the belief of our place in the universe. As the source of our livelihood, the ebbs and flows of natural occurrences were often a matter of life or death, which inherently united humanities understanding of our existence to nature. As humanity progressed towards an increasing control over nature, so did the understanding of our place in the universe. Historical references provide us with an understanding of how nature has shifted with different revolutions, from an entity that once had stability and order, to one that is viewed now as something requiring adaptability and resilience (Reed \& Lister, 2014, 3). Within Chris Reed and Nina Marie Lister's conceptual explanation of the transformation of the field of ecology, can be placed evidence of this change. Daniel B. Botkin describes the conceptual shifts that happened up until after the industrial revolution, beginning with man's understanding of nature as divinely created. As man's control over nature was limited and life highly dependent on its fluxes, it was seen to have the power and the ability to determine the future. The organic view began to acknowledge its depletion, as something that has the ability to reach a peak and then age (Botkin, 1990, 19). The development of physics began to mark the shift of power from nature to human beings (Evernden, 1992, 30), as an understanding of the laws of nature began to have calculable, tangible qualities. Botkin's view of nature as machine is reflective of this change, where the newly understood universal rules and invention of machinery put humans in control, able to manipulate their environment at an unprecedented scale and level of output. Discoveries in botany and computer science furthered humanities understanding of the natural world, as something we are able to not only control in the present, but predict for the future. (Botkin, 1990, 31) It wasn't until 1935 that the word "ecosystem" was founded as a term by Sir Arthur Tansley, which is the study of organisms in relation to their environment. This coined term describes a fundamental change in consciousness, at least from a scientific perspective, that living things are a product of their environment, and need to be studied within the spectrum of their surrounding contexts.

Neil Evernden believes that the discoveries and inventions leading up to the information revolution created a shift in humanity that began to assign meaning to nature to fulfill human functions (Evernden, 1992, 35). Though it seemed that nature had always fulfilled human functions, the shift from satisfying basic human needs to social and economic functions suggests an even greater divide between the inputs of natural resources to the outputs of human needs created by the machine. The emergence of a complex view of ecology as another form of relationship with cultural aspects such as demographics, politics, or climate (Reed \& Lister, $2014,4)$, seemed only natural, as the connection of these aspects back to nature had become increasingly complex and divided, creating a need for a specific area of study to comprehend it. 


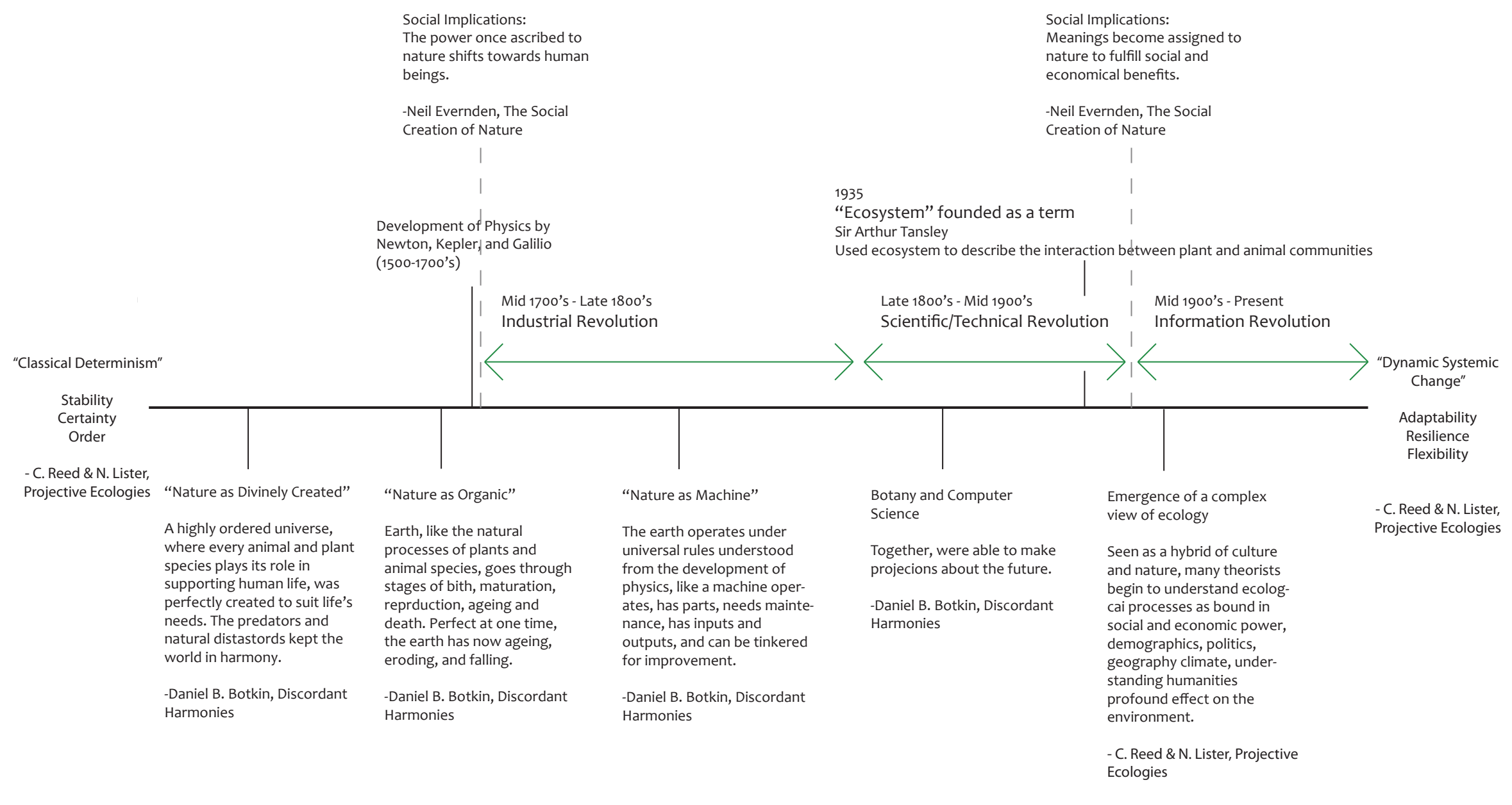

Fig.2: Our Place in Nature: A Timeline 
Within the progression of divide between man and nature, an understanding has grown that the idea of stability, certainty, and order is no longer the prevailing conceptual intellection. With our ability to change the processes and outcomes of naturally occurring phenomena, we have understood the reaction of nature against our exploitations. Today we know that it is prone to tipping points and can exhibit a chaotic chain of events, and therefore requires management that acknowledges its need for adaptability and resilience.

Through our evolved understanding of how nature operates, we have placed ourselves at the highest level of power, able to control and manipulated every facet of its output. Even within its less predictable patterns of change, we engineer our systems to resist the fluctuation of what can't be controlled. Instead, this thesis asserts that the lessons learned through the progress of human growth suggest that we should instead become participants in nature's rhythms and patterns, and that a hierarchy cannot be practiced against a system from which we are derived.

\subsection{The Reality of our Interdependence}

David Suzuki is a famous proponent of the reality of our interdependence with nature at a physiological and sacred level. Throughout history, the increased indirect connection of our relationship with nature has left us with an empty understanding of our very identity. He quotes ecopsychologist Sarah Conn in saying "We do not live on the earth, we live in it" (Suzuki, 2007, 263). He believes that we have lost the sense that our flesh and blood are made up of the earth, that we are literally made up of its particles. The way we have grown to utilize nature through industrial and mechanical processes by means of scientific understanding is responsible for creating this illusion of separation. According to Suzuki:

"Reductionism focuses on isolating, separating, and controlling fragments of nature and has been a powerful way of knowing, providing profound insights into the properties and behaviour of that bit of nature. But in focusing, we lose sight of the context, rhythms, patterns and cycles within which that part belongs (Suzuki, 2007, 259)".

We do not associate any risk to our own health with a tree that is dying outside, or an animal species that no longer exists in our neighbourhood. These things do not affect us directly, but the reasons why they might be dying or disappearing may be a reflection of an underlying problem of natural deterioration, a side effect that may appear to us with an increase in food prices on our grocery bill. Often, we are left with the problem of mending our mistakes instead of preventing them, because of the complex level of connections it takes to identify an environmental problem with its source. An example is a benchmark set by the 2015 UN Climate Summit in Paris to make sure the global temperature does not reach the dangerous increase level of $2^{\circ} \mathrm{C}$ (Kestler D'Amours, 2015, 1), a relationship between carbon emissions that has only come into recent realization. The growing need to recognize the ancient virtue of the reality of our interdependence with nature is a concept that may be able to bridge our actions with consequences more directly.

According to Bill Devall and George Sessions 
in their book Deep Ecology, two types of foundational concepts must be present in order for humankind to align their interests with the natural world. The first is self-realization, where spiritual growth or identification must go beyond the ego of the self and extend to the greater community (Devall \& Sessions, 1985, 45). The greater community refers to other human beings, and extends to the community of other living creatures as well as the non-living world, to encompass things such as the landscapes we inhabit. We often identify ourselves as within our own body or with our close family relations, but the reality is that we are an extension of the even greater picture of the earth itself, and not separate entities placed into a foreign world.

The second foundational concept is defined as biocentric equality, which is the position that all members of the ecosphere have intrinsic worth (Devall \& Sessions, 1985, 46). This definition acknowledges the biological nature of predation, but asserts that humans do not have a dominant importance in a spiritual sense over the rest of the living and nonliving world.

All of the above principles express the interrelated nature of our identity and being to everything around us, a concept that is more often present with our false identification to material goods. Our relationship to consuming material goods and preoccupation with material representations of affluence has created a false association between the realization of self by consuming excessive amounts of materials and energy, creating a never ending strain on our resources.

Another key component that links us to the reality of our interdependence with nature is our evolving existence; always engaged in a moment in time and in a constant dialog with the cycle of life. Our built environment is a part of the evolving nature of materials and organisms on the planet, as we are interrelated with the inevitable rise and fall of the process of growth and deterioration.

\subsection{Current Trends in Urbanization and} Population Growth

The anthropocentric age has been propelled in recent years by the mass increase in human habitation patterns. Urbanization and population growth are happening at a scale unprecedented in history, posing the question of how must we design differently in light of these new conditions. Up until 1945, it took the planet 10000 years to reach a population of 2 billion people (Gore, 2006, 38). Now, the current population of 7.4 billion people (World Population Clock) has tripled that number in a matter of a person's lifetime. Never before has there been such a strain on environmental resources as there is today.

According to the United Nations, $55 \%$ of the global population currently resides in urban areas, while in North America, $82 \%$ of the population resides in urban areas (UN, 2014, 1). This is up from $30 \%$ of the world living in urban areas in 1950 , and in 2050 , it is predicted that $66 \%$ of the world population will live in urban areas (UN, 2014,1). These trends indicate the future extent of the impacts that humans will have on the composition of the planet. Designing for an equilibrium with nature and its resources 
Fig. 3: Urbanization trends and projections needs to consider not only the conditions of today, but the projections of the conditions of the future. Even though $90 \%$ of the increases in population will be primarily concentrated in Asia and Africa (UN 2014, 1), our design thinking should acknowledge the globalizing trends.

These trends stress the importance of rethinking how to house the population in a way that can uphold a high quality of life. Inevitably, densities we considered normal in the past will have to be re-assessed based on how equitably we can divide space among the population, ensuring access to all of life's amenities without destroying the natural environment through massive urban concrete jungles. Perhaps suburban neighbourhoods and single detached dwellings will have to become a thing of the past, and a version of high rise living will continue to grow to be the norm. Architectural infrastructure today needs to have the capacity to evolve into the needs of the future.

Urban and rural population of the world, 1950-2050

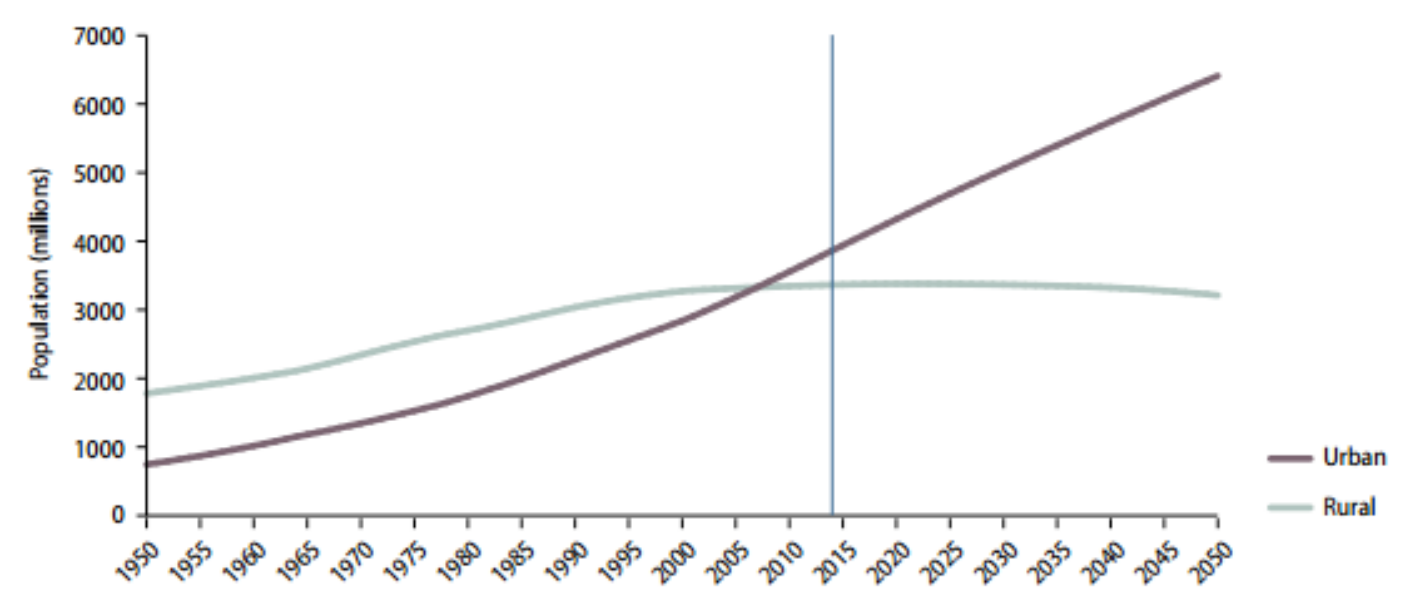

\subsection{The Need for Synthesis}

An important parameter in planning for the future development of cities is that we cannot re-imagine everything anew, despite the fact that our existing infrastructure was not designed in an anticipation of the environmental issues we would face today under the stress of urban development and population growth. Often, it is easier to imagine ideal communities when they are separated from existing conditions, and have a clean drawing board of how things should be. Many contemporary projects take on the approach of leaving or getting rid of existing conditions in the city, and re-imaging projects in places away from or segregated from the existing urban environment. Displayed to the right are some approaches to re-envisioning living standards in response to existing conditions. Whether it be a rural re-imagination of the urban network, or one that is set in an urban environment, each of these ideas came out of a particular set of issues and opportunities of their time. For Frank Lloyd Wright's Broadacre City, he developed the idea out of the freedom and autonomy the automobile would provide, for each person to enjoy an idyllic part of the countryside. In contrast, Plan Voisin came out of the need to re-envision how the issues of poor living conditions could be dealt with, and proposed the destruction of a large portion of the historic Parisian urban fabric.

Though these utopian ideas have their place in forwarding advanced ideas about re-densifying life on earth, they do not necessarily consider the important connection of existing urban conditions, which with their already developed organization, can 
provide many potential energy and resource saving benefits. Today, it is unrealistic to consider ideal societies outside of existing cities as we cannot ignore the immense social, economical, and functional benefits they already provide. This is especially true in developed nations like Canada, considering we have one of the highest global footprints of any nation on earth.

The way we design for future densification

An antithesis to the crowded conditions of the city, and arising out of the autonomous opportunties of the automobile, Broadacre City idealizes a world where each family would be given one acre of land.

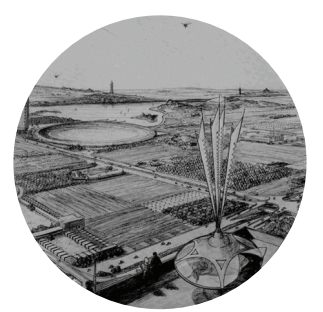

Frank Lloyd Wright- Broadacre City
Eco Villages, like the one in Ithaca, are a product of grassroots initiatives that form intentional communities centered around an ecologically sustainable way of life, evolving around a supportive cohousing structure.

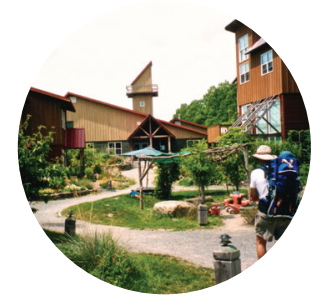

Eco Villages - eg. Ithaca

needs to consider a way of weaving or grafting new possibilities within the existing urban realm, especially to take advantage of reducing the ecological expenses related to transportation. Instead of proposing sweeping changes to what exists, we need to consider better alternatives that work in tandem with existing conditions. This way of looking at bridging existing conditions with new ways of living is the typological focus of this thesis.

Garden Cities were an urban planning method evoling around self-contained communities surrounded by greenbelts. Envisioned as satelites towns around central city, they would all be connected by road or rail.

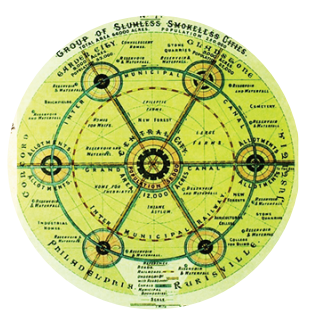

Ebenezer Howard Garden Cities
A contemporary perspective, Europa City combines an idyllic landscape and city network into one, using the project to create an elevated earthwork, a response to the needs of density and open space in one.

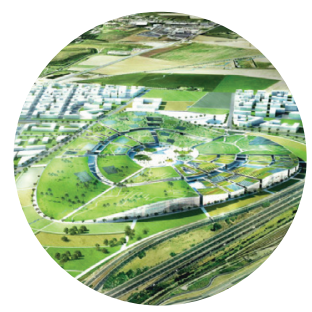

BIG architects - Europa City
A radical proposal to demolish parts of downtown Paris, Plan Voisin responded to the dense and poor living conditions of the city, proposing high rises that free up the ground plane and provide light and air.

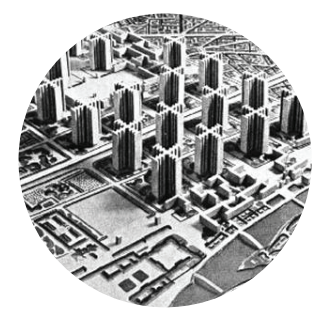

Le Corbusier - Plan Voisin

\section{RURAL}

\section{URBAN}

Fig. 4: Trends ranging from rural to urban settlements, that propose sweeping changes to existing ways of life. 


\subsection{Defining the Balance: Spatial Ideologies}

There are many different positions about how an equilibrium between nature and human activities can be achieved, and the question is especially critical considering the latest trends in urbanization and population growth. In the broadest sense, this is classified as ecological design. Sim Van Der Ryn defines ecological design as "any form of design that minimizes environmentally destructive impacts by integrating itself with living processes" (Van Der Ryn, $2007,18)$. In essence, it is the philosophy that if a building can integrate with living processes, they will have less of an overall environmental impact. According to David W. Orr in the book Ecological Design, ecological design is a part of one half of the definition of what makes up "sustainable design". The other half is what he calls technological sustainability, which is the approach that "every problem has either a technological answer or a market solution. There are no dilemmas to be avoided, no domains where angels fear to tread (Van Der Ryn 2007, 4)". Essentially, it is the view that planets problems can be fixed while maintaining the systems we currently have in place. Ecological sustainability on the other hand is "the task of finding alternatives to the practices that got us in trouble in the first place; it is necessary to rethink agriculture, shelter, energy use, urban design, transportation, economics, community patterns, resource use, forestry, the importance of wilderness, and our central values (Van Der Ryn, 2007, 5)".

The question remains how exactly these things should be re-thought. According to the
Oxford Dictionary, the definition of ecology itself is the relation of organisms to one another and to their physical surroundings, which explains the ability of the term to be used to explain a wide range of definitions. It also explains the terms ability to be used in a wide range of scales. Living processes happen at many levels, ranging from the cell to the organism, and up to the ecosystem, bioregion, and biosphere. In conjunction, the "integration with living processes" could be conceptualized at the level of a household, community, city, country, or the planet.

In studying various precedents and the thinking behind what drove their designs, three main ideologies appear to be present, and have been categorized based on the positions they take in regards to density and the interaction between man and nature. In other words, they are variations within the spectrum of "relations" within the definition of ecology. This section describes these principles, and some key projects that exemplify their concepts.

These have been categorized as interrelation, integration, and separation, and can be visualized as three principles on extreme ends of a triangle. They define how density and the relationship between humans and nature; both its physical presence and its resources, can be conceptualized. In the context of the ideas of this thesis, these ideologies form three ways of thinking that have to be mediated in a successful architectural project. This thesis asserts that too narrow of a thinking into one principle results in the negligence of the others, as they all form valuable conceptual frameworks into how a balance of density and resources can be achieved. 


\subsection{Interrelation}

The first principle, interrelation, or a ratio approach, looks at the relationship between nature and humans as a spatial balance that has associative, rather than physical spatial requirements. The idea is that as long as there is a proper relationship between resource use and the space required to provide that resource, there is no specificity about a physical relationship. As a simplified example, if a city is sustainably utilizing a forest to provide its wood products, it doesn't matter if the forest is far away, near the city, or intertwined into the urban fabric, as long as the relationship at an associated level exists in a healthy balance. However, a wide variety of factors need to be taken into account to determine if a healthy balance is being achieved, which ecological footprinting begins to define.

\subsubsection{Ecological Footprinting}

Ecological footprint calculations are one way of looking at design and design choices in a way that equates a person's impact on the environment in relation to the space that is needed to provide the resources they use. It provides a measurable account of the biotic levels that are needed to be maintained so that they can provide continued support for human life. It is also measured on a global level, meaning that consumption levels are equated with a division among the world population, and can determine who is consuming beyond their equitable share.

According to the Global Footprint Network, this equilibrium is determined by taking the 12.6 billion hectares of what they have determined is productive land or sea, leaving $10 \%$ for wildlife, and dividing the rest by the population of people on the planet (Desai, 2010, 16). The average footprint of hectares per person is the determined amount of productive space that an individual is designated, which accounts for the land required for farming, forestry, and fisheries (Desai, 2010, 17). According to the current world population of 7.4 billion (World Population Clock), this would amount to 1.5 hectares per person. This biologically productive percentage of land provides us with the resources we need such as forestry products, food, or ocean space required for fishing, as well as the amount of land we need to absorb the pollution we create to have the trees we need to absorb $\mathrm{CO}_{2}$. It also takes into account the amount of land needed for something to be produced sustainably, for example, 25 hectares of water for fishing are needed to produce 1 ton of fish per year in a way that can sustain the fish population (Desai, 2010, 17). In other words, it is the equivalent of "one planet living", meaning we only need one planet to provide all of our needs at sustainable levels. Ecological footprints can be determined for a person, country, or any given area or demographic, and can be used to compare the amount of consumption people use to what their fair share of the global resources are. When the ecological footprint is higher than the sustainable average, a person or community is over consuming beyond the naturally renewable capacity of the planet. When the carrying capacity is exceeded, it means that our resources are not able to renew themselves at the rate that we use them, and we end up deteriorating their levels. The carrying capacity of the planet was 
estimated to have reached the peak of its sustainable level in the mid 1970's (Desai, 2010, 17), and we have since been consuming at unsustainable levels.

Another way of looking at the results of the data is to equate a person or a nations consumption with how many planets it would theoretically take to support their lifestyle. If everyone in the world had a footprint of 1.5 hectares, then we would be living in a sustainable equilibrium with the planet, where our resource needs are matched with the time it takes for the sources to sustainably renew themselves. If everyone had a footprint of 3.4, twice the amount designated per person and the footprint of a country like Croatia, we would need two whole planets for the earth to renew its resources at sustainable levels.

The results of ecological footprint data have many implications towards how architecture can play a role in helping to reduce footprints. By looking at what creates a large ecological footprint, architects can begin to deal with the greatest contributors, which in most cases, are carbon emissions.

According to the Global Footprint Network, Canada's current Global Hectare Footprint is 8.2, meaning we use 5.5 times over our equitable share of the earth's resources. Interestingly, our biocapacity per capita is 16 Global Hectares because of the vast amount of resources available in Canada. Nationally, we only use about half of our countries biocapacity, but conceptualized globally if all of earth's resources were owned collectively, we use far beyond our equitable portion.
Fig. 5: Ecological Footprint by country per person, 2014

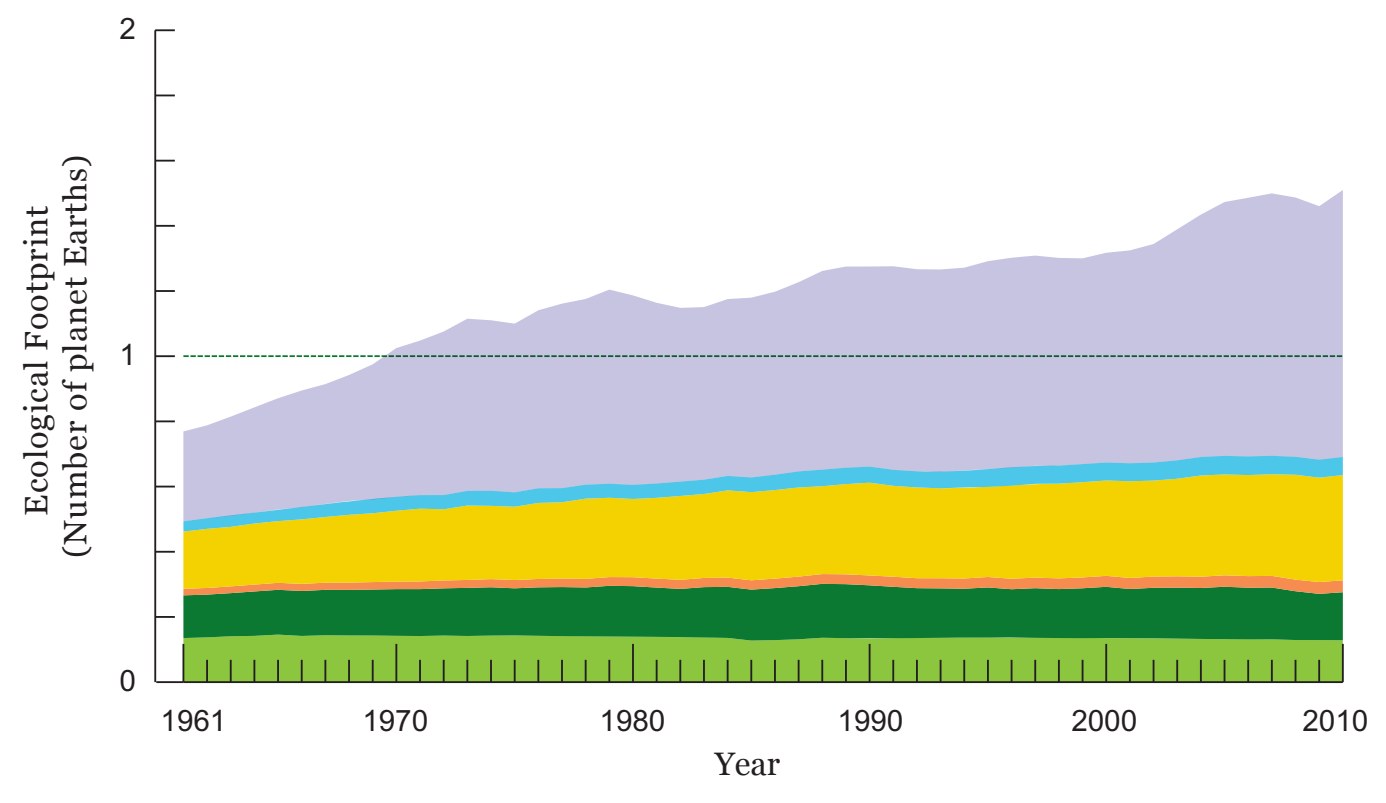
component (1961-2010)

Currently, the largest single component of the Ecological Footprint is the carbon component (53 per cent) (Global Footprint Network, 2014).

Key

\begin{tabular}{|l}
\hline Carbon \\
Fishing grounds \\
Cropland \\
Built-up land \\
Forest products \\
Grazing products \\
\hline
\end{tabular}




\subsubsection{BedZED}

The goal of much of the realm of sustainable architecture falls under this category, where a building tries to reduce the level of resources it requires and attempts to lessen its ecological footprint. Whether it's a point system method such as LEED or other quantitative ways at looking at data like Ecological Footprinting, these methods align with the purpose of the principle of interrelation which is to lessen the ratio of impact that humans are having on the planet's resources.

BedZED is an example where the idea of designing with ecological footprints formed a clear strategy for the design. In particular, the project set a focus of looking for ways to achieve one planet living, meaning to lessen the ecological footprints of its occupants to the current world average of 1.5 hectares per person. In its design stages, targets were set based on lessening the most critical components of a typical UK footprint, as well as complying with statuary targets established by the government. (Bioregional, 5)

BedZED is an ecovillage style development, located in south London in the UK. It was lead by a project team of Bill Dunster and his architectural office, together with Peabody Trust and the Bioregional Development Group (Fry, 2006, 27). The project, comprised of 99 residential units and 1450 $\mathrm{m}^{2}$ of office space, was designed in a way that would first maximize passive heating strategies, and then capitalize on on-site renewable energy sources.

Considering the UK's current three planet equivalent footprint and the fact that carbon emissions are the largest component, strategies that would lessen carbon reductions were considered first. One of the greatest contributors to carbon emissions are vehicles, leading the designers to think about siting first and the ecological costs of commuting. The site planning process considered being close to amenities to support resident's lifestyles in regards to how they would use transportation. In addition, a car club was created to encourage residents to avoid owning a private vehicle. (Bioregional, 5)

Throughout the design stages, another primary focus in regards to carbon reduction was on how to use the least amount of energy possible within the building's operation. Various methods were employed such as creating a highly insulated and air tight envelope, using wind coils to provide ventilation that lessen the reliance on a mechanical system, utilizing solar panels, or by selecting the highest level of energy efficient appliances and fixtures (Fry, 2006, 29).

Fig. 6: BedZED Eco-village in the UK

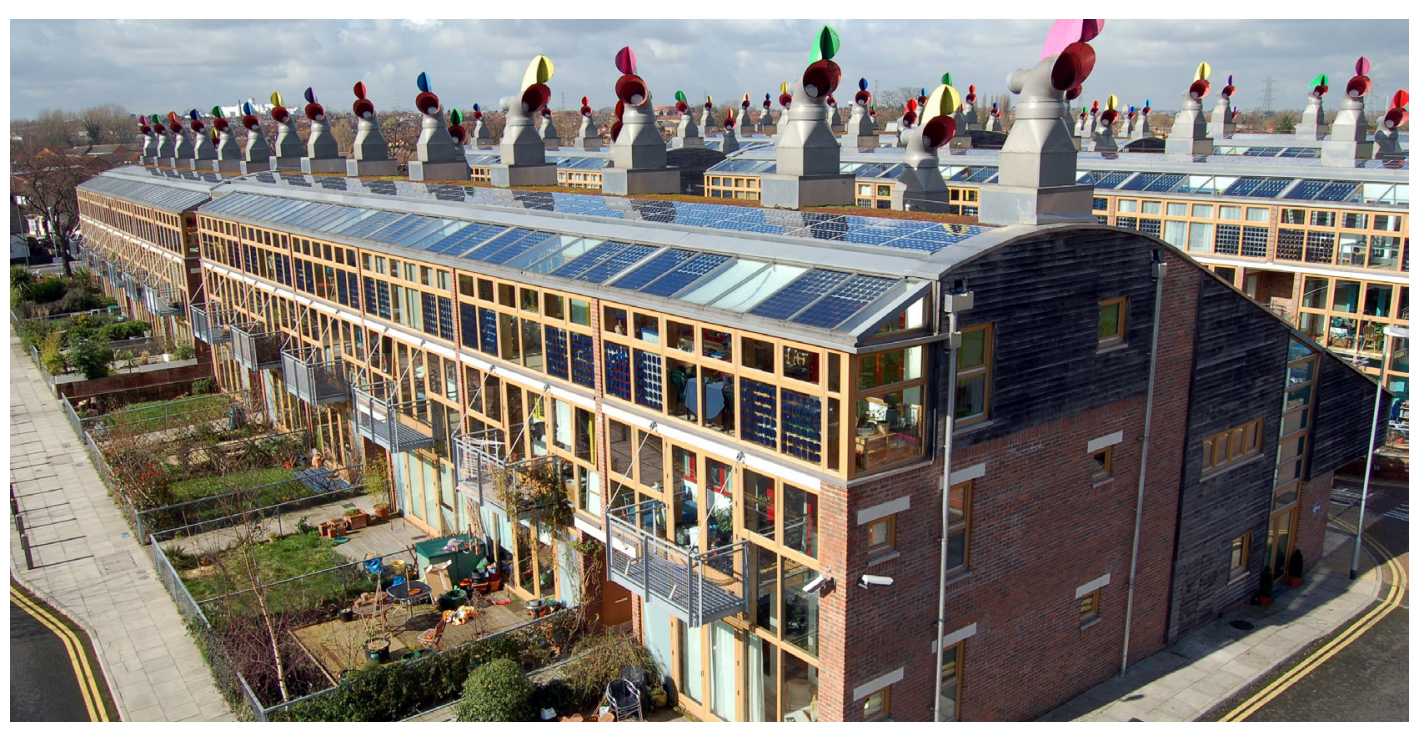


Fig. 7: BedZED's solar panels, wind cowls, and exterior walkway

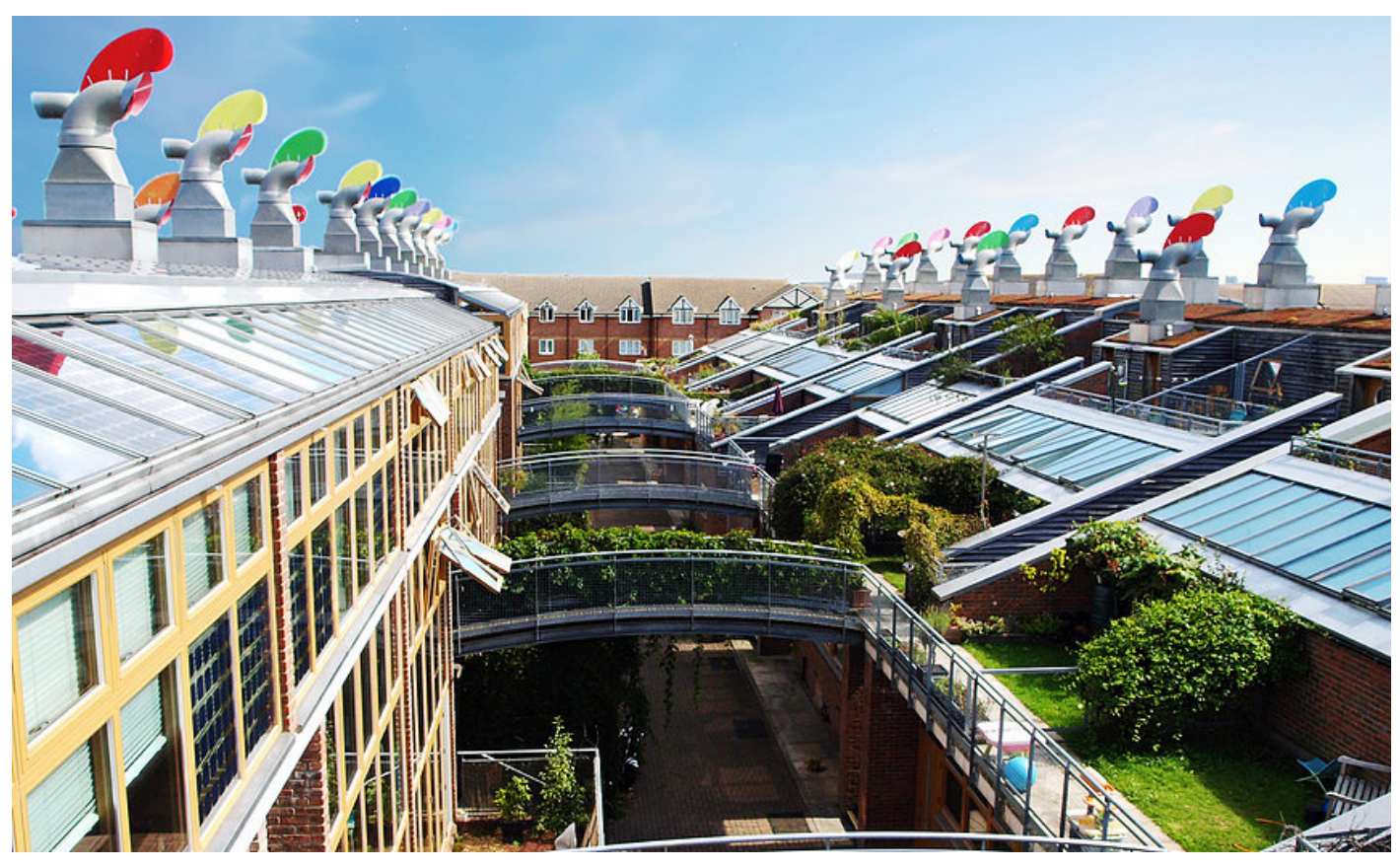
employs strict recycling standards for the users to follow. This reduces the reliance on virgin materials and can have direct impacts on the category of forest
In more indirect ways, the building attempted to contribute to a lesser footprint by taking the byproduct of nearby forestry industries, and using their wood chip waste as a biomass fuel source for space and water heating (Fry, 2006, 29). Although this system was one of the infamous failures of the project due to its maintenance costs that could not be justified for the project scale (bioregional, 5), one of its goals would have been to mitigate carbon offsets from alternative energy uses and use a forest by-product that would otherwise become waste.

Lastly, the building uses some recycled materials for its construction including recycled floorboards, and the management of the building products.

Bioregional's Publication "BedZED seven years on" provides a post-occupancy evaluation on how effective the design's strategies were at lessening the resident's footprint. The method for this analysis was the Resources and Energy Analysis Programme (Bioregional, 13), which rely's on residents to accurately report aspects of their lifestyle that make impacts on their ecological footprints beyond their built environment, such as the amount of meat they have in their diet, or the amount of air travel they do.

Overall, the analysis concluded that a typical BedZED resident's living standards equated to a value of 2.6 "planet equivalents", while a keen resident, someone that contributed a significant amount of person effort in tandem with the building technologies while assuming all technological features of the building are working, achieved a planet equivalent score of 1.7 (Bioregional, 39). In comparison to a baseline, a comparable building has a score of 2.9 planet equivalents, making the average BedZED resident's score $89 \%$ more efficient and the keen resident's score $57 \%$ more efficient (Bioregional, 39). Although these statistics demonstrate a significant impact on a resident's ecological footprint, their target of one-planet living has still not been achieved. 


\subsection{Integration}

The second principle of integration embodies another type of relationship between the connection of humanity with nature. It suggests that a complete harmonization with the natural world is the most effective way of leading the human Anthropocene into a direction that is sensitive towards the environment. This ideology sees humans and nature as one, and under this perspective, our built environment should reflect this in spatial terms.

\subsubsection{Biophilic Cities}

Backing up this theory is the idea that a key to human health is our contact with nature. E. O. Wilson, a famous biologist, explains that "For more than 99 percent of human history people have lived in hunter-gatherer bands totally and intimately involved with other organisms. ... In short, the brain evolved in a biocentric world, not a machineregulated world"(Wilson, 1984, 30). Consequently, his research suggests that we have an innate connection to other living things, and that our livelihood depends on facilitating this continued interaction. E.O. Wilson coined the term biophilia and described it as "the innate tendency [in human beings] to focus on life and life-like processes. To an extent it is still undervalued in philosophy and religion, our existence depends on this prosperity, our spirit is woven from it, hope rises on its currents" (Wilson, 1984, 1). To imagine a world where trees are only valuable for their shading and carbon offsets, or an animal species for the way they provide for a human resource, is to completely undermine biodiversity for biodiversity's sake.

Timothy Beatley, a researcher on sustainable cities, makes a further interesting connection between how we cannot possibly care for the things we do not know. In his classes, he has experimented with giving his students a questionnaire of identifying images of local flora and fauna. Unsurprisingly, the results are always quite low. In a metaphor connecting this to the concept of love, he states that a relationship cannot possibly flourish with a person that you cannot name. He concludes that if students can't name their local flora and fauna, they simply cannot possess the caring attitude towards them that environmental stewardship requires. (Beatley, 2011, 12) The concept is simple: can you care for something if you don't even know it exists?

If nature was an integral part of our architectural and urban fabric, we might be able to bridge these concerns. According to Beatley, a biophilic city is one that sees the physical integration of nature as a key component to a city's design for the purposes of our innate need for connection, rather than prioritizing the agenda that typically focuses on saving energy or conservation (Beatley, $2011,12)$. He also emphasizes that this idea often gets confused with city planning strategies that aren't necessarily green in a literal sense- things such as compact transportation planning, the creation of bike networks, etc. Although those idea's form a part of the bigger picture, the idea that differentiates a biophilic city from a "smart" or "sustainable" city is that it is engaged with nature itself - rather than elements that deal with the treatment of nature at an associated level (Beatley, 2011, 13). 


\subsubsection{Ken Yeang's Biointegrative Design}

Ken Yeang's approach to achieving harmony with nature and the built world lies the literal integration with natural surroundings and ecological processes. His work goes beyond seeing nature as a resource, and acknowledges it as a presence within his buildings. He describes ecological design as an integrative process that "strives for a seamless and benign biointegration of the human environment with the natural environment" (Yeang, 2009, 15). His work is of particular interest because he deals with nature not as a resource of energy or water that needs to be reduced within his buildings, but as an element within the design that adds to the human experience of the space and the integration with the surrounding context. Another famous analogy of Yeang's is that the built environment should be "a collection of prostheses requiring biointegration with the host organism, i.e., the ecosystems present within the biosphere. (Hart \& Littlefield, 2011, 19)." His work is significant because it begins to bridge the human and nature divide through a meaningful integration of nature back into the built form, rather leaving it as something that exists in isolation in the wild, or as something designated within cities park spaces. His motives appear to be twofold; first, his aim is to rid the urban realm of synthetic and lifeless environments for the sake of the well being of humans. He often uses the evidence of Robert Urlich's work to describe how hospital patients recover faster when exposed to natural surroundings (Hart \& Littlefield, 2011, 19), pointing to the fact that the concrete jungle of the urban environments we live in is not good for human health. Secondly, his aim is to heal or repair the actual natural environment, or propose architectural interventions that are as benign as possible. By doing this, he equalizes the health of the natural environment with the health of the human environment, a view not often followed because it doesn't necessarily help humans in any direct way. Instead of focusing on nature as a resource to be minimized that affects melting icebergs or deteriorating forests in some far off location, he focuses on how nature can be improved on the site.

He defines his approach to ecological design at an urban scale as being driven by four primary considerations. The first is integrating with green infrastructure, which is the infrastructure of nature. The second is the integration with blue infrastructure, which deals with the overall hydrological management of the site, the third is grey infrastructure, which is the engineering infrastructure such as drains and sewage that support the urban environment, and the fourth is what he defines as red infrastructure, which is the built environment used to support human activities (Yeang, 2009, 16). Addressing these four principles constitutes the baseline of his approach, where he aims to seamlessly integrate each of these elements into his designs. Overall, his designs claim to mimic natural processes, and often have an agenda of increasing biomass or biodiversity.

Ken Yeang's designs often work best in hot climates, where they can benefit from the evaporative cooling effects of vegetation, and from exposure to the outdoors. Therefore, all of his approaches have a twofold benefit - first to create conditions that 
will allow for the building to maximize its passive potential on the site, and secondly for the sake of increasing the biodiversity of the site. That being said, his philosophy is more in tuned with tropical climates, and does not have the twofold benefits when applied to buildings in temperate climates, that benefit from enclosure and minimizing surface area.

In addition, his approach for integrating with the four types of infrastructure, especially concerning green and blue infrastructure, is much more suitable for sites where natural areas or existing hydrological flows are present. His strategies become much more vital when they relate to providing a wildlife corridor that can help maintain a habitat for a certain species, or providing site drainage that works in tandem with the existing organism and material flows of the topography. Most of his theoretical projects are within sites that have natural characteristics.

Solaris, a project in an urban context, illustrates the extent to which his ideas are successful. The continuous vegetated ramp that runs around the building provides shading and cooling benefits, as well as a social breakout space for the adjacent internal spaces. One of its key functions is to increase the biodiversity of the site, which it does by providing a greater amount of space for trees to grow then if the site was left unbuilt.

Its success lies within the theoretical position that natural diversity is just as important as human needs. The cooling benefits could have been provided in a different fashion that did not take up as much floor area in the building, maximizing the amount of usable space. Instead, they are given equal importance. Further, he could have employed

a conservation ethic that maintained the existing floral diversity on the site, but instead he proposed a way forward that would benefit humans and even increase the amount of biodiversity on the site.

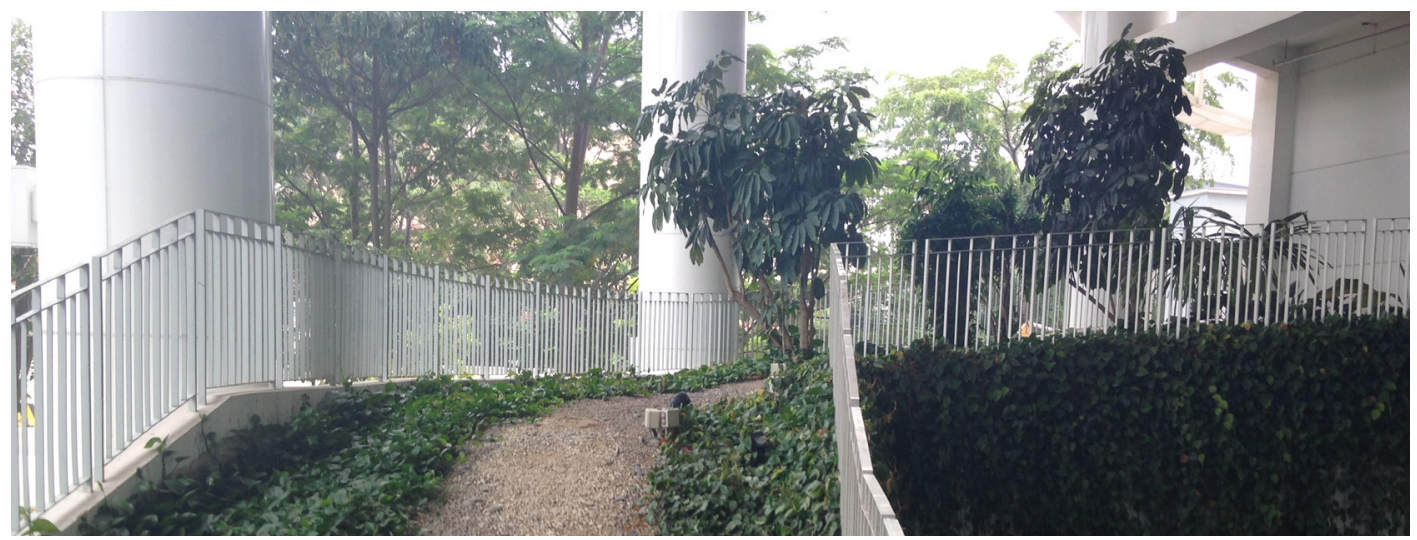

Fig. 8: Beginning of ramp that makes a continuous spiral around the building

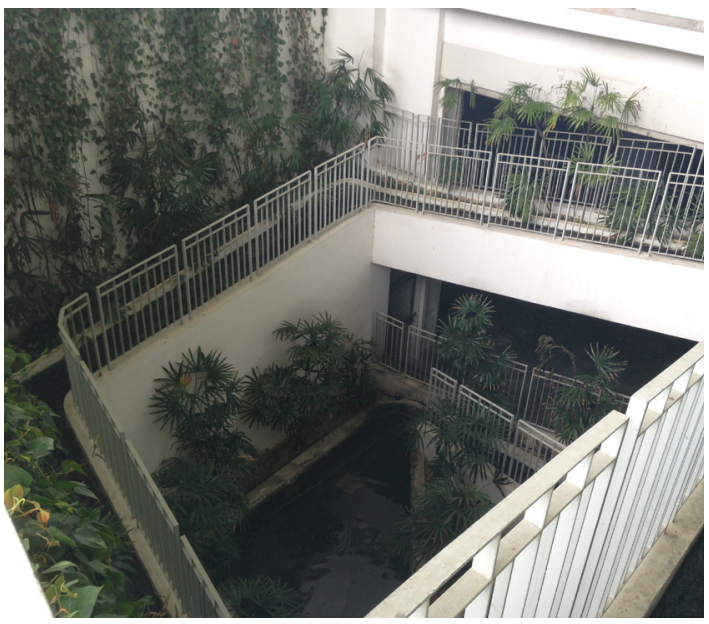

Fig. 9: "Eco-cell" rainwater collection feature within Solaris

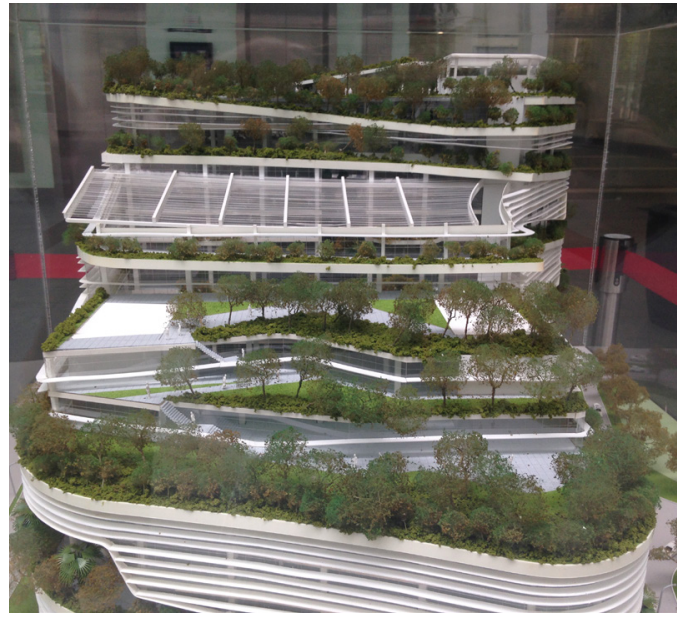

Fig. 10: Photo of 3D model of Solaris 


\subsection{Separation}

The third principle on the spatial ideology triangle can be defined as the idea of separation, or de-coupling. It is the ideology that humans can, and potentially should, transcend their dependence on nature and evolve in a way that could go beyond needing it. It is the idea that we should form a closeness with one another, in order to leave nature as much untouched as possible.

\subsubsection{An Ecomodernist Manifesto}

The Ecomodernist Manifesto is a contemporary online document by a group of scholars, scientists, and researchers. It has the position of nearly the direct opposite of Ken Yeang's thinking - that an equilibrium should be achieved by leaving nature alone as much as possible. The Ecomodernist's believe that as long as we rely on nature's resources for our well being, we are subjecting it to exploitation. For example, as long as we rely on wood as a building product, we are exploiting it for human uses, and even though we might attempt to use it "sustainably", it is only sustainable under the perspective of its use for humans.

Specifically, they state "we affirm one longstanding environmental ideal, that humanity must shrink its impacts on the environment to make more room for nature, while we reject another, that human societies must harmonize with nature to avoid economic and ecological collapse" (An Ecomodernist Manifesto, 2015, 6).

They believe that we should begin to engage in a process of de-coupling, where we must intensify and shrink all of the current resource- demanding activities so that we are less engaged with the resource itself (Manifesto, 2015, 5). An example they use is farming - which takes up a lot of land. According to their principles, beginning to use urban farming or a form of vertical farming to separate our dependence on the earth would be a strategy that achieves their goals - of reducing the dependence on the natural environment less and less to satisfy human needs.

Their ideology acknowledges that the technologies created which enabled the process of de-coupling are responsible for flourishing human populations and creating a greater demand on resources altogether. They also acknowledge the fact that compact urban populations require a greater reliance transporting resources from greater distances to serve them. Yet, they still assert that despite all that's been created, the process of de-coupling is the way to move forward in a responsible protection of the environment from further degradation.

With currently available options in place, they argue that we should always take the route of least dependence, even though we have not come up with ideal solutions. An example stated that is beneficial to the process of de-coupling is the use of nuclear energy. Even though it uses natural products, its overall impact in comparison to an alternative of using renewable energy sources is considered to be less. The Ecomodernists ideology suggests that the current projection of urbanization is on the right track, as it begins to compact human activities. 


\subsubsection{Paolo Soleri's Hexahedron}

Paolo Soleri, an Italian architect who studied the idea of the city being a hyper-organism, explored this theory with his theoretical proposal of the Hexahedron in the 1960's. It is interesting to observe the first architectural responses that shed light on the topic of our place in nature, amidst the beginning of the environmental movement. This project suggested humans could live in a way that transcended the need for nature by literally disengaging from the earth's surface. Although much of his later work centered around what he defined as "archology", meaning architecture + ecology (Taylor, 2004, 1), it seems that his ideas surrounding the Hexahedron were a critical exploration of the inverse of the idea, which is more representative of architecture - ecology.

According to his drawing specifications, the city embodied within the Hexahedron was designed to hold a population of 170,000 people at a density of 1200 people per acre. The total height of the structure is 1,100 $\mathrm{m}$ high, and took up a land area underneath of $1 \mathrm{~km}^{2}$. The idea was that these elevated community pods would be able to support all of the facets of life internally, housing functions such as residential units, commercial spaces, factories, warehouses, and spaces for agriculture (Taylor, 2004, 1). With all facets of life available in one megastructure, nature could be left as it is without the interference of human exploitation.

It is significant in its early thinking about the suggestion that perhaps a de-coupling from nature is the moral route that humans should follow in order to attempt to lessen their negative impact on the environment. In its form, it even embodies the idea of creating a "lighter" impact on the earth's surface by organizing the structure in a way that touches the ground plane as little as possible.

At the far end of the spectrum where de-coupling is taken to the extreme, this project is certainly ambitious with the idea that humans can design a way to evolve out of the need for nature. Many missing connections are expected with this type of ambitious thinking, such as how sunlight would reach the internal spaces, where the agriculture gets its soil nutrients, or how waste is dealt with within the community to name some obvious few. In its extremity, it almost positions humans as parasites on the earth's surface, that don't belong in the intermingling of other forms of life.

Fig. 11: Paolo Soleri's Hexahedron cities

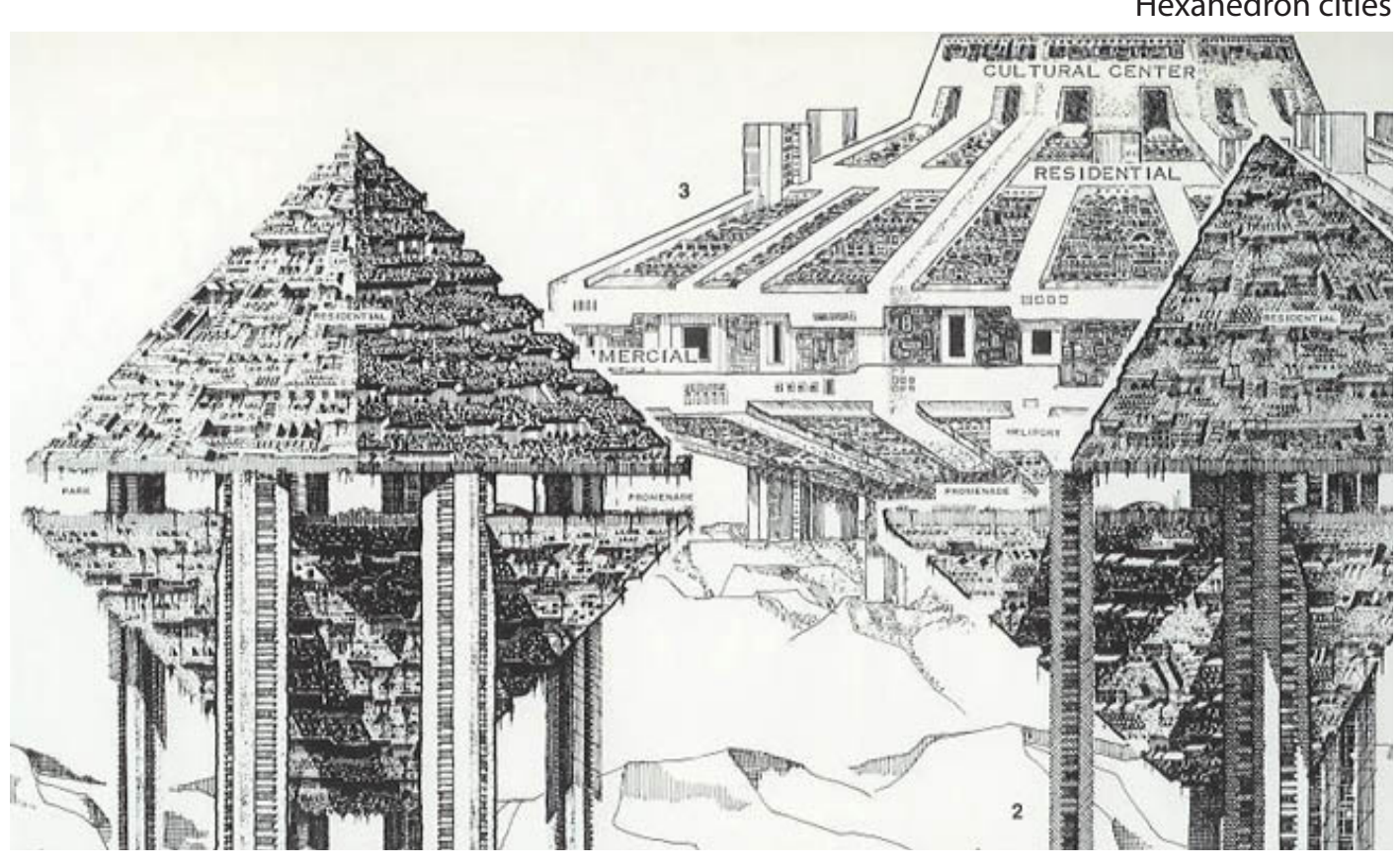




\subsubsection{Buckminster Fuller's Dymaxion} House

The idea of intensifying human activities was a concept that was profoundly explored in Buckminster Fuller's work, particularily through his explorations of the Dymaxion house. One of the first thinkers behind forwarding the idea of "autonomy", Fuller designed the Dymaxion House to be the house of the future in the 1920's. Similar to Paolo Soleri's Hexahedrons, its elevated configuration positions the human environment as a separate realm from Fig. 12: Buckminster Fuller and a Dymaxion House prototype designed for its flexibility to be built in any location, in order to be strong enough to be earthquake and storm resistant (Fracalossi, 2013, 1). The house was also designed to use the least amont of resources possible, through conservation measures such as a shower that only need one cup of water, and a toilet that needed no water at all (Fracalossi, 2013, 1).

Advocating for the opposite of harmonizing with place through the use of local materials, the Dymaxion House was intended to be mass produced and could be shipped anywhere in the world through its innovative ideas about compacting its components into packaged parts. In order to achieve this, the structure had to be made of lightweight aluminum for its properties of high strength and low weight (Fracalossi, 2013, 1). The idea of its potential for global adaptation alone speaks to how humankind can begin to transcend the constraints and resources of a place, unbounded from locally available resources for building materials. Its mass production would also contribute to the intensification of human activities, enabling the quick and efficient production and assembling of housing for the masses.

Considering his ideas emerged well before the wide-spread environmental movement, the focus wasn't on resource conservation alone, but rather the idea of independence and lack of constraints. Even within its interior layout, the flexibility of walls allowed the tenants to configure their own spaces (Fracalossi, $2013,1)$. Although the Dymaxion House was not realized as a mass produced housing typology, the ideas behind it are some of the fundamental ideologies that aim to de-couple, unharmonize, and gain independence from nature. 


\subsection{Conclusions}

The ideas of interrelation, integration, and separation form a broad spectrum of the conceptual framework that designers have dealt with when designing for the needs of the population in regards to density and the corresponding relationship with nature. The framework is not a spectrum between right or wrong, most used to least used, or a hierarchy of importance, but a framework of moral and methodological parameters that form a taxonomy of thought.

Each idea as a separate entity describes a false extreme that cannot operate in its own regard. The idea of separation, where we can transcend nature and its resources to evolve beyond needing it, disregards that we are tied to the nutrients the earth provides us. While it is beneficial to intensify our technologies to make the most out of the resources we use, or to build compact neighbourhoods, we will never be able to de-couple from natural resources altogether. The idea of interrelation is quite comprehensive, as it formulates an approach where we can exist in a quantitively stable relationship with nature's resources. What it disregards on its own is the value of a qualitative experience, and the importance of creating engagement. BedZED is a development that isn't solely based on the interrelated approach, as it also considers the quality of life of the occupants. However, if the interrelated approach was used in total isolation, an outcome for an office space might be one that has no windows, views, or access to the outside, but is utilizing resources efficiently. Lastly, integration in extreme isolation would be a false fantasy that a primitive life in the woods could adequately provide for all of our needs today. A complete harmonization would disregard all of the progress humankind has made in the built environment for our comfort and safety, that nature on its own cannot provide. Its presence still has extreme value for our quality of life, but only in association with today's current building technologies. Overall, an adequate balance is needed between all three.

Figure 13 illustrates how the previous projects described can be put on relatively extreme ends of the spectrum, while other projects discussed such as Le Corbusier's Plan Voisin, Ebenezer Howard's Garden Cities, and various other typical typologies can also be identified within these ideals.

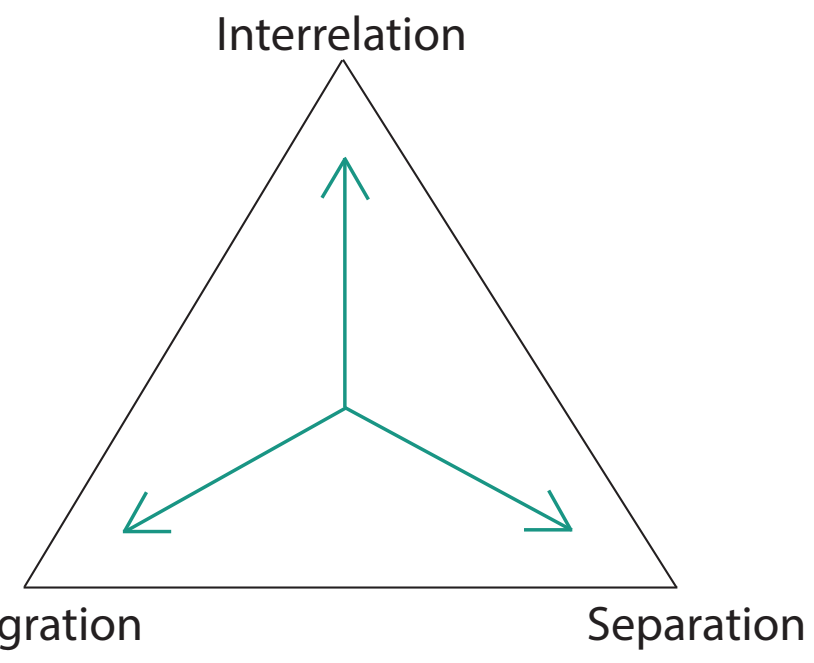

Fig. 13: Triangle of Spatial Ideologies 


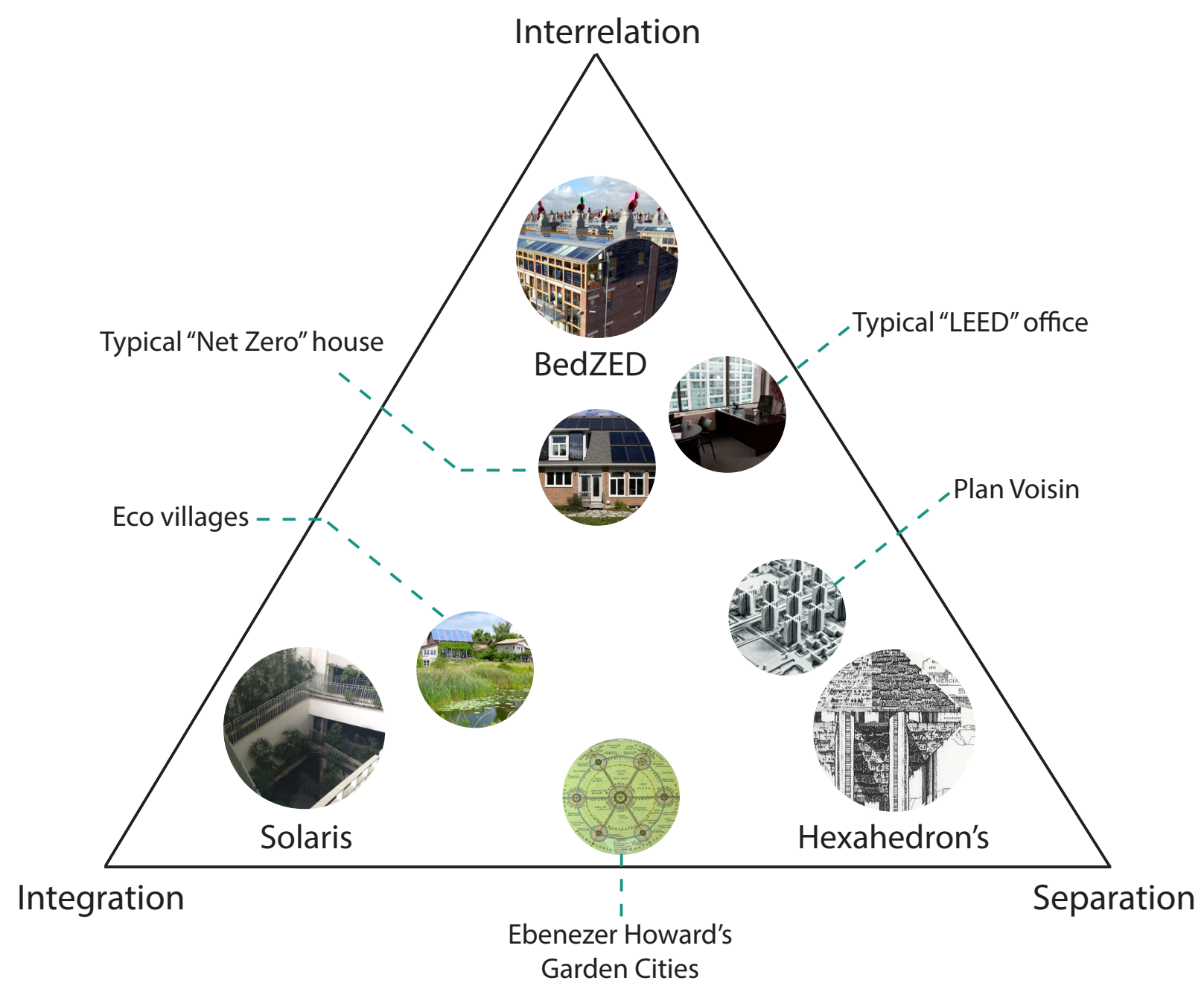

Fig. 14: Triangle of Spatial Ideologies - Project placements 


\subsection{Perspectives from Precedents:}

Although the previous projects described to exemplify each ideology illustrated their ideas in a clear way, they inevitably have overlapping facets. In the following set of precedent examples, projects were chosen that took a particular hybrid approach to defining nature within our spaces. Each one begins to redefine nature itself to form a broader understanding of the concept, under the specific conditions that the project has evolved in.

These projects begin to place architecture's role within nature towards the adaptability, flexibility, and resilience that this thesis is advocating for. In order to achieve this, they show the importance of a place based approach that finds solutions to specific problems in certain regions or neighbourhoods. Each one has a different idea about the question of merging into the ecosystem that the project is formulated in. Taking a combination of viewpoints from the interrelation, integration, and separation ideologies, they are all interpretations of how a rightful balance between man and nature should be achieved.

In a sense, they all showcase a particular way of looking at an architectural project to take a greater responsibility in becoming a part of the city's or urban areas ecological network, stemming from the precondition that when a part of nature is lost or cannot be experienced, it is a loss to the greater human experience.

Architecture can take a greater responsibility in this role by ensuring that the idea of nature is taken into account. This can be achieved in a variety of ways. As mentioned, it can be a design tool like in Ken Yeang's proposals, a design parameter like in the BedZED project, or a design sensibility such as in the idea of compactness exemplified in Paolo Soleri's Hexahedrons.

Whatever approach or hybrid approach is deemed appropriate by the architect or city builder in a given area is always up for subjectivity. The following projects showcase how a responsibility has been taken into account in innovative ways, demonstrating the ways in which architects can think about nature within their designs.

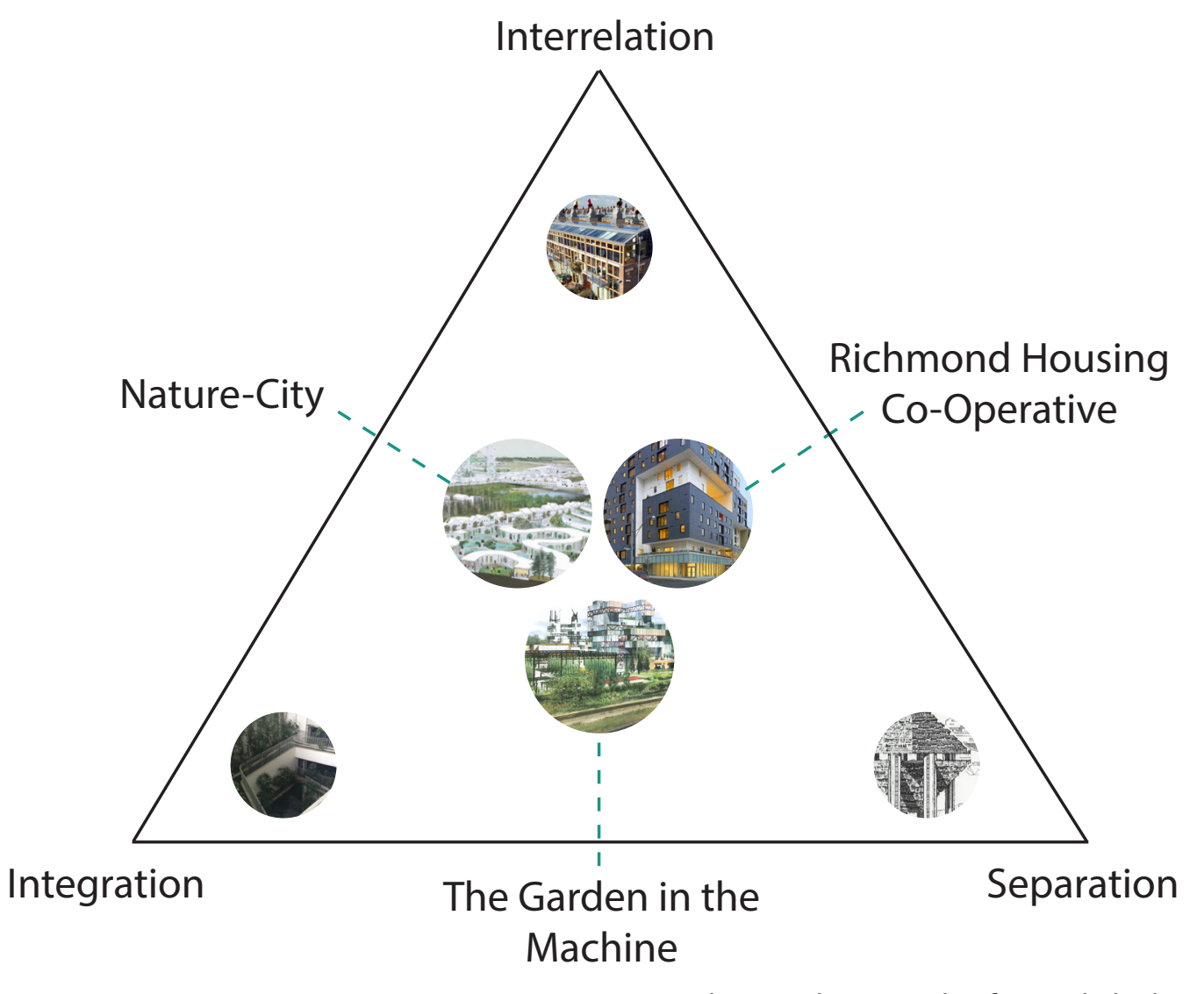

Fig. 15: Precedents within Triangle of Spatial Ideologies 


\subsection{Nature-City}

Nature-City was a part of a series of proposals designed for MoMA's exhibited entitled "ForeClosed: Rehousing the American Dream" in 2012. The exhibit centered around the idea of forwarding ideas for development within suburban contexts to offer alternatives to urban sprawl, particularly focusing on affordable housing. Nature-City is a proposal by WORKac that provides solutions to how a closeness to nature can be achieved with a high density while meeting ecological objectives. In the context of this thesis, the project showcases how a greater integration with nature was achieved while keeping the interrelated ratio of resources in check. It proposes a method for adding a more environmentally conscious housing scheme through densification that simultaneously maintains the connection and recreational opportunities of the outdoor environment. The development, situated on a site in Keizer, Oregon, is able to increase the density by five times as much as the existing suburban network, while creating three times the amount of open space that would be primarily communal.

WORKac's approach to nature is both conservative and creative. By building into an existing natural setting, the project was able to identify habitats that it intended on preserving, and could develop a plan around these areas. One of the major parameters of the project was the incorporation of a wildlife pass-through, which was accommodated by maintaining a linear through-way across the site on the ground level. The second aspect was the creation of nature-based spaces and activities, used to make up for some of the density being provided. With all of the outdoor spaces being communal, a greater variety of shared landscapes could be incorporated that contrast the monotony of personal yards in the suburbs. This includes areas such as ponds and aquaponics, designated areas for orchards or fruit bushes, and different types of gardens special to certain areas (community gardens, flower gardens, greenhouses). Each area also corresponds to an aspect of environmental infrastructure. For example, the ponds and aquaponics are also a water treatment facility, orchard groves correspond to spaces for geothermal energy extraction, and a spiral park for jogging corresponds with a methane dome used for composing. Many moves have a dual objective of harmonizing and protecting the natural environment, while providing on-site resources.

The variety and configuration of housing typologies contributes to the effective densification of the neighbourhood while increasing the variety of outdoor spaces. Studio or one bedroom spaces may have views directly onto a rock climbing wall or public pool, while two or three bedroom units may have a variety of outdoor spaces that range from direct access to public communal space or personal yard space elevated in the condominium blocks.

The project remains utopian in many regards. The incorporation of the service spaces needed for the industrial functions, such as the methane dome and water treatment facility is unaccounted for, as well as the question of whether the scale of these functions on the site are appropriate in providing an adequate amount of energy. Sometimes the pairing of functions does not appear to have any necessary 
correspondence, such as why a fuel cell/power plant is placed underneath patio style housing. In addition, the maintenance of certain public areas is idealistic in terms of management, such as who would care for the fruit trees planted for foraging. It seems that the project might benefit from a greater incorporation of mixed uses that could make the connection between communal public spaces stronger.

Despite its faults, this whimsically imaginative proposal turns the development into an ecological playground with rock climbing areas, lakes, and waterfalls, that places a high value on opportunities for people to interact with the outdoor environment and with each other. The American Dream is certainly re-imagined in its reversal of the values of autonomy and privacy, transformed into values centered around community space and active engagement with nature. Nature is either a preserved native area or built to facilitate a human need, eliminating its aesthetic utilization as adornment for personal property. This type of devaluation of personal property attempts to create social cohesion through the collective ownership of outdoor space, re-formulating traditional notions of harmonization where man has ownership over nature.

Through its specific objectives, the project lies both in the realm of integration through its fabric that deliberately intertwines with natural surroundings, and has aspects of the idea of separation, by advocating for an alternative to sprawl. The idea of interrelation is also present throughout, especially in its efforts to create energy through geothermal extraction, or reduce waste with the methane dome, sparing nature at an associated level.

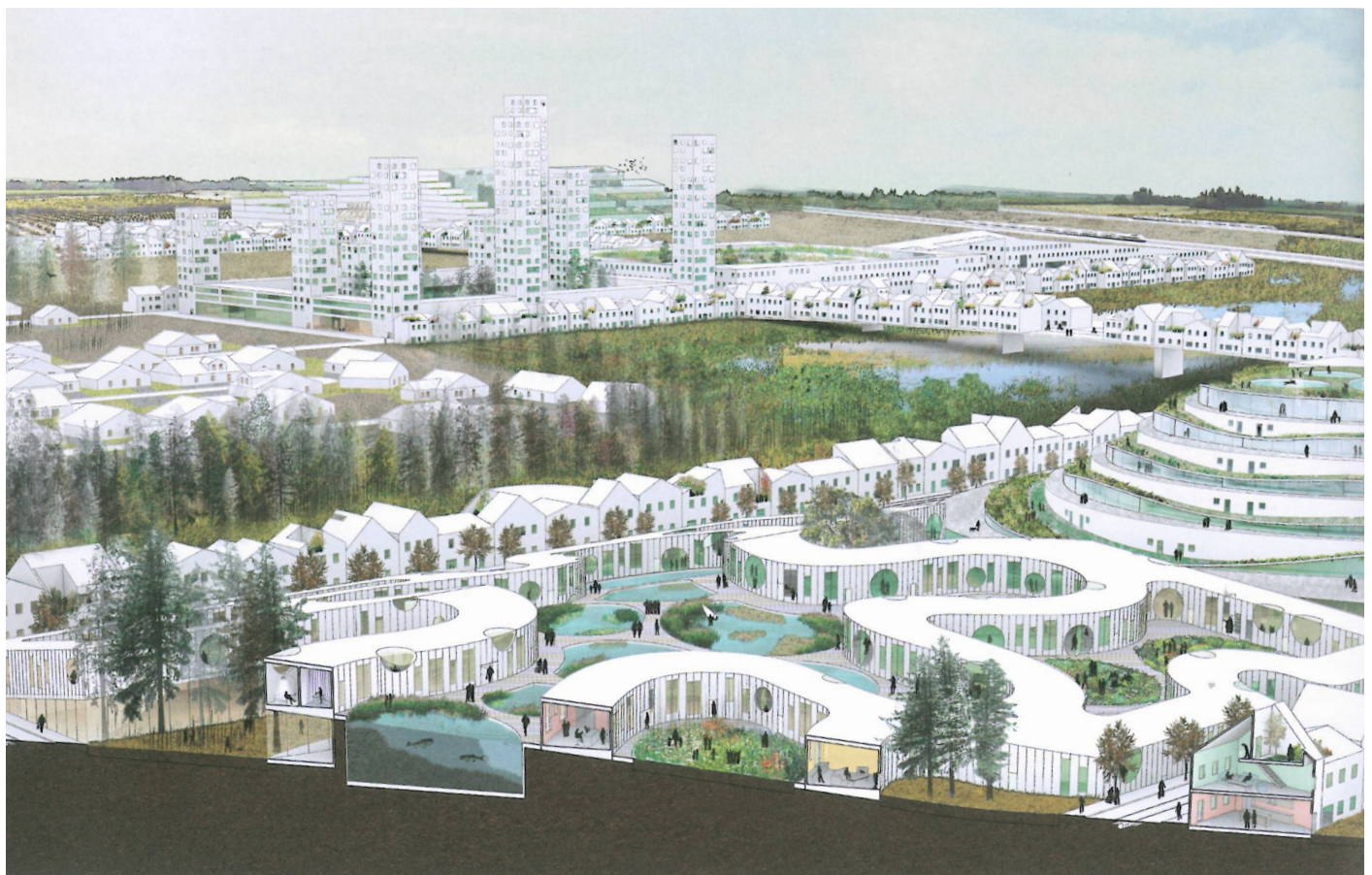

Fig. 17: Arial view of Nature-City proposal
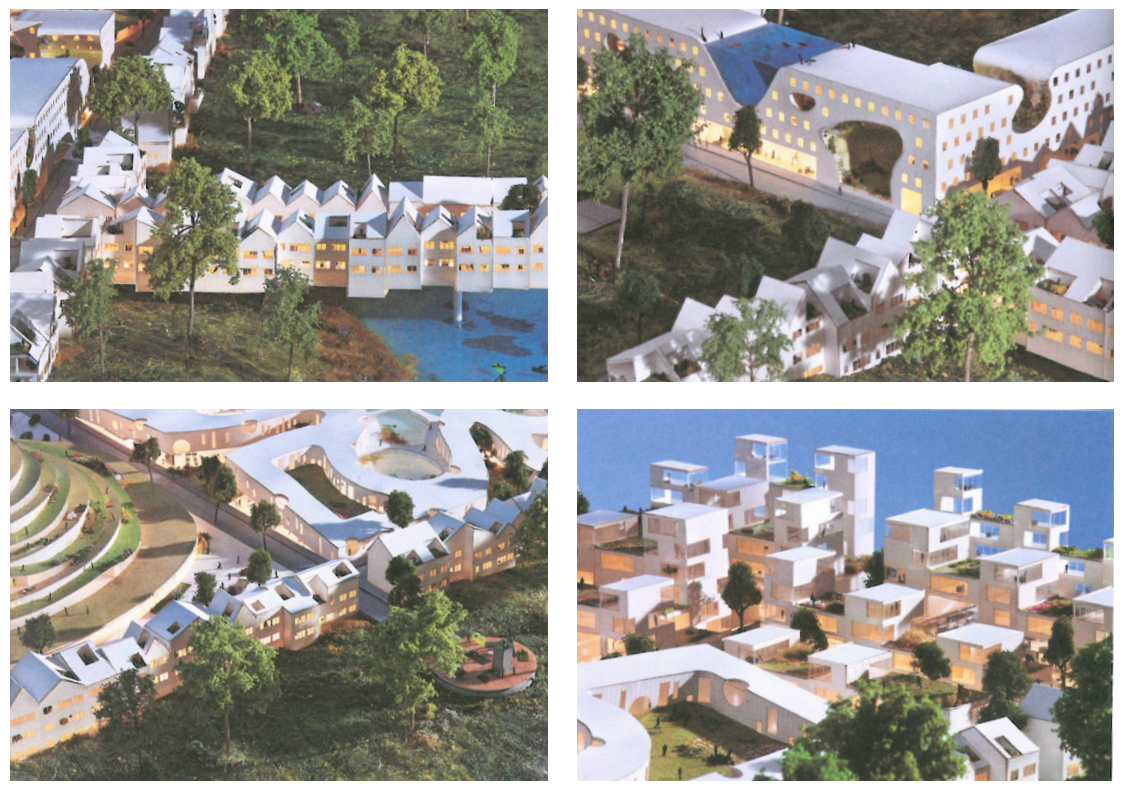

Fig. 18: Collage of various housing typologies 


\subsection{The Garden in the Machine}

Another proposal for the "Fore-closed: Rehousing the American Dream" exhibit developed by Studio Gang Architects explores the idea of housing in a previously industrialized setting as an answer to the need for densification and ecologically reviving an area. Located in Cicero, Chicago, the project is significant to this thesis in its vision that a declining industrial area dealing with environmental contamination can be an opportunity to use architecture to strengthen an urban ecosystem's resilience. The idea of the "American Dream", a guiding theme in the exhibition, is re-imagined socially from the suburban refuge and autonomy of the past to increasing the level of opportunity available in cities for employment and business. Primarily, its flexibility and material evolution are what give it a balance between the various spatial ideologies.

The project responds in a reaction to the divergence created by suburban sprawl, caused by the escape from the industrial setting of the city center. Sprawl, a leftover physical manifestation of the industrial era, does not necessarily align with the environmental and social agendas of today. The project seeks to reconcile the ideas of progress, freedom, and a healthy environment that were once attributed to the suburbs into a renewed integration into the urban center. This spatial convergence is seen as a catalyst for re-joining a fragmented nature in a process that can be restorative.

Studio Gang's answer to these objectives was to create a "vertical neighbourhood", built near an existing train line. In order to make the housing af- fordable, the idea was to create stacks of housing components that could fit into a steel framework, and could be added to depending on the resident's financial abilities. Outdoor spaces are a part of these modules, and can be stacked around the units either for individual use or for shared green space and gardening. Modules for small scale employment such as bakery shops or repair stores could also be incorporated into this framework, mimicking the flexibility already haphazardly employed in the surrounding low-rise neighbourhood from converting areas of the home into workshops or resteraunts. Using a permanent structure of vertical cores for circulation and services, a permanent network of communal spaces could make a ribbon around the structural framework. Surrounding these areas, housing and working units could be flexibly arranged within the steel trusses. The configuration of the incorporation of living and working units also plays on the idea of a compact neighbourhood that encourages walking and reduces reliance on private or public transportation. The primary driving factor for this configuration is the issue of affordability, though it poses an interesting idea about how a neighbourhood network can be created above a ground level. Overall, flexibility and adaptability is configured within the architecture to respond to social dynamics, mimicking the resilience of a natural ecosystem.

The project takes on a depth of affiliations when it comes to the idea of having an interrelated relationship with nature. One way is through reducing the project's footprint by using recycled materials, which cuts the use of virgin materials and the carbon associated with production and transportation. 
This is done within the permanent structure which is made up of re-claimed materials from a nearby demolished factory. Another way is through the use of flexible modules that can be moved around the structure to accommodate the building's evolving needs. Accommodating future needs with the design of existing materials again lessens strain on the need for future virgin materials, as well as relieves the pressure on landfills that have to deal with materials that with a closed-loop projection. Overall, planning for the effects of time can reduce many valuable resources. 60 Richmond Housing Cooperative / Teeple Architects. (2010, November 02). Retrieved August 01, 2016, from http://www.archdaily.com/85762/60richmond-housing-cooperative-teeple-architects

On a level of integration, the project uses the opportunity of the contaminated soil to bring natural features back into the area. Trees such as poplars and willows are used as phyto-accumulators, which cleanse the soil contaminated by the sites previous industrial use. Re-naturalizing the site has a threefold benefit of increasing the ecological biodiversity of the area, cleansing the soil, and creating usable public space for the residents. These spaces also become the area for community gardens and various cultural activities, contributing to well-being and helping satisfy the biophilic need for connection. Outdoor modules that fit into the structure also provide an intimate, productive engagement with nature and the residents, achieving the integrated need for people to associate with nature.

By building up a compact urban neighbourhood like the previous projects, the project also engages with the ideology of separation, where a
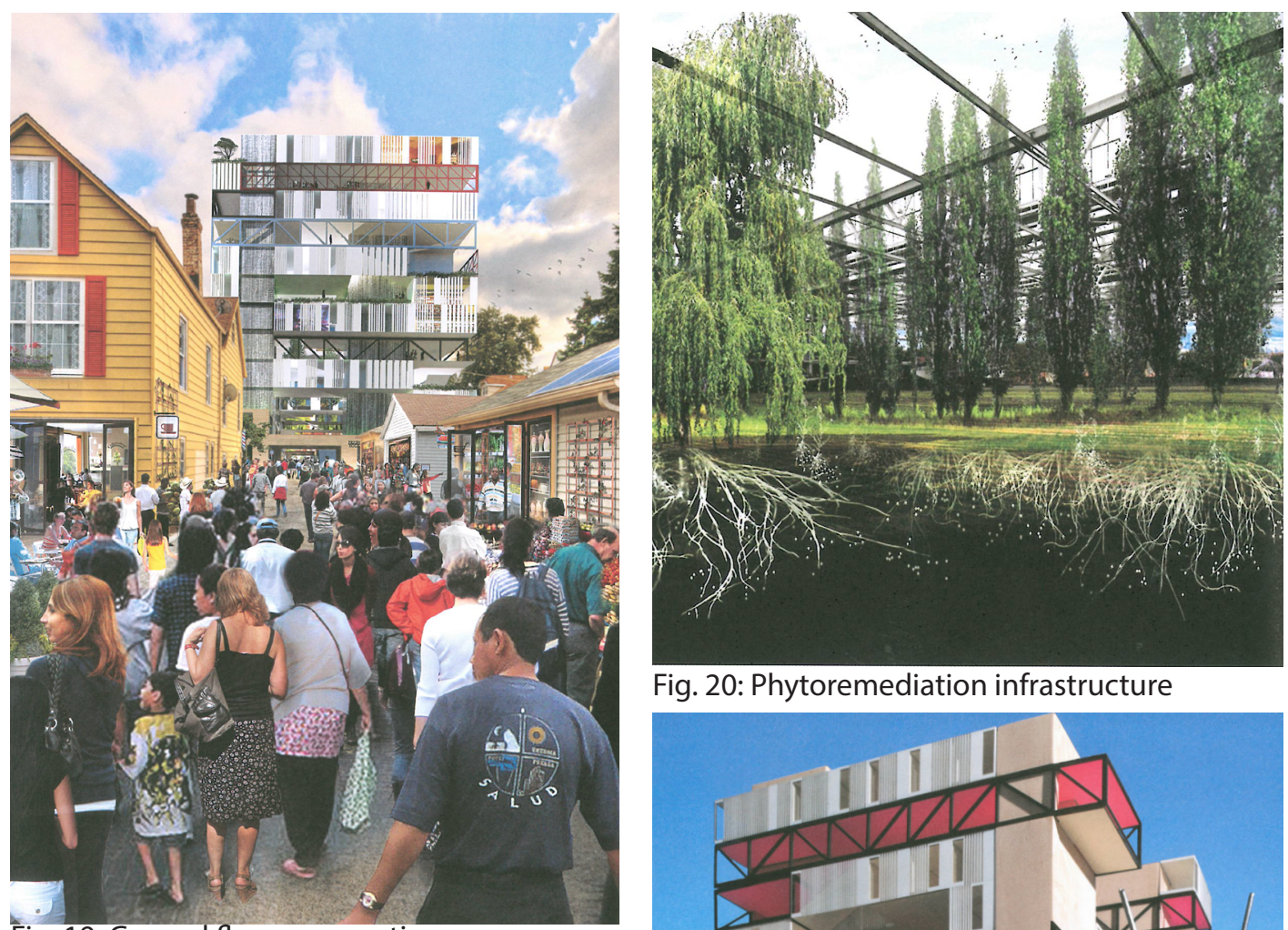

Fig. 20: Phytoremediation infrastructure

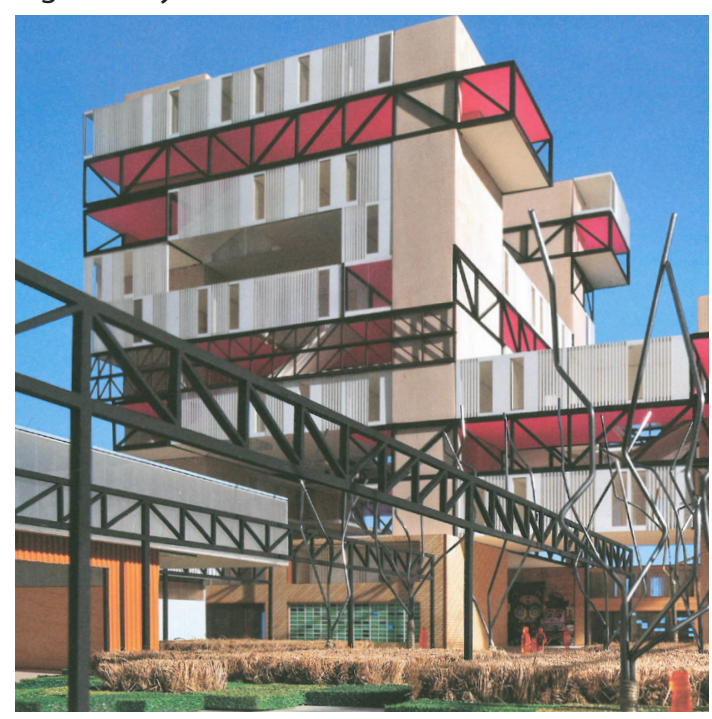

Fig. 21 (left): View from railway line Fig. 22 (above): View from community space 


\subsection{Richmond Street Housing Co-Operative}

Designed by Teeple Architects, the Richmond Street Housing Co-Operative is a built example of how a degree of hybridization between the three concepts can be manifested. Built in 2010, this 11 storey and 85 unit mixed use building has become notable for its exploration of a sustainable community and lifestyle in an urban environment.

Its LEED gold rating begins to speak to how the project has explored facets of the interrelated approach. The construction of the building utilizes various energy saving strategies. The first is within its envelope, using highly insulated fiber cement cladding and high performance windows. In addition, the mechanical system in the building utilizes air heat recovery and water heat recovery from its laundry facilities (60 Richmond, 2010, 1).

Designed as an urban infill project, it has many factors that lead it to fulfill some of the separation objectives. Situated close to existing amenities and public transportation, it takes advantage of all of the life-supporting accommodations already existing in the city. It also aims to create a form of self-reliant food production, in theory lessening the reliance on external food systems such as farms outside of the city. Instead of a machine that utilizes nature's resources, it attempts in some degree to function like an ecosystem in its own regard.

The incorporation of the food system within the building's design also lends itself well to the idea of integration, by intertwining a full cycle ecosystem into its design and operation. Green roofs help to collect stormwater, which is stored in a cistern on the upper levels. In turn, the stormwater is used top provide irrigation for the community gardens, which are owned and operated by the residents. Once grown, the produce produced in the garden is used within the restaurant and training kitchen on the ground floor. Afterward, the food waste is used to create compost, and gets put back into the nutrient cycle by providing fresh soil for the community garden ( 60 Richmond, 2010, 1). Resident's get to experience the gardens and green walls as they navigate the building through the visual transparency between spaces, adding to the life enhancement that a biophilic connection provides.

It also has an interesting take on density, reflecting how the community experiences one another and also affects the daylighting strategy within the spaces. The core of the building is hollowed out and opens to the sky, which becomes conductive to passive ventilation flowing through the space. Since it's open to the outside, windows can be placed within the interior of the structure, a sensitive way of creating an awareness between residents that can contribute to the sense of community. The outdoor garden spaces that are cut out of the cubed volume also contribute to providing natural light deeper into the interior of the structure. The shared community garden spaces further this concept, encouraging a collaboration between residents to share a common goal. While the architecture plays a part in this, its organization as a co-op plays a fundamental role, ensuring within the management structure of the building that each resident contributes to the functioning of the community. 

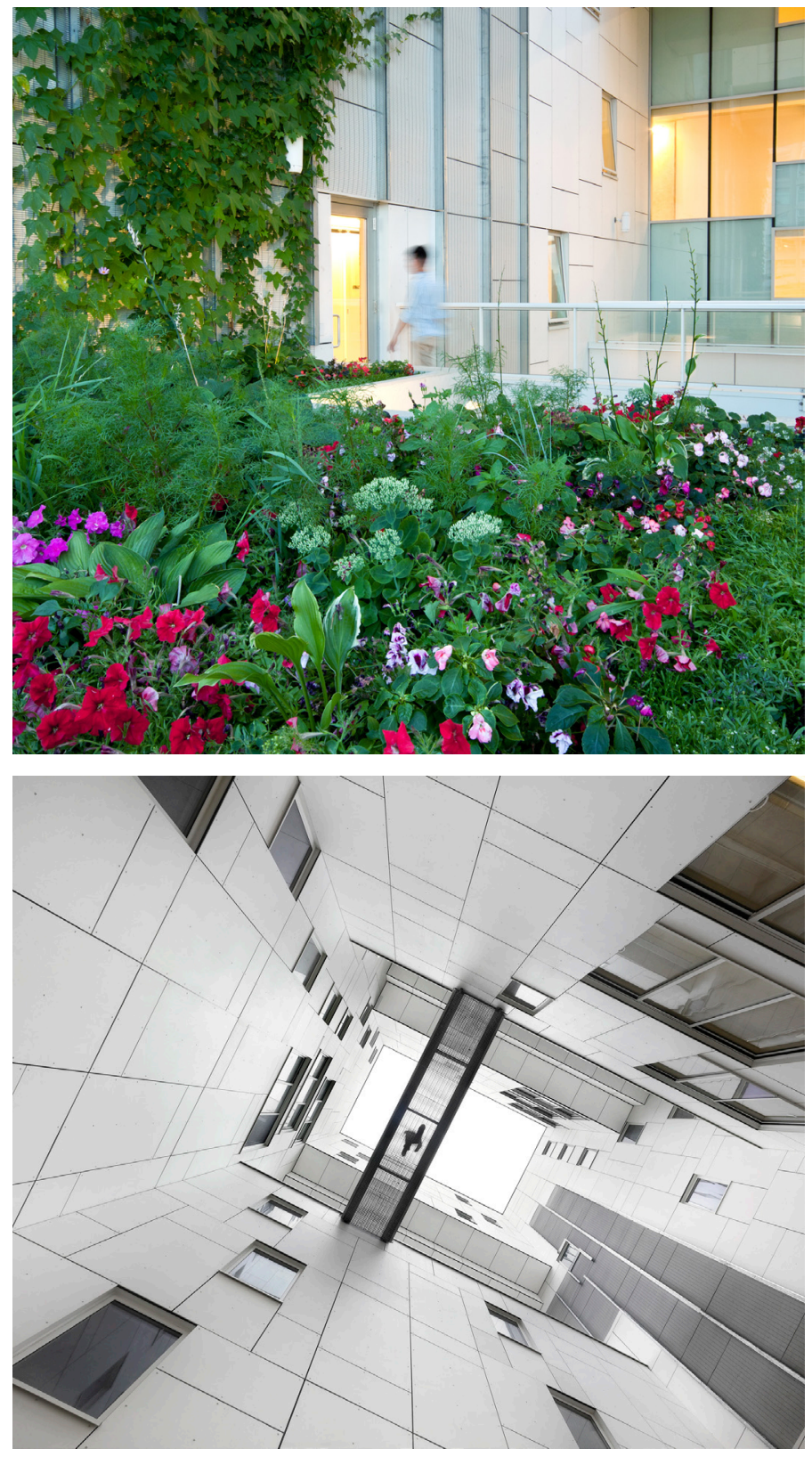

Fig. 23 (top): Community garden

Fig. 24 (bottom): Open core strategy
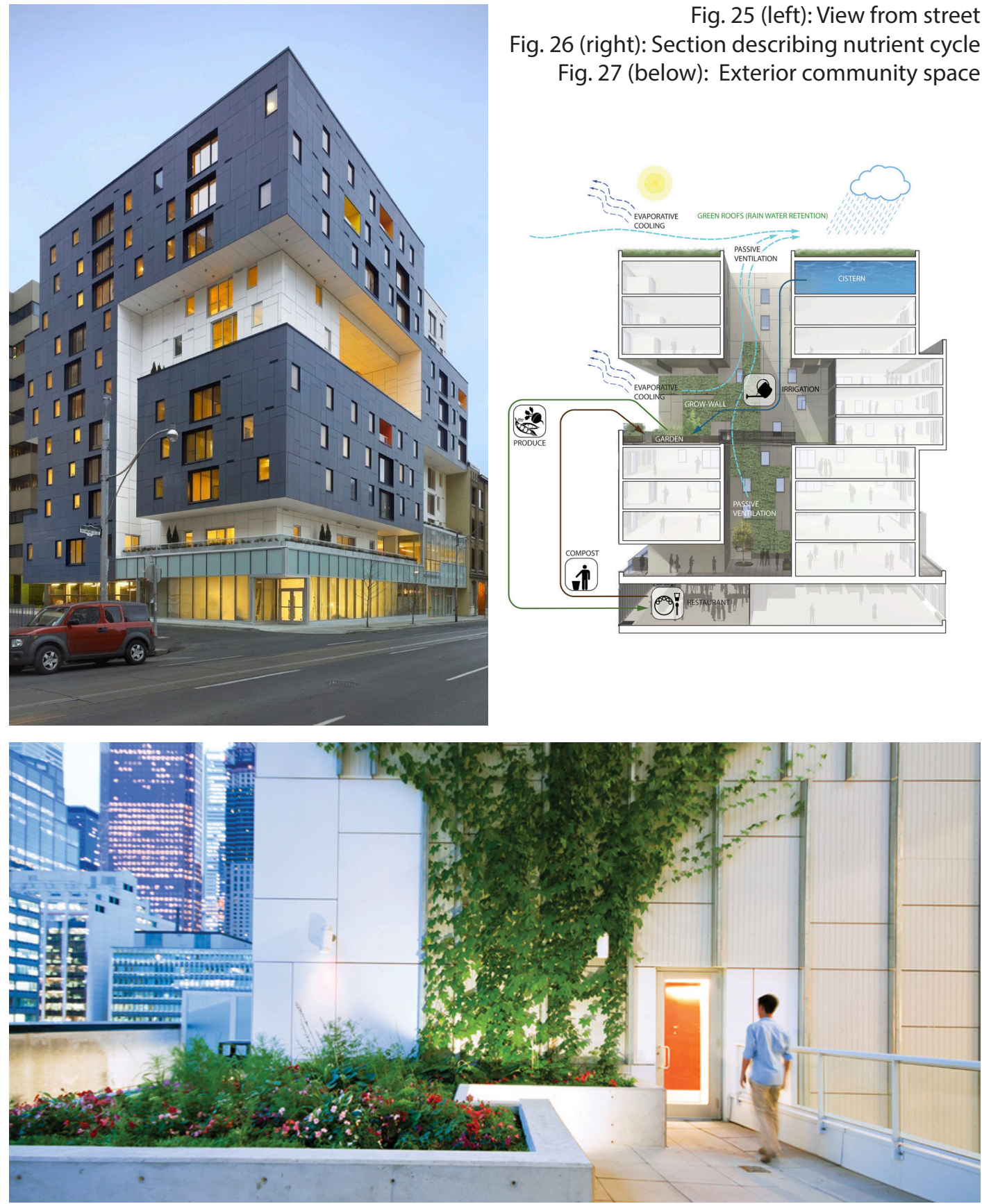


\subsection{Lessons from Singapore}

Singapore is a city that has become highly regarded for its integration with nature and green design. It is fascinating that an entire country has taken on the image of a "city within a garden", but it isn't a surprise considering its strong regulatory framework that supports sustainable initiatives, along with its booming economy. The city itself is a primary example of how the two seemingly opposite concepts of integration and separation have been attempted: limiting sprawl by creating compact urban neighbourhoods, while integrating nature into the smaller scale details of their urban environment.

A key to understanding how these unique conditions emerged is to understand the country's context. Surrounded by Malaysia and the Indonesian islands, it is a small tropical island that has a steady temperature of around $30^{\circ} \mathrm{C}$ daily. It was ranked the 4th country in the world in the Environmental Fig. 28: The port of Singapore Performance Index in 2014, illustrating that its

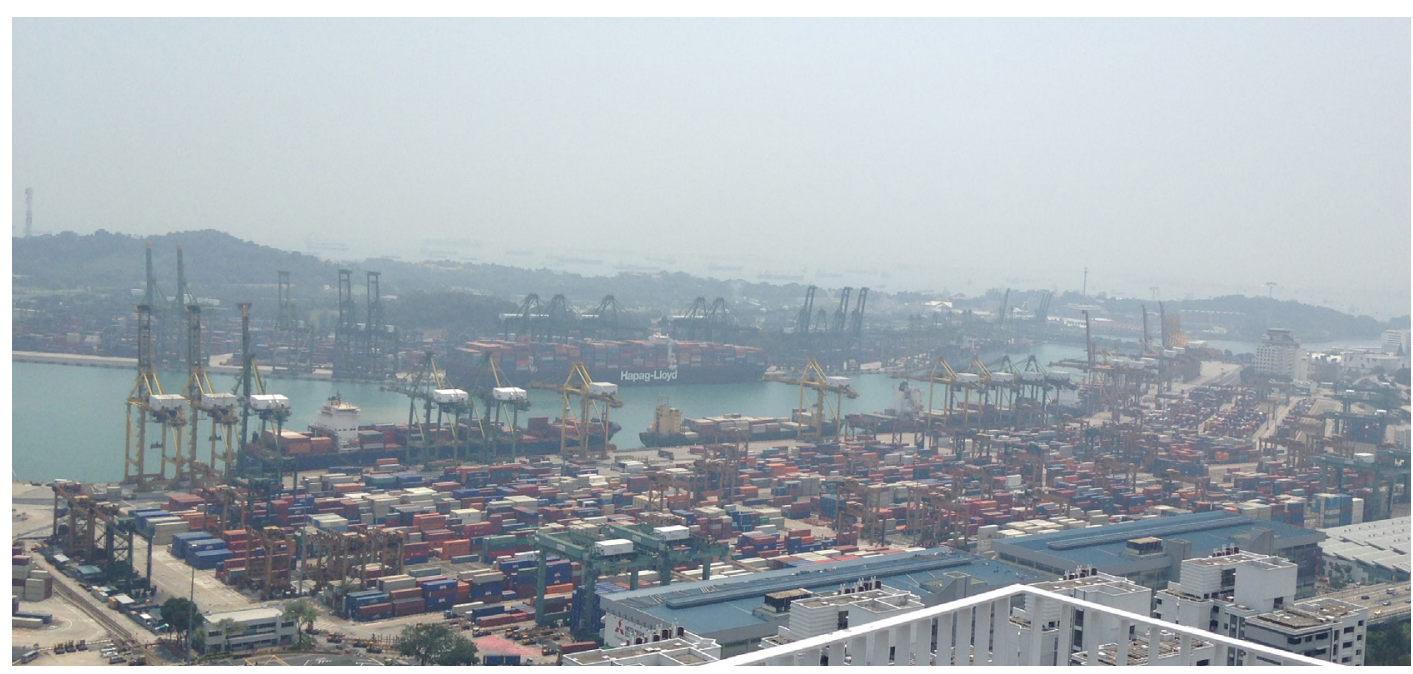

29 green image goes beyond appearances and has real relevance to the health of the environment. The trip to Singapore was driven by the curiosity to understand how an ecologically centered design sensibility has been adopted within its architecture and urban design, and what about its man-nature balance is important for highly urbanized centers.

Singapore is one of the smallest countries in the world, taking up a total area of $697 \mathrm{~km}^{2}$, but totaling a population of 5.6 million people. This limited land availability could be considered one of the key ingredients for the opportunistic conditions that have lead to their compact urban framework. However, there is virtually no land available for large scale agriculture, and the entire country relies on imports to sustain its population, where most of their food comes primarily from Malaysia and China. In this regard, Singapore falls short of both the separation and interrelation ideologies, as they cannot operate their food system in a self-sustaining manner and need a considerable amout of resources to import it from elsewhere.

Still, the small country size has its benefits, primarily through their transportation system where the subway extends to nearly every end of the country, contributing to the ability to have high density compact neighourhoods spread throughout. This, coupled with high taxes placed on owning a vehicle, have lead to only $15 \%$ of their population owning a form of private transportation. This contributes to lessening their resource ratios to satisfy some interrelated objectives, as transportation accounts for a high percantage of carbon emmissions.

Primarily, Singapore showcases how the 
ideology of integration has been achieved in all scales of the urban network. Natural infrastructure permeates their urban environment in a variety of ways that helps with buffering the density. At the urban scale, there are many moments that truly feel like the city is embedded into a jungle. Many buildings are buffered with a generous amount of growing space for trees in between the road and the sidewalk. Acacia trees are very popular for the immense shading canopy they provide, and are often placed together on opposite sides of a street so that they merge together and cover the road in a shaded tunnel. A continuous wildlife corridor becomes created at this elevated level above the ground. Along with providing the necessity of shade for pedestrians, the urban heat island effect is a very prevalent issue, and a lot of attention is given to surrounding buildings with dark green vegetation.

This network of ecological infrastructure creates various horizontal levels within the city that are prioritized by nature and the pedestrian experience independent of the transportation network. On some streets with many laneways, overhead walkways were provided and were often adorned with plants that provided a comfortable visual barrier between the walkway and the road network, as well as a continuation of the ecological network of greenery planted below. Even in walkways underneath bridges, trees and vegetation were planted in a way that added a human touch to the loud and otherwise uncomfortable experience of walking under a loud, rumbling bridge. In many moments when walking around the city, the sound of birds was louder than the sound of cars. Since Singapore has no sustainable freshwater supply, they also had to deeply ingrain the rainwater system into their urban drainage network, so that it could be cleaned and re-used for drinking water. In order to achieve this, they engineered twothirds of their urban surfaces to be able to channel water into their reservoirs.

Singaporeans understand that access to greenery and nature contributes to the well being and happiness of residents, and more importantly,

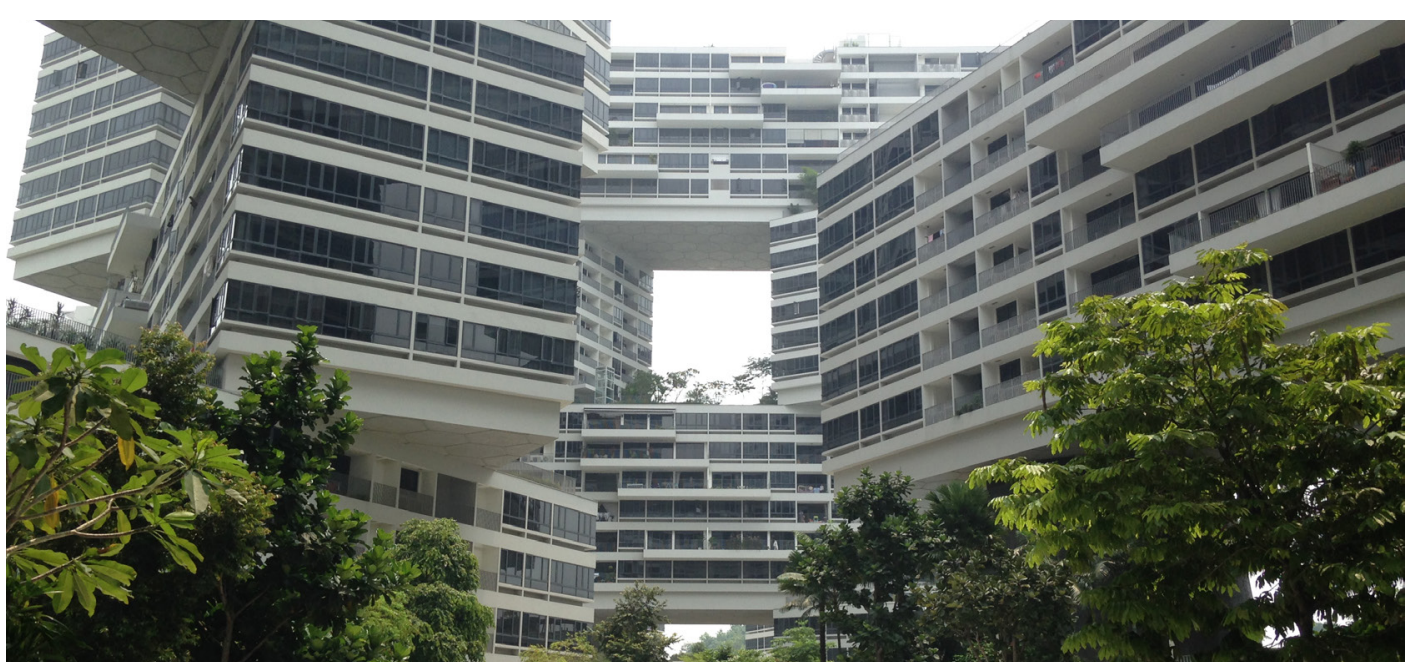

Fig. 29: Interlace development by OMA

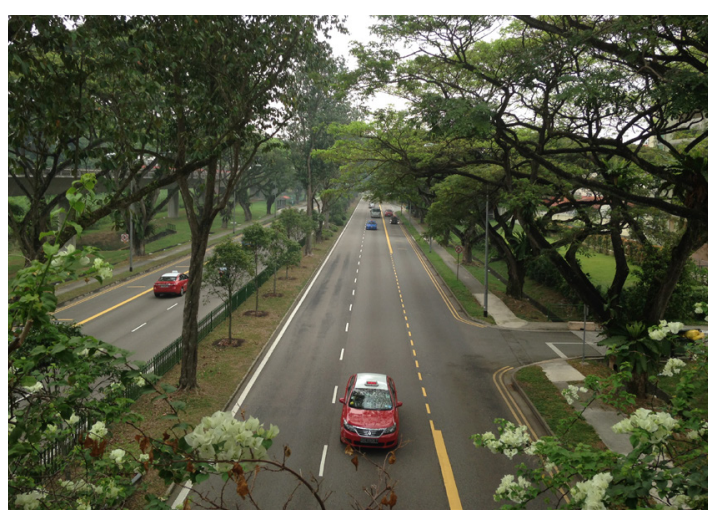

Fig. 30: Highway ecological infrastructure

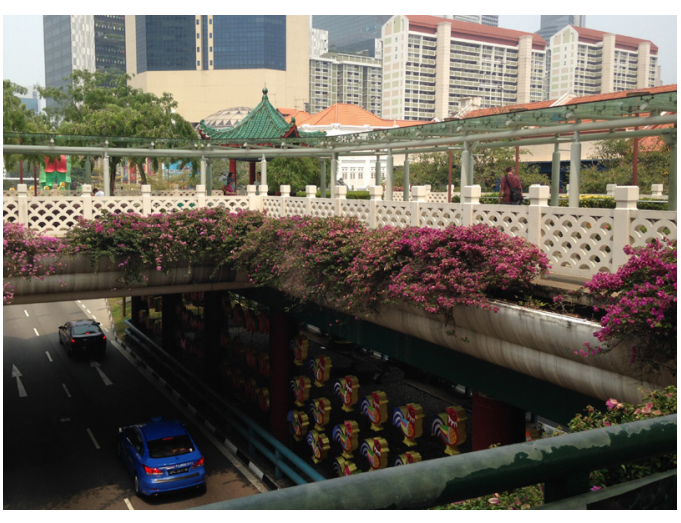

Fig. 31: Pedestrian walkway 


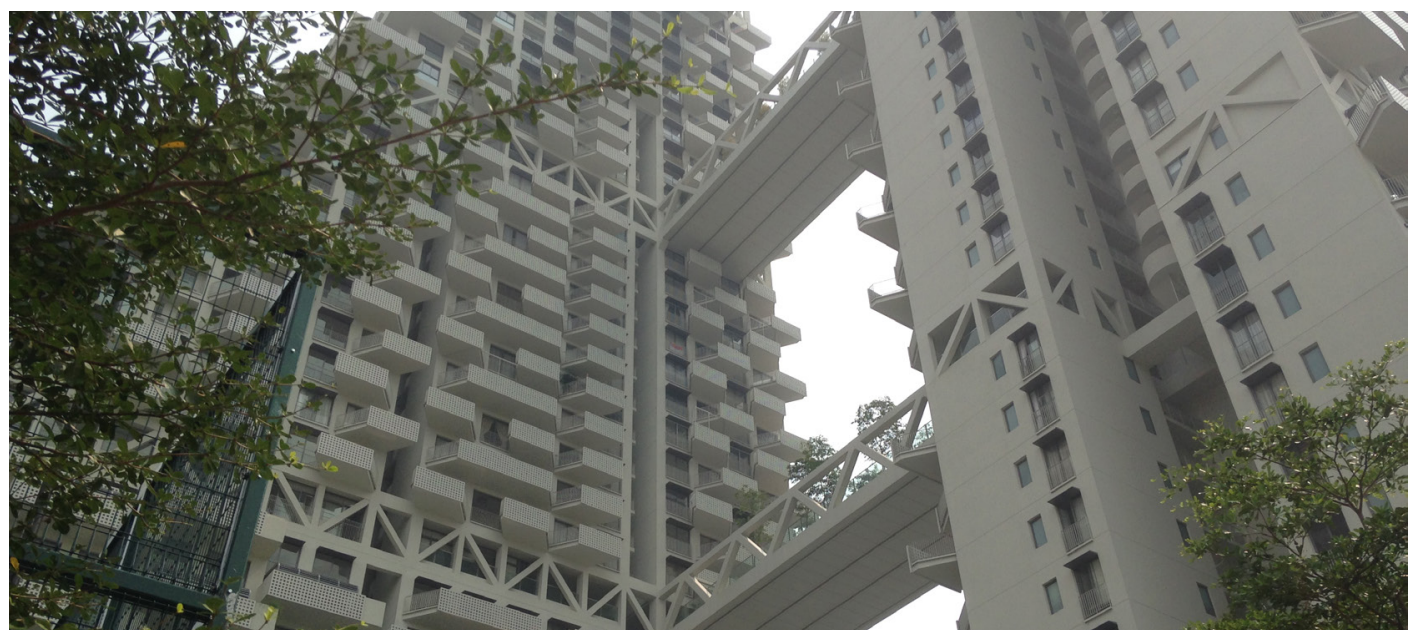

Fig. 32: Sky Habitat by Moshe Safdie makes high density urban living more liveable. There seemed to be a renewed interest in the idea of creating re-claimed ground planes in the sky. Sky Habitat, a project by Moshie Safdie, was a development that experimented with this idea. By using bridges to connect the two buildings in his project, he took them as an opportunity to create sky gardens. These spaces became areas for vegetation or rooftop pools, and by creating them within the buildings circulation rather than a distinct destination, he was able to push the idea of these being neighbourhood streets. In addition, the cascading form of the balcony spaces was intended to recreate the "community texture of an ancient hillside".

A few projects were keen on the biophilic agenda, taking significant steps to address the need for access to nature for our fundamental well being. The first was Interlace, a large scale condominium developed by OMA. Stacks of residential complexes were arranged in a manner to create porosity, views, and maximize surface area important for cooling benefits. In order to make up for this density, the ground plane was turned into a communal network of activities centered around nature, including swimming pools, gyms, BBQ areas, and various seating spaces. In contrast to North American condominiums, the first floor levels were the most desirable, as the amount of greenery provided the same privacy level felt in personal outdoor spaces of suburban developments, and each ground floor level had their own front yards. Overall, it was a successful idea in the realm of separation, where the architecture was able to create a more comfortable, closer relationship to one another, in turn making the idea of high density more habitable and creating a lesser impact on their limited natural surroundings.

There was a clear prioritization of nature given to many projects. Hotel Parkroyal is an upscale hotel in the downtown district designed by WOHA Architects. It displayed a very critical idea that the needs of nature actually shaped the buildings form, as oppose to a building shaping its surroundings. In order for vegetation to thrive on the building, surfaces were carved out of the south facing side of the façade, out of a typical rectangular floor plate generated from the street network. This provided adequate lighting conditions that both helped grow the plants, and in turn created shading for the units. On the mid levels, hotel amenity spaces are tucked within the comfortably shaded areas, feeling more like a carving in a cave then typical amenity spaces that often just get the remainder of space left on the roof. It also displayed a beautiful acknowledgment of change over time, with attention given to how vegetation clings to surfaces, falls along edges, and grows after the buildings completion. 
Another project was the Khoo Teck Puat Hospital by RMJM Architecture, that capitalized on the healing benefits provided by the incorporation of nature. Inside the hospital's courtyard space, a large expanse of green space was provided that infiltrated through to the upper level circulation and breakout spaces. The therapeutic and calming benefits of nature are intended to help the residents heal, as well as increase the biodiversity of the area and create space for community activities.

At a detailed scale, green is more than just an aesthetic element. Primarily, plants and trees were located within cavities of buildings to take advantage of their evaporative cooling benefits, which worked especially well when integrated in a way that channeled wind. In the Oasia Downtown tower designed by WOHA, a double skin facade is utilized as a mesh for a network of vines to take over the building. Behind each outer skin was a planter that sat in between the cavity separating the building from the mesh facade. The planters were placed at all levels in the building and were already creating a vegetated surface as the building was nearing completion. As wind gets channeled in between the cavity, cooling is provided by the evaporation of water from the leaves, creating a decrease in air temperature.

Overall, their urban and building strategies work well to fulfill the ideas of integration. In many cases, the integration with nature also contributed to the lessening of resource use within the interrelation concept, with all of the benefits of cooling and shading. Still, Singapore falls significantly short of the interrelated and separation concepts as they still
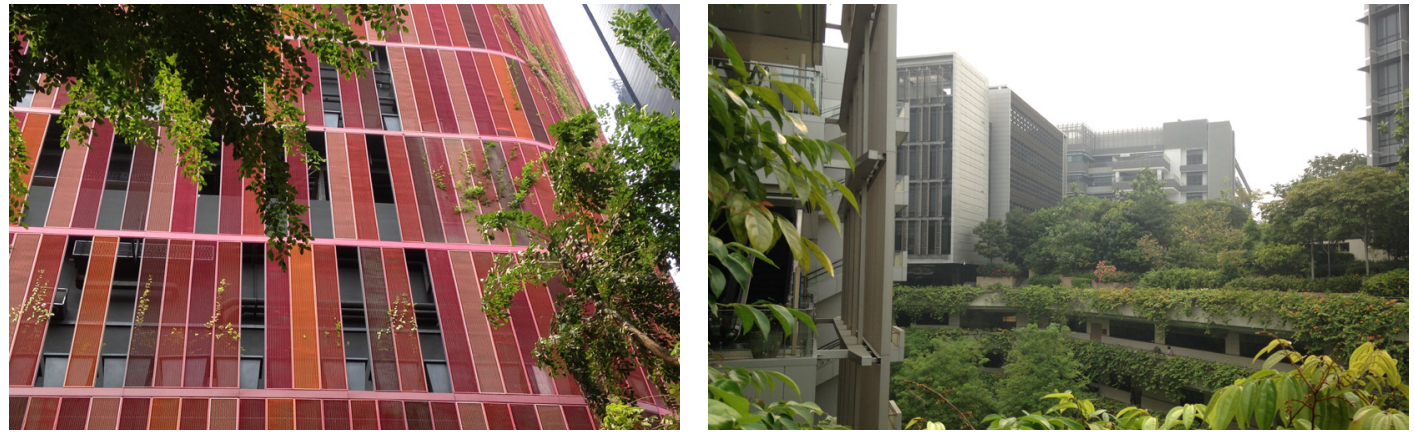

Fig. 33: Facade of Oasia Downtown

Fig. 34: Khoo Teck Puat Hospital
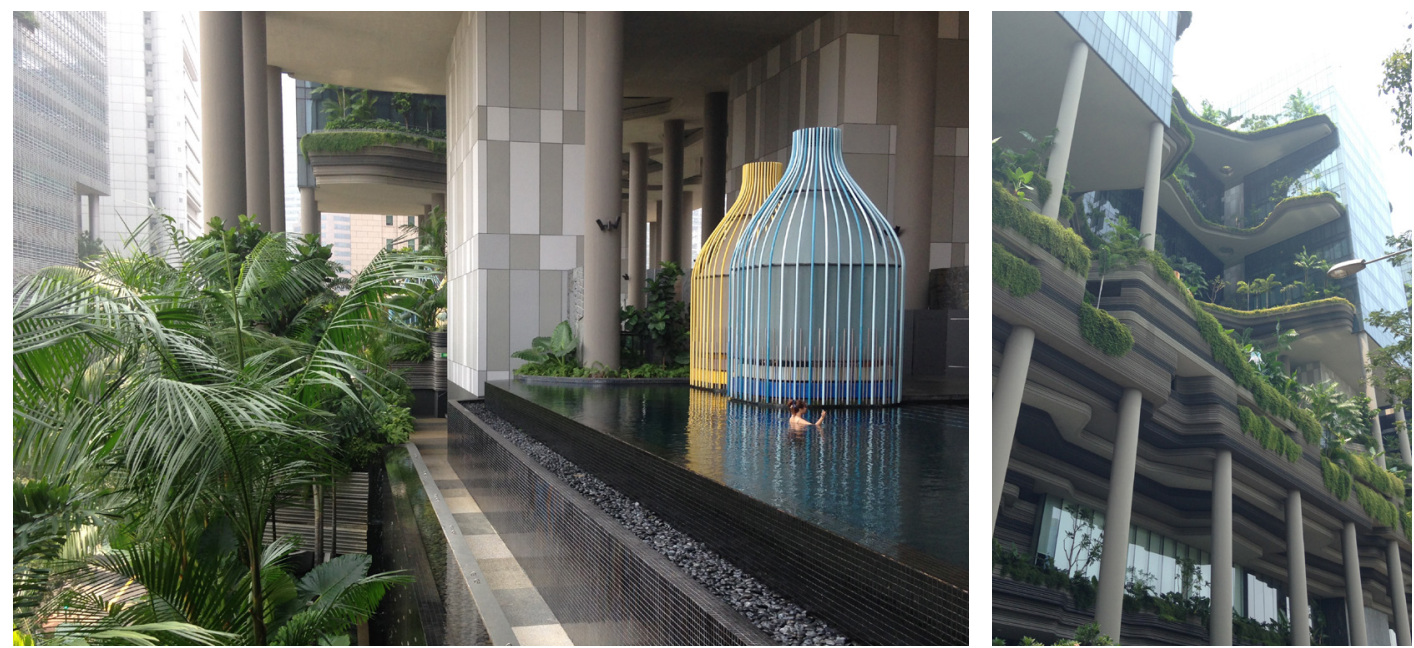

Fig. 35: Hotel Parkroyal by WOHA Architects

Fig. 36: Hotel Parkroyal

have one of the highest environmental footprints in the world, having an ecological footprint of 8 Global Hectares per Capita (Ecological Footprint Network). Since Singapore has close to no biocapacity and ability to grow their own food, they are unable to acheive a level of self-sustainment, and rely heavily on external resources. This case study provides a lesson in the importance of equality within all three concepts, and how the scale of investigation is an important parameter. 


\subsection{Opportunities in Post-Industrial Landscapes}

\subsection{Overview}

Upon reflection of the theory developed and its investigation into various precedents, it was decided that a specific type of site would be chosen that could give the thesis the greatest ability to provide benefit to an area. The search began into industrial landscapes as they exhibit a design thinking that is symptomatic of the negative anthropogenic direction discussed earlier as the problematic issue. First and foremost, they are the areas that are responsible either from their immediate output, or from the products that are a result of industrial processes, cause the greatest amount of harm to our environment. They are the areas used to extract and create energy, or the areas that are responsible for transforming our resources into various different forms. They are the energy and material generators of our society; the machine that absorbs nature and transforms it indefinitely. They represent the transformative threshold between the way we live now, and wilderness.

The built urban and architectural forms of industrial areas are reflective of their function - a sweeping destruction and transformation of once untouched landscapes. One of the greatest imbalances with nature within our urban ecosystem are the industrial landscapes that are inevitable for the functioning of a society. Often, the places responsible for our functioning as a societal network - transportation infrastructure, industrial areas, or places of waste management, are treated as waste compared to the spaces where we live. Unlike biological organisms in natural habitats, we leave these areas behind as dead zones, spatially dividing them in our urban organization because of their inhospitality. Though this approach is beneficial to some areas of the city, others are left in close proximity to these spaces that we can call "waste", stuck with what society needs to function but left with the losing end of the "not in my back yard" argument.

One of the greatest motivators for people to move out of the city is to escape proximity to these places and their associated noise, pollution, and unpleasing environments. Humans have a desire to be surrounded by nature, quiet, and fresh air. However, the impending needs of housing the global population and the need to reduce urban sprawl call for a new way of looking at which parts of the urban environment are habitable for humans; a new way of dealing with the industrial parts of our nature. For this reason an industrial site was chosen for the intervention, to propose a way of moving forward that envisions living within the entirety of our "nature" as a functioning society. This thesis insists that we do so not by isolating the parts that we use for its extraction, but by acknowledging the entire spectrum of the man and nature divide.

\subsection{Site}

The West Toronto Railway line is one of the earliest pieces of infrastructure built into the city, showing up on maps of the City of Toronto as early as the late 1800 's. It is representative of 
the beginning of industrialization, helping evolve the built infrastructure of Toronto into what is has become today. As much as it has helped the successes of human progress, it is also representative of the destruction we needed to cause to create it. In the urban context, the railway line became a catalyst for the build up of a surrounding industrial environment. This was a natural tendency as the railway line provided the transportation of materials necessary for industrial processes, and otherwise was an inhospitable landscape for any uses beyond industry.

The areas around the railway line were chosen as a starting investigative point because of their historic emergence. They represent a type of landscape with a common thread that can begin to provide a common set of denominators in which to base a process of change. The areas around the railway line were also of particular interest due to their changing nature, in particular the growing popularity of the West Toronto Railway Path. The railway path is a significant catalyst in the transforming ideologies about how cities should be sensitive to the environment. In particular, it weaves a pedestrian and bike transportation network into the city that is completely separated from automated vehicles. Currently, it spans from south of Bloor Street to Dundas Street West, with future expansion plans to extend it to the Martin Goodman Trail that runs parallel to the waterfront. This would make it the longest independent bike and pedestrian axis to cross the west end of the city.

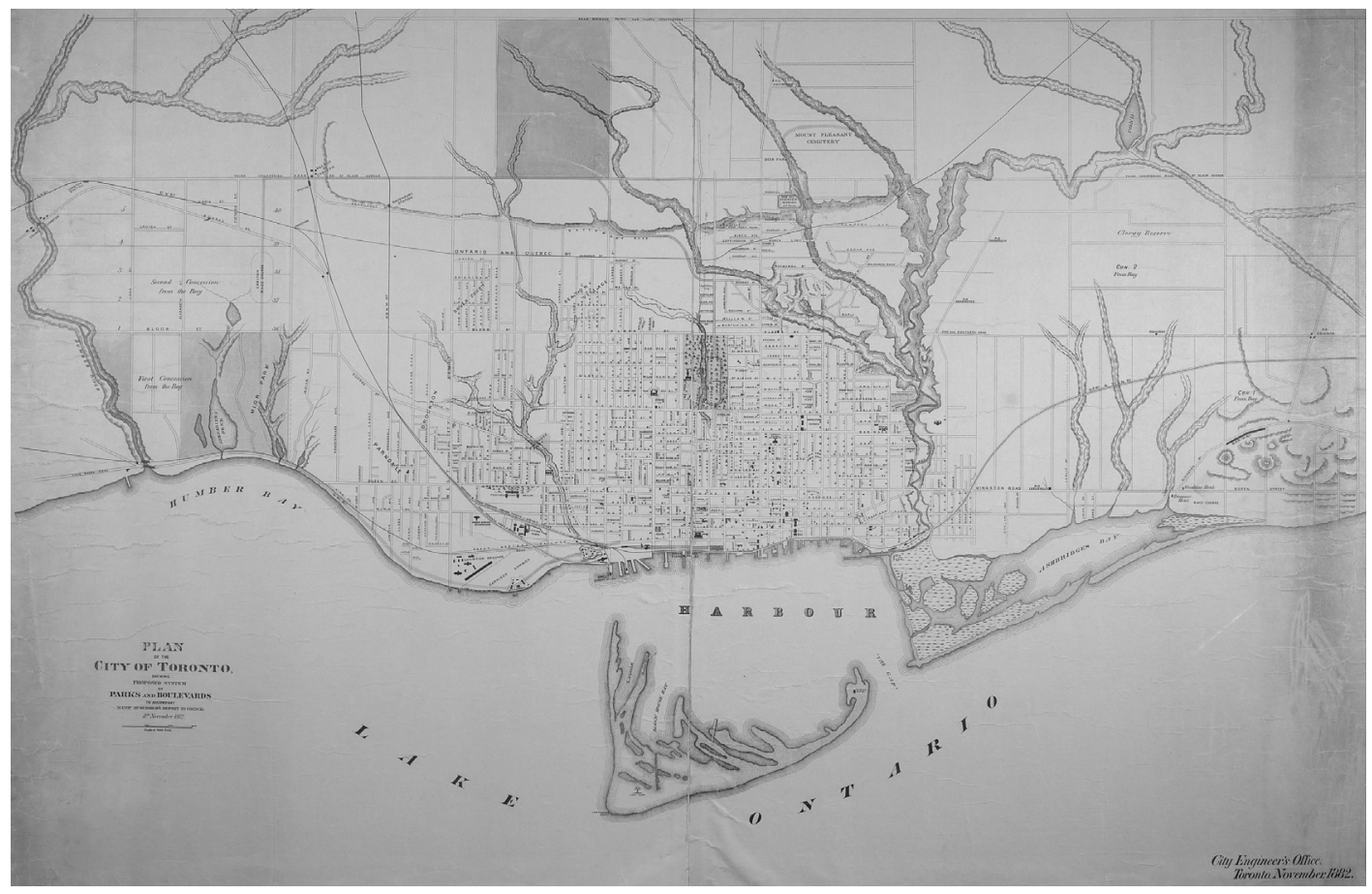

Fig. 37: Map of the City of Toronto, 1882 


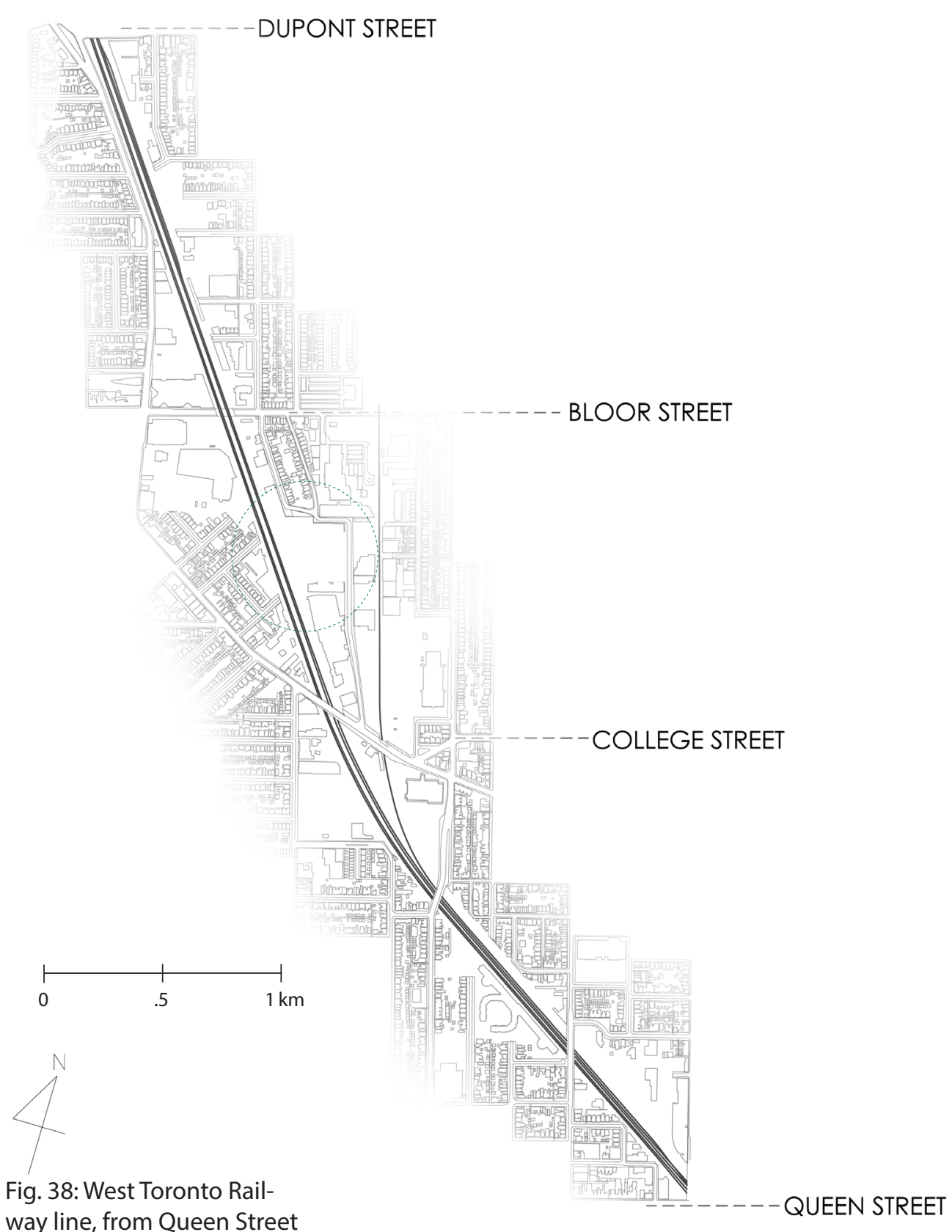

way line, from Queen Street

to Dupont Street
Out of a large variety of post-industrial landscapes available adjacent to the railway, a site was chosen close to Bloor Street for its size and proximty to city ammenites. It was also chosen for its state as a large underutilized brownfield site, one of the ideal places where nature has been neglected. The large industrial building shown in the 2D image to the left has since been demolished, and remaining on the site is the Tower Automotive Building, a designated historic site. The Automotive Building was built in 1919, and currently has plans for the Canadian Museum of Contemporary Art to move into its ground floor spaces, and offices in its upper units.

The location is ideal for a community development as Bloor Street attaches to the GOTrain line, connecting people from the inner city core to the outer city suburbs, as well as the Go UP Station connecting to the Pearson Airport Express, created access directly to and from the airport to downtown.

The neighbourhood around the site is primarily residential, industrial, and houses a variety of functions into retrofitted industrial buildings. Some of these include cultural uses such as gallery's, artist spaces, and art centers. Other uses include recreation centers such as an axe-throwing facility, a cross-fit gym, and sporting clubs. The roughness of the neighbourhood combined with low rent prices creates a type of allure that brings in eccentric and unique programs to the area.

It sits between the Roncesvalles neighbourhood and Dufferin Grove. Culturally, it is home to a large Polish community, as well as many hip bars, restaurants, and bakeries. 


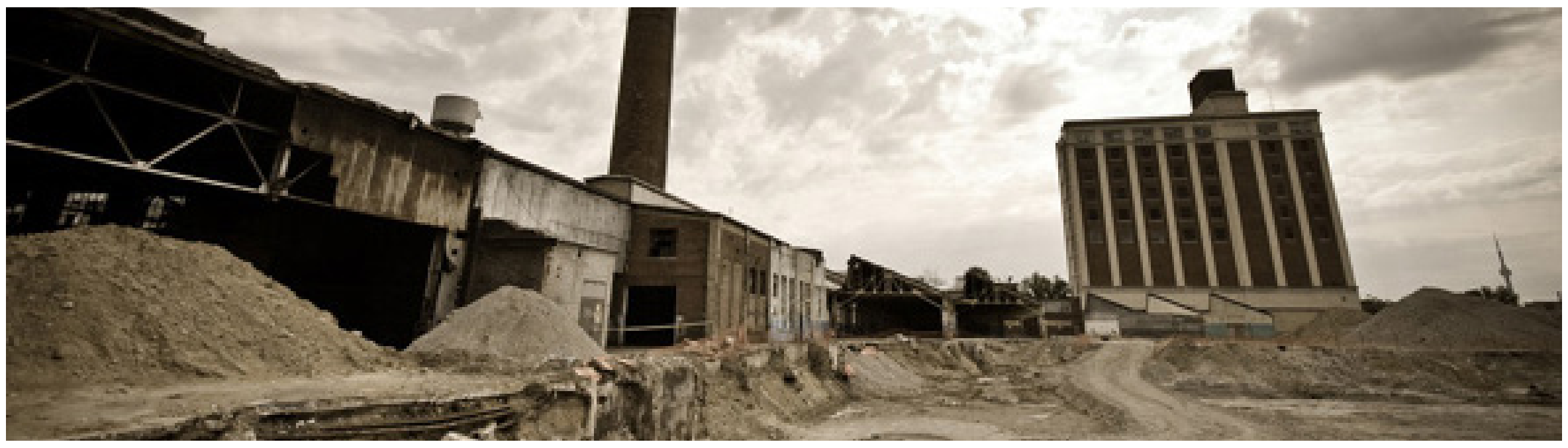

Fig. 39: Project lot with partially demolished industrial building in tact
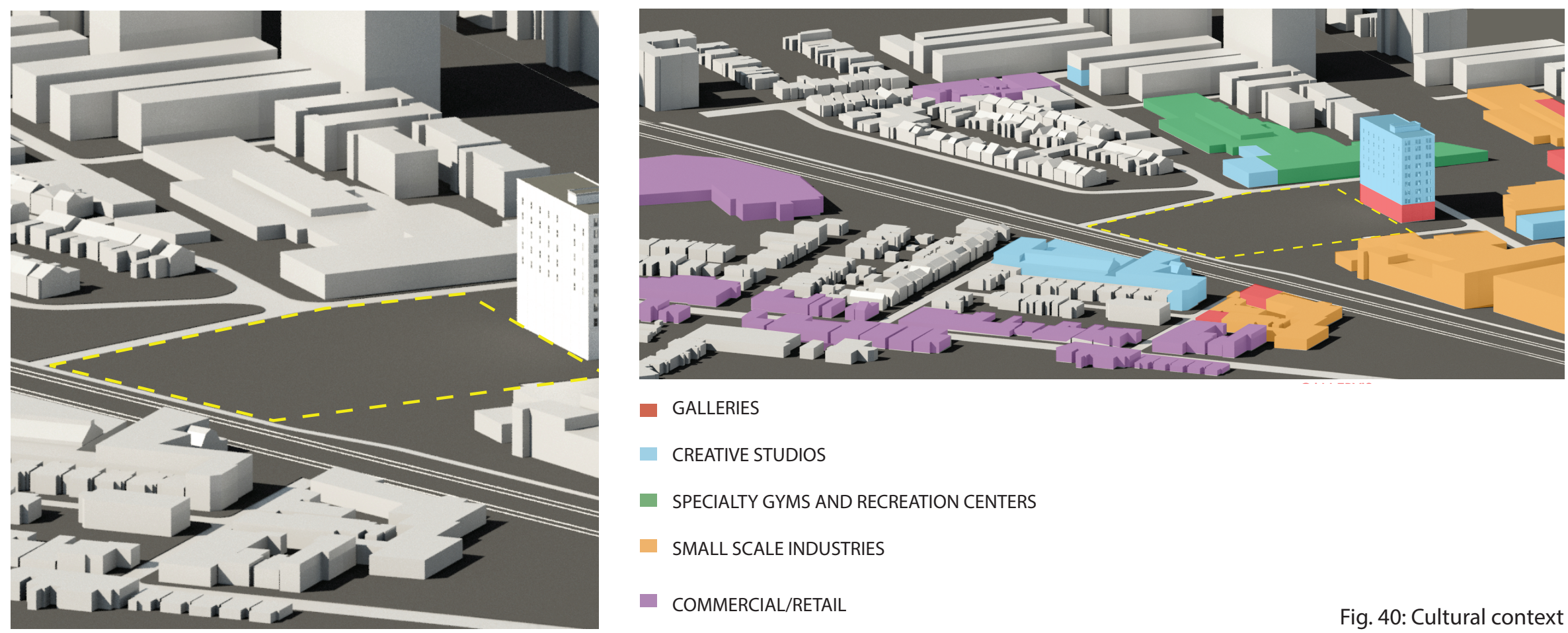

- galleries

- CREATIVE STUDIOS

- SPECIALTY GYMS AND RECREATION CENTERS

SMALL SCALE INDUSTRIES

COMMERCIAL/RETAIL

Fig. 40: Cultural context 
4.3 Site Analysis
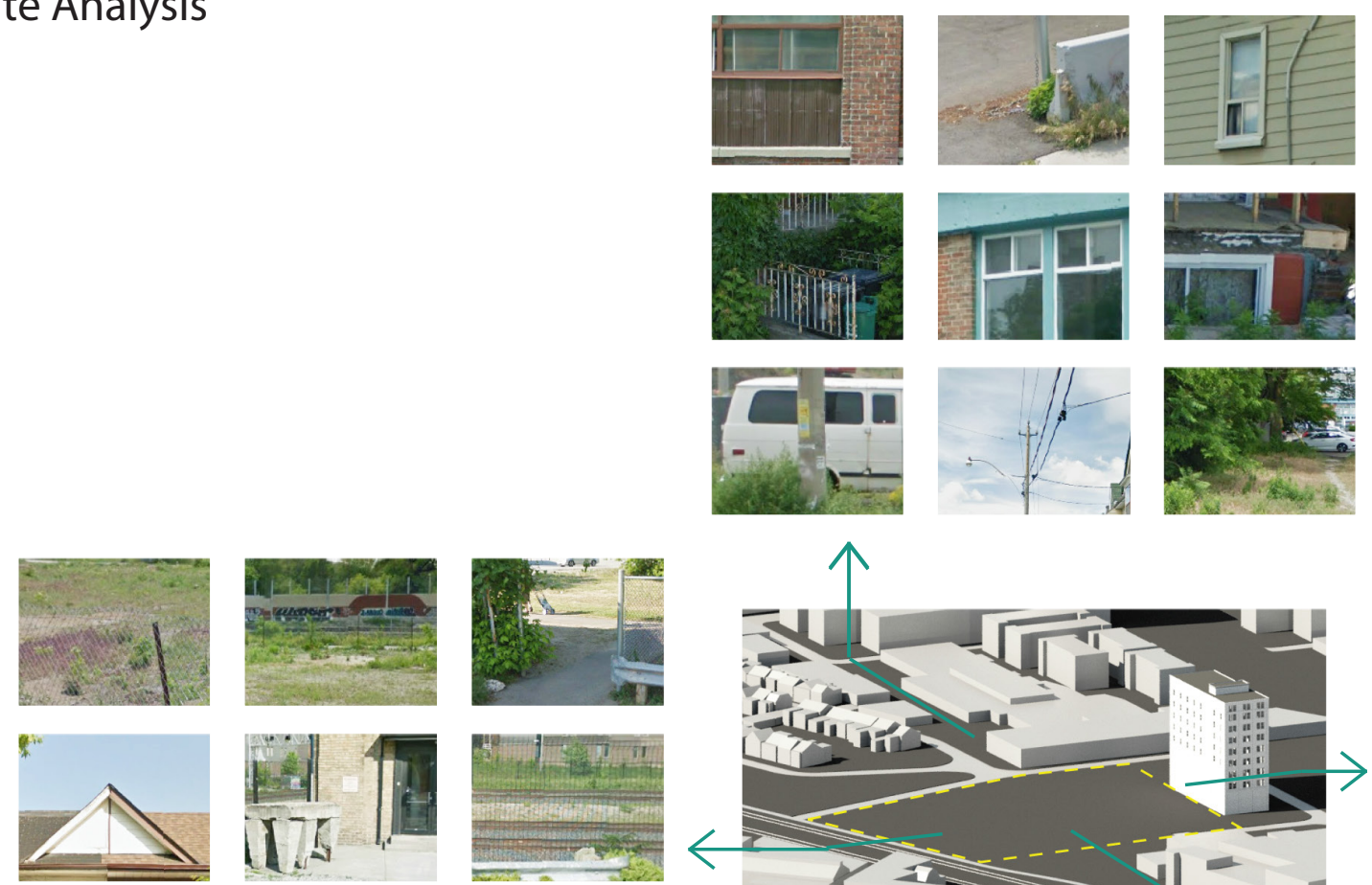

$\left.\frac{1+3}{117}\right]_{1}$
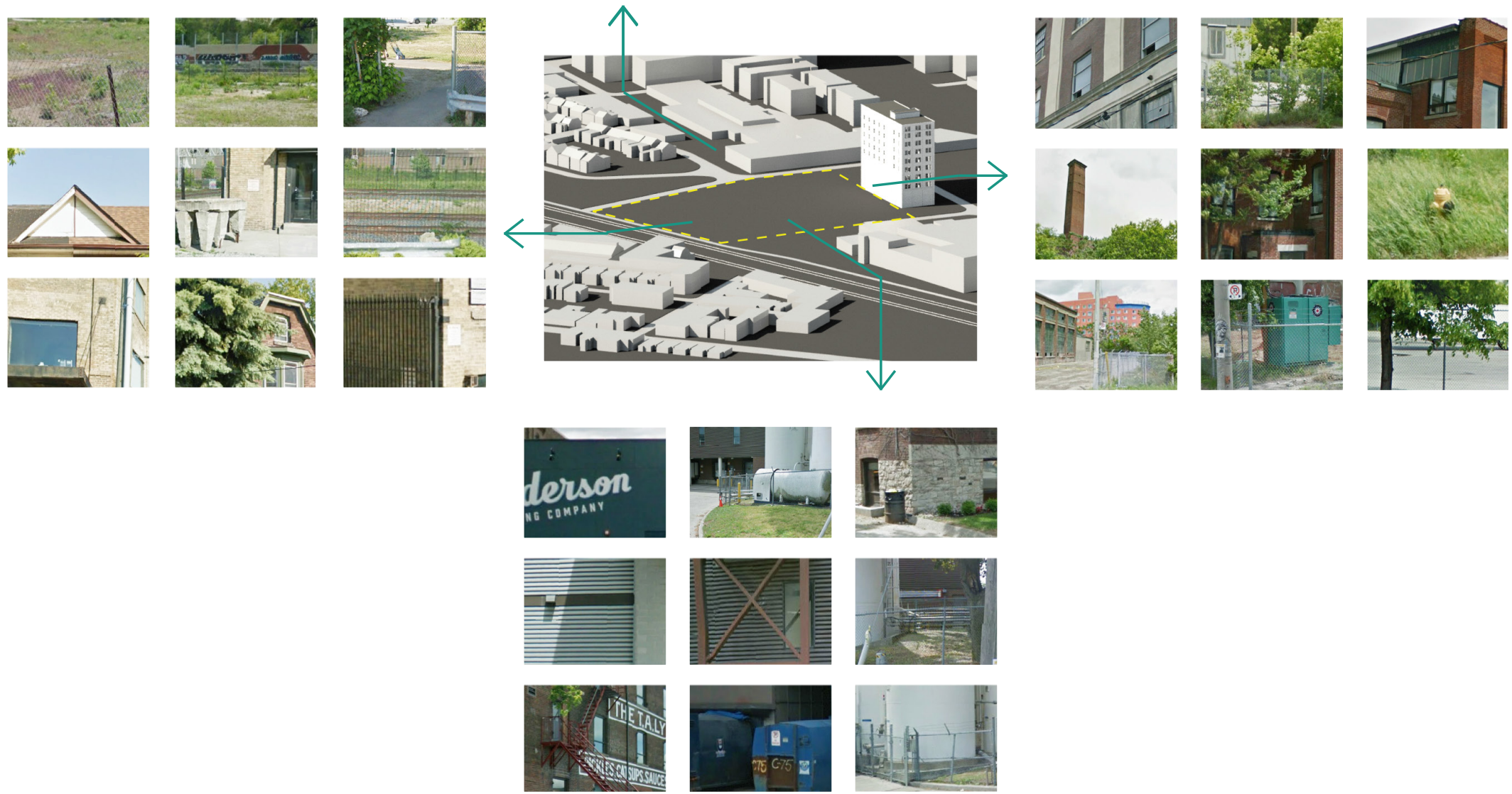
TRAIN STOP

- SUBWAY STOP

I STREETCAR/BUS STOP

$\checkmark$ SUPERMARKETS

- SPECIALTY LOCAL MARKETS

- SCHOOLS

뭄ㅁㄴ SUBWAY LINE

STREETCAR/ BUS LINE

RAILWAY LINE

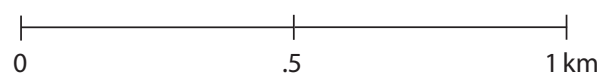

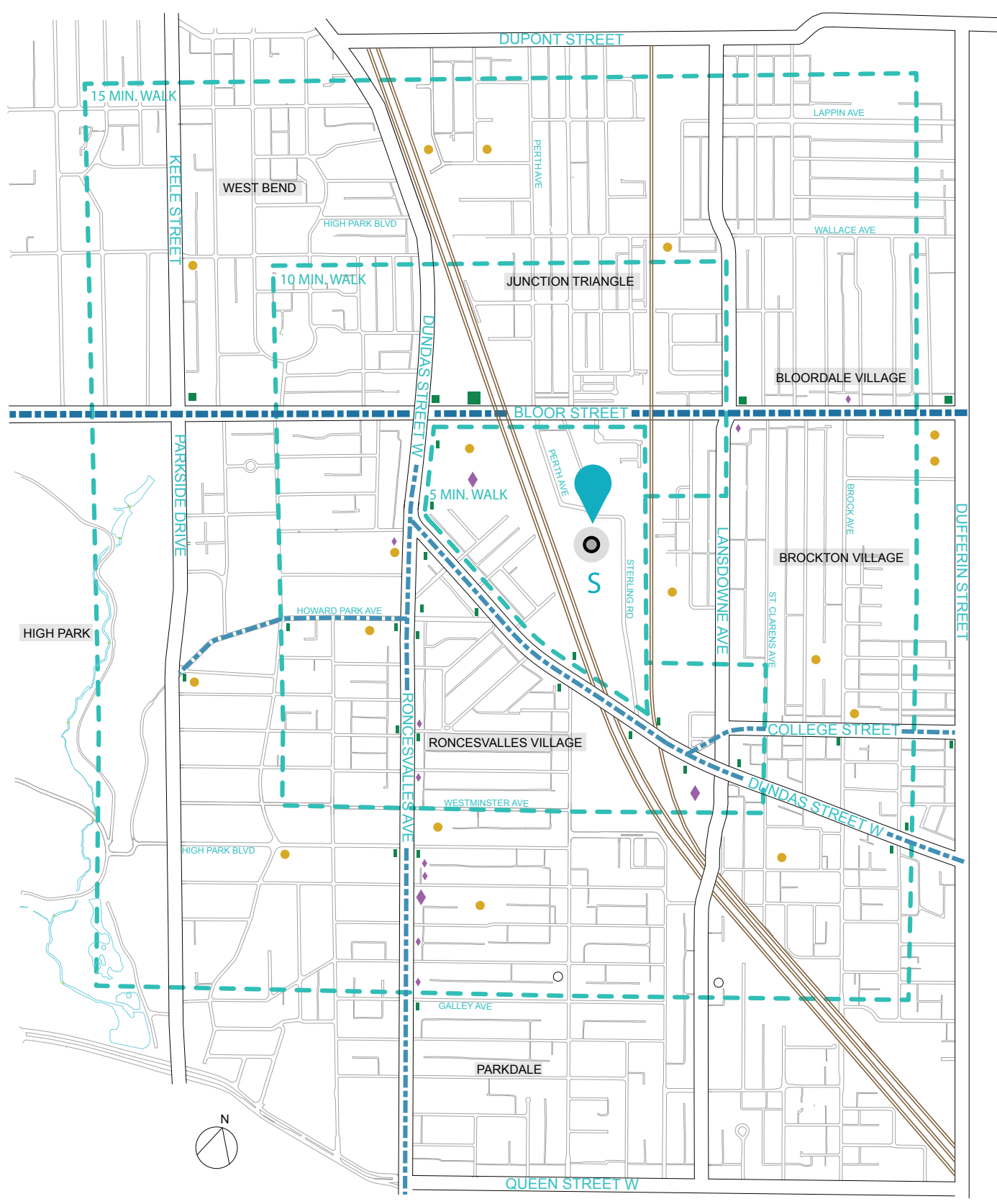

Fig. 42: Site Analysis 
The site wasn't chosen for its ideal need for a residential development, but for its what if potential, of how a residential development could be configured in a post industrial area such as this one and become a catalyst for how the neighbourhood can evolve. It was also chosen to form an alternative proposal to the one being developed by Castlepoint Numa developers.

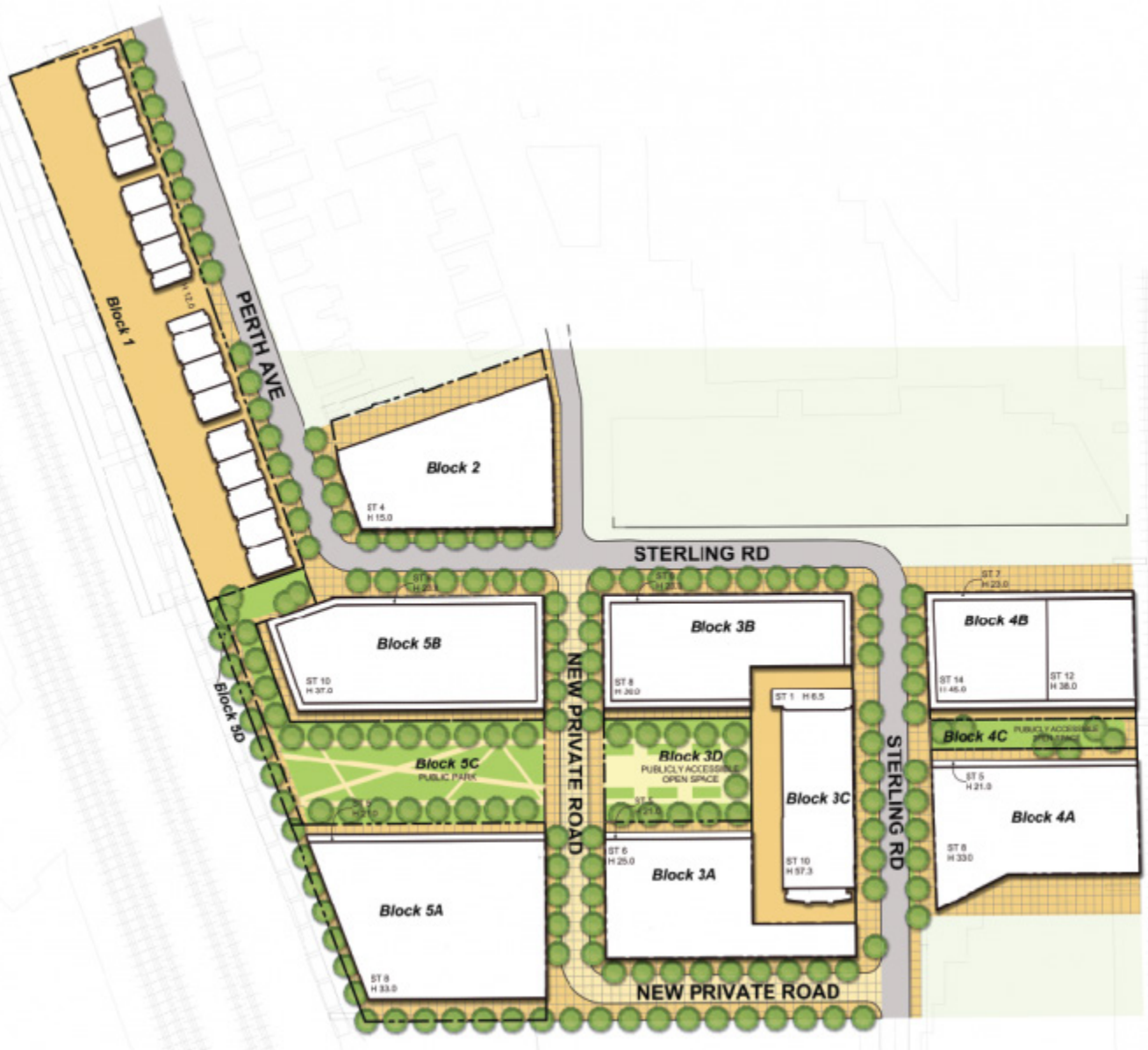

Fig. 43: Site plan proposed by Castlepoint Numa
Castlepoint Numa is proposing to build 565,000 square feet of commercial, retail, and cultural spaces on the site, as well as 540,000 square feet of residential according to their "Update on Perth Avenue - Sterling Road Revitalization Plan" published in 2014.

The goals of the proposal are focused around creating new employment opportunities, specifying that retail, cultural, and commercial spaces will be the main programmatic focus of the site. It is unclear where the residential components will exist in the development, but from the ground level commercial spaces they plan on incorporating, it appears that they will most likely be stacked on top. As the extent of their site goes beyond the boundaries determined for this thesis, they also have plans to restore the historic Tower Automotive building.

It is difficult to critique the proposal in comparison to the thesis project as both projects stem from different objectives. However, the design of the proposal doesn't appear to be based on any specific environmental agenda, whether it be an attempt to re-incorporate nature into our urban surroundings, or to try and protect our resources by engaging in any interrelated approach. The site itself appears to be organized by efficiency alone, although it is difficult to tell from the lack of information available on massing and elevations.

A comprehensive soil remediation program has been used to clean the site contaminants and has been doing so over the last several years. Instead of this intensive approach, the development may have benefitted from using more ecological strategies such as phytoremediation to restore the area naturally. 


\subsection{Intervention 1.0}

Intervention 1.0 was the first attempt at developing a response to the theory outlined in the research. In order to create a balanced hybrid between the three spatial ideologies, and in order to come up with a unique solution that could address development in post-industrial landscapes, the first attempt developed through an iterative design process that began to see the design solutions inherent in ecological principles.

\subsection{A Framework for Emergence}

While the concepts of interrelation, integration, and separation are used as ways of analyzing a built proposal, there are many different routes a project can take to get there. Looking into principles of how ecological communities operated inherently began to satisfy these objectives. In other words, natural communities seemed to operate in a perfect balance between integration, separation, and interrelation, so in order to achieve this balance, principles that could be applicable to a building were picked out to help provide a set of guidelines. If the man-made environment could become more in sync with a natural-made environment, could architecture become less anthropogenically driven and more integrated into the greater ecological sphere of life on earth? If so, could it also begin to satisfy a relationship with nature that is equally resource conservative, protectively compact, yet an integrated part of our health and well being?

The concept of creating a framework for emergence evolved around the idea that the design parameters shouldn't be rigidly tied to a specific building, but could serve as a framework to consult with when intervening in a post-industrial area. The principles arose from thinking about how things in nature begin: their formation, growth, and emergence out of the earth. More specifically, how would an ecological community emerge from an area that has been previously deteriorated? If architecture emerged more like a plant growing out of the earth, or a biodiverse community forming in a forest, wouldn't it be naturally sustainable? As these questions were being evaluated, continual links began to form with how inherently tied we are to the needs of a simple living organism, and how solutions to our complex issues are already encoded into the basic building blocks of life. The three spatial ideologies do not merge into the six principles directly, but through a common middle ground of an ecological community that satisfy's both, in the hope that one would then make a direct link to the other.

The links resulted in a set of guiding principles that began to formulate a set of rules for the intervention. Six principles were developed which consist of self cleansing, emerging in a succession, forming to face the sun, forming to face water, building upon local/existing materials, and expressing changes through time. An exploration began into how these concepts could be used to create the density necessary for the urban population by using them to revive a post-industrial area. 


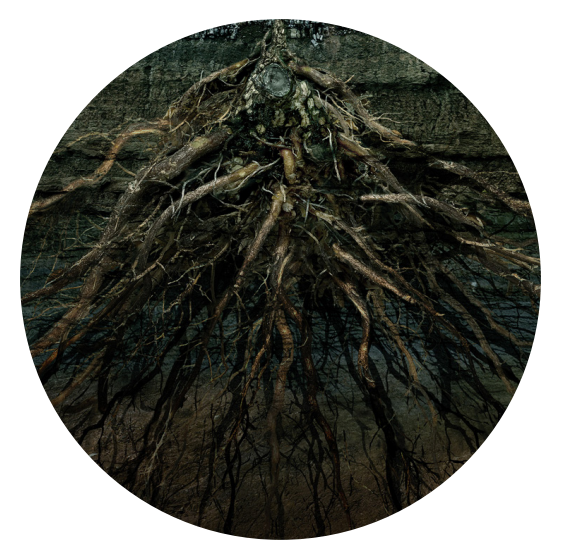

PRINCIPLE \#I: SELF- CLEANSES

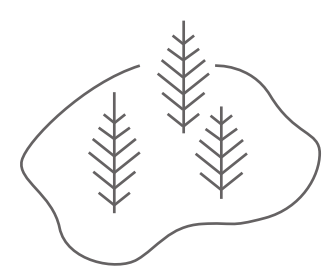

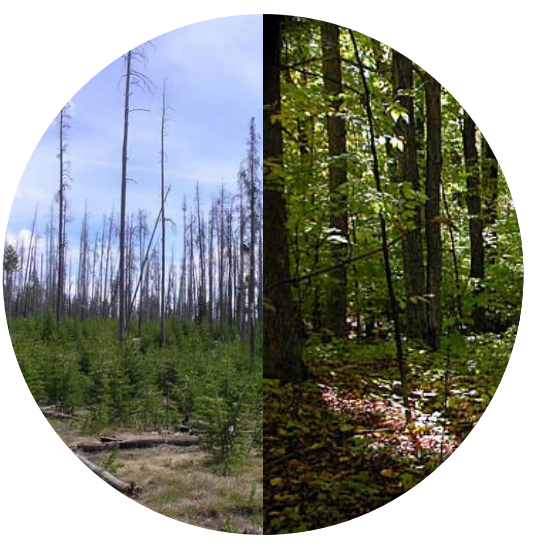

PRINCIPLE \#2: EMERGES IN A SUCCESSION

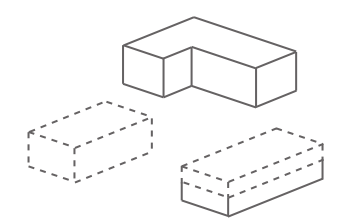

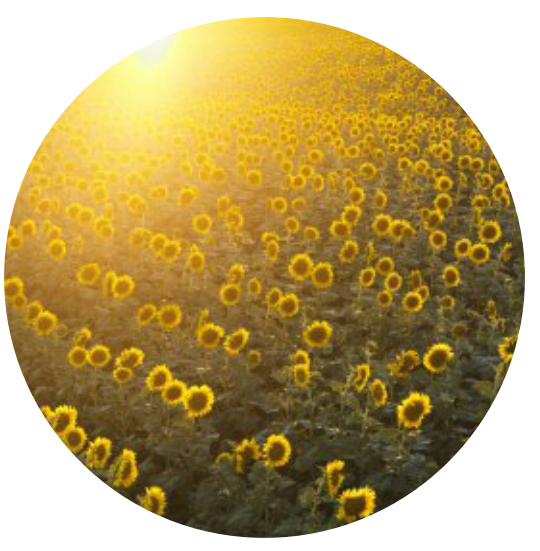

PRINCIPLE \#3: FORMS TO FACETHE SUN

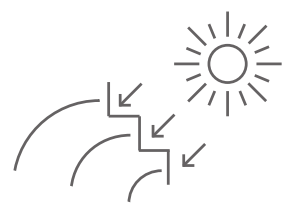




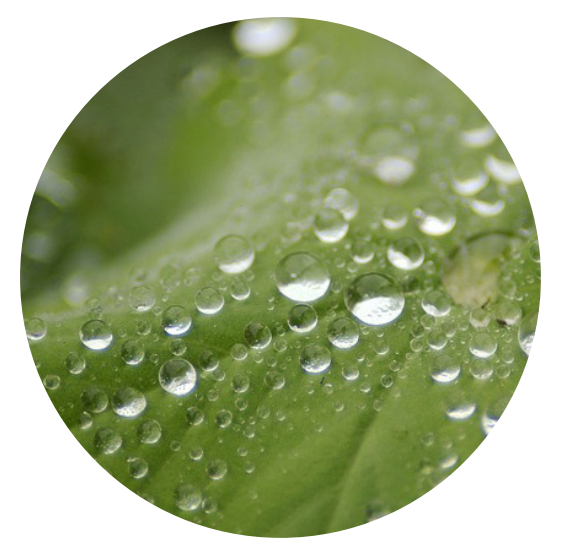

PRINCIPLE \#4: FORMS TO CAPTURE WATER

$$
\left.\sum_{2}^{0}\right|_{20} ^{0}
$$

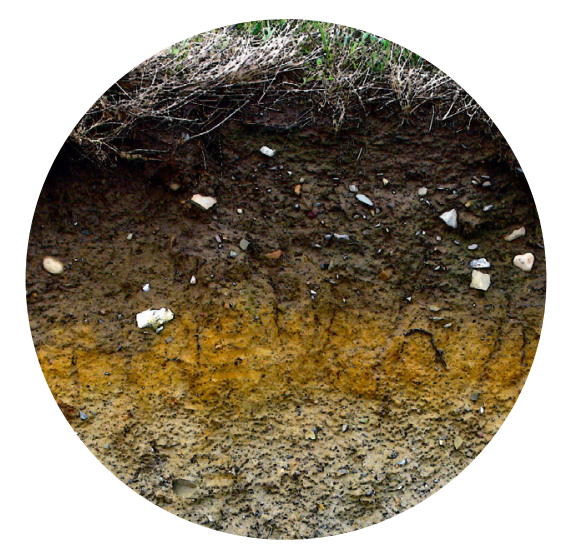

PRINCIPLE \#5: BUILDS UPON LOCAL/EXISTING MATERIALS

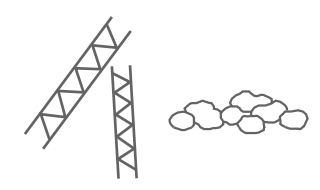

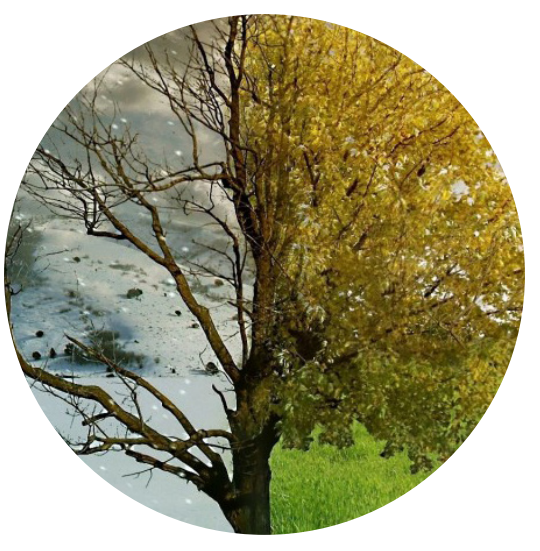

PRINCIPLE \#6: EXPRESSES CHANGES THROUGH TIME

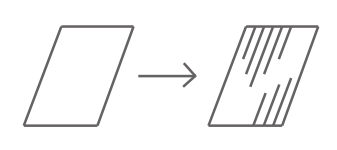




\section{PROJECT SUMMARY}

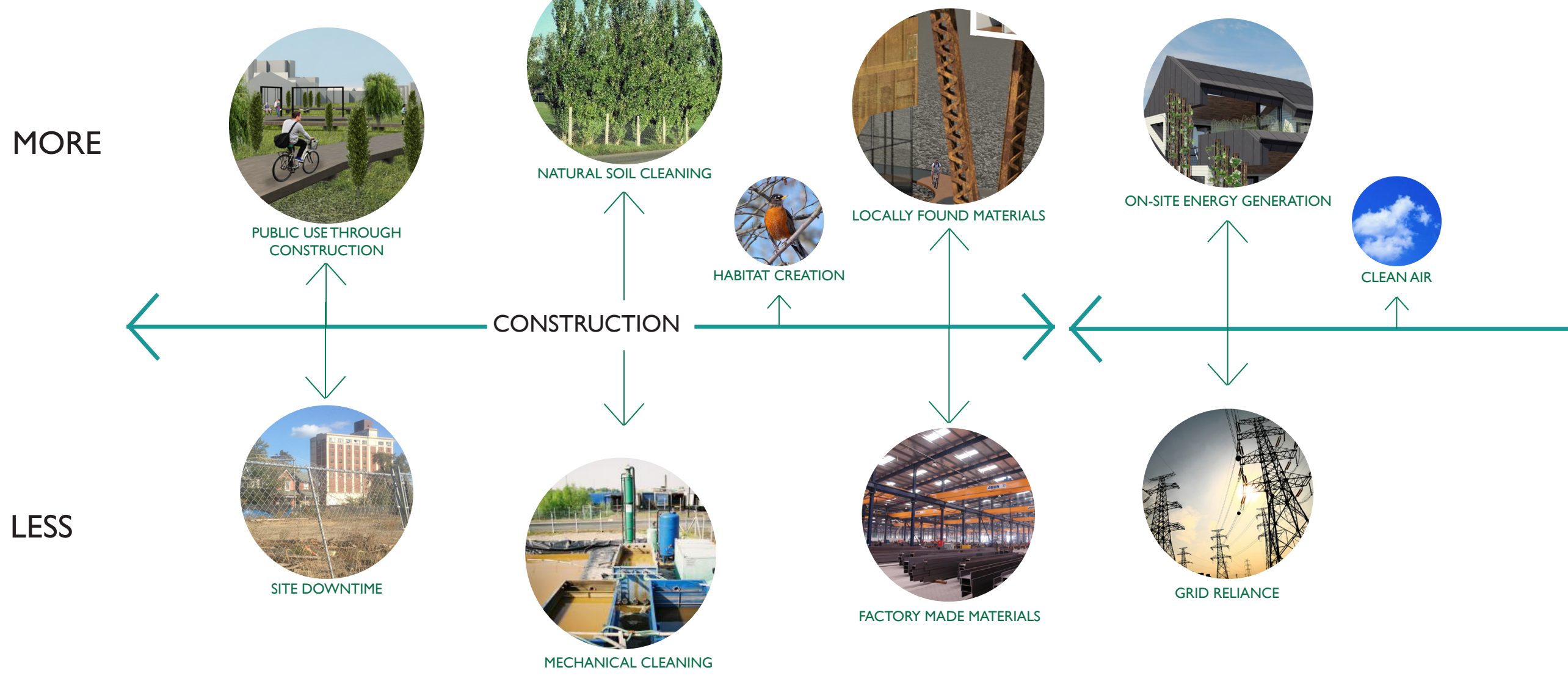




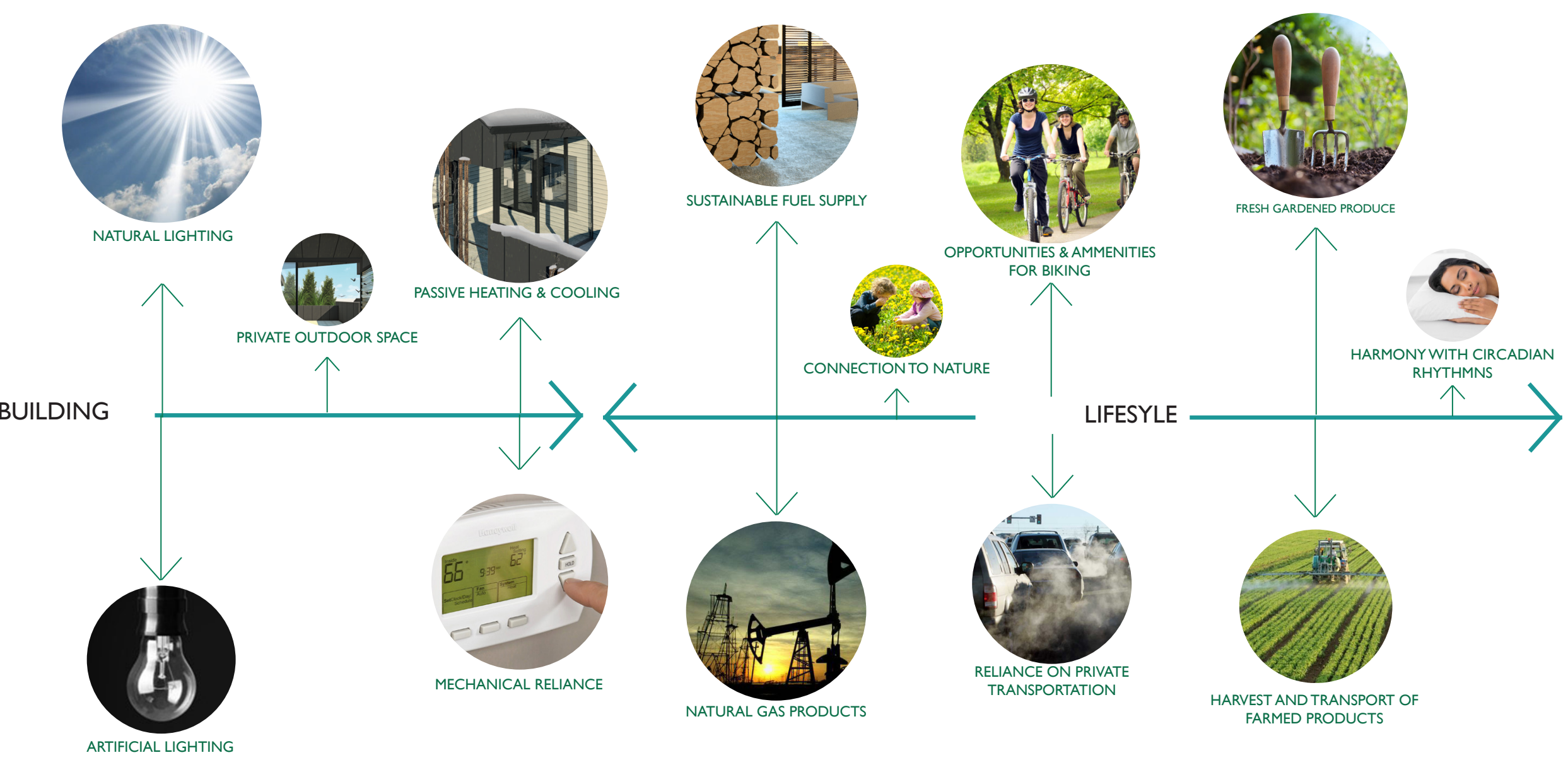


Fig. 46: Site massing development

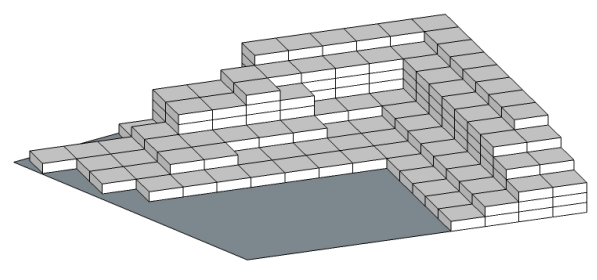

Forming to face the sun and forming to capture water were the two fundamental form shaping generators. Experimenting with abstract units, the initial exploration attempted to maximize sun exposure in a cascading configuration to capture water.
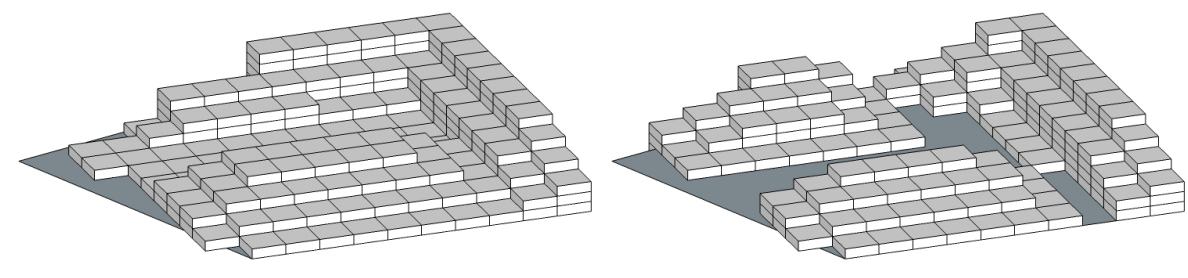

A U-shaped curvature around the south-western sun orientation was the initial starting point, but left a lot of unused space on the site. Placing a lower building in front maximized more space while adding minimal shading, while the larger portion behind needed a decrease in width.
A further carving away of form, in tandem with shadow simulations, began exposing areas where the buildings needed to be cut back to create appropriate building depths, site access, provide sunlight exposure for units, and avoid shading on the others.

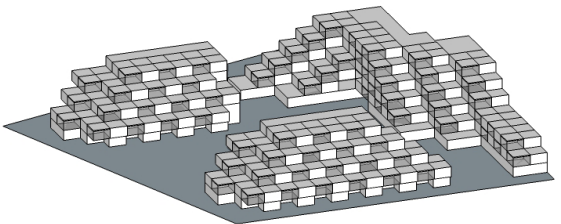

More refined unit configurations, which created 3 faces that could be exposed to the southwest, were implemented with the same massing strategy as before. Refining unit sunlight access, shadow avoidance, and creating the internal hallway circulation strategy finalized the form. 


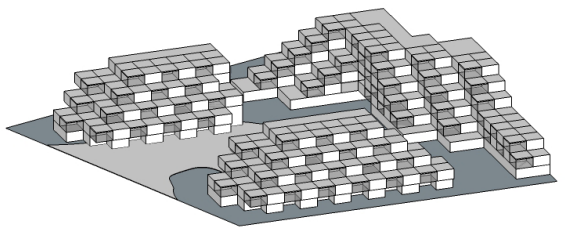

The carved away building mass created 3 separate forms which began to inform the decisions about the site process. One building would be fully emersed in the contaminated section while the others only partially, leading to the idea of incremental development.

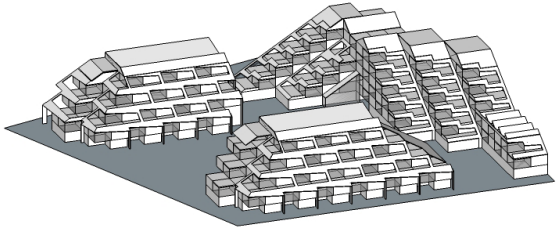

A roof was added to implement rainwater collection strategies, and informed the location of solar panels, the network of vine infrastructure, and balcony configurations.

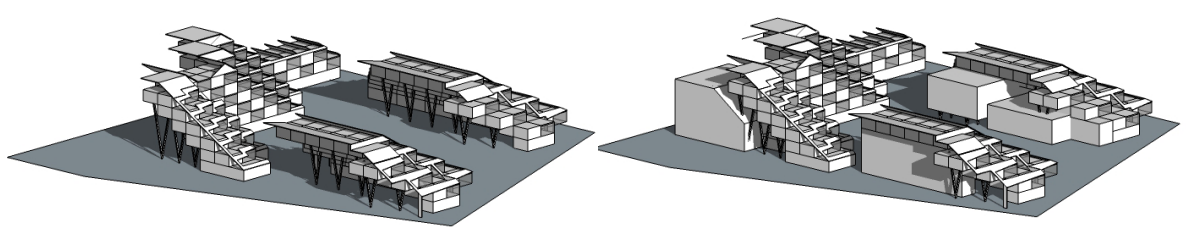

In order to hold up the under-side of the units on the north, the material strategies came into play. It was decided that a recycled steel structure could be used as the structural support, mitigating the excessive structural need.
Underneath these spaces, various multi-use and commercial spaces were created to take advantage of northern light conditions, and to create programmatic opportunities for a more self-sufficient community. 


\subsection{1}

\section{Principle \#1: Self-Cleanses}

The idea of self-cleansing came from the prinicple of how in an ecological community, there isn't the key of human consciousness to extract chemicals and fuels, or manipulate substances that create the "artificial". Therefore, waste as a material or a space is non-existent, as every substance is simply a part of the local cycle of the flow of energy. There are no dead zones, areas left behind, or places that organisms can no longer inhabit because of degradation from a previous use.

Unlike a biological organism, human communities divide their spaces into "use" and "waste", one is used for living, and the others to support it. At an urban level, this can be seen as the divide from industrial spaces to living spaces. At a building level, contamination or garbage is treated with an out of site, out of mind mentality. In the case of this particular site, mechanical efforts such as a pump and treat system have been used to clean up the trichloroethylene spill, putting a large amount of effort and energy into a problem caused by waste from a previous industrial process. Similarly, out of mind mentalities are used for processes such as rainwater and greywater disposal, relying on external sources to move it away and clean any contamination.
The first iteration of the project took the circumstance of a chemical spill as an opportunity to re-green the site, using it as a reason to bring biotic life back into the community. The benefits of this are many - cleaner air, the creation of access to nature that fulfills our biophilic need for connection, the increasing of land values of the community, the creation of a community park for recreational uses, and it grafts permeability into the paved industrial surfaces of the area, helping with rainwater runoff.

The site of investigation is currently a brownfield site, which was formerly an aluminum plant that was attached to the Tower Automotive building. According to the notes from the Sterling/ Tower/Castlepoint meeting on March 23, 2012, a representative from Rio Tinto Alcan, the previous owners responsible for cleaning the site contaminants, gave an update on the current remediation status of the land. The update illustrated that the land is currently contaminated with $\mathrm{TCE}$, a volatile organic compound, as well as a gasoline spill that exists under a building on the south side of the site (Gedrick, 2012, 1). At the time, a process described as "groundwater pump and treat" was being used to clean the contamination, and was intended to be replaced by a "permeable reactive barrier" to further filter the groundwater (Gedrick, 2012, 1).

In an effort to regenerate the site using ecological methods, the idea of phytoremediation was explored to be utilized as an alternative to the mechanical measures currently in place. Phytoremediation is the process of bioremediation 
with the use of plants, where they are capable of simulating biodegradation adjacent to their roots (Pathak, 2014, 586). Various mechanisms work within the plant structure to either contain or remediate toxic substances, and can include processes such as breaking down contaminants, absorbing, metabolization, or immobilizing the contaminant's structure.

The process of phytoremediation has many benefits, as well as a few downfalls. One of the benefits includes cost reduction in comparison to mechanical remediation efforts (Pathak, 2014, 586). It also creates an aesthetically pleasing landscape for local residents in the area, that benefit from the increase of nature provided during the remediation period, and afterwards if the plants are retained. It can also be an effective way of increasing the biodiversity on a site, and helping create local habitats and wildlife connections. However, one downgrade is that the phytoremediation process is time consuming, and often doesn't get chosen over mechanical options (Pathak, 2014, 595). Despite this, the idea of phytoremediation was chosen for the site considering that the former use was demolished in 2010, and even six years later the site still sits vacant as a brownfield lot. The idea of phytoremediation seems applicable in this type of area where development and re-zoning leaves a large period of time for the neighbourhood to have to experience this industrial wasteland.

In addition, phytoremediation has been recommended specifically for petroleum contaminated sites, as studies have shown that cost, timing, and effectiveness are particularly well suited

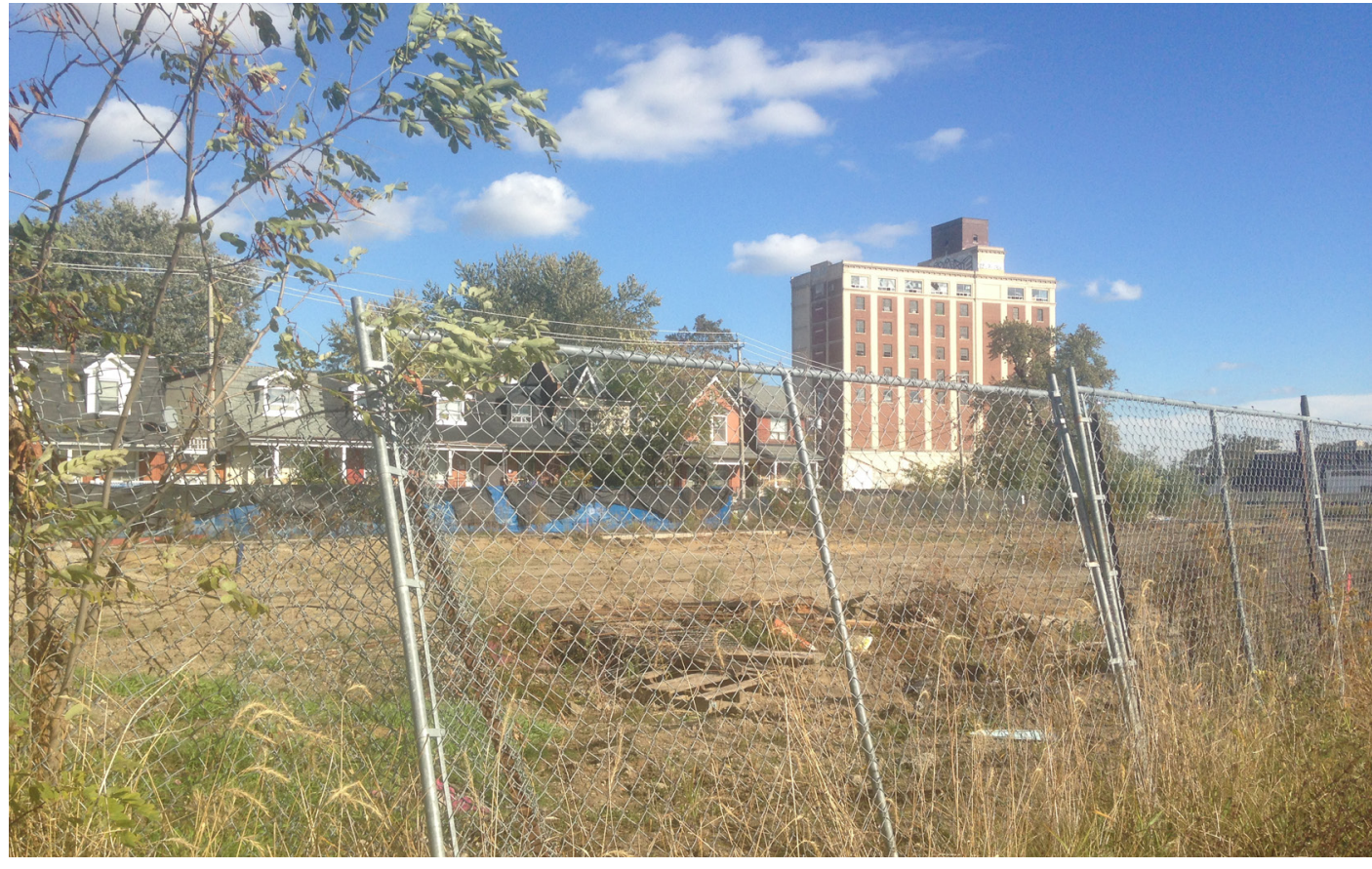

for these areas (Pathak, 2014, 595). Trichlorethylene, the contaminant identified on the site, has also been successfully proven to be remediated through phytoremediation (Pathak, 2014, 587).

Plants most suited for phytoremediation have been identified as willows and poplars, due to their rapid growth, extent of root system, and their ability to extract large amounts of water from underground (Pathak, 2014, 587). In order for the plants to maximize their remediating potential, it is important to plant them so that their roots have the greatest opportunity of reaching into the soil. Although planting requirements differ, one guideline suggested that poplars be planted with a 2.4 meter spacing between rows, and a 1.2 meter spacing within rows (McCutcheon \& Schnoor, 2003,
Fig. 47: Site condition, October 2015. 
594). Both poplars and willows would engage in a process of phytodegradation, which means the roots perform the cleansing process within the soil, and the contaminant does not get absorbed into the plant structure itself (Pathak , 2014, 595). Therefore, site uses throughout the cleansing process can be proposed as no adverse health effects for humans or animals are expected.

On another dimension, the benefits of providing trees can extend to the resident's well being, engaging in the idea of cleansing through the perspective of holistic health. The presence of being in a natural environment has proven to reduce stress, and the sights and sounds of nature have been proven to reduce sympathetic nervous activity,

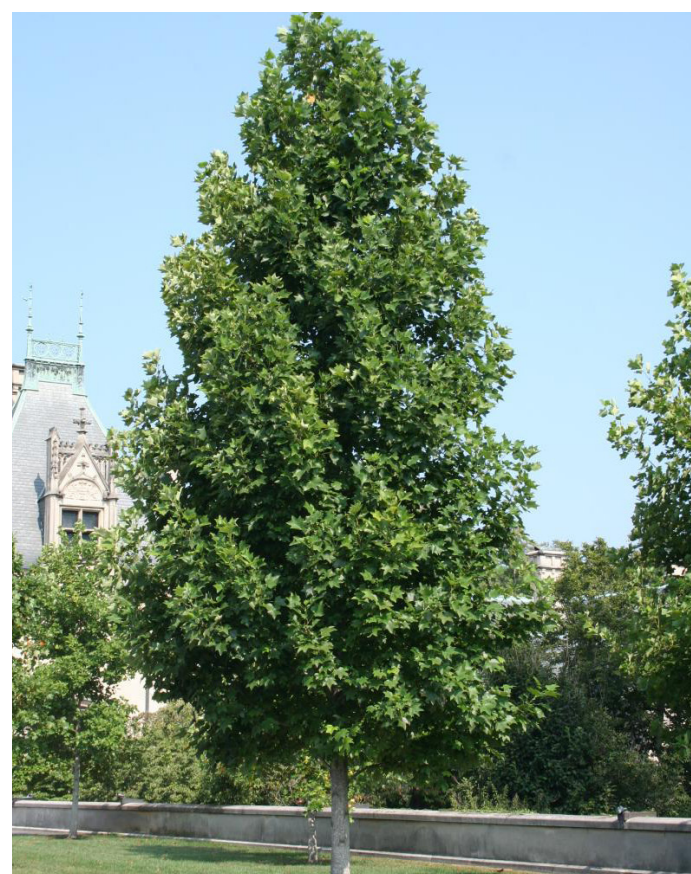

Fig. 48: Example of poplar tree

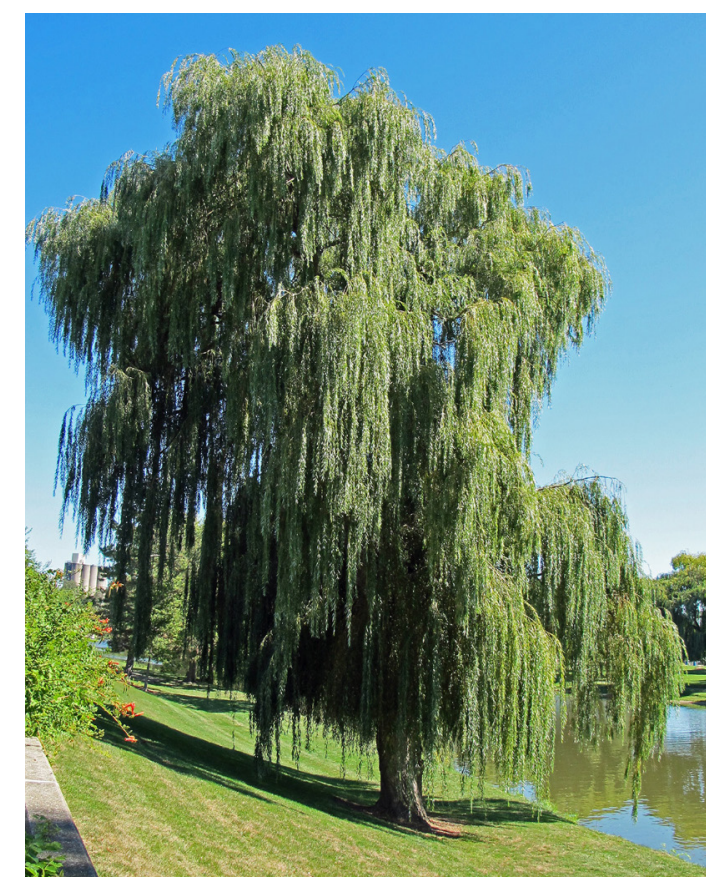

Fig. 49: Example of willow tree restore attention, and promote healing from surgery (Kuo, 2015). For children, the ability to explore and understand the natural world is important for their development, as spending an increased amount of time indoors deprives them of the necessary adventure and engagement that enables learning (Buchanan, 2015). This engagement is addressed by providing various access points and activities around site, as well as within the personal outdoor spaces.

The quality of air may be significantly impaired in urban areas, increasing the need for plants to provide healing and cleansing benefits for the air quality. Plants are known to emit phytoncides (antimicrobial volatile organic compounds) which have been proven to reduce blood pressure and boost immune functioning (Kuo, 2015). The absorption and reduction of pollution that plants are able to absorb decreases negative health effects associated with poor air quality, including myocardial inflammation and respiratory conditions (Kuo, 2015). Forests also have a high concentration of negative air ions, which contributes to naturally reducing depression (Kuo, 2015). Because of the industrial nature of the site, air quality is of paramount importance.

Some of the critiques and ways to move forward that arose out of this section were to employ the planting guidelines more strictly around the site, making sure that they follow the 1-2 trees per 4 meters squared as per the recommendation. In addition, a more critical understanding was needed when it came to the health of the soil and air quality, especially regarding how it is intended to be used throughout the phytoremediation process. 


\subsection{2}

\section{Principle \#2: Emerges in a Succession}

Ecological communities are formed through a process of emergence, whereby an area becomes suitable to larger forms of life after the creation of conditions from smaller organisms. In a forest, a community might begin after a forest fire, and small plants and weeds would be the first organisms to move in. Afterward, larger bushes might capitalize on the new material composition created in the soil, and then make way for even taller trees. The cycle of life is embedded within a process of renewable, filtration, and evolution. This process is reflected in an engagement between different species, as well as within a given organism itself.

Transformation in cities is hardly ever sensitive to existing patterns, ecological or social. New buildings emerge swiftly out of the ground and transform the area indefinitely, cutting off flows of natural organisms through the destruction of vegetation or the paving of surfaces, even creating their own set of weather patterns. The social and cultural context of neighbourhoods tend to be developed with the same velocity, prioritizing change over an incremental development. Instead of slowly emerging and growing into an area, architecture tends to take over a place without addressing an ecological or social context.
This principle sought to reverse some of the ecological disengagement caused by its previous industrial use by looking for ways of integrating a new set of design parameters slowly into the neighbourhood, utilizing the principle of growth developed over time. The intent was to re-weave ecological considerations into the development, while engaging in the areas cultural development.

The phytoremediation process created an opportunity for the site to emerge more gradually, allowing it to be used throughout the construction period, and helping it develop a sense of a community before the architecture got built in. It was intended that this process would begin to promote the site as a new walkable neighbourhood connected to the bike path. Walkable neighbourhoods are as important to human health as they are for urban health, by reducing the need for dependence on transportation. Besides a close connection of various uses, the walkability of a neighbourhood tends to also be determined by the amount of trees that are in the area, for their comfort of providing shade and shelter (Buchanan, 2015). A re-centering of design around natural features can promote physical activity by creating comfort and enticement.

The incorporation of green landscapes into the area is especially important considering the surrounding context of industrial uses that are typically all paved. It was the hope that the principle of succession would become a framework that other industrial sites around the railway could take on as the area evolves and re-develops. Increasing the number of

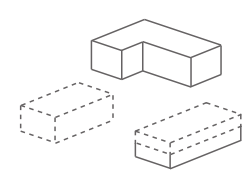


natural landscape connections in an area has also proven to increase levels of floral biodiversity, ecosystem processes and ecosystem services (Francis \& Chadwick 2013, 38). This is because the flow of energy and materials is more robust when a greater number of connections are in place. These connections can range in intensity from forested areas and ravines, connections of park spaces, or even within neighbourhoods that have gardens and tree canopies. The character of any of these connections or corridors has effect on what type of species or organism is able to move through it. For example, a highly mobile bird population may easily make their way through a series of isolated green patches, but the green patches may not be substantial enough in size to allow for the dispersal of a tree population (Francis \& Chadwick, 2013, 40). In looking at a study done by the City of Toronto mapping the tree cover in the city by neighbourhood, the most drastic differences in tree cover occur between the west Toronto railway corridor, Queen Street on the east end, Victoria Park Ave., and a corridor near Dufferin Street. This suggests that the urban conditions created around railway and road infrastructure networks play a large part in cutting the connectivity of tree species, whether it be from the infrastructure itself or from its surrounding urban context. The City of Toronto has a strategic master plan to increase the tree canopy of the city to $40 \%$ from the $28 \%$ as calculated in 2013 , which is estimated to give a carbon storage value of 25 million dollars ("Sustaining and expanding" 2013). The project intends on supporting this goal through its growth structure.

In addition, the health of faunal biodiversity also has direct connections to landscape connectivity and quality. Generally, biodiversity is decreased in urban areas due to the increase of impervious surfaces and a replacement of natural habitats. However, urban regions can have surprisingly high biodiversity levels with generalist and opportunistic species (Francis \& Chadwick 2013, 67) that adapt into the given conditions. These are animals that have a high tolerance for environmental conditions, and are able to flexibly adapt to disturbances. These often have high reproduction rates and short life spans, and are adaptable to foraging activities and food sources (Francis \& Chadwick 2013, 108).

At year 0 , the site would begin its transformation by planting the first set of poplars and willows around the contaminated area. Surrounding rubble would be formed into gabion walls that would help enclose the contaminated area. To allow access, a series of elevated paths would be created throughout the site, protecting the ground plane. The paths would be divided between pedestrian and bicycle circulation to facilitate easy movement patterns. Additionally, small platforms would be created as off-shoots from the path. These could become areas for playgrounds and benches, engaging citizens of all different ages, and creating a reason to meander through the area that allows the opportunity to engage with the plants in the phytoremediation process.

By year 2, the first building would make its way onto the site. During the construction phase, it was intended that all paths throughout the site would be maintained. By building only one building at a time, the phytoremediation process could continue for 
longer periods of time on the land where the future buildings were intended to go, instead of building all foundations at once. It also helped promote the site being used throughout the construction process as only one area would be cut off at a time.

By year 4, it was intended that the second building would be in place, which would begin to add some commercial uses on the site, including businesses that could be, but are not limited to places such as a bike repair shop, health food store, used book store, and gym.

The third building on the north side was intended to be built last because of its citing on the part of the site most contaminated by the spill. It was intended that by year 6 , the phytoremediation process would have run its course and would be safe to put in a permanent development.

After all construction phases are complete, the park would remain inside the development and serve as an enjoyable place for both the new residents and the neighbourhood to use. In conjunction with the material strategies, it was intended that the site will continue to transform as it becomes a productive landscape for the generation of wood. (See principle \#5 for details).

One of the biggest critiques from this section was the allocation of years (0-6), even though it is very difficult to tell how long the phytoremedation will take. Instead, the project could be thought of in "phases" depending on how the process goes. More importantly, the idea of how can the building itself also engage in the idea of succession was brought up and how could it evolve with the transformative process of the landscape.
In addition, the idea that each building was going to be built separately throughout the years had an ecological burden on its own by having to bring construction equiptment and workers back every few years, as oppose to building everything at once. The inefficiency of a gradual development of each building at a time, along with the uncertainty of the phytoremediation timeline was taking a toll on the viability of the concept.

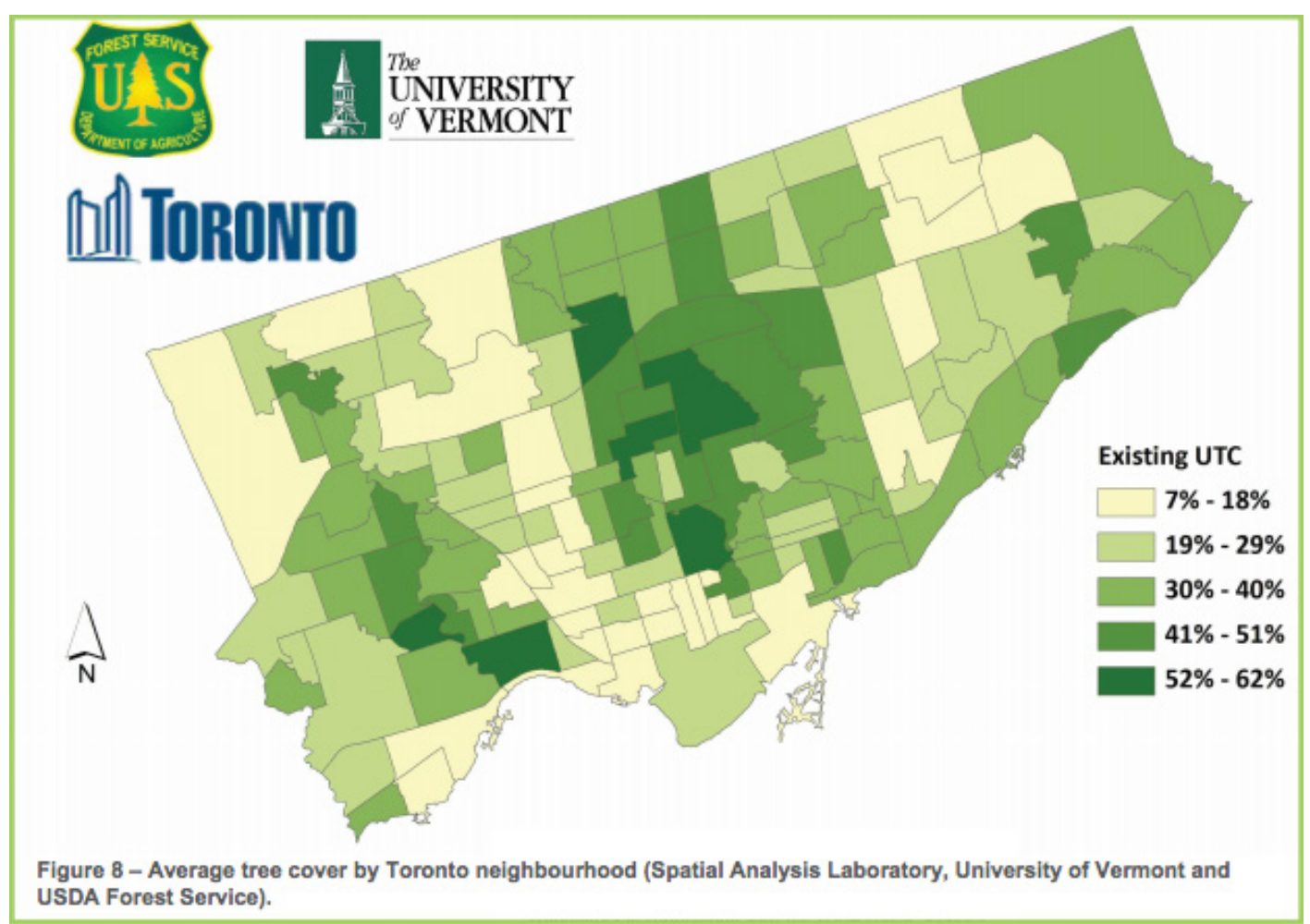
USDA Forest Service).

Fig. 50: Existing Urban Tree Canopy Map 
YEAR 0

WILLOWS AND POPLARS ARE

PLANTED IN AND AROUND THE

EXTENT OF CONTAMINATED

SOIL, INITIATING

PHYTOREMEDIATION PROCESS

TREE GROWTH RATES:

YEAR 2

AS CONSTRUCTION BEGINS

ONTHE FIRST BUILDING,TREES

BEGIN SIGNIFICANT GROWTH

AND ROOT ESTABLISHMENT

\section{TREE GROWTH RATES:}

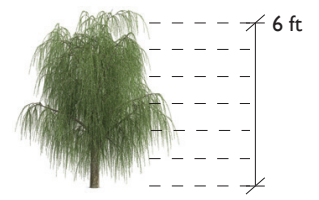

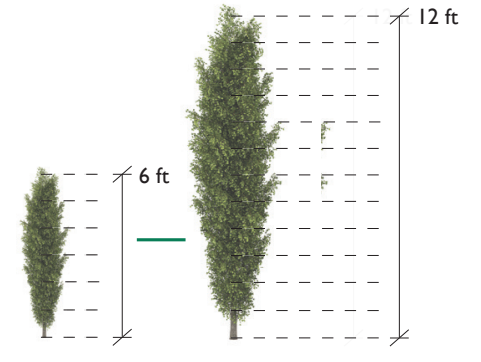

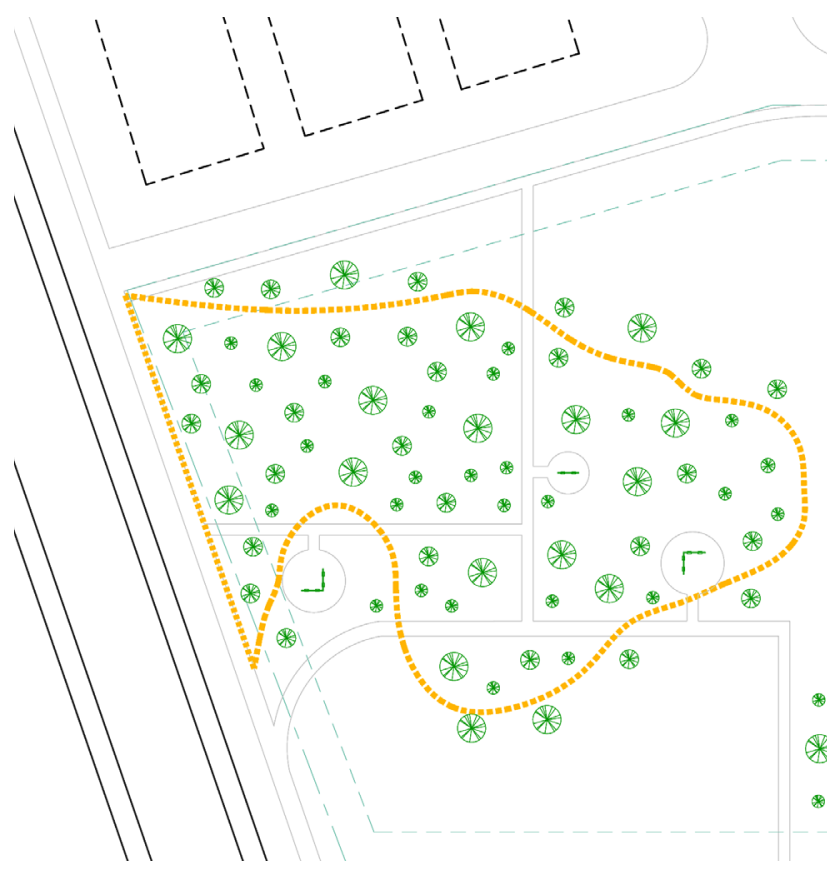

$*$

Fig.51

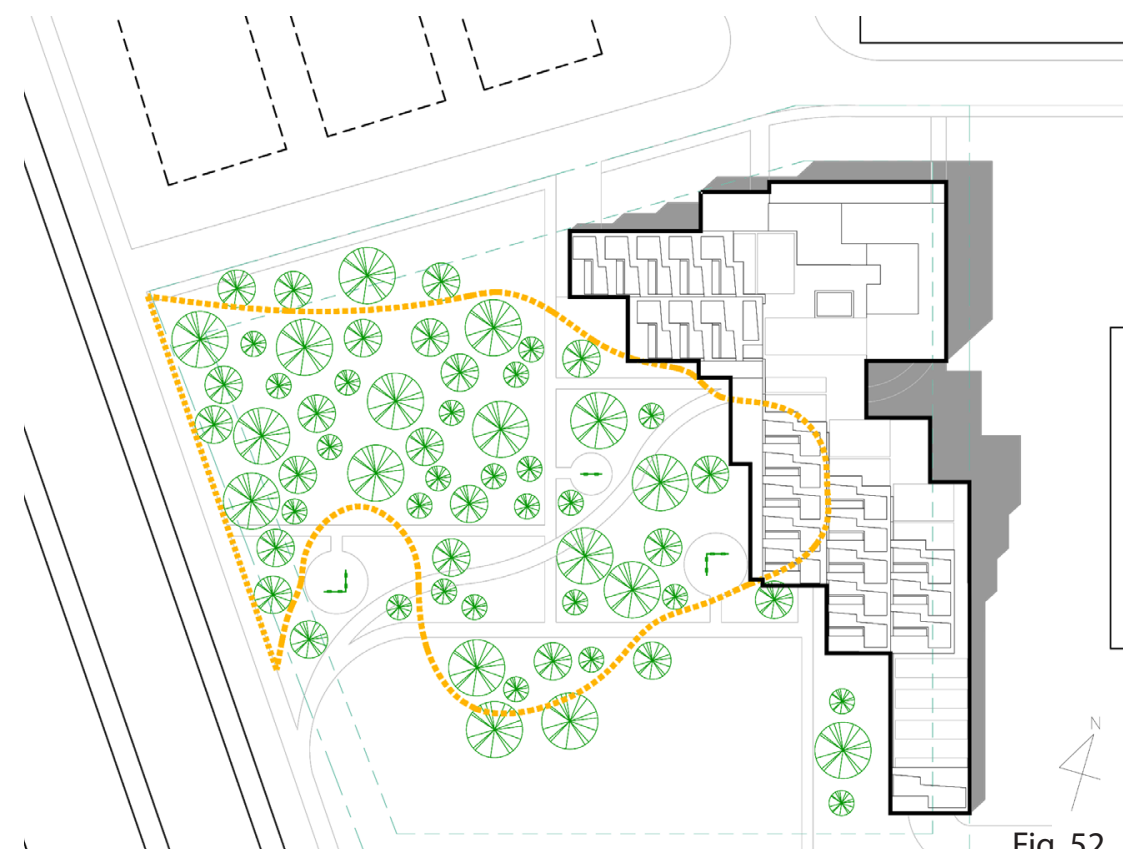

Fig. 52 
YEAR 4

THE FIRST HARVEST OCCURS AT YEAR 4, BEGINNING OF THE SECOND PHASE OF CONSTRUCTION,TO BE ABLE TO CREATE THATCHED SCREENS MADE FROM WILLOW LEAVES

\section{TREE GROWTH RATES:}

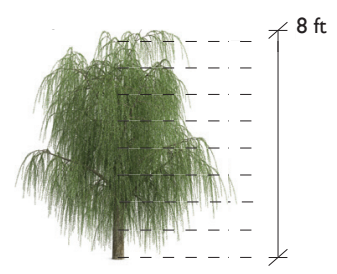

\section{YEAR 6+}

BYYEAR 6, THE CONTAMINATED SECTION IS ESTIMATED TO BE SAFE TO BUILD ON.THE TREES REMAIN ON SITE FOR FUTURE ENJOYMENT,AND CONTINUTUAL HARVEST FOR FIREWOOD.

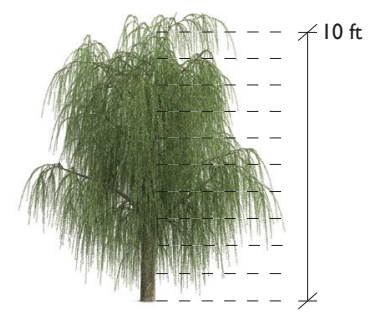

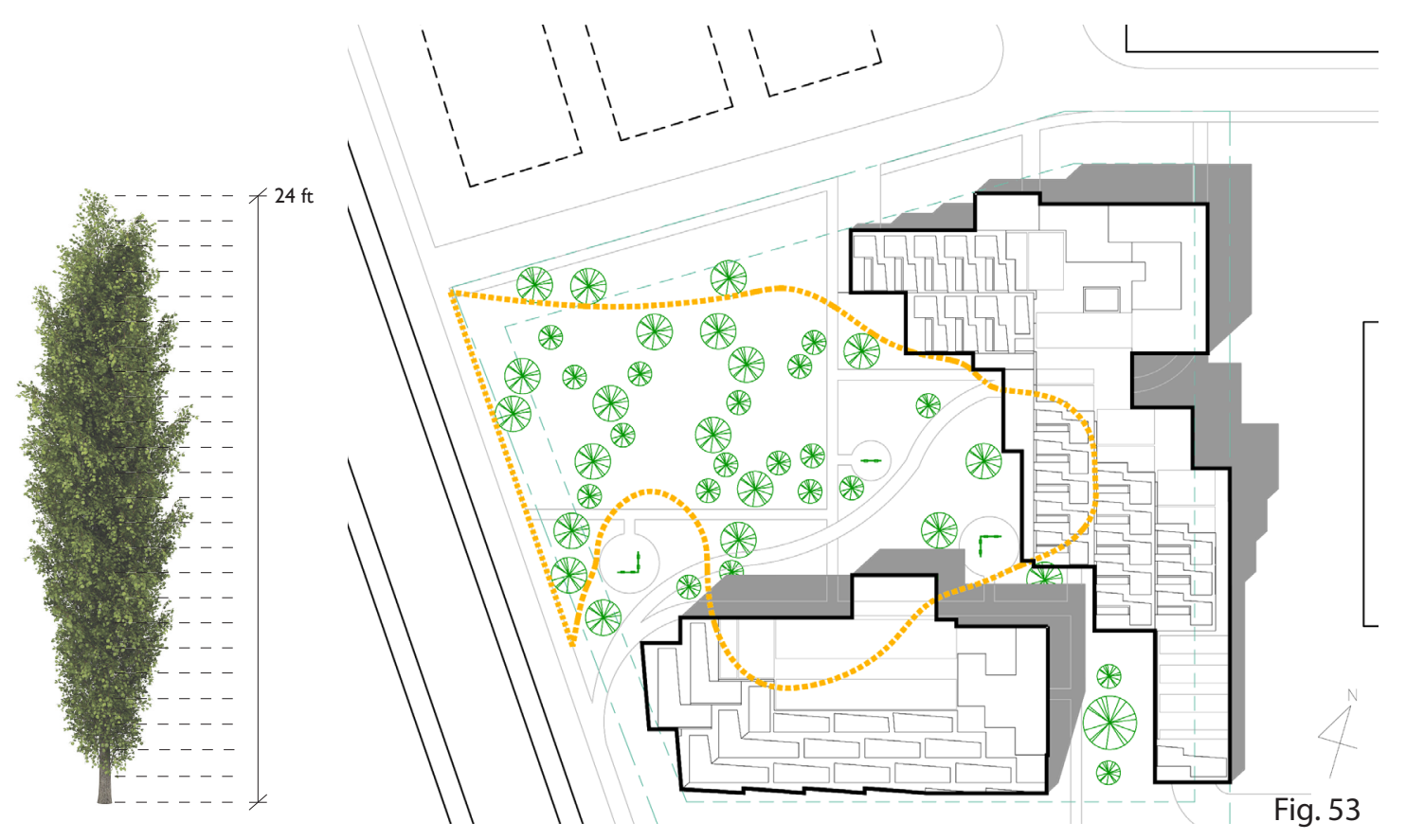
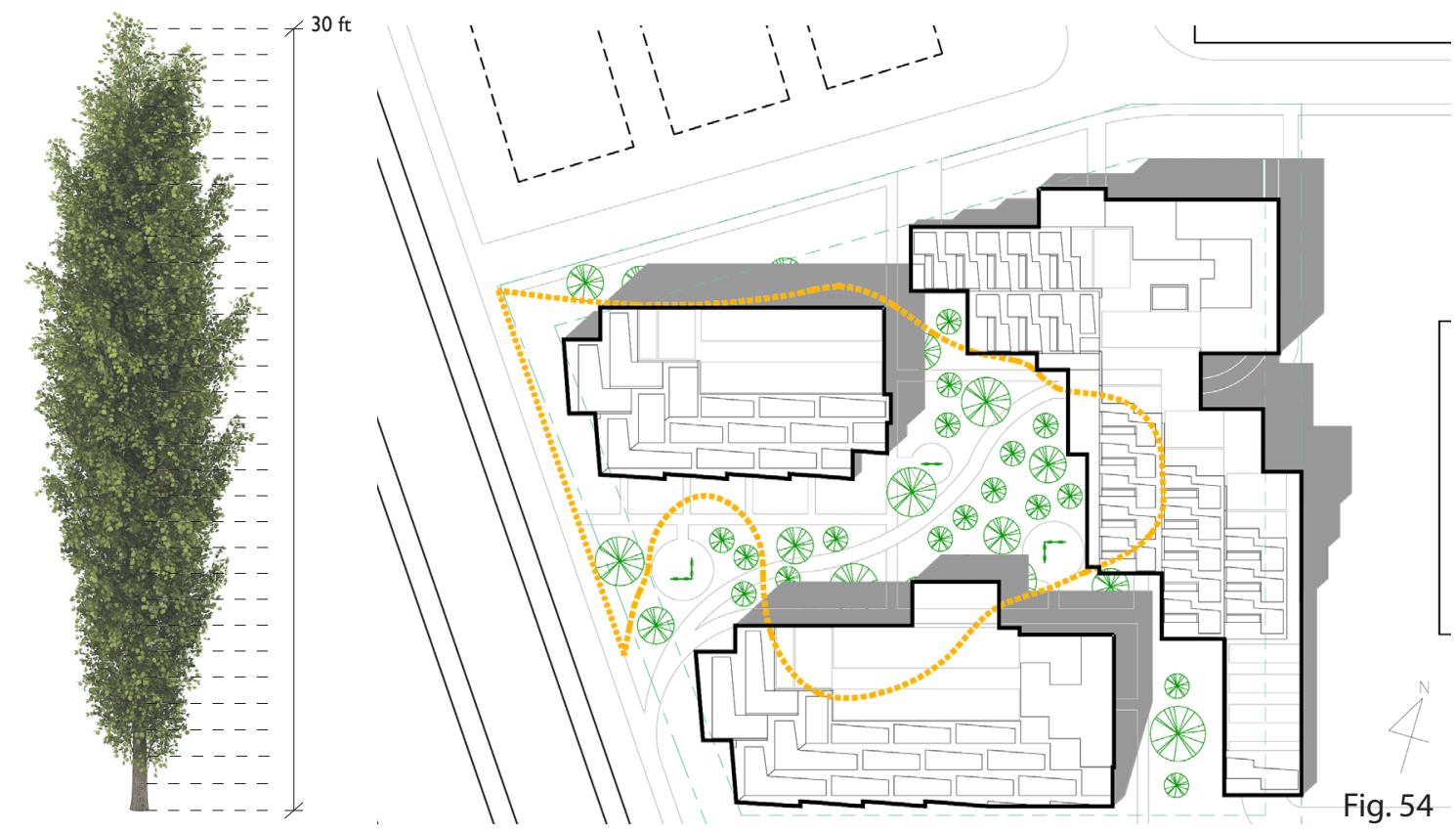

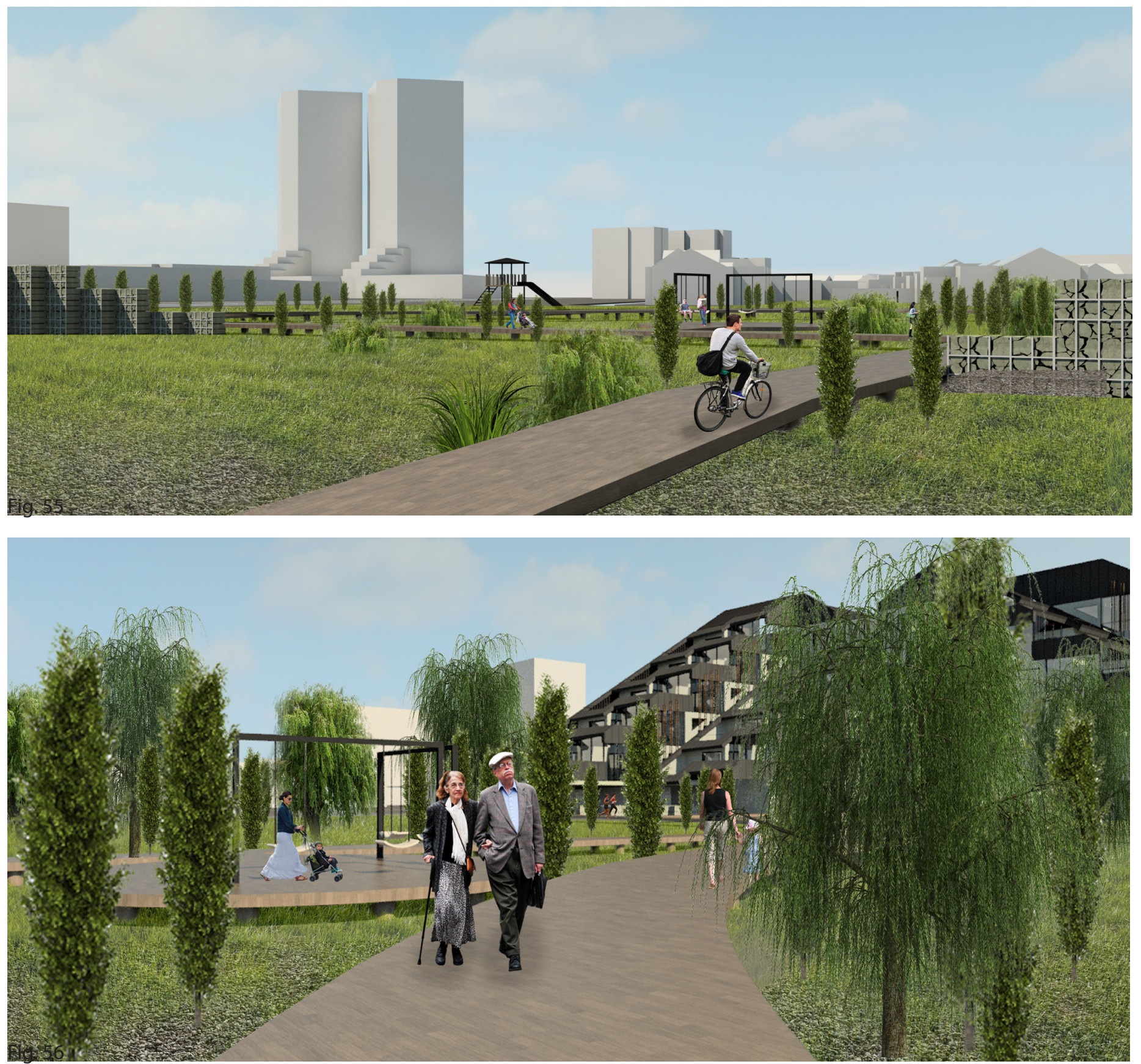

YEAR 2 


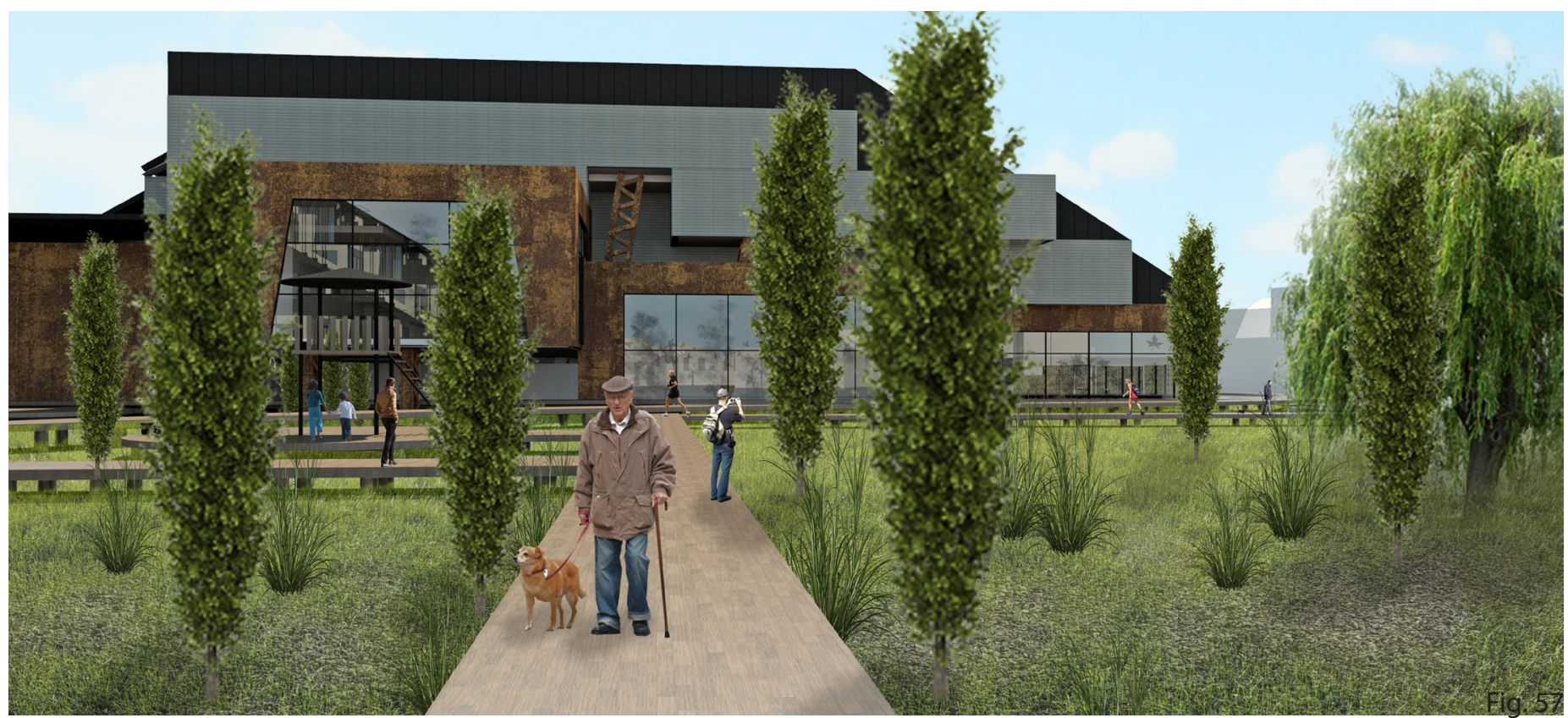

YEAR 6+

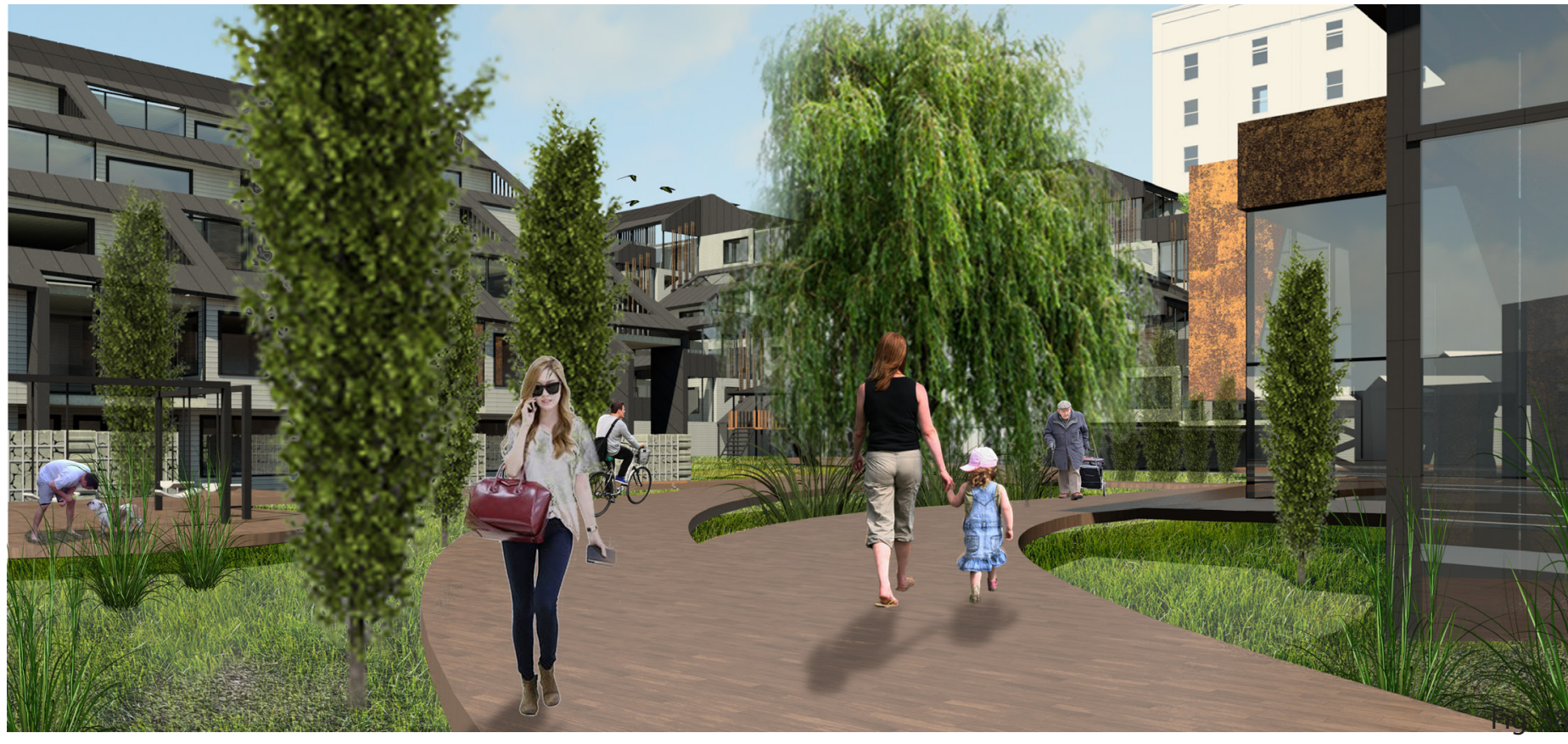




\subsection{3}

\section{Principle \#3: Forms to Face the Sun}

The most basic instinct of a biological organism is to search for sources of energy. On earth we see the greatest amount of biodiversity flourishing where the sun is the most direct, in places such as the Amazon with its closeness to the equator. Without the consciousness of the human mind and our ability to extend our resources beyond their origin, organisms thrive in a direct reflection of the proximity to the source of life. Energy is an immediate resource captured whenever available, and stored only in local metabolic systems or natural flows of energy. In form, organisms tied to the ground emerge in the direction of the sun, expand their surface area to capture light, or fight for their share of sunlight in their given ecosystem.

Today, we take advantage of how we do not need to rely on this direct relationship for our sustenance. We have sophisticated networks of energy grids that connect us to sources of extraction, that can be transported vast distances to serve our needs in the locations that we desire. We prioritize this efficiency, disregarding how our connection to daylight could improve the quality of life. In turn, architecture is not always designed with the first principles of orientation and solar exposure in mind. In response, this project takes these first principles as the guiding factor behind the design.
To maximize solar exposure, the complex was divided into three separate buildings, placed strategically so that one does not cast a shadow on the living spaces of the other. The building took a very assertive stance about how every single unit in the complex deserves access to the southern and western sunlight path. At the very least, studio units had access to either southern or western light. This was created by structuring all of the residential units on the south side, and tucking the public and commercial spaces underneath on the north. This inevitably de-prioritized otherwise typical considerations such as the minimization of hallway space, focused on the economy of layout. Instead, it saw the layout as an opportunity to experience the building for a longer period of time before entering the units, and engaging with the public functions through windows that peak into the activities on the north side.

Inside the units, 3 or 4 faces were typically exposed to the southwestern side of the site, with unit layouts corresponding to morning and evening light conditions. This allowed people to have an intimate relationship to the times of day, an inherent link between us as a species living on the planet that is often ignored in urban settings. The importance of access to daylight has an impact on one of our most basic physiological functions of our circadian rhythm. Like every other organism on the planet, we share a deep relationship to the rhythms of day and night guided by the rotation of the planet, governing our chemical levels of cortisol to stay awake and alert, and levels of melatonin that lower our blood pressure and body 


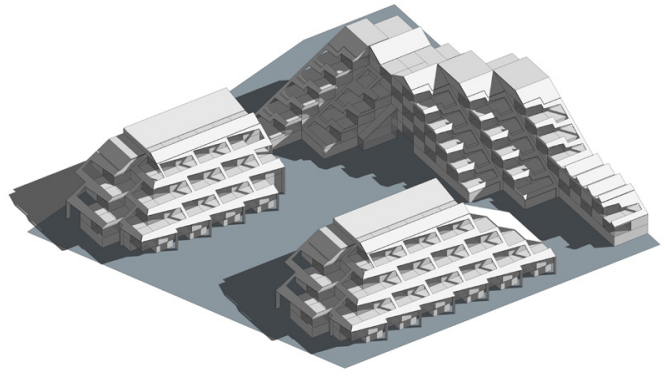

10 A.M.

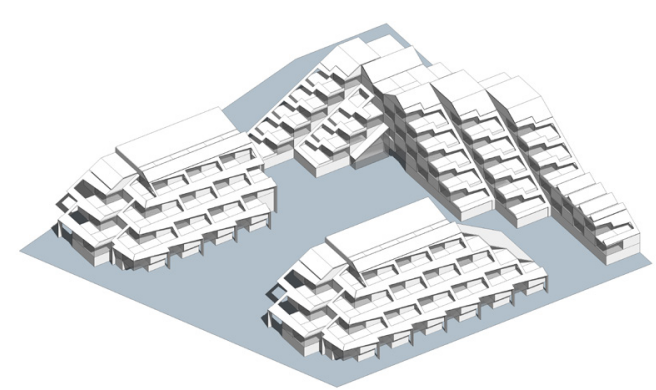

2 P.M.

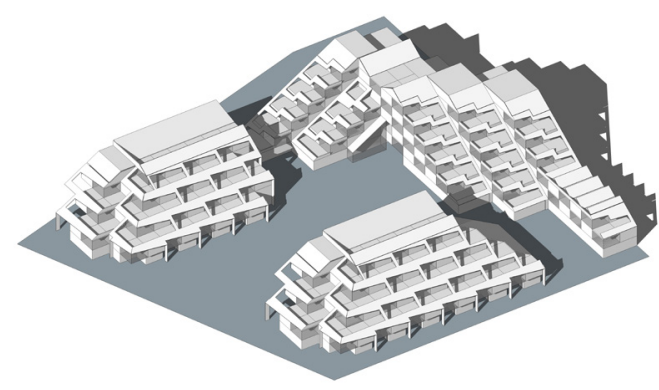

6 P.M

Fig. 59 (above) : Shadow studies on Sept. 21 Fig. 60 (below) : Arial view of project proposa

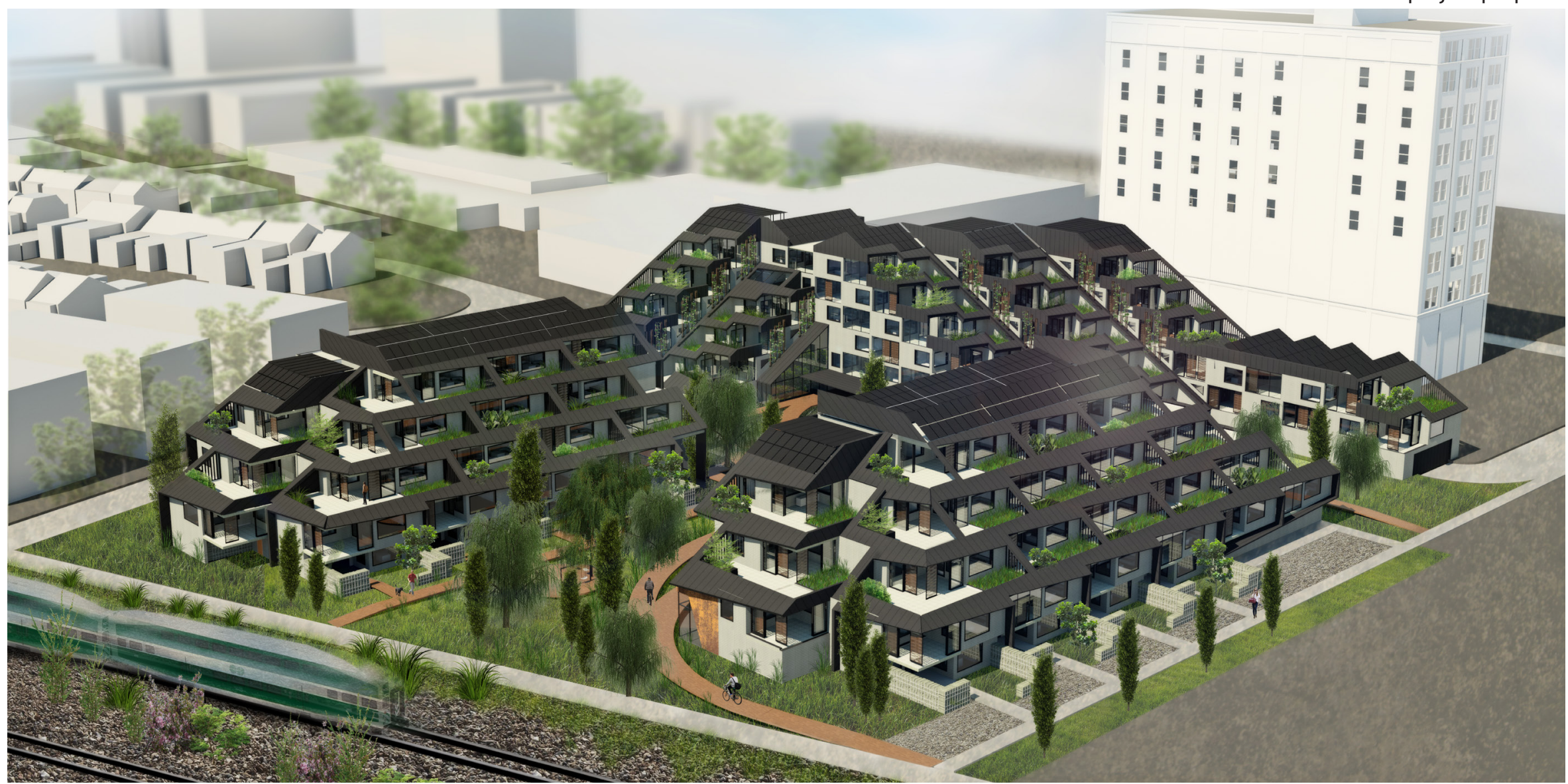


Fig.61 (left) : Balcony space Fig. 62 (right): Diagram of therma buffer zone operation temperature at night (Buchanan, 2015). The layout of the units would help break the bond we have with artificial lighting, extending the period by which we can use immediate sources of energy and help with better sleeping patterns. An interdependence could be re-aligned, improving human health by giving us the opportunity to experience a sacred connection, and the energy that can be derived from it.

Enclosable thermal buffer zones created an added level of capability in extracting temperature and sunlight patterns to benefit from the climate at various times of the year. Deep overhangs enclosed the buffer zone, allowing sunlight to penetrate in the winter months, and kept the high sun angles out in the summer. These spaces were highly convertible with operable glass panels on the south and west sides that could completely open or close. On the western facing sides, thatched screens were provided to shelter from the low western sun angles when de-

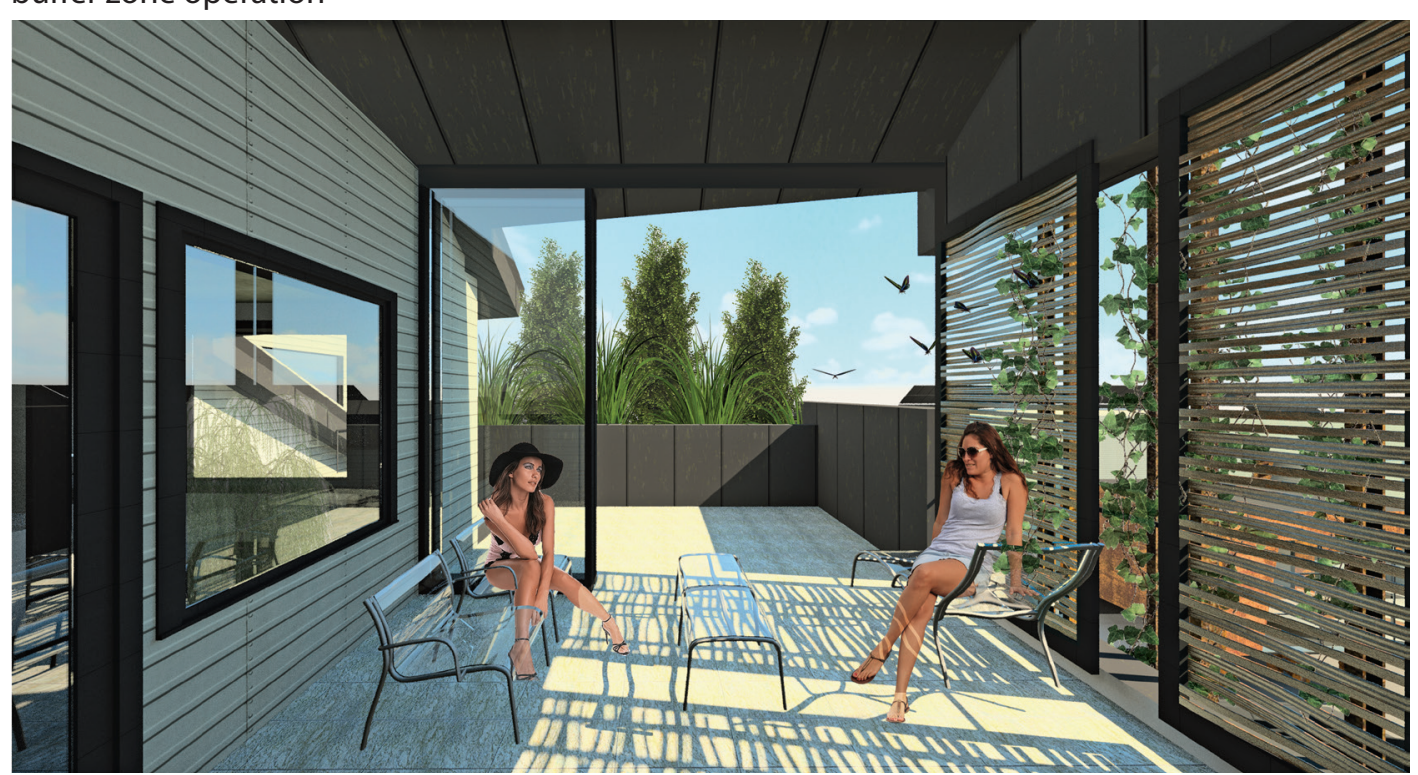

sired (see material strategies for detailed explanation, p. 65). These became intermediate spaces residents could enjoy that extended the use of outdoor space later into the fall, and started it earlier in the spring. The quality of space would feel more like a backyard than a balcony with the presence of vegetation surrounding the outdoor space. Coupled with a mechanical system of an air source heat pump, each unit could extract the benefits that a space enclosing a temperature more desirable than the direct outside could offer, including a cost and energy savings for the input of the air source heat pump.

As a final measure, solar panels were incorporated into the form of the roof to derive energy in the most direct way possible for needs more intense or specialized that natural light could not provide. There was a total of $7195^{\prime}-6^{\prime \prime} \times 3^{\prime}-6$ " panels incorporated into the development, offsetting some of the energy requirements.

A major aspect that needed to be considered in regards to light and quality of space were all of the commercial ammenities and hallways tucked in behind on the north side, unable to get the same benefits as the south-western facing units. Underdesigned at this point, they needed to be an extended part of the concept and not an area left behind.

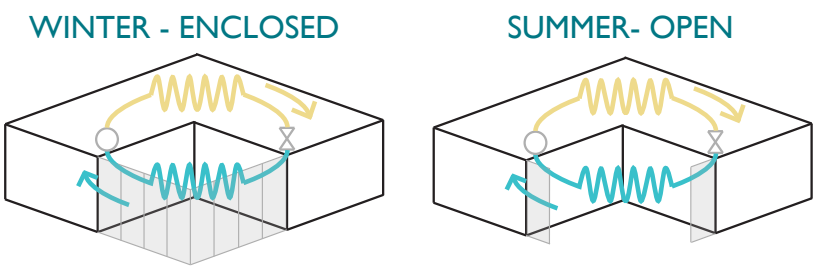


ONE BEDROOM + DEN

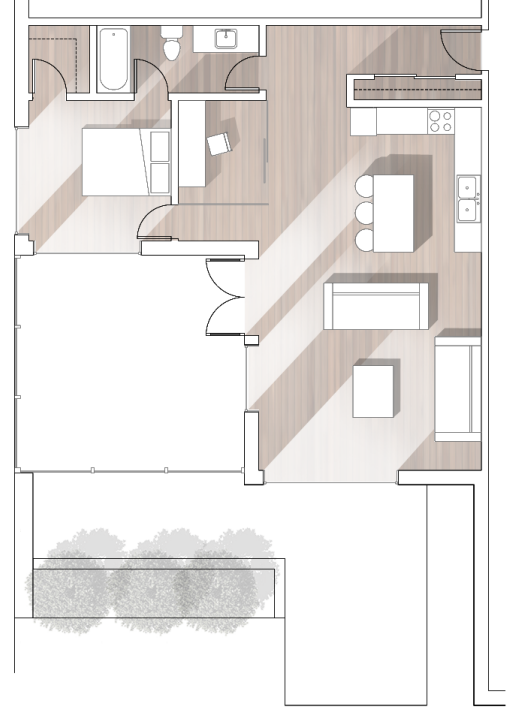

ONE BEDROOM + LIVE/WORK OFFICE (GROUND FLOOR ONLY)

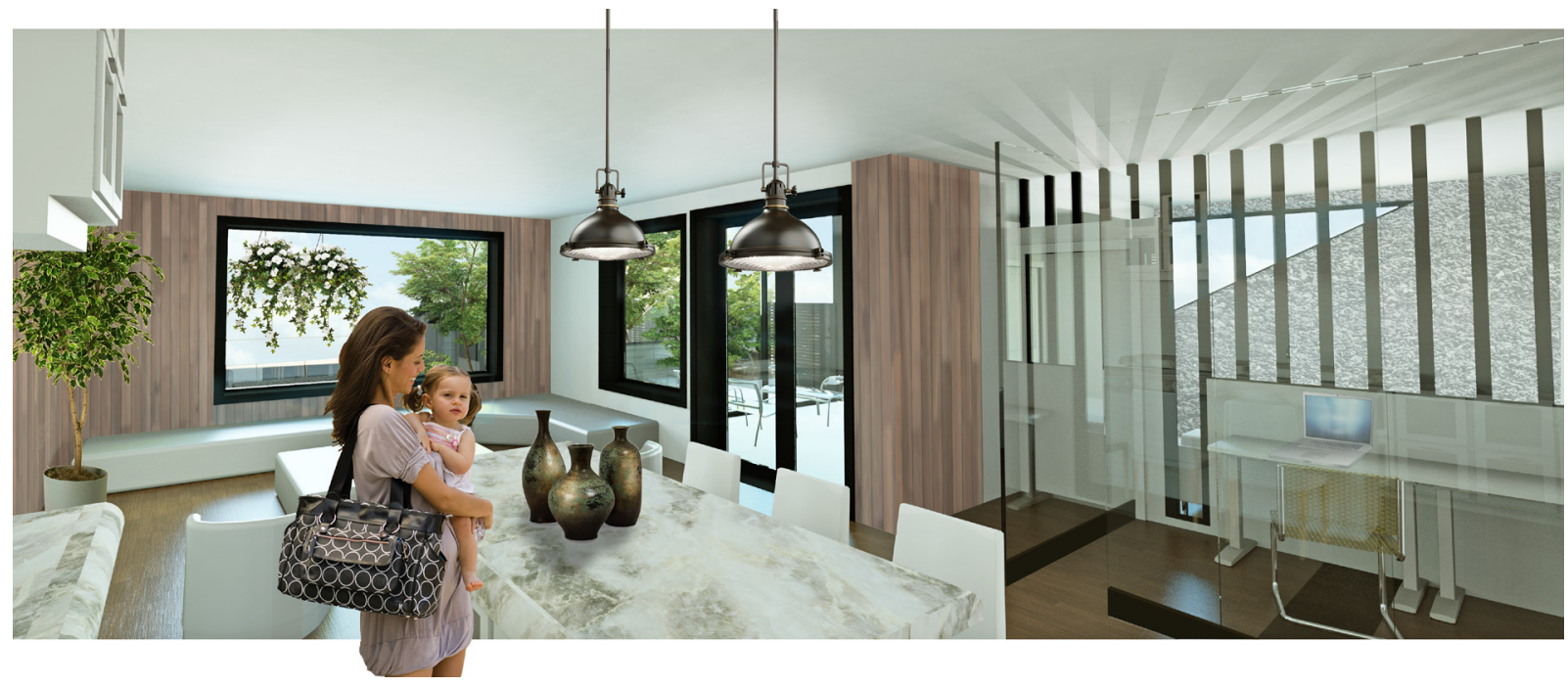

TWO BEDROOM + DEN

\section{UPPER LEVEL}
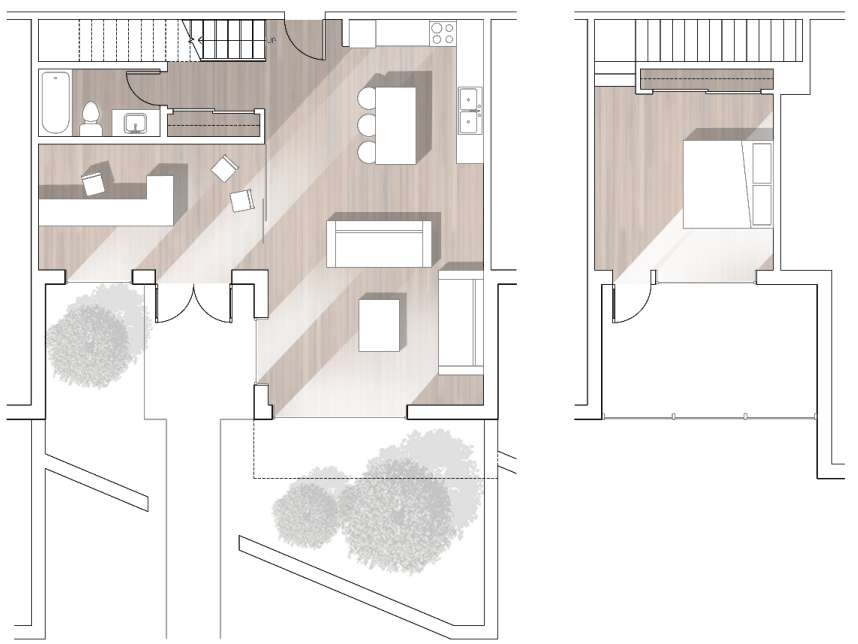
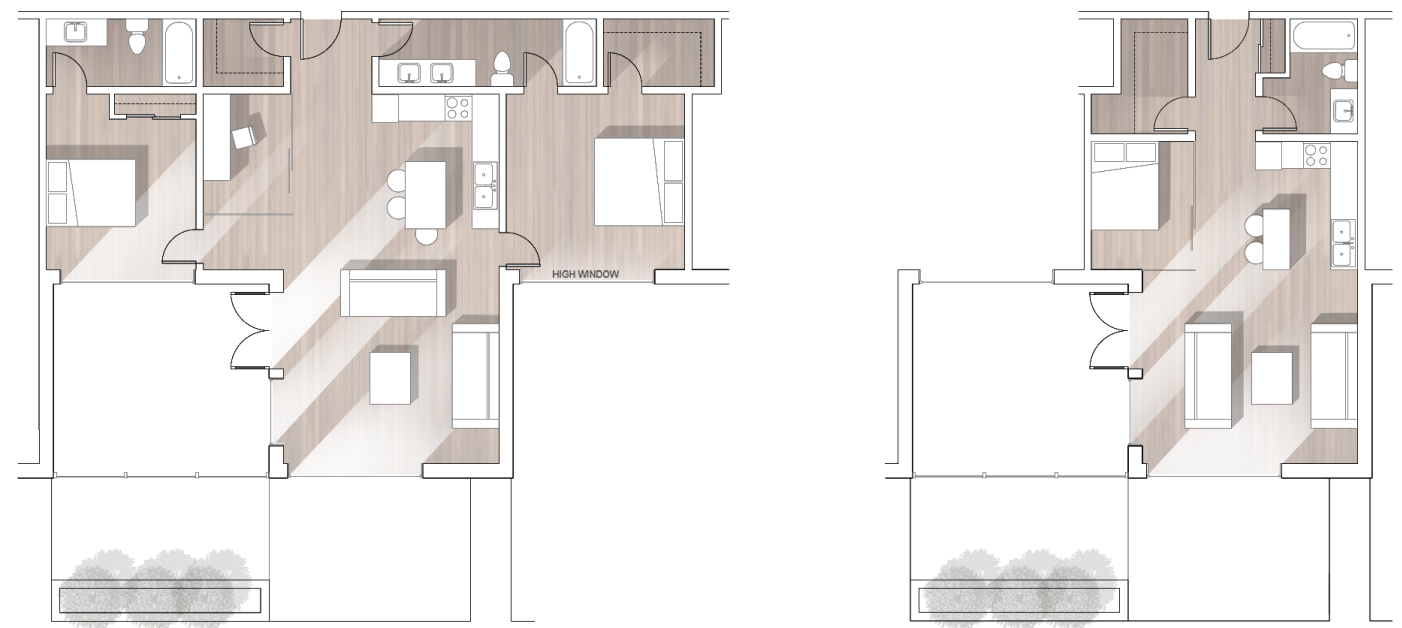

Fig. 63: Unit Layouts and One Bedroom + Den Render 


\section{ENERGY REDUCTION CHART}

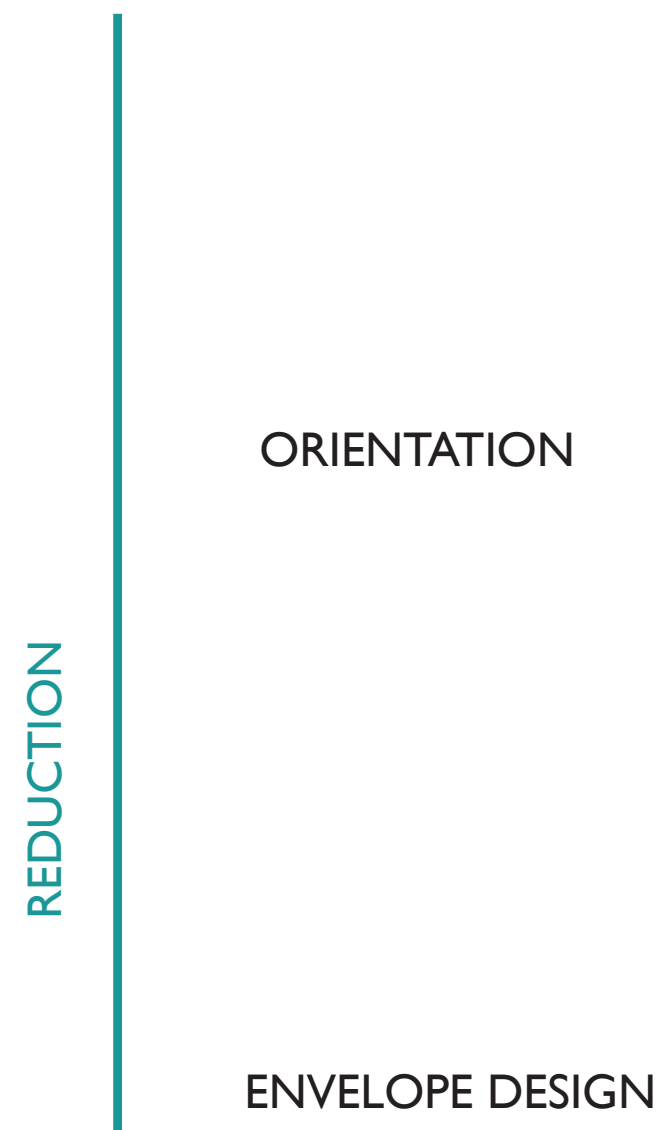

INSOLATION DIAGRAM

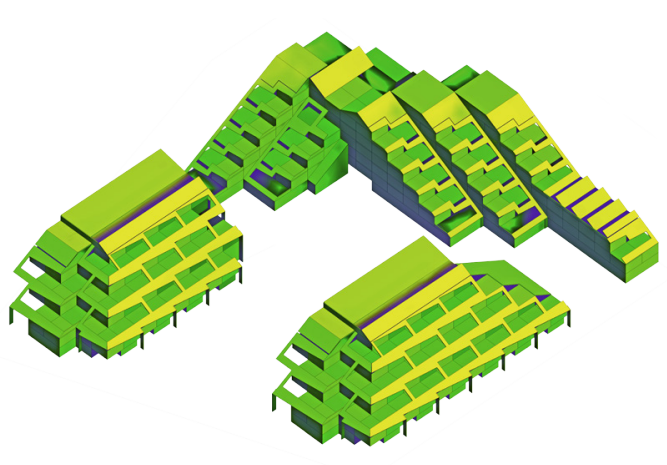

ENERGY USE SAVINGS

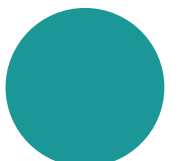

2,326,210 kWh/yr $148 \mathrm{kWh} / \mathrm{m}^{2} / \mathrm{yr}$

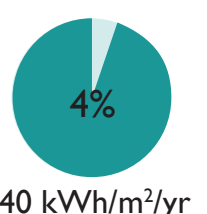

TYPICAL VALUES

SB-12, Compliance Package B

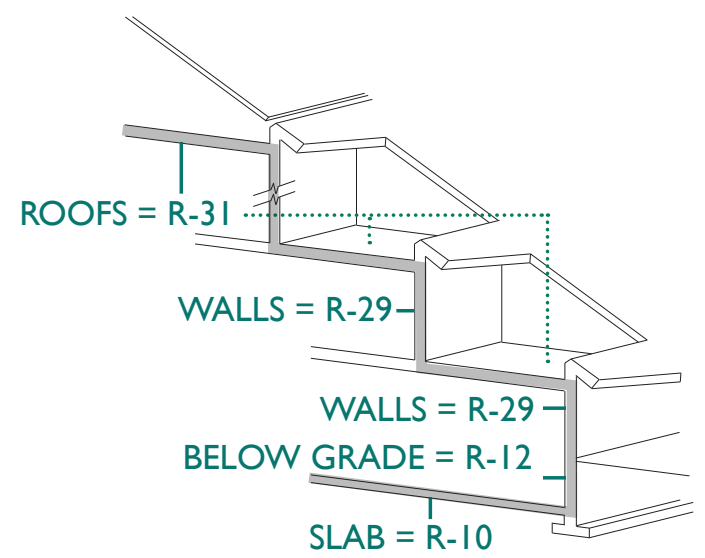

PROJECT VALUES

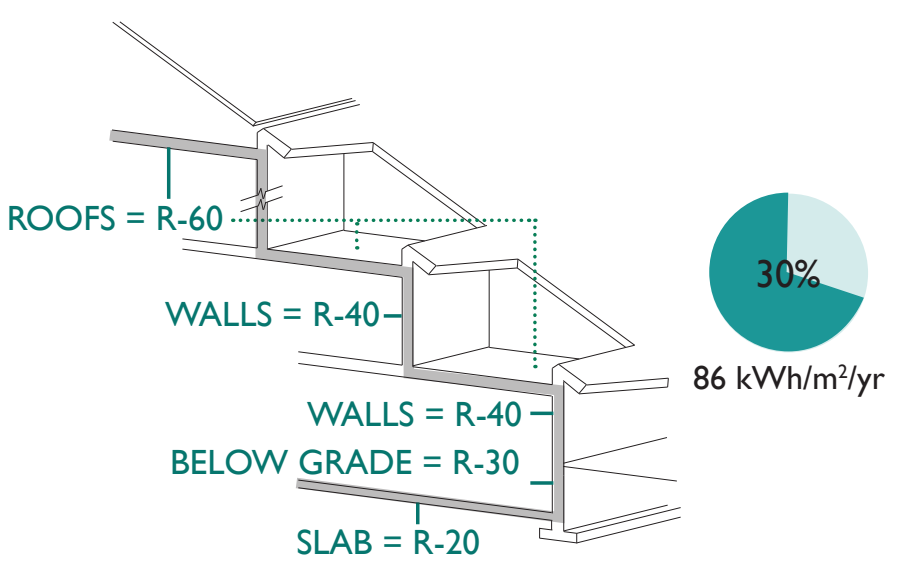




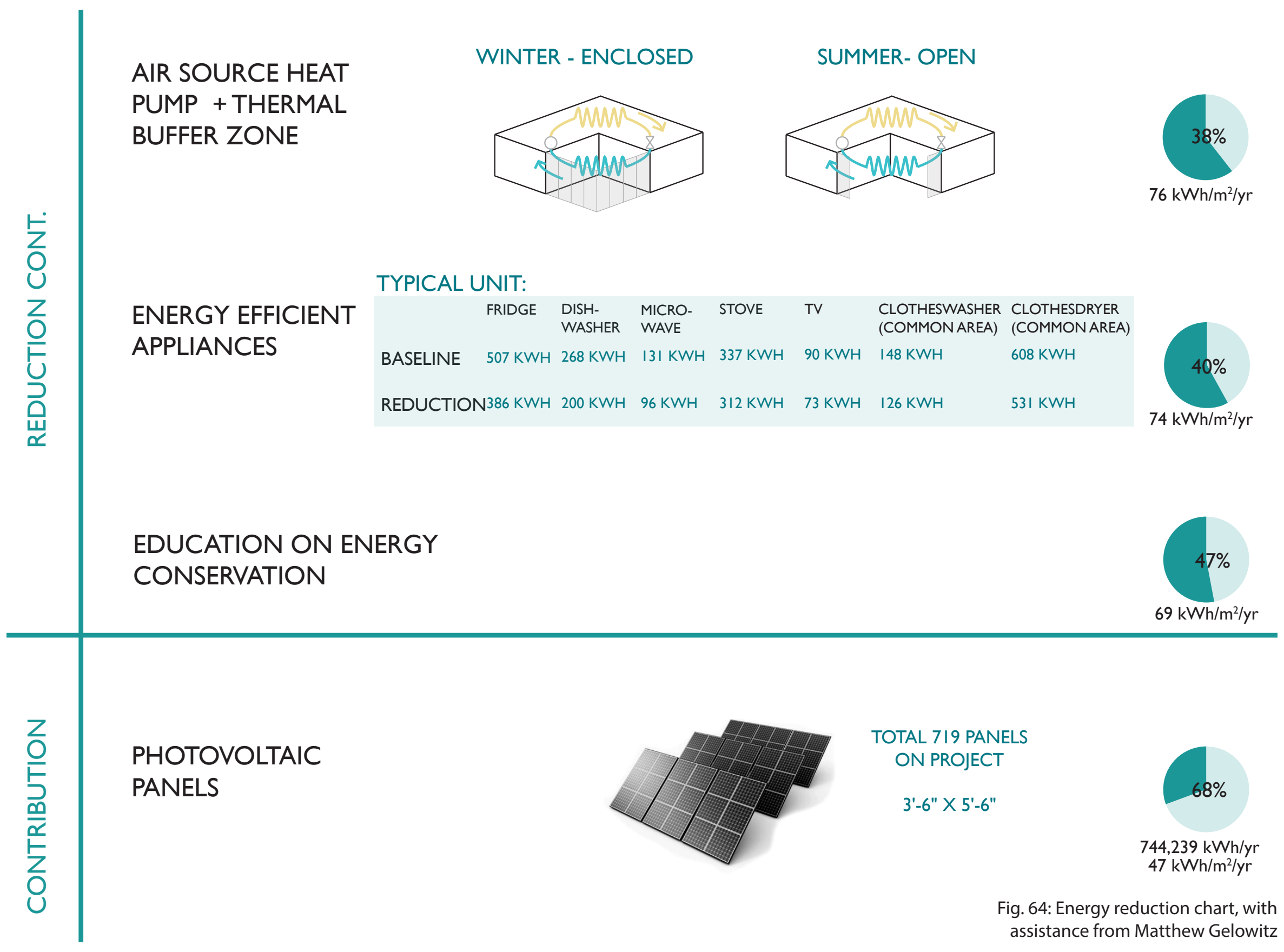




\subsection{4}

\section{Principle \#4: Forms to Capture Water}

The second ingredient to life - water - flows through ecological communities in an intricate network throughout soil, trees, and living organisms, all tied into the greater hydrologic cycle. Ecosystems interact with water in a dynamic interplay between the sky and ground, through processes such as evaporation, condensation, precipitation, transpiration, and percolation.

One of architecture's main roles, to provide shelter in protection from water, has led it to become completely disengaged from locally available water sources. Architecture simultaneously shuts out water, but channels it in through specific artery's, making it available for human use. This lack of a more dynamic engagement has created some issues and untapped opportunities. These include the lost opportunity for urban gardening, the untapped opportunity for capturing local water for greywater uses, and the opportunity to help issues surrounding strain put on urban drainage systems when faced with a lack of permeability in the urban network.
This project took a moral stance that architecture should always provide the opportunity to thrive off of available resources - instead of compartmentalizing living in units that derive energy and resources from elsewhere. Specifically, this related to how the project provided space for urban gardening, where every unit got a portion of green roof and adequate exposure to rainwater to grow their own food. Some of the many benefits to urban gardening include creating healthier food choices, reducing reliance on transportation of food from farms to grocery stores and then to households, and provides a meaningful pastime.

Instead of looking at this as a balcony space, the building was intended as more of a vertical network of personal backyards. The project's take on personal outdoor space sought to find an equilibrium between two cases that are inefficient: the condominium balcony, and the suburban backyard. Balconies in urban areas are often left unused, too small to enjoy as a real space outside the unit, or in better cases can accommodate a few chairs. They often never provide the same kind of experience as the enjoyment and comfort of a personal backyard. Suburban yards, on the other hand, tend to be adequately used, but typically only by a portion of the backyard. Large grassed areas require fuel to cut and maintain, and the overall network of suburban neighbourhoods creates the spatial issues related to sprawl, creating another level of reliance on fossil fuels by needing personal means of transportation. The project sought to provide a level of ac- 
commodation that wasn't often found in urban areas, which is space for adequately growing food that does not require a single detached home. It was the hope that this project provided the alternative to moving out of the city to those people who were interested in experiencing the well-being of more privacy and a closeness to nature.

The building was designed in a way that the entire roof surface channeled water. This fed a variety of things. Some of the water was channeled along the edges of the roof surface, feeding a network of vines that grew into a natural infrastructure along a series of trellises. This provided shading for the western facing facades of adjacent units, and added to the feeling of being grounded to the site and to the earth. Excess water collected at the ground floor level, and then filtered through a living machine greenhouse to be used again for internal greywater uses.

Paved industrial areas are one of the worst locations in the city that have been cut off from the permeability naturally present on untouched land, putting strain on man-made systems of water control such as the cities stormwater runoff and sewage system. The ground in industrial areas is cut off from its ability to absorb water at a local level, and even worse, creates water movement that spreads industrial chemicals.

The lack of impervious surfaces in urban areas is responsible for creating many issues in the City of Toronto. Residential areas tend to carry the least amount of impervious surfaces, while industrial and commercial areas are responsible for covering the greatest (Francis \& Chadwick, 2013, 59). Impervious surfaces create problems during heavy
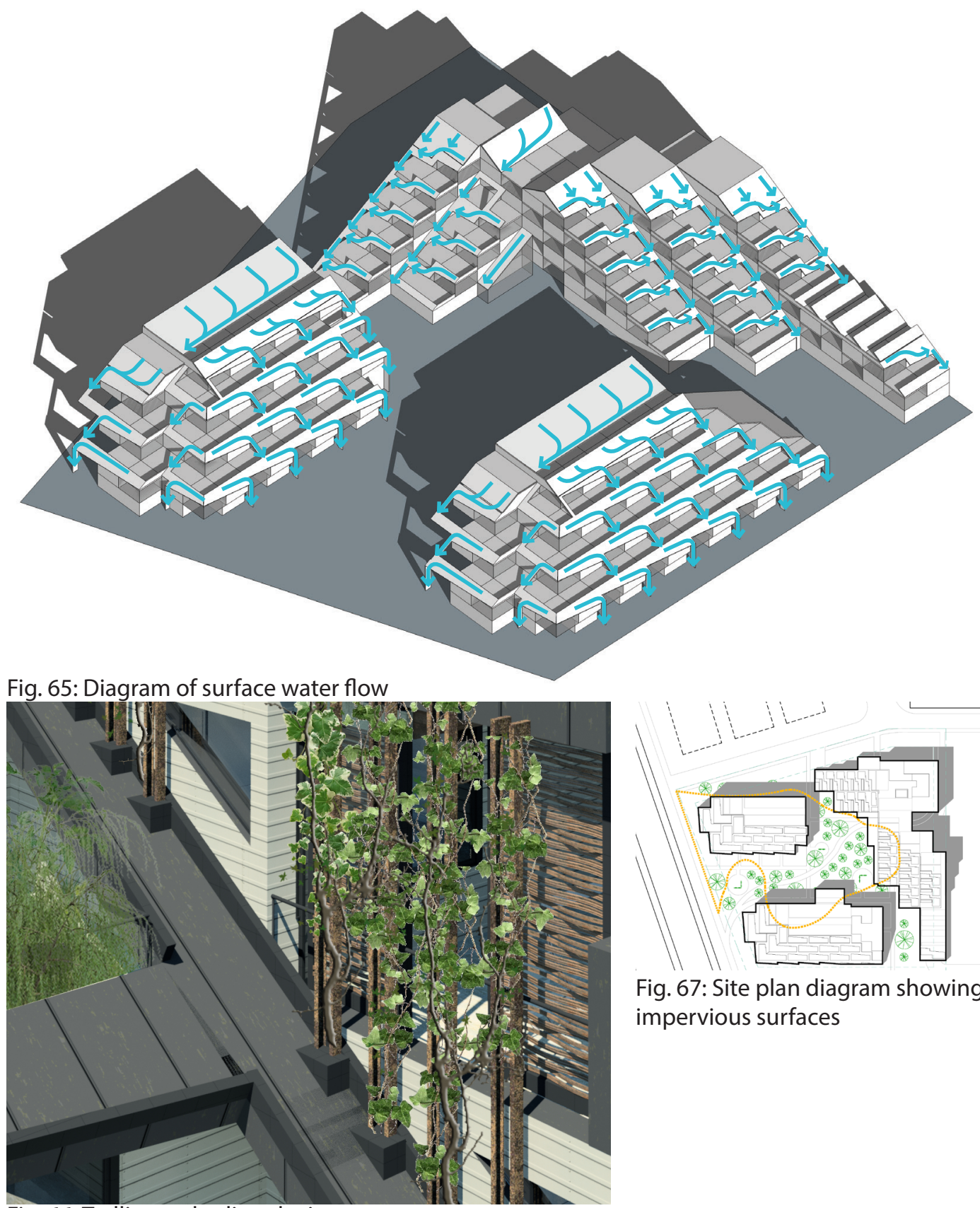

Fig. 67: Site plan diagram showing impervious surfaces 
rainfall that can lead to flooding and overflow of the cities sewage system. In Toronto during one of the most highly recorded rainfalls in July of 2013, the overflow of stormwater was $w$ in with the sewage system, and treatment plants were not able to absorb the excess surge of water. From the Humber Wastewater Treatment Plant, the overflow of sewage had to be bypassed into the Humber River. Afterward, samples from the Humber River were collected and were determined to have $\mathrm{E}$. coli levels of 20x above the provincial guidelines (Tully, 2014). The lack of balance between hard surfaces and impervious surfaces is having very unhealthy consequences for the surrounding waterways and in turn the health of Toronto's citizens. It is a clear example of the unhealthy relationship between the natural and manmade, that affects us directly at an urban level.

In response, the project manages its own water that accumulates on the site, by the previously mentioned strategies of absorption from gardening, reusing greywater, and also maintaining a permeable ground plane that begins to weave absorptive surfaces back into the industrial landscape.

As a final measure, the project intended on using low flow fixtures and appliances to reduce the need for potable water, and intended on creating an educational program that would help with raising awareness about consumptive behaviour.

One critique of the water strategies was that the roof only provided for $13 \%$ of the buildings water collection, and according to the water reduction chart (p. 68), more water was already being collected than was needed for the greywater supply. In turn, it was creating unneccessary shading that was counter-intuitive to the gesture of forming to face the sun. In addition, the idea that everyone had a significant amount of garden space was unflexible as some residents may not be interested in the upkeep. Exploring the benefits that could be provided from a community garden configuration could also contribute to the social cohesion of the neighbourhood.

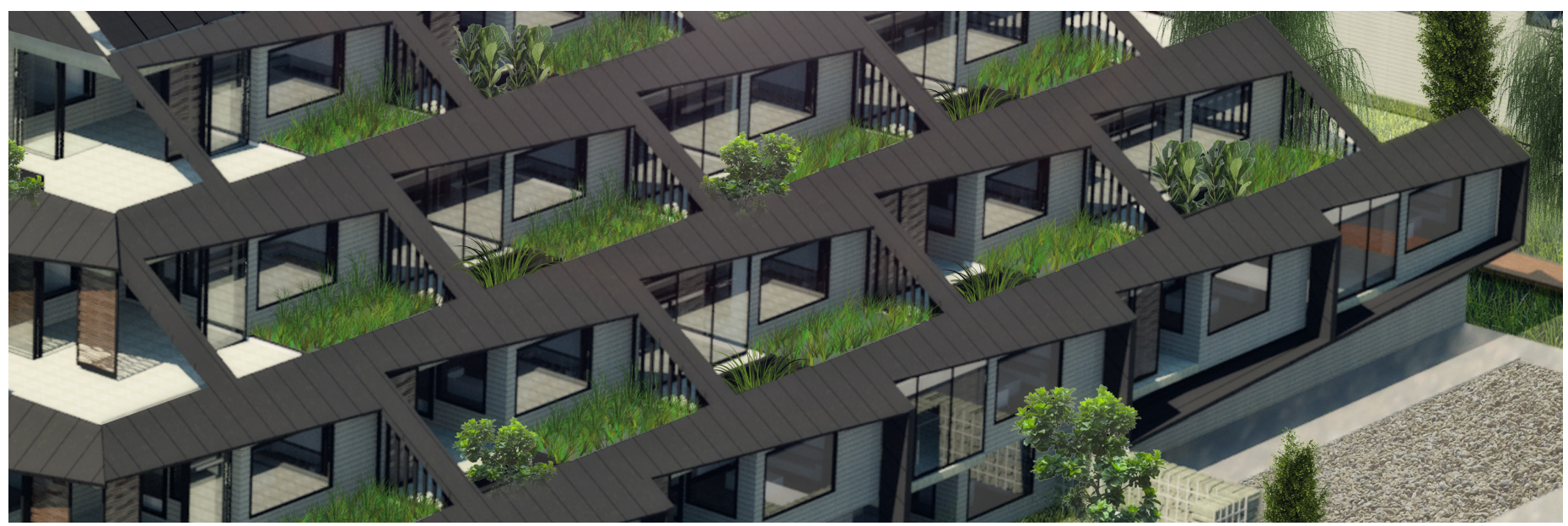




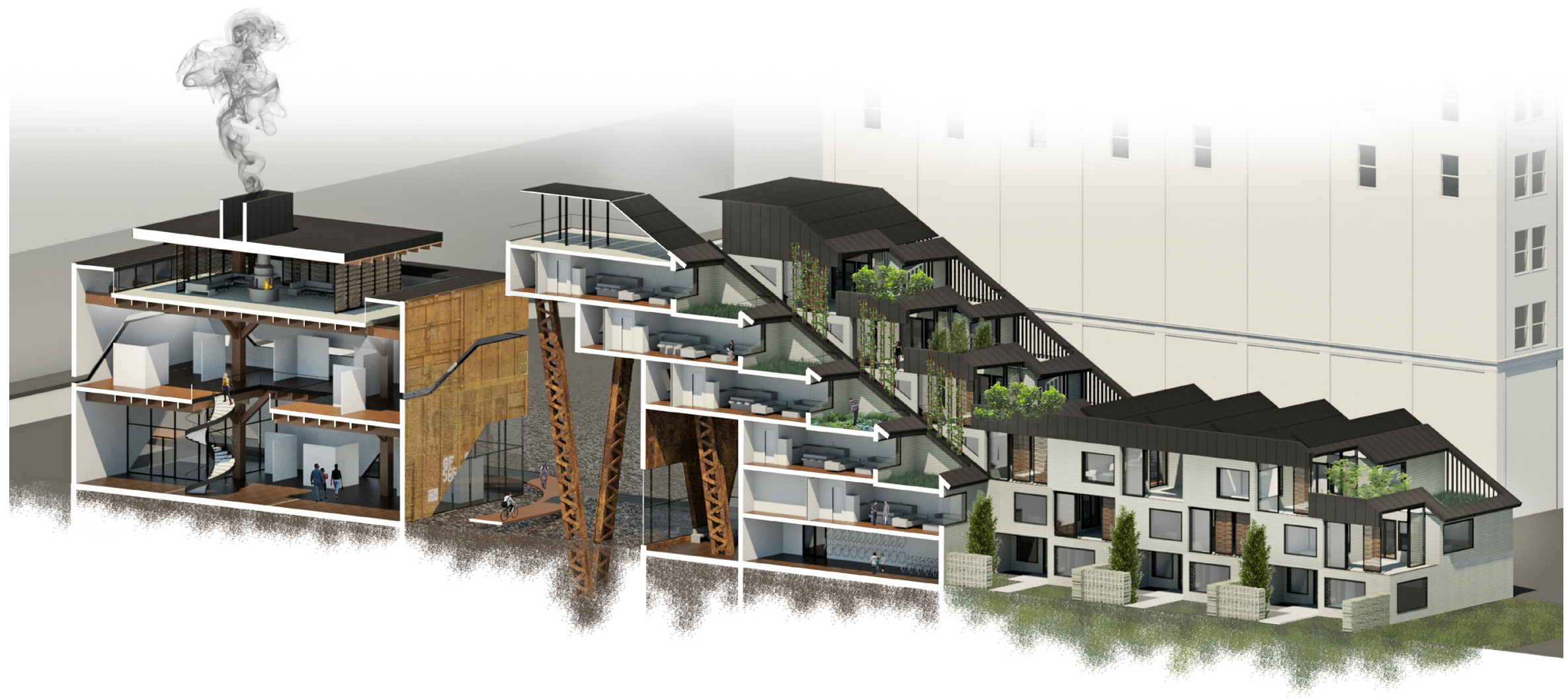

Fig. 69: Sectional perspective 
LAND

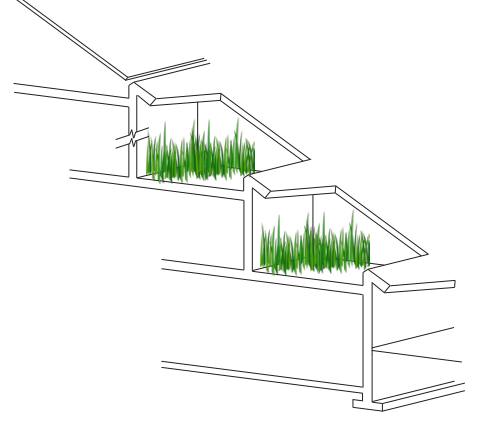

TYPICAL UNIT:

$\begin{array}{lllllll} & \text { TOILET } & \begin{array}{l}\text { LAVATORY } \\ \text { FAUCET }\end{array} & \begin{array}{l}\text { KITCHEN } \\ \text { SINK }\end{array} & \begin{array}{l}\text { SHOWER } \\ \text { HEAD }\end{array} & \text { DISHWASHER } & \begin{array}{l}\text { CLOTHESWASHER } \\ \text { (COMMONAREA) }\end{array} \\ \text { BASELINE } & 3.6 \text { LPF } & 2.2 \text { LPM } & 2.2 \text { LPM } & 2.5 \text { LPM } & 12.5 \text { LPU } & 160.9 \text { LPU } \\ \text { REDUCTION } & 1.6 \text { LPF } & 1.5 \text { LPM } & 1.75 \text { LPM } & 1.5 \text { LPM } & 5.0 \text { LPU } & 73.8 \text { LPU }\end{array}$

EDUCATION ON WATER

CONSERVATION
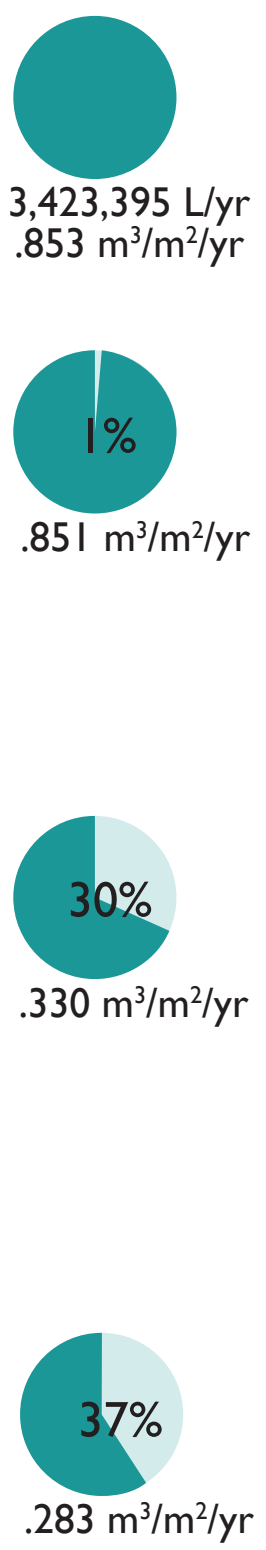


\section{ROOF}

COLLECTION FOR

RE-USE

GREYWATER

RE-USE
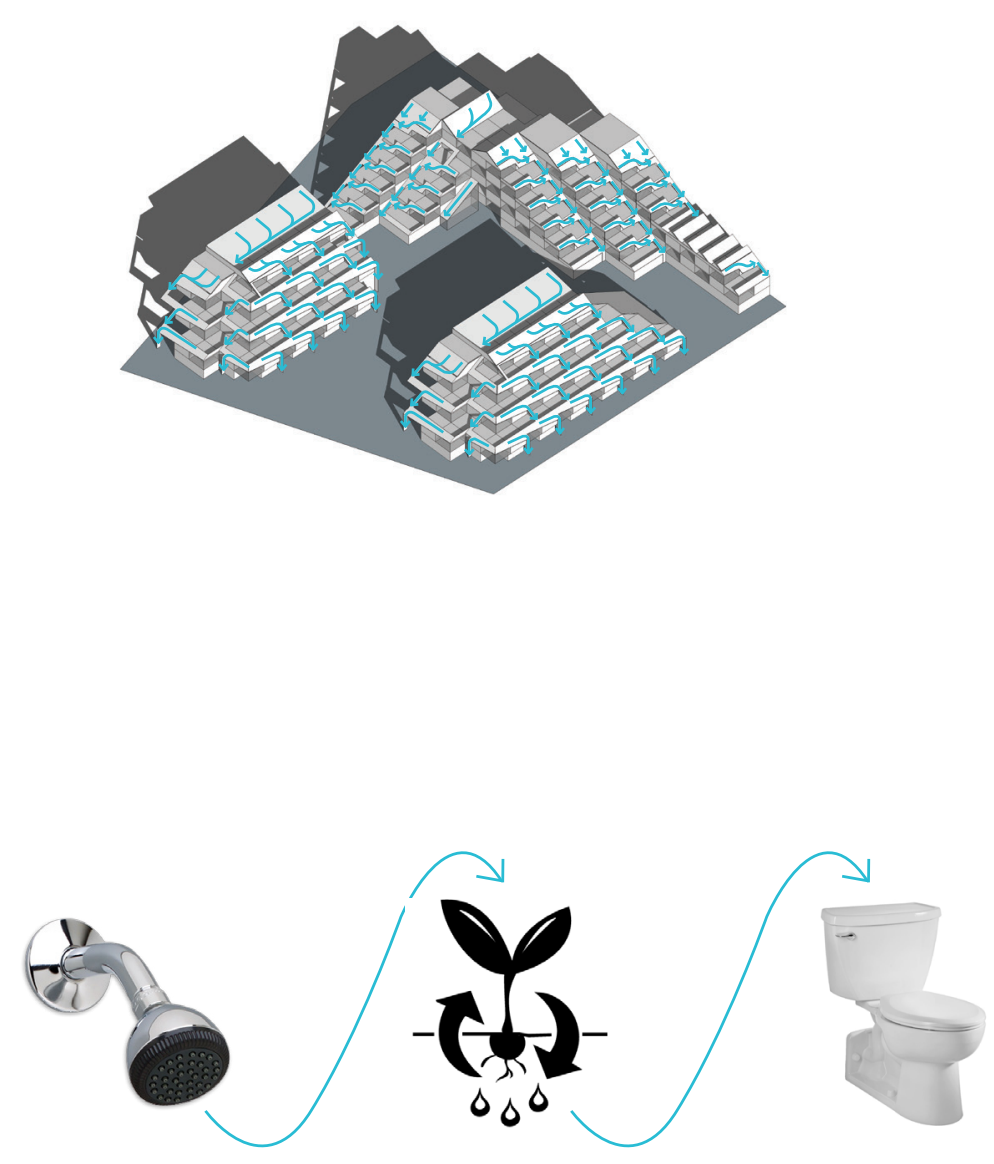
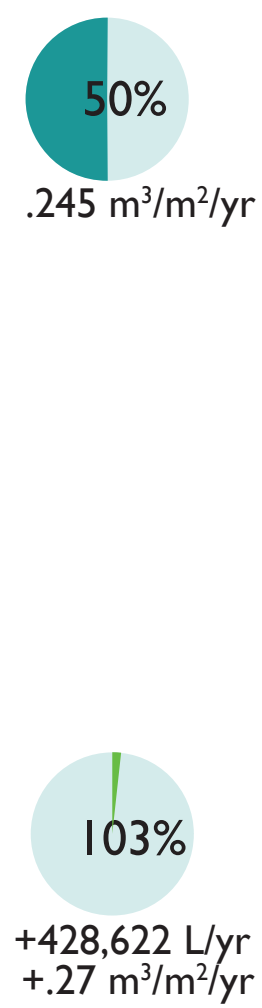

Fig. 70: Water reduction chart, with assistance from Matthew Gelowitz 


\subsection{5}

Principle \#5: Builds upon Local/Existing Materials

The third ingredient to life - earth - is the vast storage vessel of all of the precious metals and gasses that enable the composition of all living things. Organisms emerge from the opportunities presented in a given area from the combination of the elements provided in a series of complex relationships, evolving along with combined levels of sunlight and water. The purest form of what is indigenous to an area is the result of this extraordinary equation.

Architecture in urban areas is composed of a complex series of material compositions, often difficult to identify from their source and compounded by an indefinite series of manufacturing processes. The economics behind material choices available in cities has lead to the monotony and disengagement with place that is often criticized and categorized under the machine of globalization. The practical need for the functionality of processed materials is unequivocal, but in some cases, architecture misses an opportunity to evolve from the materials of a place.
The project looked for opportunities to use the materials of a place to offset some of the manufacturing needs.

The first level of this engagement was direct, by using recycled materials around the city as part of the building's material composition. Due to the needs of the building's cascading form designed to capture sun and water, the north side of the building required a substantial amount of structure to hold up the units. In response to this need and to offset a large amount of energy required to process steel, the project proposed to use steel from an abandoned bridge crossing the Don Valley. The steel could be deconstructed from its original form, but would maintain the unique colours and damages from its use in the past. In addition, some of the cladding used to differentiate the public functions in the complex was proposed to come from the steel enclosure of disused boxcars. A direct reference to the site's railroad connection, this cladding would also be deconstructed from its structural framework, but maintain all of its damages and weathering. The last material to be re-used in raw form was the concrete rubble found around the site, that could also be gathered from other demolition sites around the city. The concrete rubble could be used to create gabion walls and be used during the site preparation phases to close off desired areas. Afterward, they could be moved to serve as walls in the final design, or the concrete rubble could extend into a facade treatment created by a thin version of a gabion enclosure that acts as a form of cladding. Alternatively, the concrete 


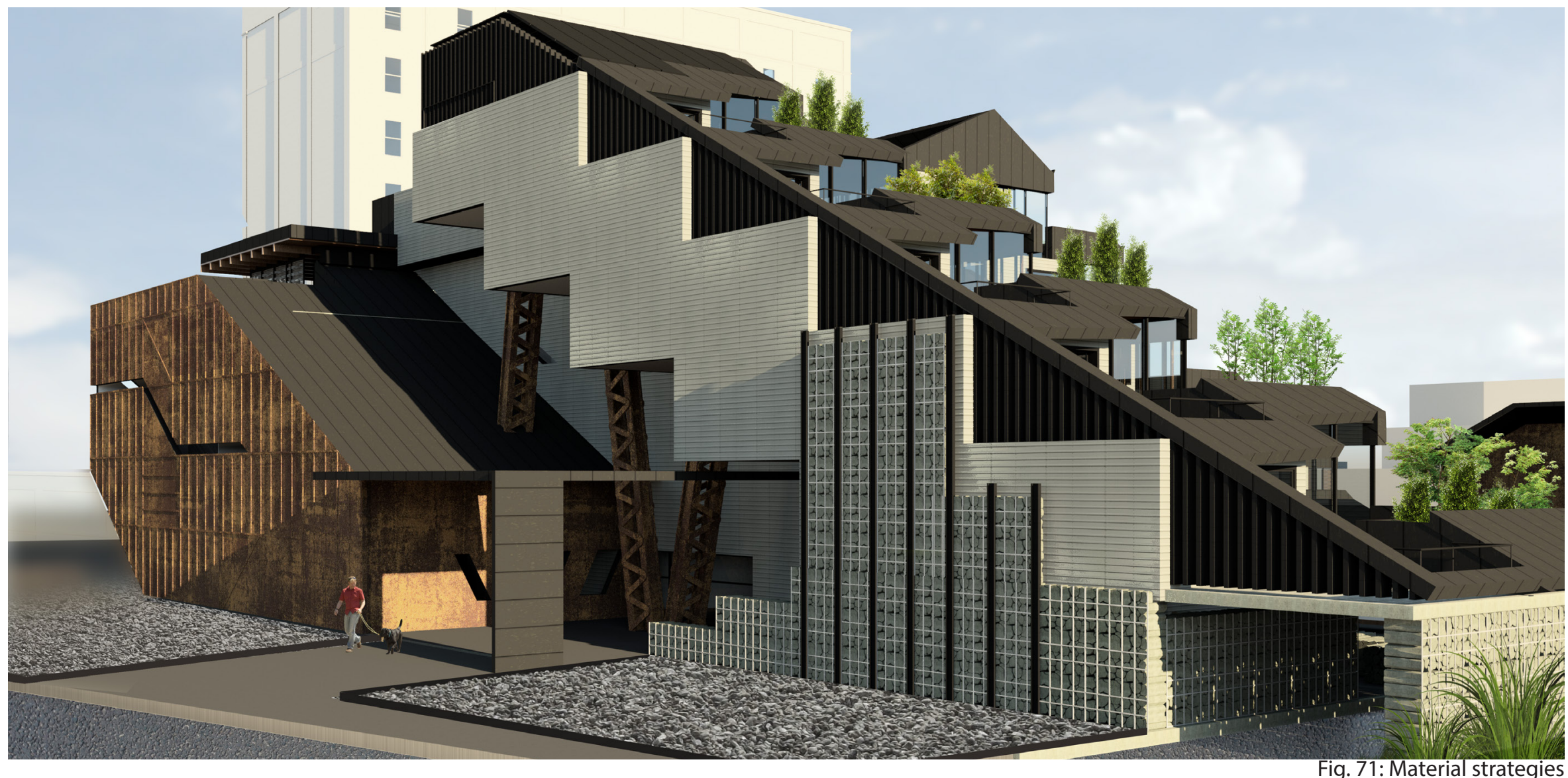

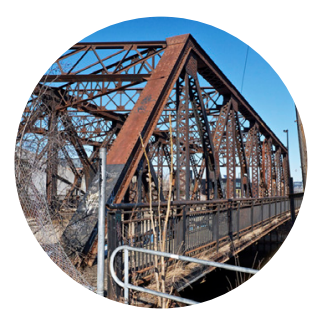

ABANDONED STEEL BRIDGE CROSSING THE DON RIVER

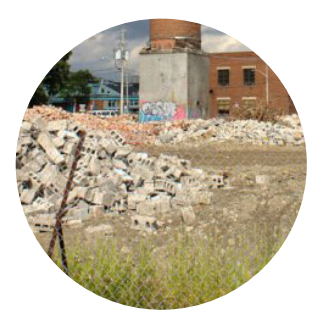

CONCRETE DEBRIS FOUND ON SITE

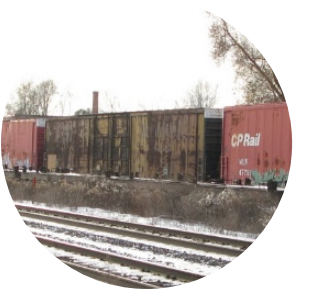

STEEL CLADDING FROM DISUSED TRAIN BOXCARS

Fig. 72: Material sources 
Fig. 73 (left) : Thatch s creen Fig. 74 (right): Community hearth room

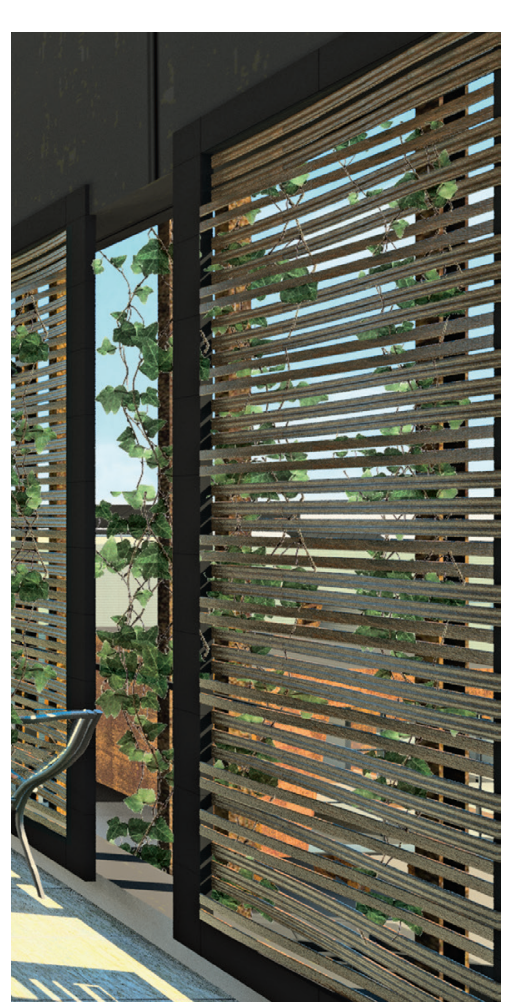

rubble could also transition to form a part of the landscaping, creating a continuous gesture from ground to wall. These material choices captured an engagement to place that is often lost through the central network of available manufactured materials.

The second level of this engagement strategically emerged from the site through time. In conjunction with the phytoremediation process proposed for the site, the building simultaneously used its output as a productive landscape (see Principle \#2 for details). After the first harvest of the willow trees planted on the site occurred, their fibers could be used to create thatch that could then be woven into screen panels. These panels could become a part of each thermal buffer zone space, and act as movable partitions that help with filtering out the low western sun. In addition, a continual harvest of the fast growing plants used for phytoremediation (poplars and willows) could be used as a fuel source for the community hearth. Since the plants engaged in a process of phytodegradation, which cleaned the site through an interaction with the plant's roots, the chemicals did not get absorbed into the plant's fibers and the firewood was considered safe to burn. This helped create a communal space that could engage with the outdoors at every time of the year, connecting people socially and spiritually to an ancient utilization of nature's power.

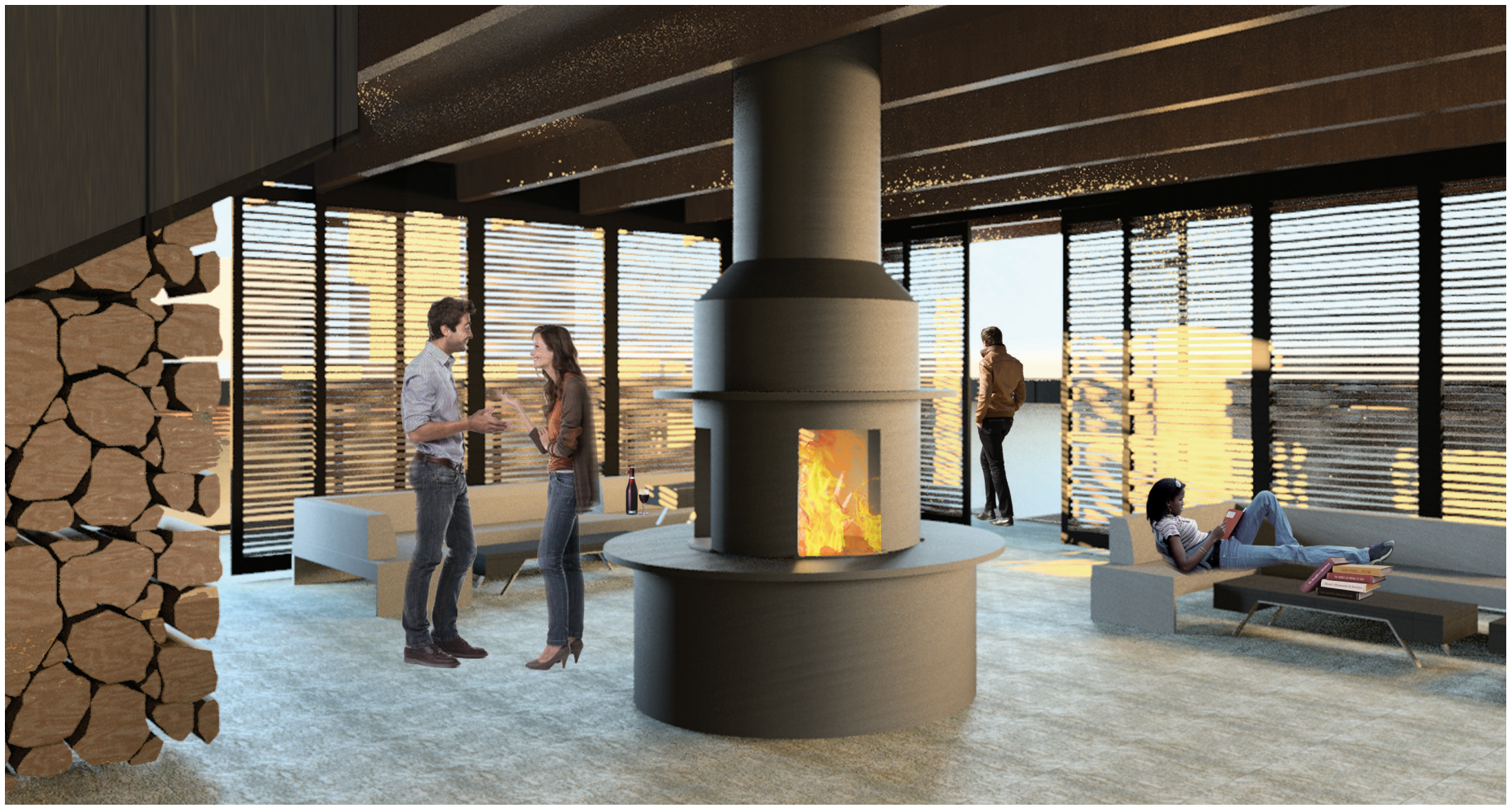


The project recognized that these principles could only be implemented in certain key areas of the design. Where conventional material choices seemed more appropriate, a material selection criteria was developed and used in an effort to minimize the life cycle impacts of materials on the project. The selection criteria were based on choosing materials that were as local as possible, eliminating the environmental costs of transportation. As described earlier, directly recycled materials were considered where applicable first, while recycled materials through processing were considered second. In instances where these weren't suitable, priority was given to materials that could be recycled after their use, either directly or through processing.

Some of the aspects within this section that needed improvement included re-thinking about where some materials were appropriate. For example, the steel taken from the recycled bridge might not be structurally substantial enough to be used to hold up the north side of the units, especially since its original use was a beam and not a column. In addition, the risks associated with using the phytoremediated plant fibers and wood for the project components and firewood had a safety issue with whether they would emanate the absorbed chemical, which could not be adequately determined. Using the thatch to create screens, as well as collecting the firewood for the hearth were both ideas that required a fundamental re-thinking about the construction and site maintenance process, ideas that were not explored deep enough to be considered real options.

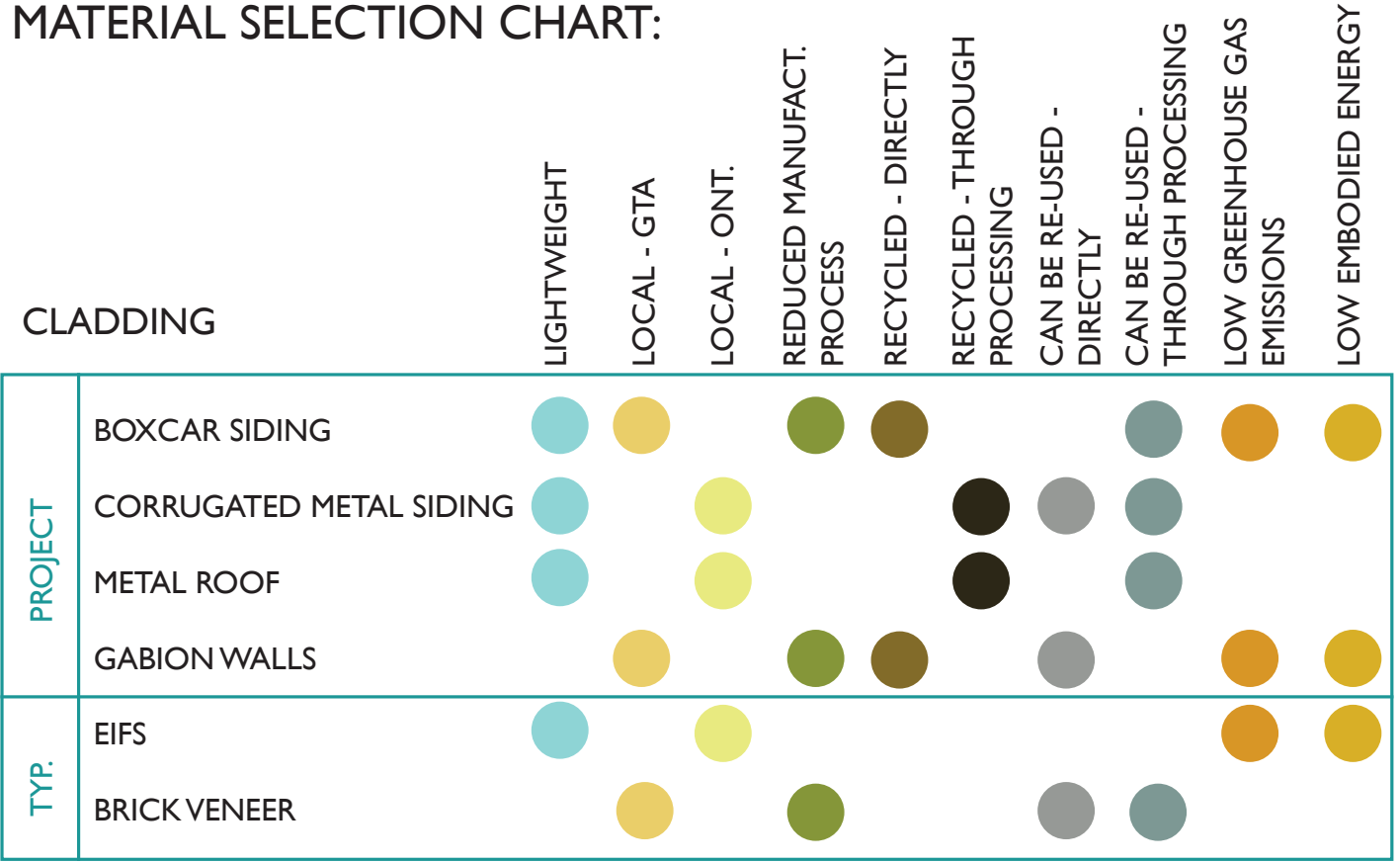

INSULATION

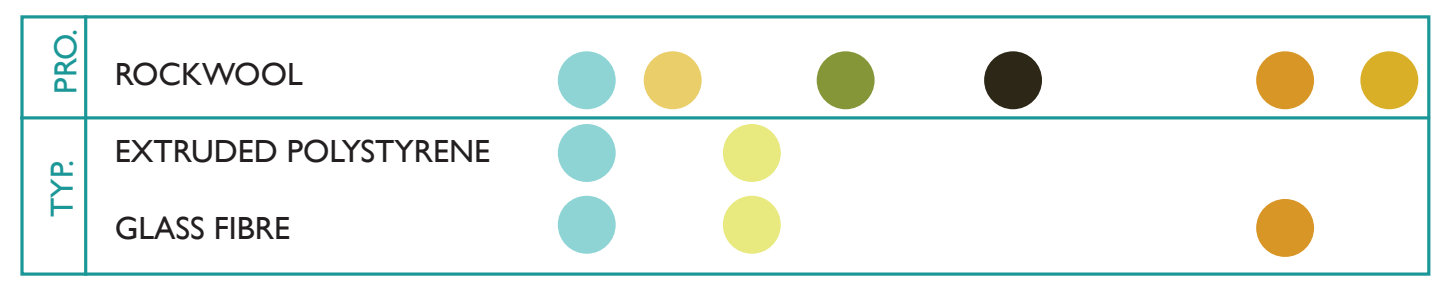

STRUCTURE

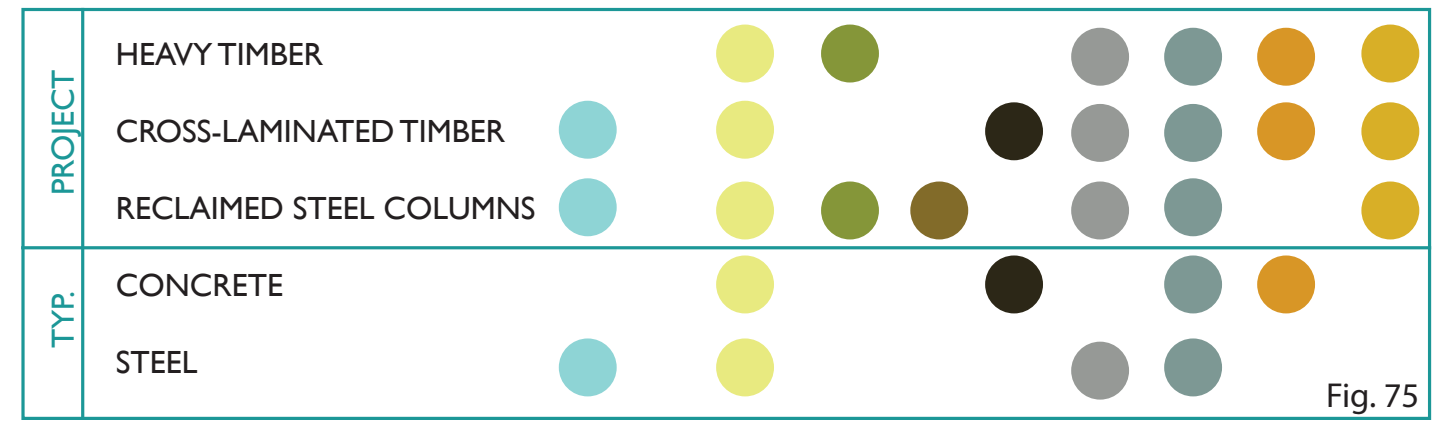


In an extension of the growth proposed by the

\subsection{6}

Principle \#6: Expresses Changes Through Time

The nature of a living organism is that it is in a constant engagement with changing external conditions - never in a moment frozen in time. At any given moment, it is engaged with the cycle of life - whether it be birth, growth, reproduction, or the process of death. This cycle is influenced by the given environmental conditions, where ample access to energy can elongate life, or swift changes in weather can speed up death. In tandem, external cycles of day and night, or seasonal rotations can reflect in an organisms form, adapting to the changes at hand.

Typical architecture today seeks to capture a moment in time, and remain a fixed creation permanently set into history. It has been able to do so by using materials that once had life, crystallizing them into an unchangeable physical form, and hiding them from further deterioration. In conjunction, architectural form seeks to eliminate all reflection of external environmental conditions, liberated from any ecological or geographical forms of reference. It tends to purport itself as living "on top" of nature, rather than being a part of it. idea of succession, the project continues to capture the idea of changing through time after its completion.

The first is through the growth of the natural infrastructure on the site, which as a living material, matures with the building and grows into the buildings form after the typical "end" of the growth period of the construction process. It engages with the material process before the materials are "killed", as happens when using wood products, and sees natural infrastructure as a true member of the architectural palette, rather than an ornamental furnishing placed within the project as an afterthought. This is done through the detail of planting a network of vines along the roof surface, creating a directed growth pattern and a deliberate surface to cling on.

The form is configured in a way that also makes it change drastically in appearance throughout the year. In the winter, the building would nearly completely change in colour from its cascading form, where snow would accumulate and remain in place. Instead of hiding from weather conditions, it embraces them. In the summer, the gardens and natural infrastructure would be in full bloom, incorporating what is typically observed on the ground within the architecture itself.

In conjunction with changing sun and weather patterns, the form would also change by the variability of its enclosable thermal buffer zones, and also by the particular way the thatch sun shading devices would be configured by the users. Overall, the time 
of year would have a dynamic reflection on the appearance of the building.

Upon a critique of this section, the idea of having the building change through time was such an embedded part of the ecological process of evolution that it might be better to re-consider it as an over-arching theme. Many of the previous ideas had ties to this concept, especially self-cleansing with the evolution of the plant growth, emerging in a succession with its phased development, and the material uses that were a reflection of the past, as well as had ties to materials that would be created in the future.

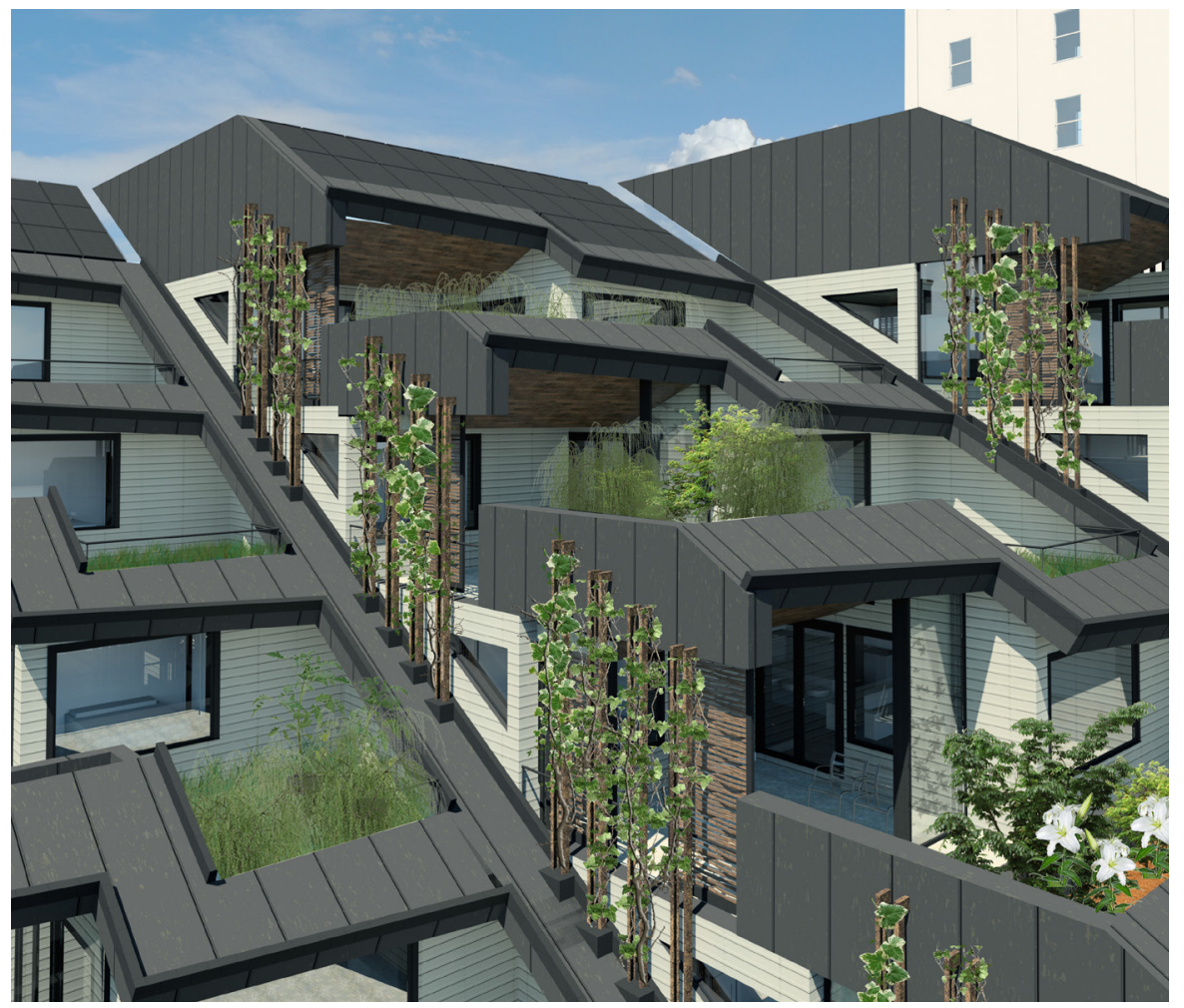

Fig. 76: Building in summer

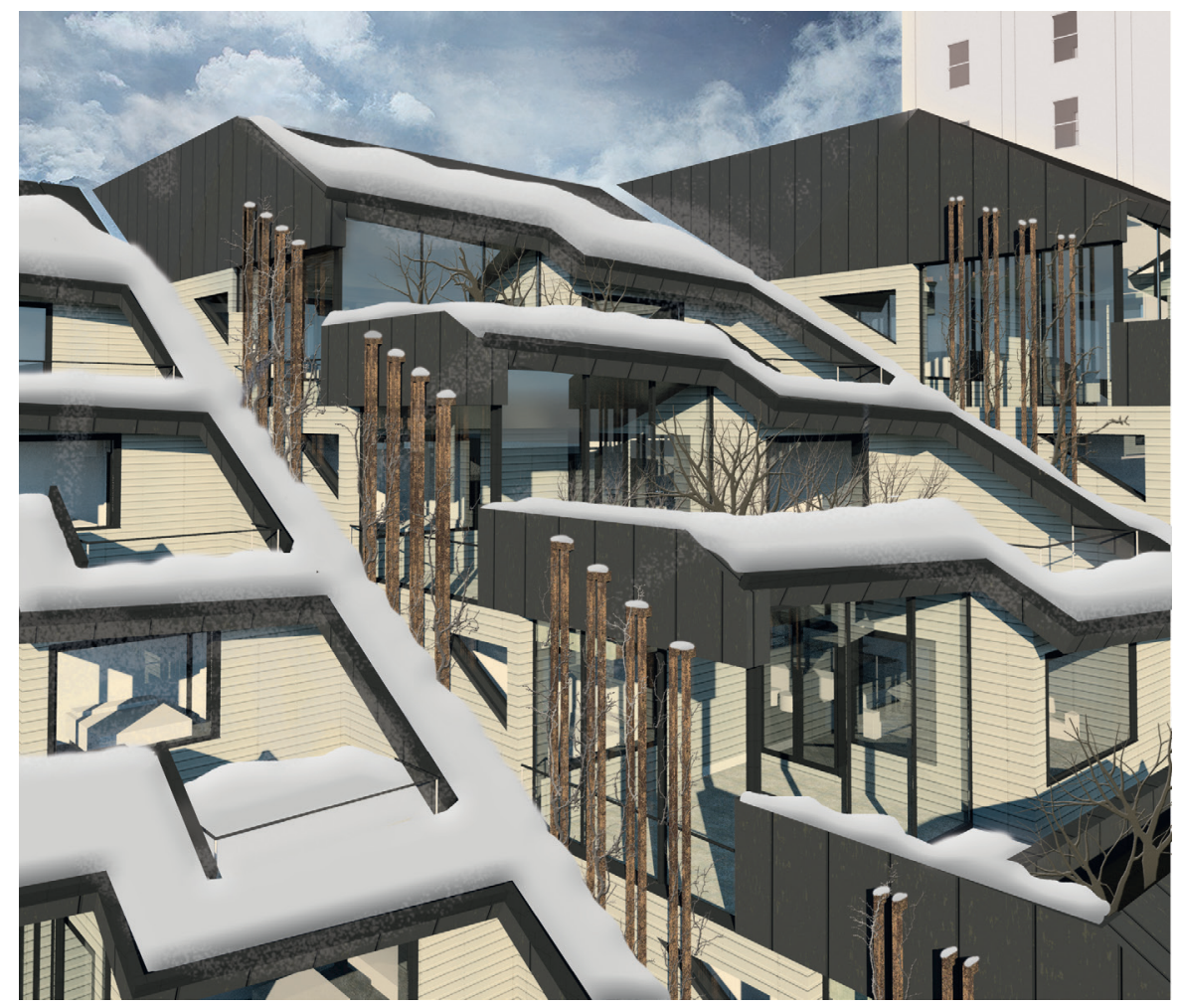

Fig. 77: Building in winter 


\subsection{Analysis}

The first iteration was able to satisfy many of the objectives of all three spatial ideologies. Most evidently, the interrelated ideology was addressed through minimizing resources, where a total of $68 \%$ of the buildings typical energy was reduced, and $103 \%$ of the buildings water. Additional resources were saved through the material strategies and choices, saving both embodied energy from using materials found on site, and for choosing materials that were local, lightweight, recycled, or recyclable.

The separation ideology was achieved from capitalizing on the existing neighbourhood's connections, especially in regards to transportation. No parking is provided because the stance is that the development does not need it. The access to pubic transportation, pedestrian and bicycle paths, and its short proximity to necessary ammenities creates a self-sufficiency that does not need to rely on private transportation. The mixed uses integrated into the community development also help with providing a closer set of commercial facilities and potential work spaces. In addition, the minimization of resources also plays into the idea of self-sufficiency, by having to rely less on external systems.

Integration was satisfied primarily through the large portion of green space provided for each unit, along with the immersive experience of the site and its development process. Still, each design choice had the capacity to be improved on to push the boundaries of the objectives.

Although these are one way of guaging the projects success, the principles themselves could potentially have their own indicators. While a gauge for indicating the success of the principles is easy to prove from the perspective of energy and water savings, the other strategies have less typical standards for comparison. For the material strategies, an indication of success rate could be based on the percentage of recycled material used in the project by weight or cost. Another way of looking at it could be assessing what percentage of materials, by weight or cost, have been extracted from a maximum radial distance around the site to account for added transportation embodied energy.

For the self-cleansing principle, a success indicator could be how the percentage of toxins that need to be expelled or removed from the site are treated, at the most desirable level treated on site, the second most desirable level to be treated through natural versus chemical or mechanical cleansing methods, and the least desirable method to be shipped elsewhere for removal. The primary toxins on this site are the chemical spill and the project's blackwater, both which could potentially be assessed by weight or mass.

The emerging in a succession principle and expressing changes through time can probably only be measured in a qualitative assessment. If any types of indicators for success were developed, they might be centered around how far of a timeline is embedded into the projects consideration, whether it is within the development phase, within the projects operation, or whether it extends to the projects destruction or de-construction. 
GROUND FLOOR PLAN

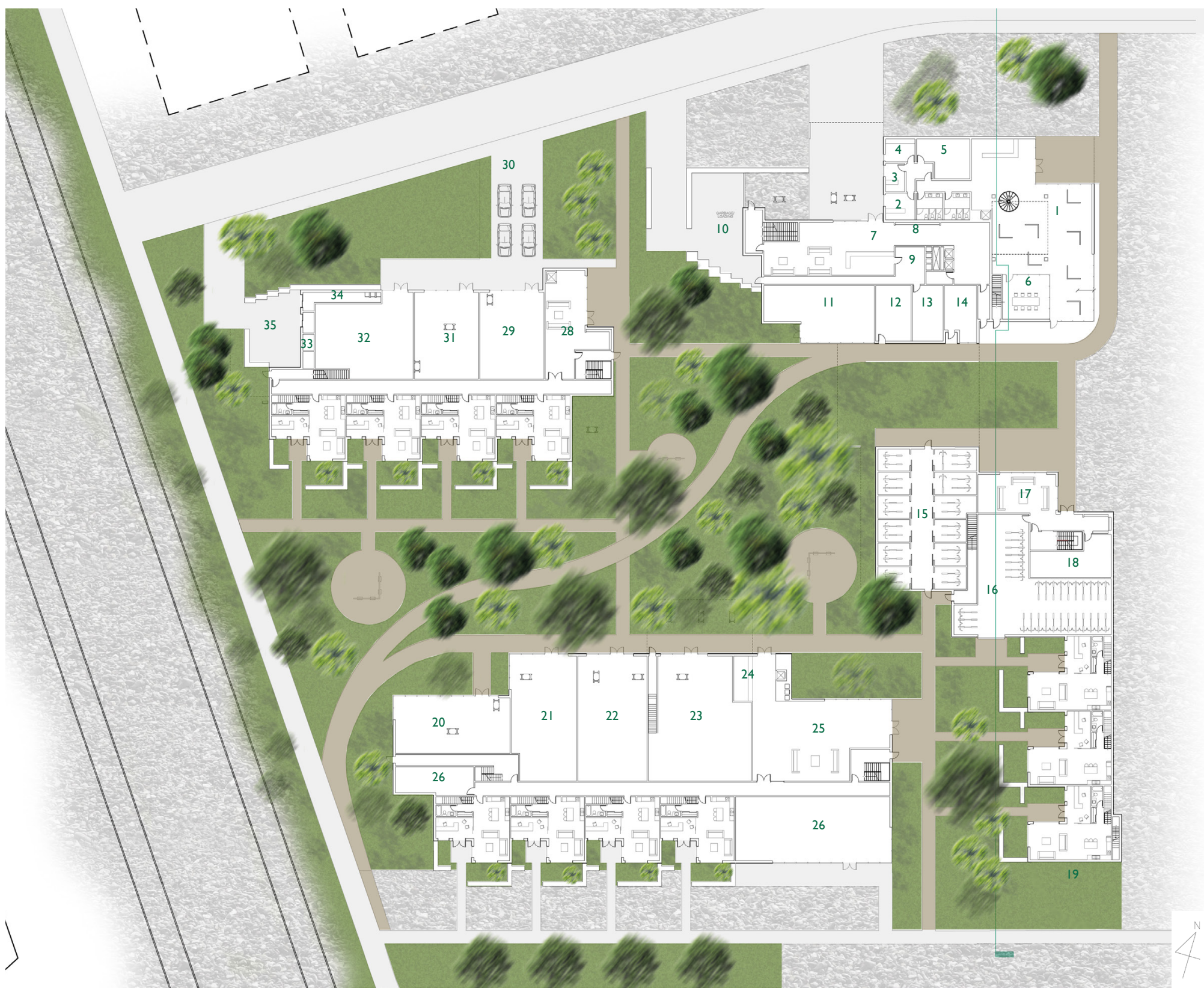

BUILDING ONE I. PUBLIC GALLERY 2. CURATOR OFFICE 3.ASSISTANT OFFICE 4. KITCHENETTE 5. STORAGE 6. WORKSHOP 7. CONDO LOBBY 9. GARBAGE ROOM 10. GARBAGE/LOADING II. LIVING MACHINE ROOM

12. SITE STORAGE 13. MECH/ELECT. 14. SITE OFFICE

I5. BIKE LOCKERS 16. BIKE STORAGE 17. SECONDARY LOBBY I8. MECH/ELECT. 19. RAMPTO PARKING

BUILDING TWO

20. BIKE REPAIR SHOP 21. HEALTH FOOD STORE 22. USED BOOK STORE 23. PUBLIC GYM 24. GYM RECEPTION 25. CONDO LOBBY 26. FLOWER SHOP 27. $\mathrm{MECH} / \mathrm{ELECT}$.

BUILDING THREE

28. CONDO LOBBY 29 CAR SHARE OFFICE 30. CAR SHARE PARKING 3I. LEARNING CENTRE 32. CONVENIENCE STORE 33. STORAGE

34. GARBAGE ROOM 35. GARBAGE/LOADING

Fig. 78: Ground Floor Plan 


\section{THIRD FLOOR PLAN}

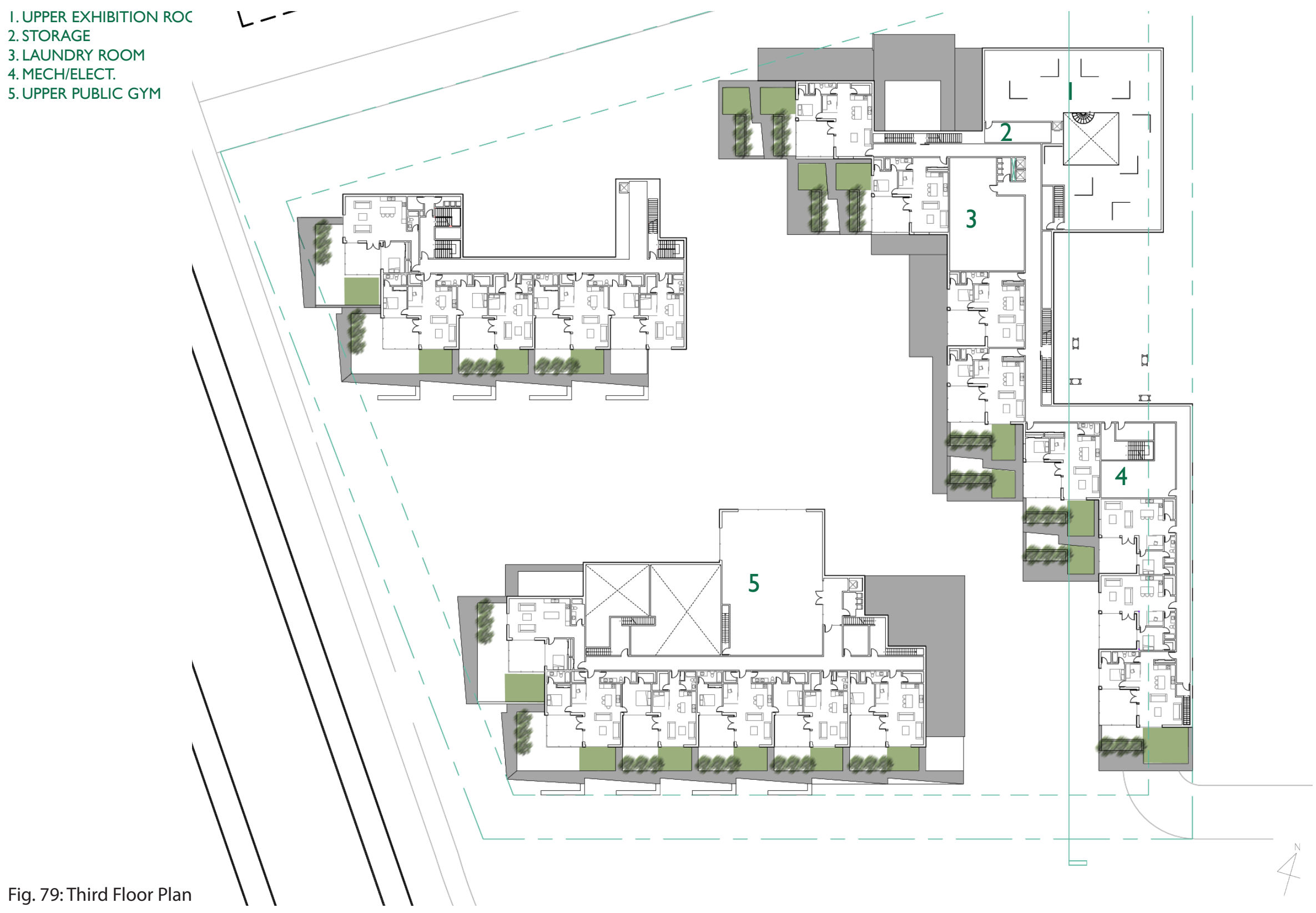


FIFTH FLOOR PLAN
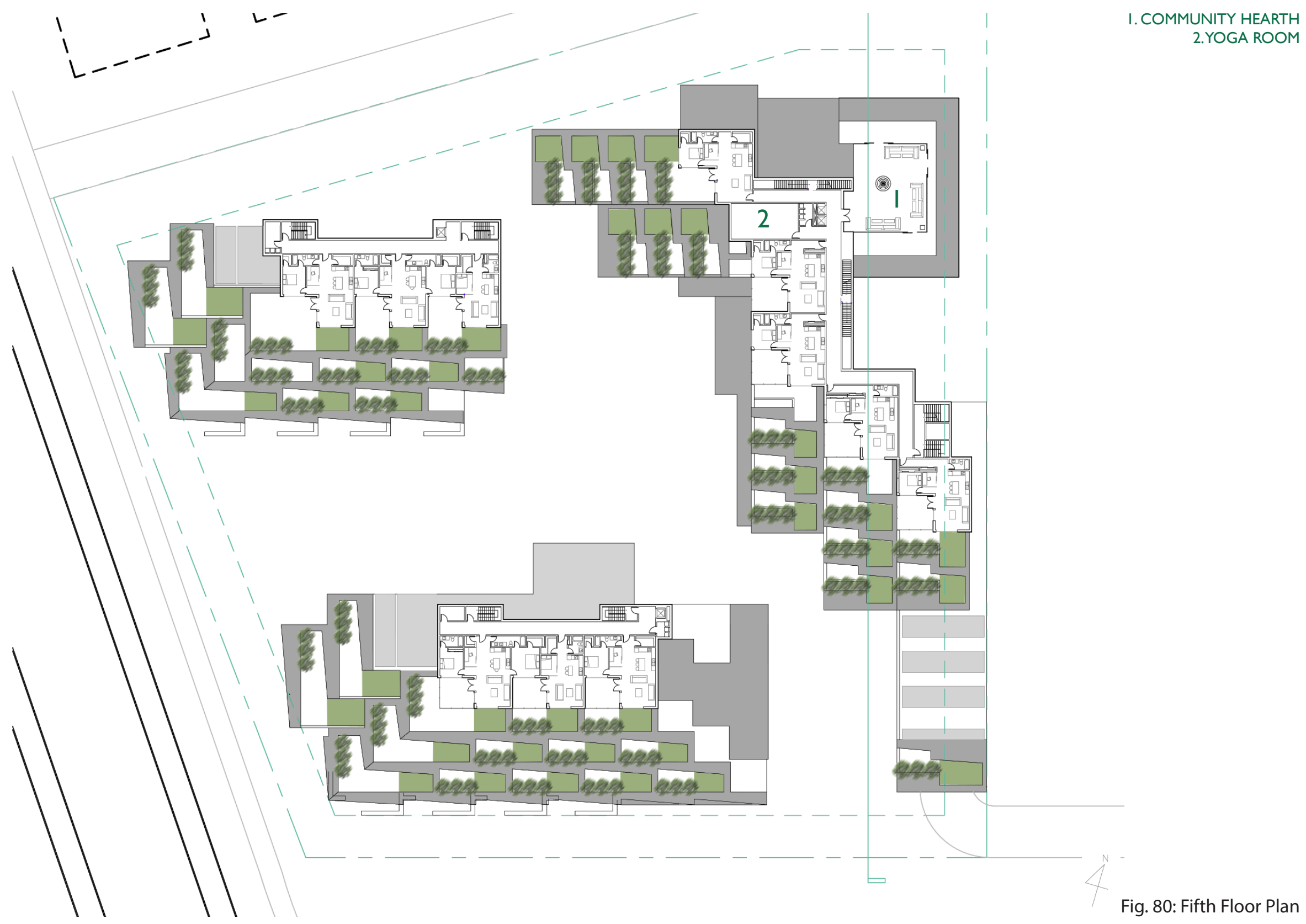

Fig. 80: Fifth Floor Plan 


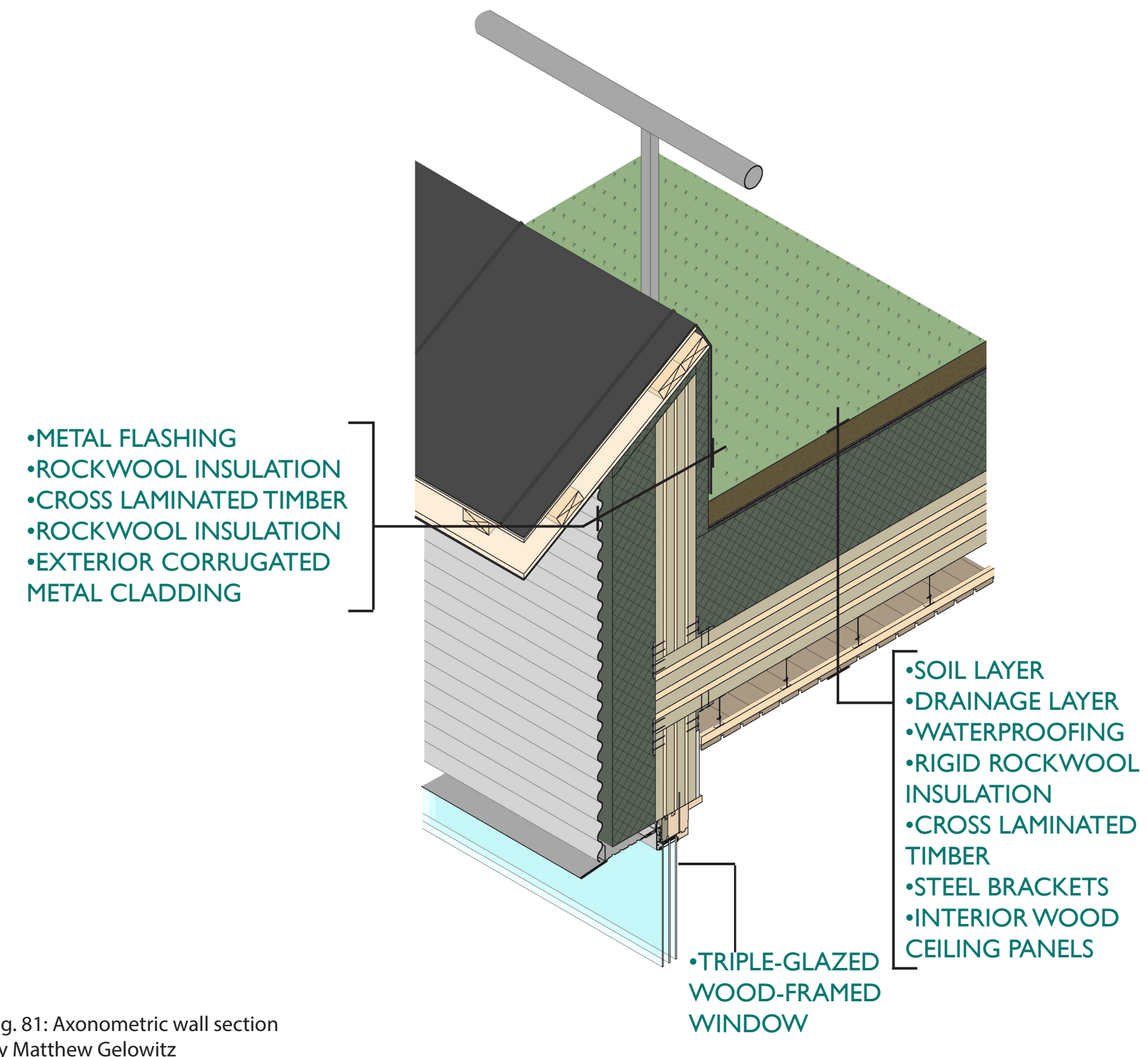




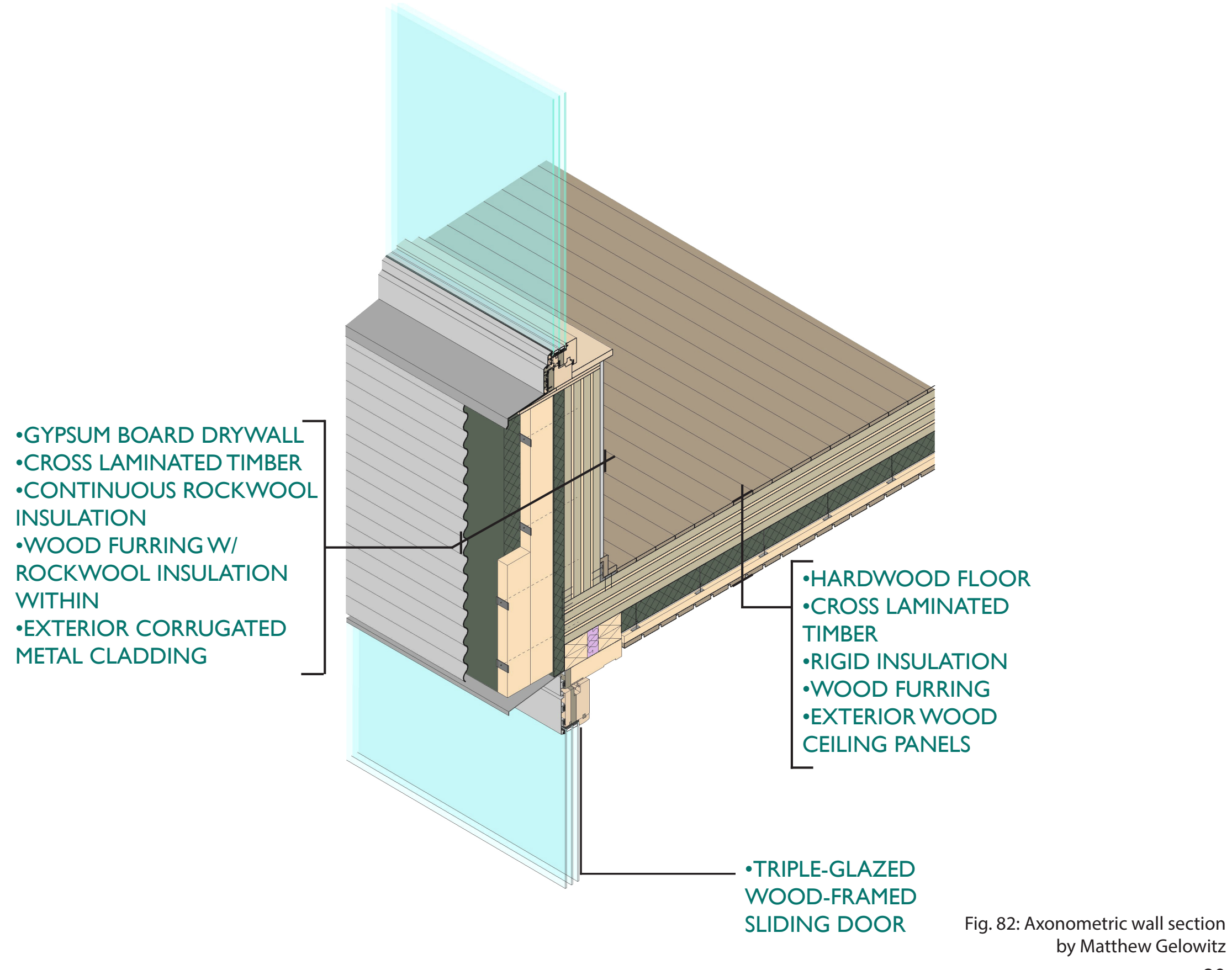




\subsection{Intervention 2.0}

\subsection{Framework Reevalution:}

Reflection upon the previous six concepts revealed that forming to face the sun, forming to capture water, and building upon local/existing materials reflected the generation of the built form as they were all steps that were taken during the design and construction stages. Self-cleansing, emerging in a succession, and expressing changes through time were three that were a part of the building's operation as they reflected continuous processes that would happen throughout the building and the site's lifetime. A better way to organize the concepts would be to suggest that the three built form concepts are in fact prerequisites or foundations for the building's evolution to happen, as oppose to equal facets of the project. In addition, the ideas of self-cleansing and emerging in a succession were decided to be re-conceptualized to be encompassed within the idea of expressing change through time. The idea of expressing change through time, or engaging in a process of evolution, became evident as a more encompassing concept that embraced the foundation of how nature operates. It also better reflects the theoretical framework regarding our place in nature, which points in the direction of rejecting the stability, certainty, and order that we once aspired to, to embrace that we are a part of the ever evolving process of change. In turn, the final iteration took the opportunity to build upon the concepts of the last design and clarify the framework to embrace the idea of the evolving nature of ecological principles.
The changes to the final design come from a threefold approach. The first was to address the practical architectural strategies, taking into account the committee comments as well as consulting the strategies from the building science analysis and determining where improvements could be made.

Most of the previous strategies are present in the final design in a clarified form, after assessing how effective they were in their previous configurations. An example is the recycled steel structure that was previously used to hold up the cascading form of the residential units. It is now utilized in a less structurally intense component of the project to hold up the exterior walkways, and simultaneously used to create deep floor plates to hold up the planters and the soil loads above. Another example is the roof and solar panel configuration: since the steep roof was collecting more stormwater runoff than was needed and was creating unwanted shading, it was eliminated and replaced by a greater number of solar panels, as the energy generation capacity was something that needed improvement. Other improvements include decreasing the sectional width created by the previous organization of the units - which was creating large amounts of dark unusable spaces underneath. Instead, units were tightened up in the vertical direction which also improved their structural efficiency. In response to the dark hallway spaces that were counter-intuitive to the concepts of providing natural light, a design decision was made to explore the idea of exterior walkways as passageways to units. These decisions could be classified as the technical improvements to the design. 

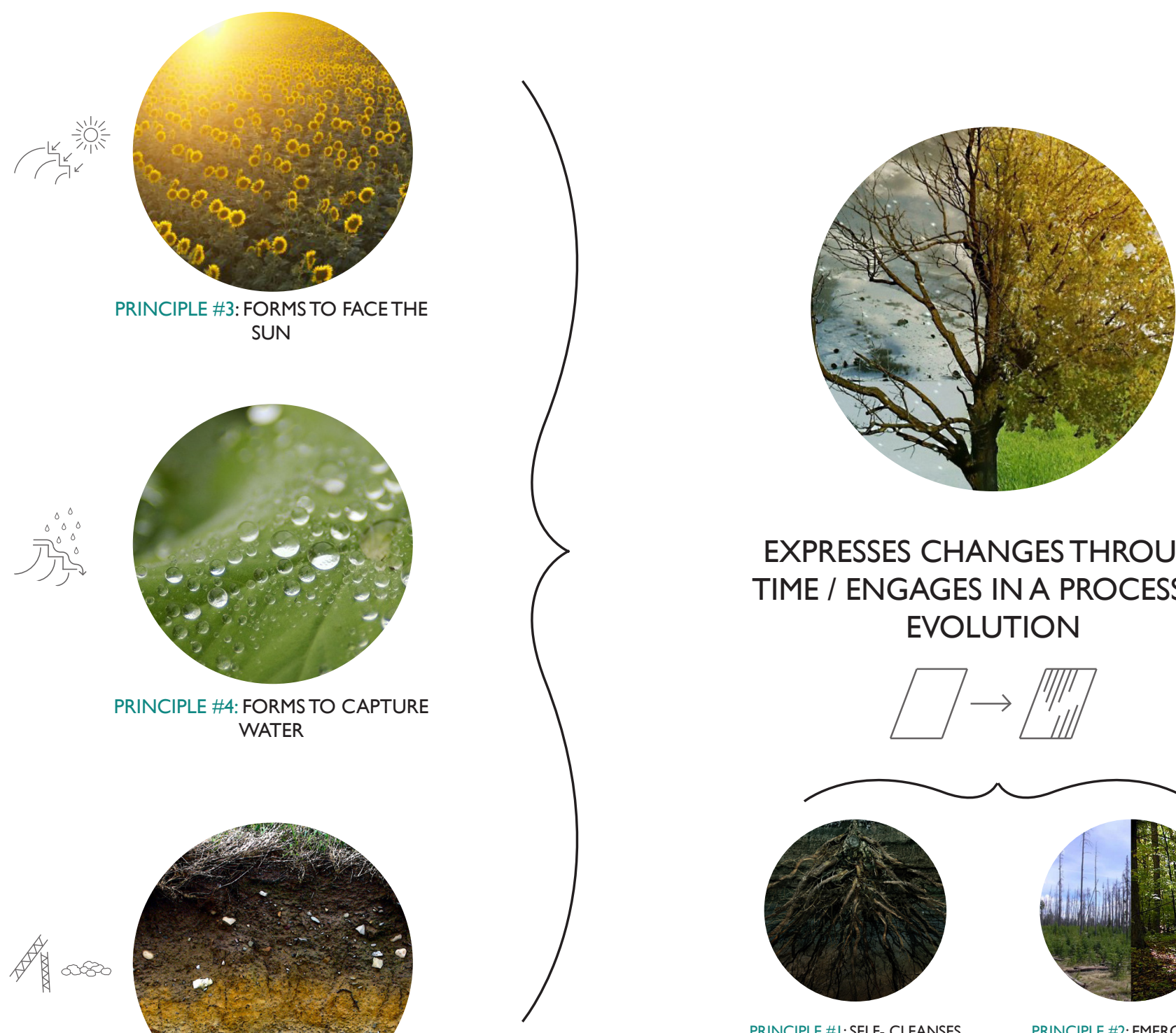

\section{EXPRESSES CHANGES THROUGH TIME / ENGAGES IN A PROCESS OF} EVOLUTION

PRINCIPLE \#4: FORMS TO CAPTURE WATER
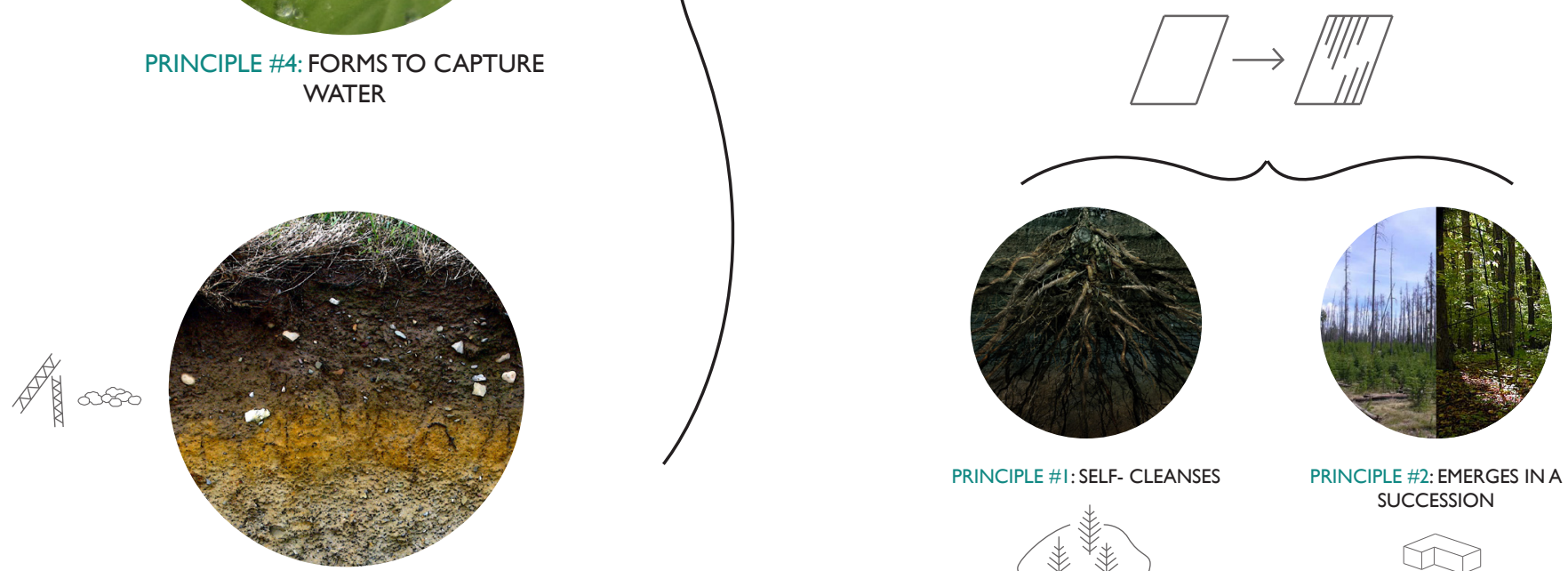

PRINCIPLE \#I: SELF- CLEANSES

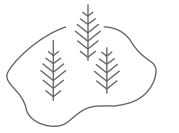

PRINCIPLE \#2: EMERGES INA SUCCESSION DD

Fig. 83: A Framework for Emergence redeveloped 


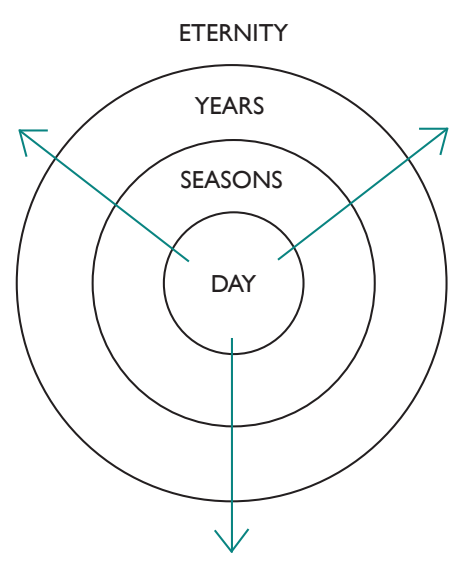

Fig.84: Conceptual re-development through time
The second approach was to clarify that the proposal would be a balanced combination between the ideas of interrelation, separation, and integration. From the building science analysis, the project managed to satisfy many interrelated objectives from minimizing its use of resources. It was able to cut energy use by $68 \%$, and generated more water on site than could be used for greywater purposes. The self-sustainment and the experiential qualities of separation and integration were facets that needed more attention. One major move that contributed to both of these included the creation of a communal greenhouse at the vertical circulation spaces of each floor. It both increased the capacity for urban agriculture that makes the development more self-sustaining, and contributes to heightening the daily experience of users as the greenhouse becomes the threshold between the elevator and walkways to enter the units.

The third and most encompassing change of pushing the idea of time is illustrated in the next few pages. One of the defining characteristics of the age of the Anthropocene is our linear and static view of time - that humans create change by building permanent structures to last forever. Instead, this project attempts to reflect the cyclical nature of ecological time, embracing how changes through time happen between days, seasons, and years.

\subsection{Site}

Reconceptualized with a reconsideration of the idea of time, both the site and the building have taken on different conceptual parameters. One of the major changes to the site was to reconsider the idea of emergence and cleansing so that the time frame was in sync with the building after construction, instead of a slow site growth process that happened before construction. In order to expedite the process, it was decided that the contaminated portions would instead be dug up, and then isolated in certain areas of the site to ensure that they could more safely be closed off from access. This created many benefits - the first was that initially it was difficult to ensure that the roots would reach the depths of the contamination within the soil. Now, the contaminated soil can be measured more accurately and placed in planters where the roots will be able to adequately reach the contamination. By digging up the contaminated soil and creating an excavated area, there was now an opportunity to have a raingarden on the site that could collect and store rainwater that could be used to feed the planters. Depending on weather conditions, it could fluctuate between a raingarden, marsh, or even a small body of water, reflecting exterior weather conditions

This way, all of the buildings can be built at once, saving time during construction and making the process more efficient. Once the soil has been cleaned of its contamination, barriers between the path and the planters can be removed and residents can enjoy the spaces beneath the trees. 


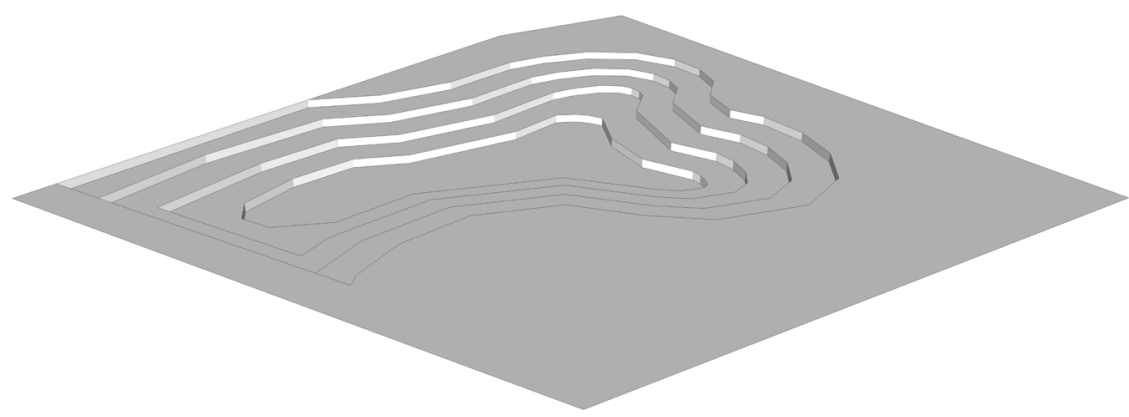

Phase 1: Contaminated portion of the site is dug out to make sure that all of the soil can be adequately cleaned.

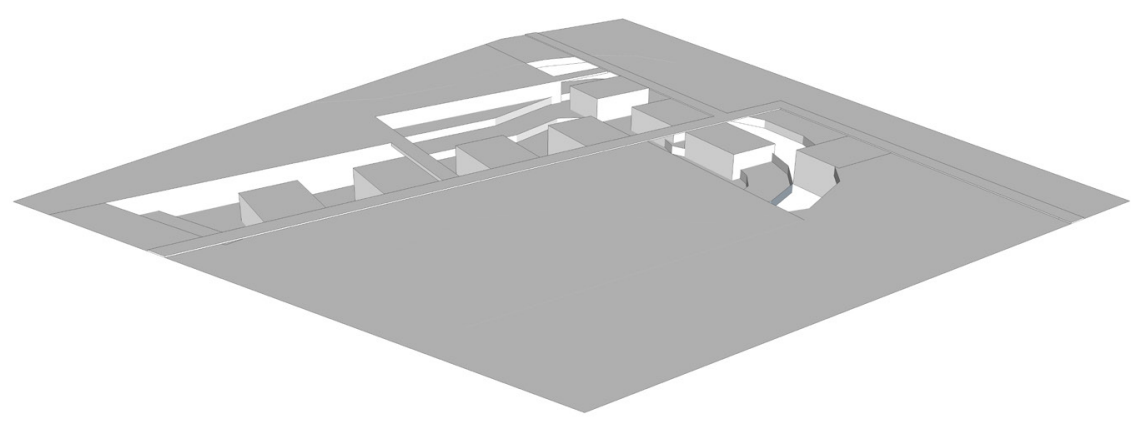

Phase 3: Building foundations are built into portions of some of the excavated area and are waterproofed.

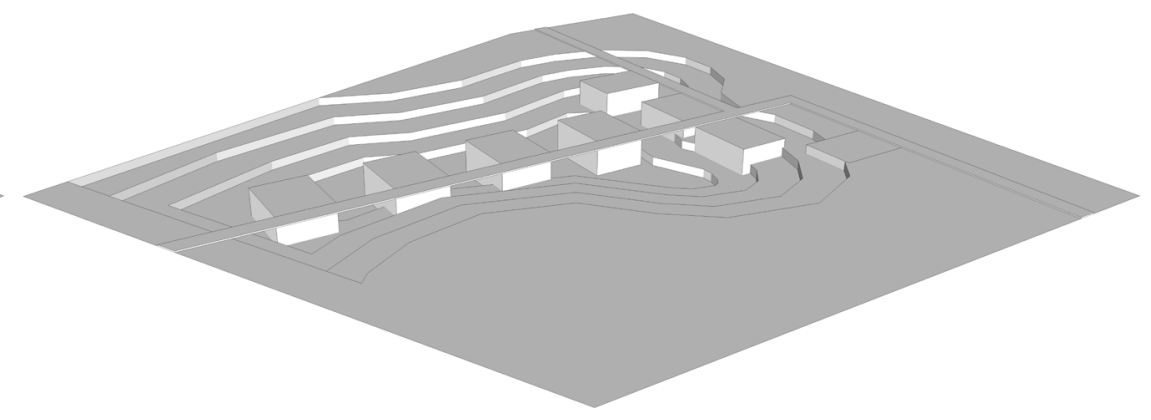

Phase 2: Soil is re-located into planters that are offshoots from the path. These planters are protected from access until the soil is certified clean.

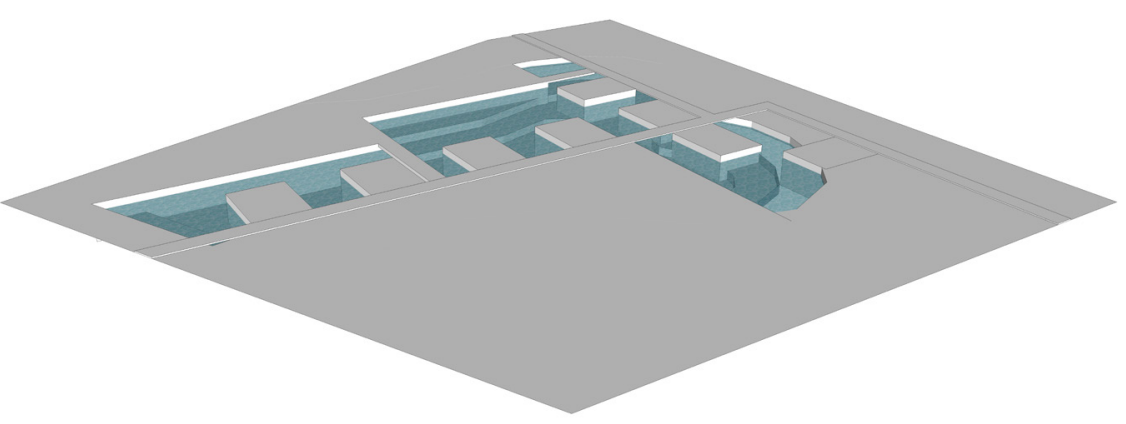

Phase 4: Excavated area becomes an isolated portion of the site that depending on weather conditions, could fluctuate between a rain garden, marsh, or small body of water. 


\subsection{Building Form}

The previous iteration saw the building form as a combination of the principles of forming to face the sun, forming to capture water, and building upon local/existing materials. These concepts remain the primary driving factors of the buildings configuration, but are now entwined with the idea of how these spaces might evolve through time. The masses were re-thought with the idea of permanence and ephemerality in mind. The diagram to the right describes how the darkest most solid portions are reflective of the most permanence, and the lightest are reflective of the most ephemerality. The cores of the project are intended to take on the most permanent unchanging configuration, as they are the backbone of the design. Housing the elevators that lead both to the residential units and to the commercial spaces in behind, as well as the mechanical and service spaces, they would be the least likely to be taken apart or reconfigured throughout the lifetime of the building.

Secondly, the residential spaces would take on the second most level of permanence, but would also incorporate some aspects of ephemerality. Generally their configuration would remain the same, but throughout the lifetime of the building, many of their components could be adapted to change. Components like exterior walls and walkways might remain the same, but throughout the buildings lifetime there may be changes in the need for solar panels, changes in exterior materials and levels of deterioration, or personal unit adaptations that differ from resident to resident. Even changes in the types of plantings that differ from user to user would slowly change the exterior configuration of the residential spaces.

The most ephemeral or evolving portion of the complex are the greenhouse spaces on the south side of each condo, and the multi-use spaces on the north. Within their designs, an embedded change with their facade configurations facilitates a flexibility that allows the spaces to respond to various interior conditions. The greenhouses have shading devices that can be utilized for overheating, and the commercial spaces have exterior panels that can be configured to suit any of the changing needs inside. Internally, both spaces would have to accommodate for a high degree of change. The greenhouses would literally house plants that grow, bear fruits and vegetables, and eventually die. The summer growing season would be busier, and the winter would slow down. When extra produce is available, market spaces could open up on the ground floor of the northern multi-use portion, creating additional income for the residents. The commercial areas also have to accommodate for a high degree of internal change from the different external tenants that come in and use the spaces. The spaces would serve as a shell for various activities to move in and adapt to the space, while providing structural and mechanical infrastructure along with the changeable facade.

Like a plant that emerges from the earth, there are parts that grow, parts that die, and parts that generally do not change; the roots that support the infrastructure of the organism. In a way, the complex has taken on the same parameters, acknowledging and awareness of where time may take its eventual configuration. 


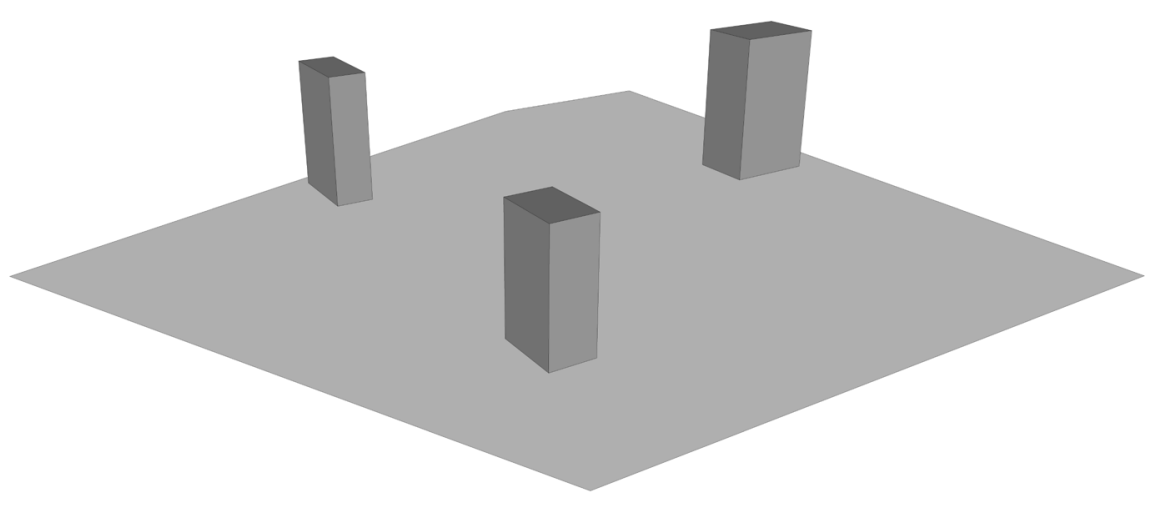

Permanence: Building cores that house elevators, mechanical, and service spaces, become the backbone of the design.

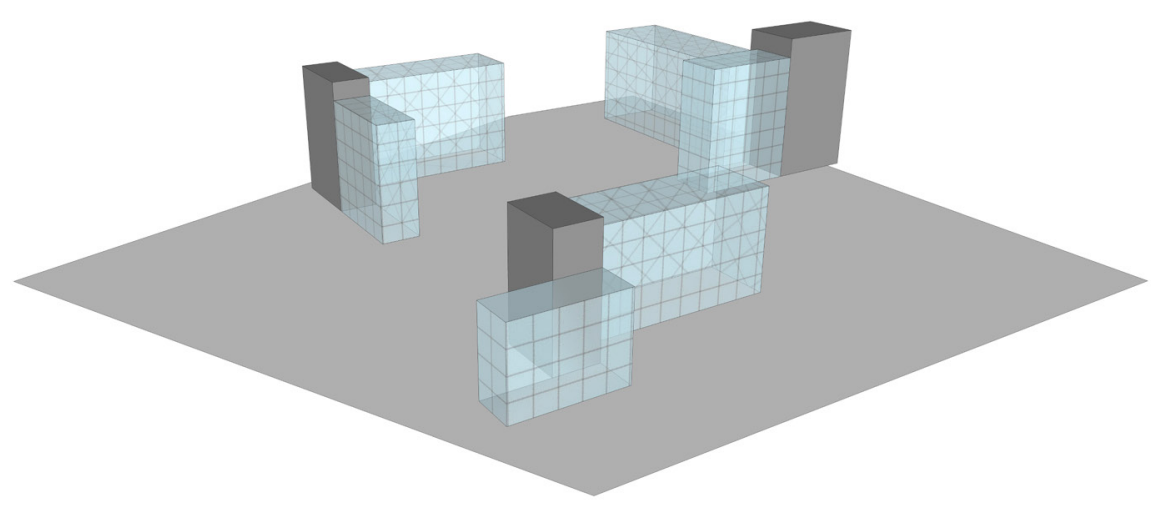

Ephemerality: Spaces known to have evolving programmatic needs have a higher level of embedded flexibilty.

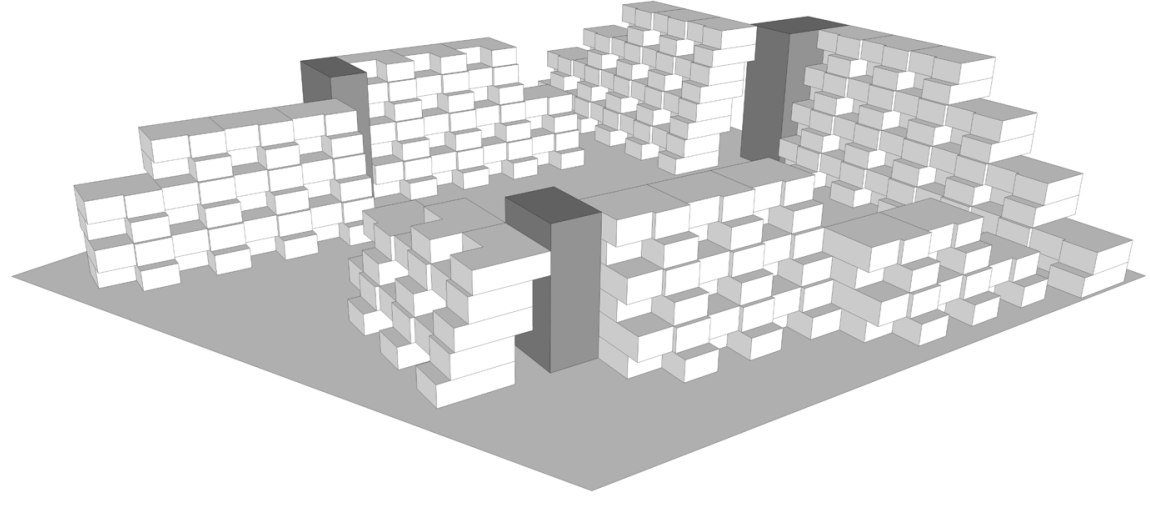

Semi - permanence: Residential spaces that will maintain their overall form and use, but have replaceable exterior components.

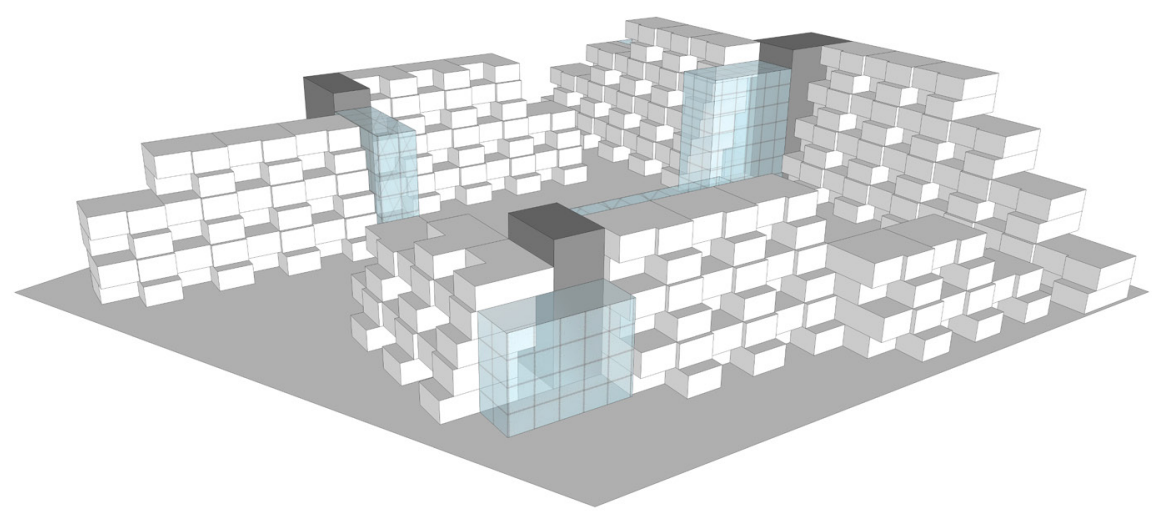

All three components together.

Fig.86: Building mass strategy 


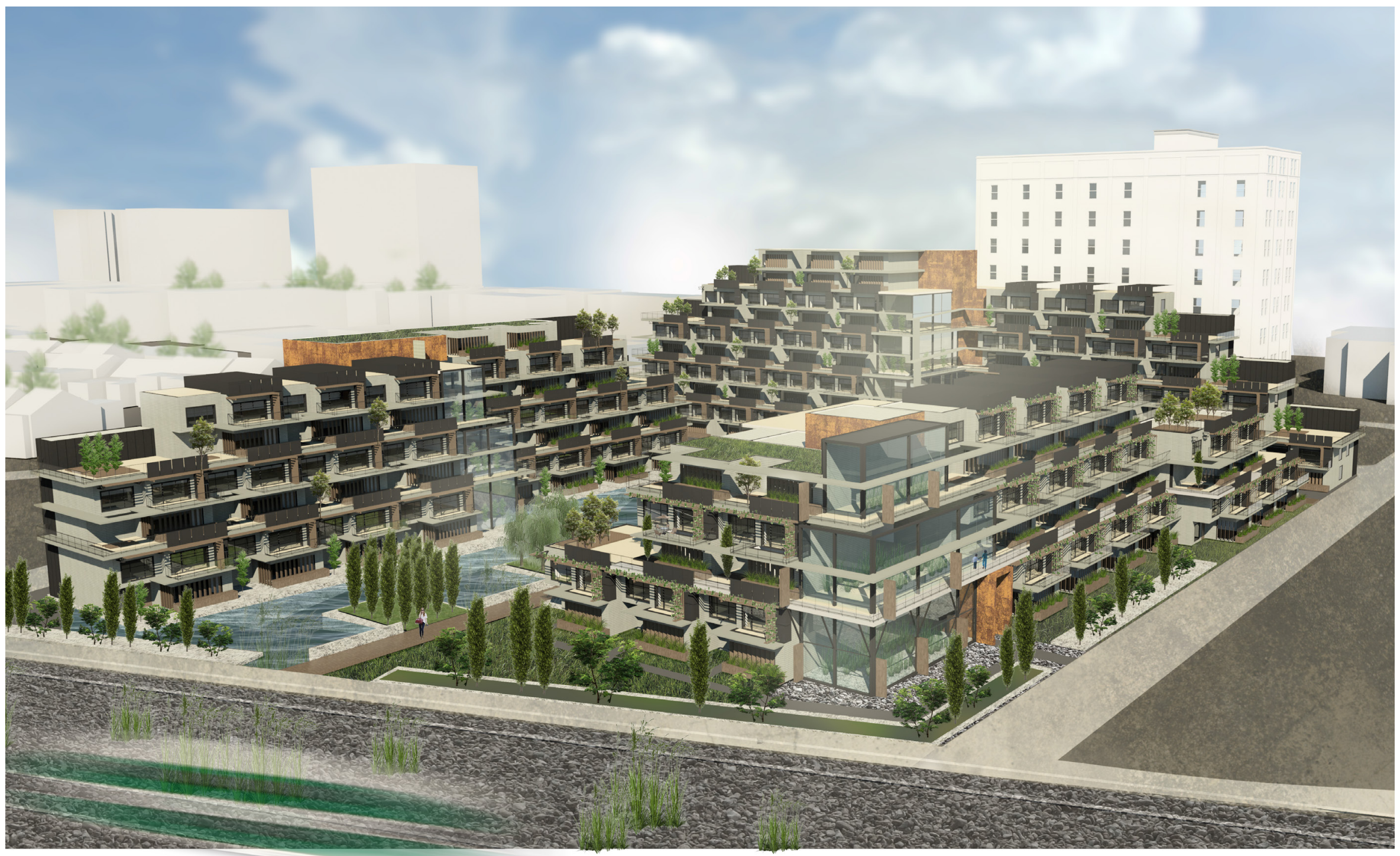

As seen from the south, the building's massing maintains its south-western facing units with the addition of greenhouses in the corners at circulation junctions. A sloping of units at edges provides variation for larger green spaces, helps with avoiding shading, and reveals the historic building behind.
Fig.87: Revised Arial Perspective

87 


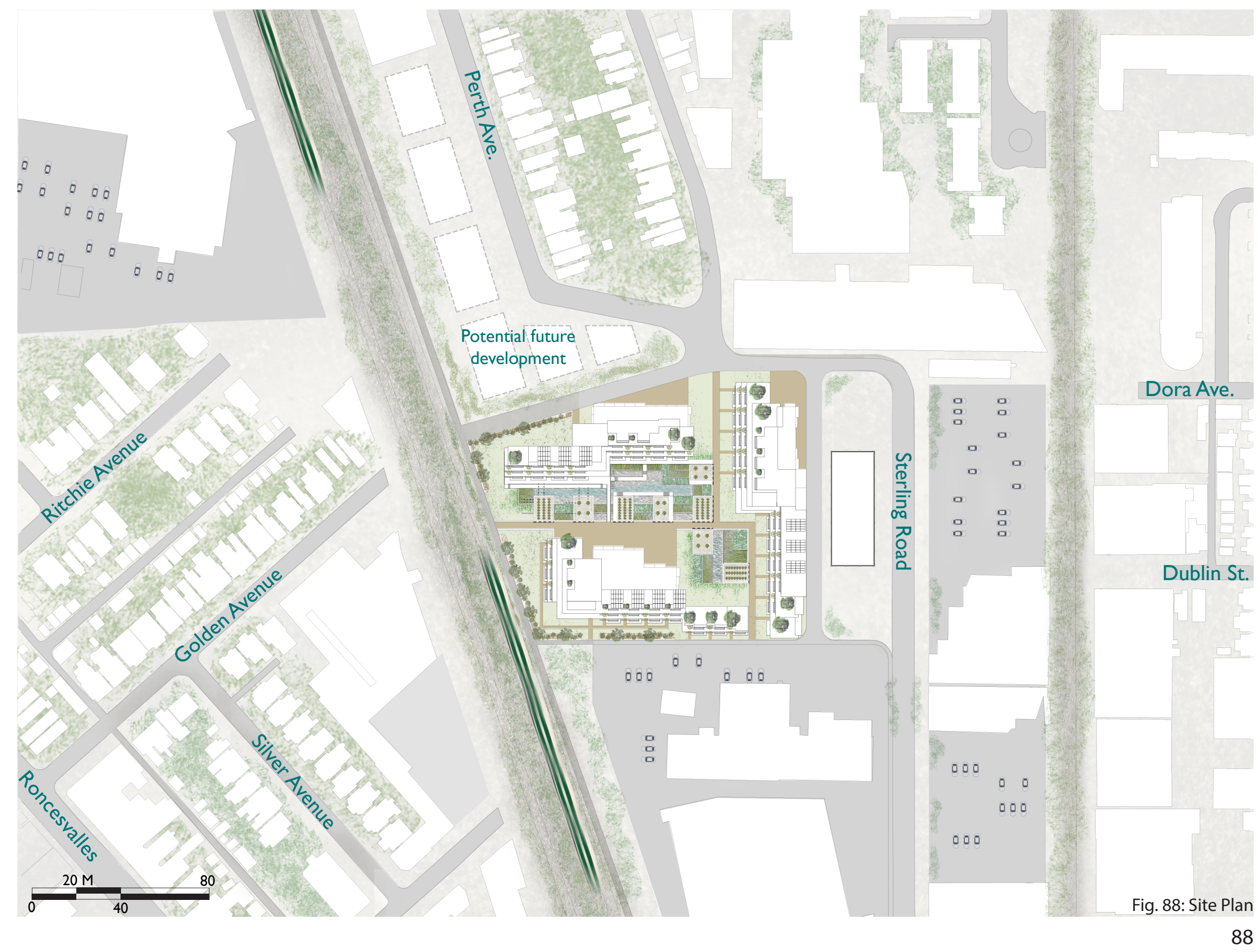




\subsection{Daily Time}

Even within a day, nature engages with the process of change. The final design aims to reflect daily changes within its configuration that help with the technical, social, and experiential aspects of the space.

At the smallest scale, each unit is equipped with louvers that can be rotated based on daily preferences. Louvers are placed outside of the

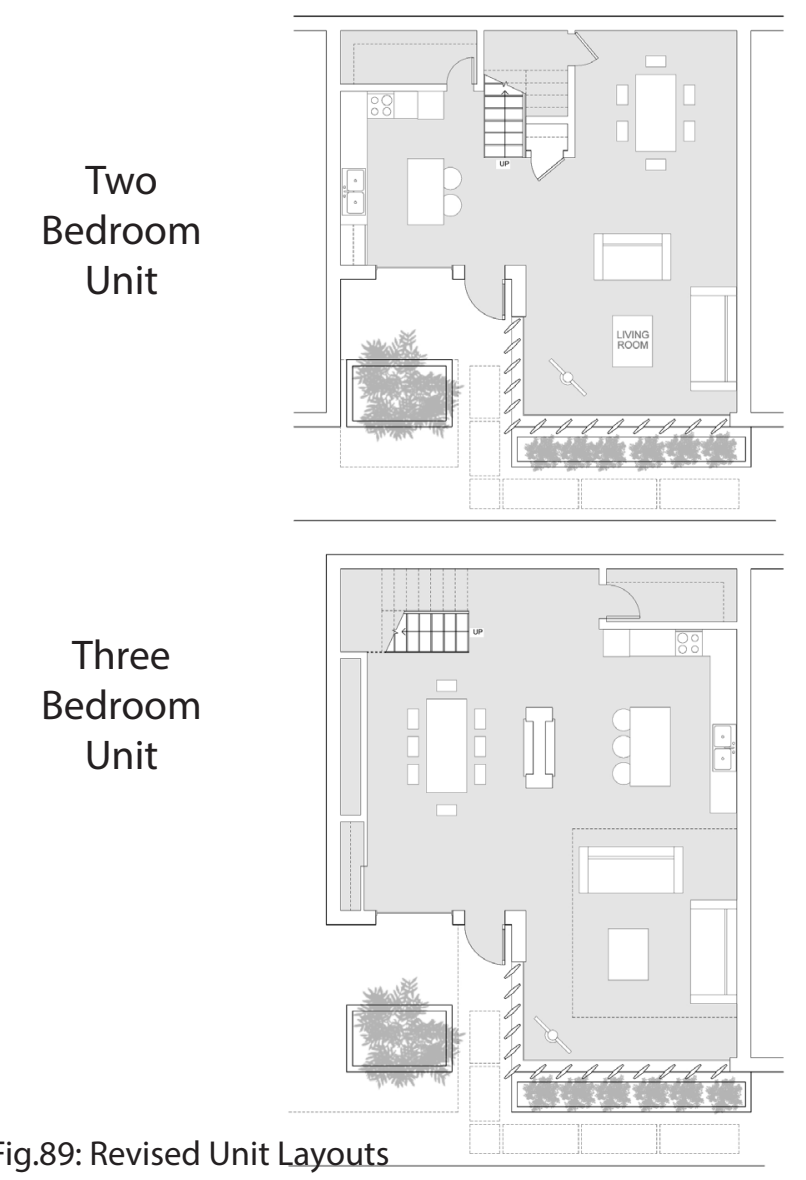

windows on the ground floor, and can be operated from the interior. The intent is that they can be rotated based on sunlight preferences, such as blocking out an afternoon glare or letting in the morning sun. In turn, they would help the heating and cooling loads in their respective seasons, engaging users to be active participants of their spaces. Acting like a built in set of external blinds, their rotations would create a dynamic form visible from the outside.

The louvres also have many social implications

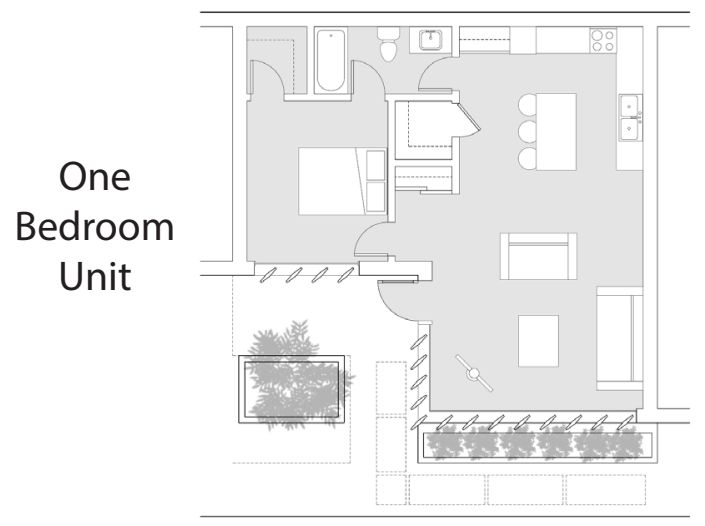


as they are an extra boundary for privacy between the walkway and one's living space. The creation of exterior hallways as entrances into the units is a move that aims to re-create the relationship between ones home and their exterior spaces, pushing the idea that a different density can re-formulate ones relationship with their neighbours and environment. It fundamentally re-structures the experience of living in a condominium building, and in a way, forces residents to engage with the community they are a part of. In order to create this, each unit also had to become a double storey unit (with the exception of one bedroom units) so that bedroom spaces could remain private. Throughout the day, the building becomes dynamic with the movement of residents to and from their units. Mornings come alive with residents walking to and from work, afternoons would probably slow down with people scattering at various times, and evenings might be filled with children playing outside. These daily occurrences that happen on the street and engage people with their neighbours is a stark contrast to the monotony and lifelessness of an unchanging condominium form, with activity hidden in brief moments in a hallway. There is a slight push towards the idea of de-privatization, aiming to foster a social conscience where residents would have an awareness of each other, more like the neighbourly social atmosphere that comes with living in a single detached home. An awareness of who is home at what times, or the aesthetic of the personalization of exterior spaces would reveal the character of each resident. This type of configuration would also require a type of stewardship for maintaining one's exterior spaces, for
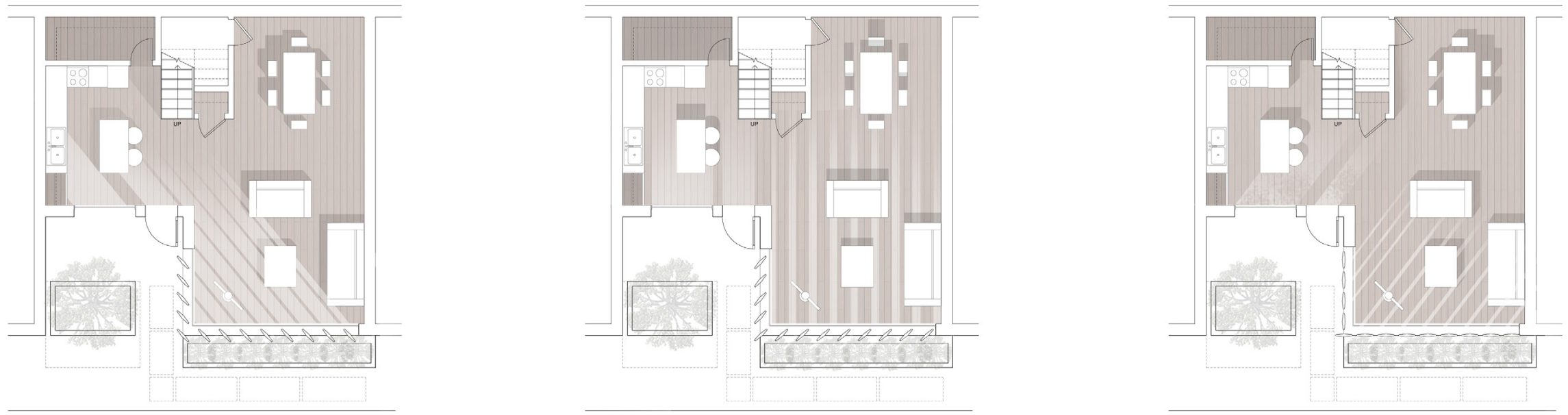

Fig.90: Daylight control 


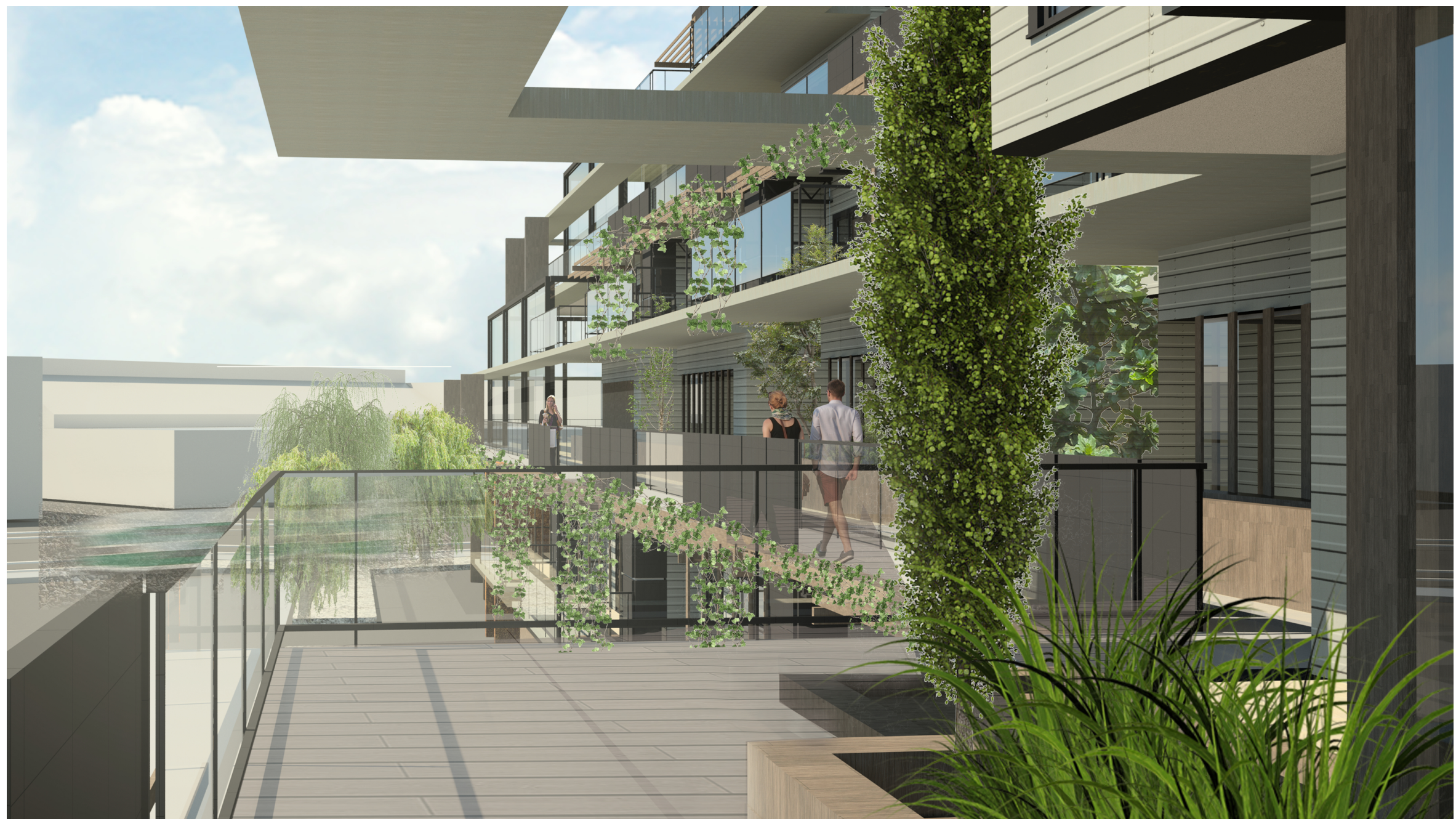

Fig.91: Exterior walkway during the day things such as upkeeping the trees and gardens, or shoveling snow and dirt that might accumulate on the walkway. It contributes to the ideas of integration by bringing natural elements closer to the users daily experience of their community, rejecting the idea that humans should live in isolated boxes in the sky, void of any awareness about their neighbours or the outside world. In a typical condominium, the idea of time could be considered obsolete. Nothing changes from day to day, or hour to hour. This proposal aims to foster a reconnection and awareness of ones exterior surroundings, reminding residents of their place within the realm of their community throughout various timeframes. 


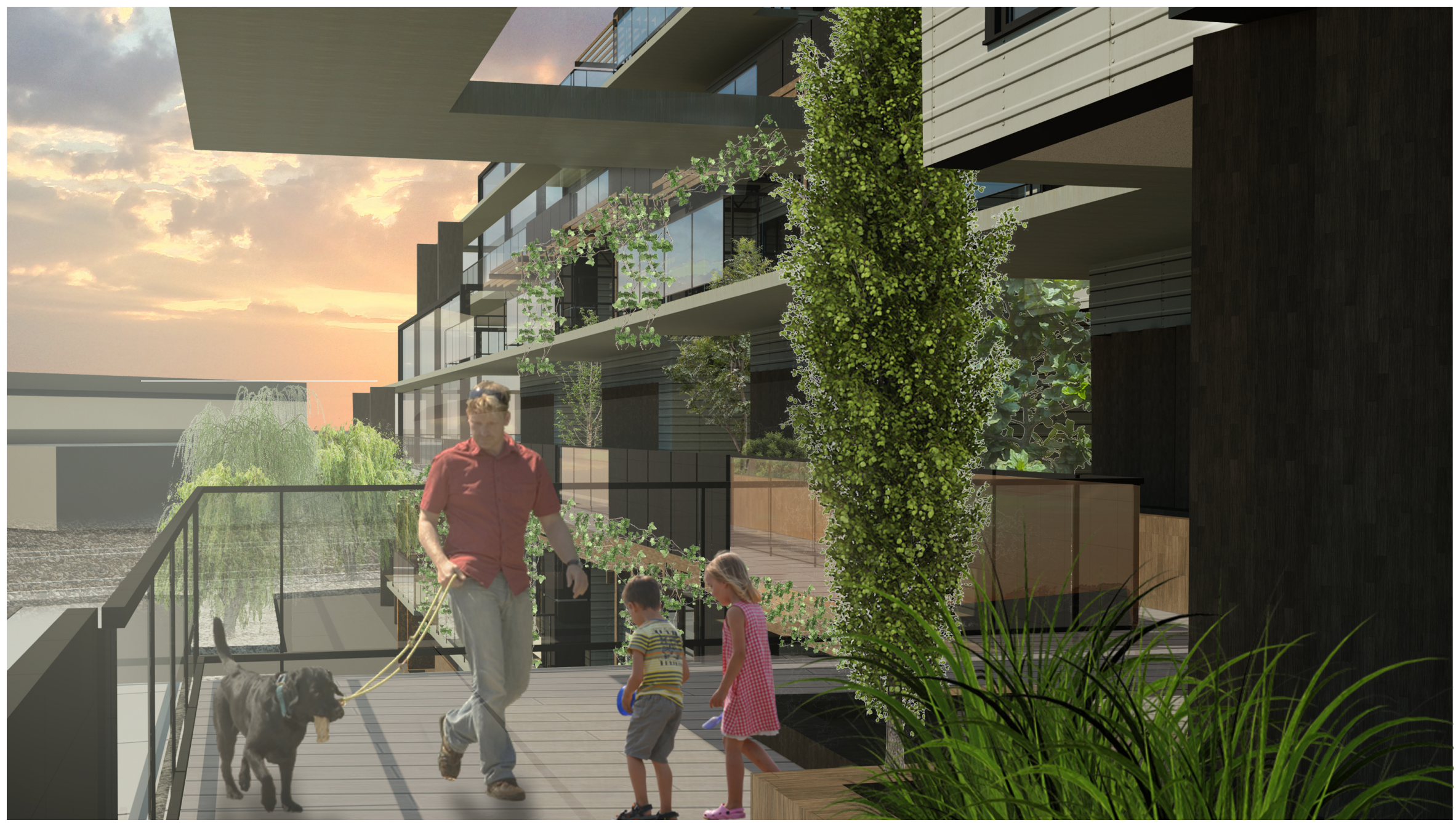

Fig. 92: Exterior walkway at night 


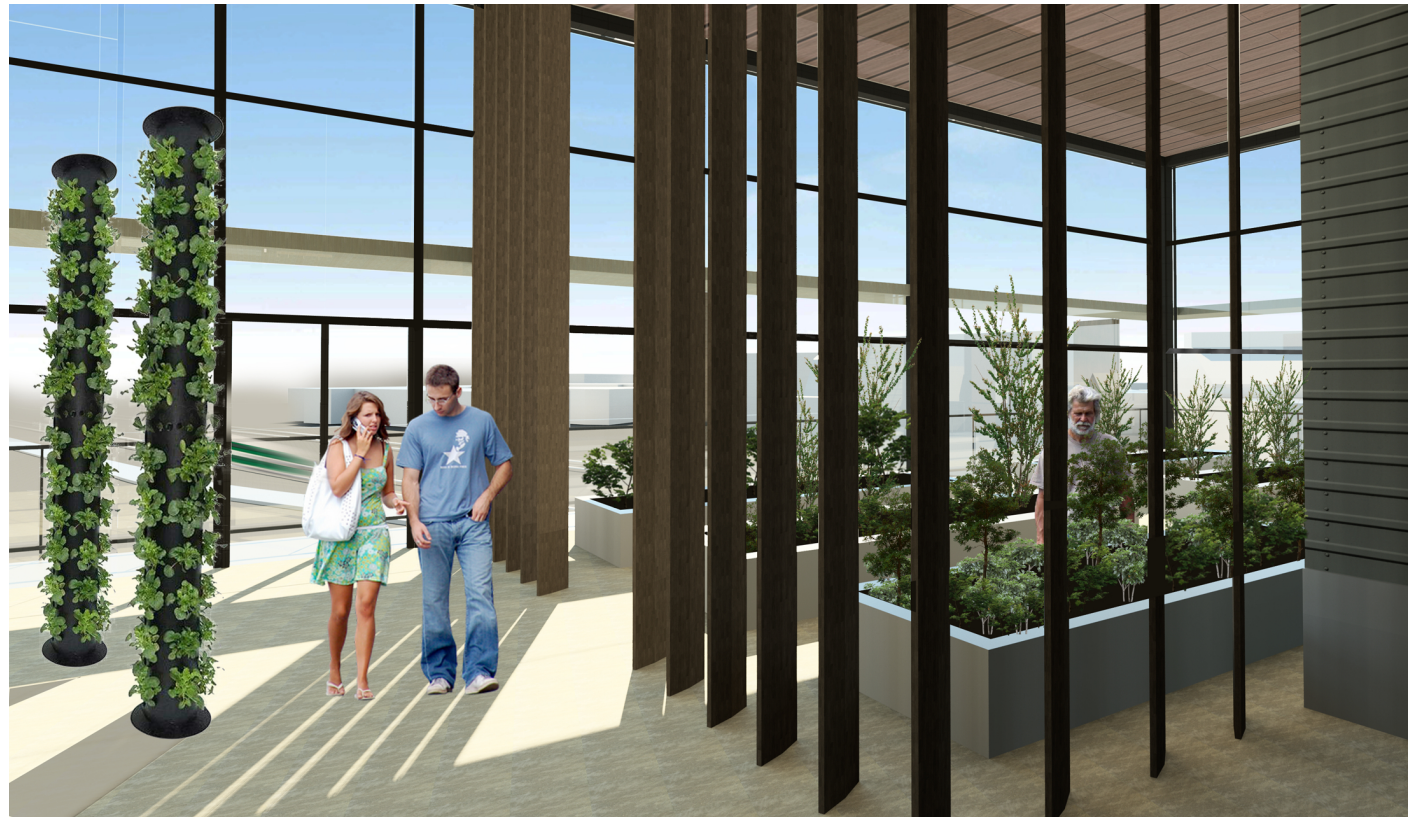

Fig. 93: Greenhouse interor spring/fall

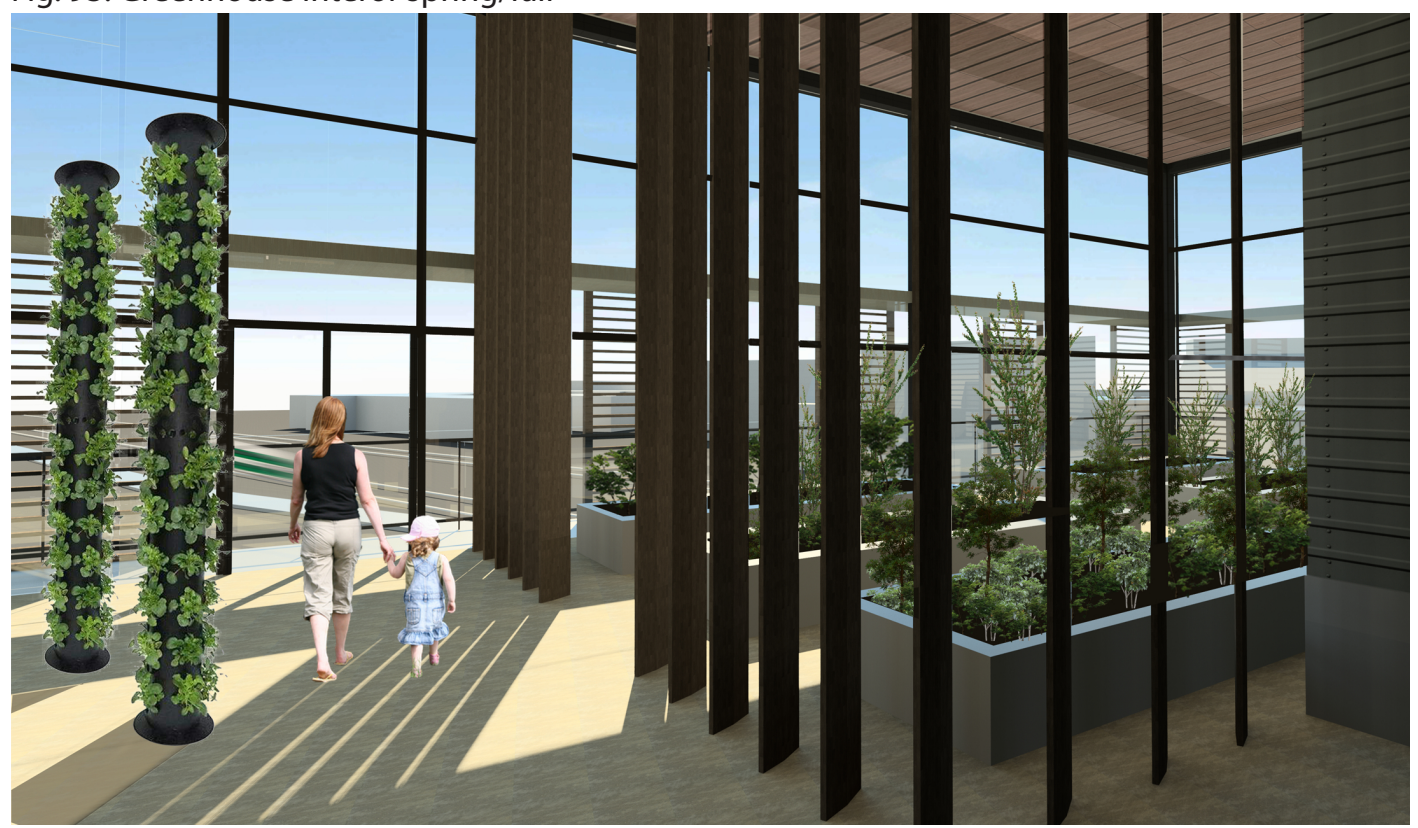

Fig. 94: Greenhouse interior summer

\subsection{Seasonal Time}

Seasonal time also reflects on the buildings form and operation. Most evidently is its relationship with natural infrastructure and the colours and forms of the plants and vines that change throughout the seasons. Trees will loose their leaves in the winter and allow a greater penetration of light into the spaces, and will grow back in during the summer to provide shading. Horizontal overhangs that cover the exterior walkways will also create an overall more shaded atmosphere in the summer, and allow for a deeper penetration of light in the winter.

The creation of greenhouse spaces at each circulation intersection have aspects that change seasonally both in their operation and external form. Externally, shading panels are attached to the edges of the walkways and can be unfolded along the outside, providing some shading when the greenhouse spaces can overheat in the summer. In the winter, panels would most likely remain decompressed for the maximum amount of heat gain. Their closed and open configurations can slide and move along the walkway edge depending on where shading may be needed more.

The operation and social dynamics of the greenhouse would also have seasonal aspects, operating at various capacities throughout the year. In the summertime, the extra produce generated from the greenhouse spaces could be sold in market spaces on the ground floor, creating a small circular economy within the building's organization. 


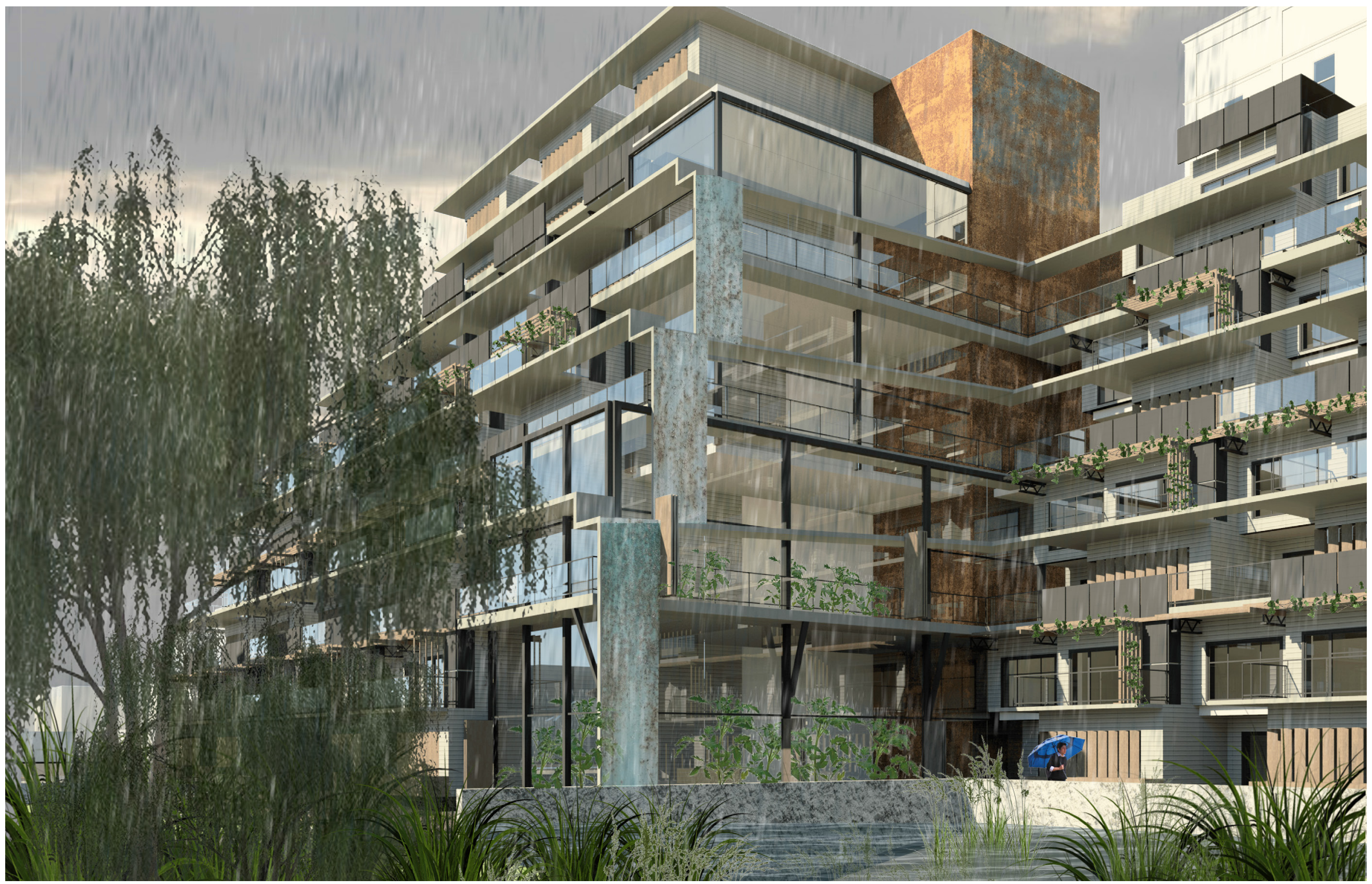

During seasons of rainfall, the building embraces the natural occurrence with an emphasis on its drainage patterns, turning them into an aesthetic feature of the design. The oversized rainwater leader is purposefully made out of a rustable steel material, so that every rainfall can gradually create a permanent imprint on the aesthetic of the exterior. 
Fig.96: Ground floor commercial spaces, warmer months
Seasonal variations and beyond would be reflected in the muti-use spaces behind the residential buildings. In the warmer months, shops can open their facades into overhangs that create an extension of the interior spaces that merge with the public realm outside, creating a vibrant cultural atmosphere among the gardens. This creates many live/work opportunities for the residents, and the ability for the development satisfy the self-sufficiency of separation, by providing for basic needs such as groceries and community amenities on site. As the years progress, the open flexibility of the interior layout and the

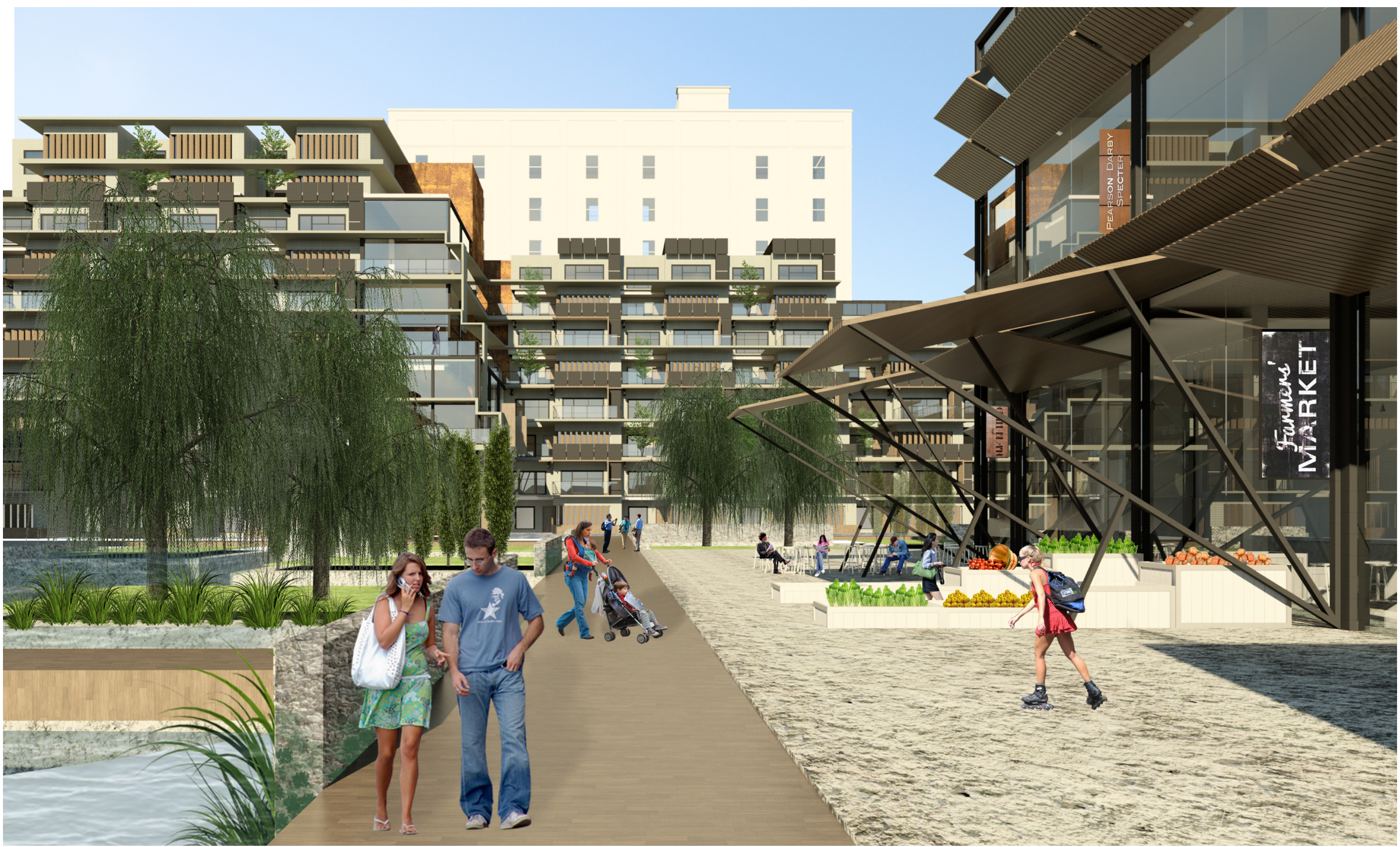


transformability of the facade enclosure creates the opportunity for businesses to move freely in and out, creating a resiliency by providing for easy adaptation. Functions most appropriate for these spaces can range from small scale commercial spaces such as farmers markets and cafes, to small scale offices and studios that might require more privacy from being on the upper levels.

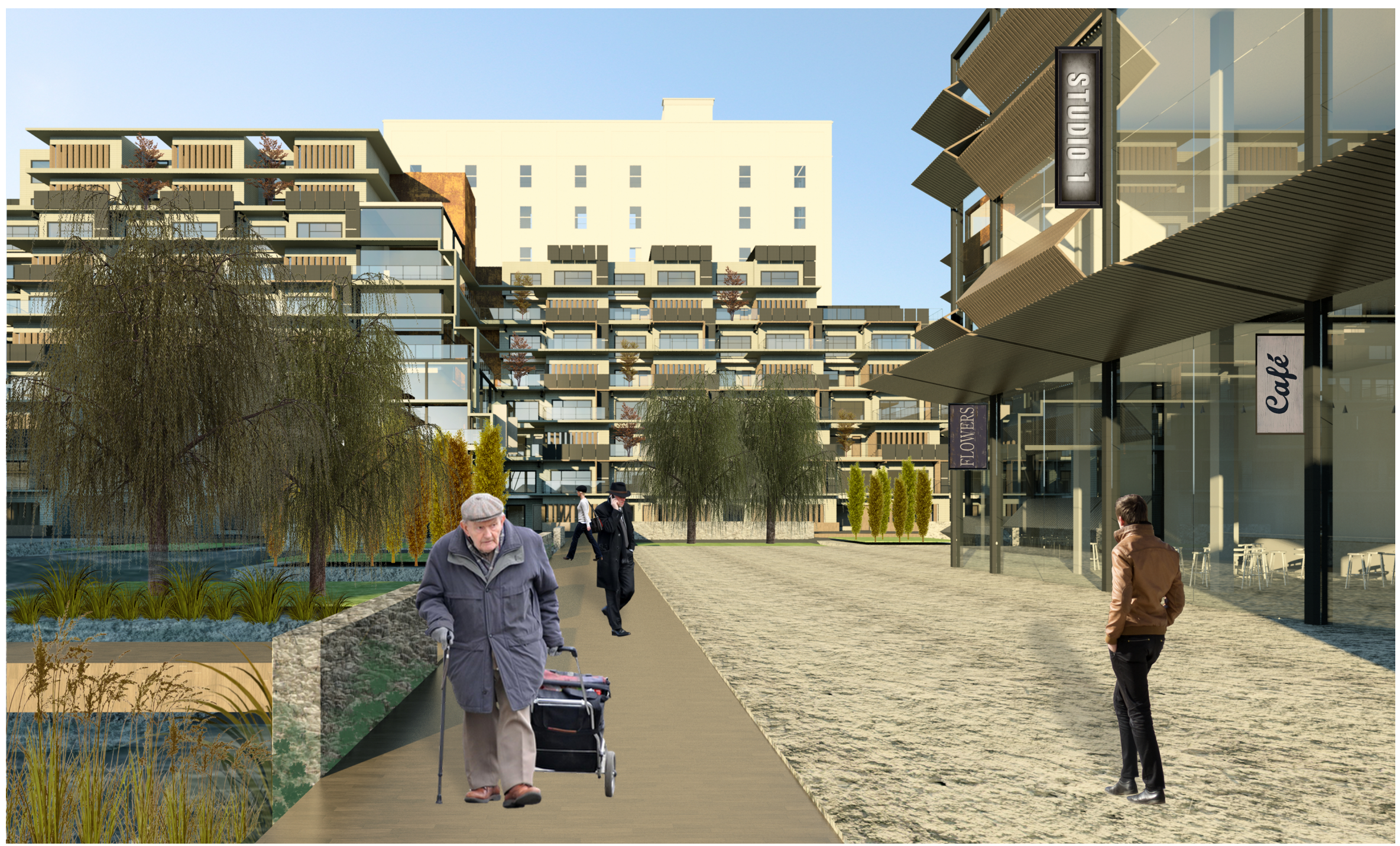




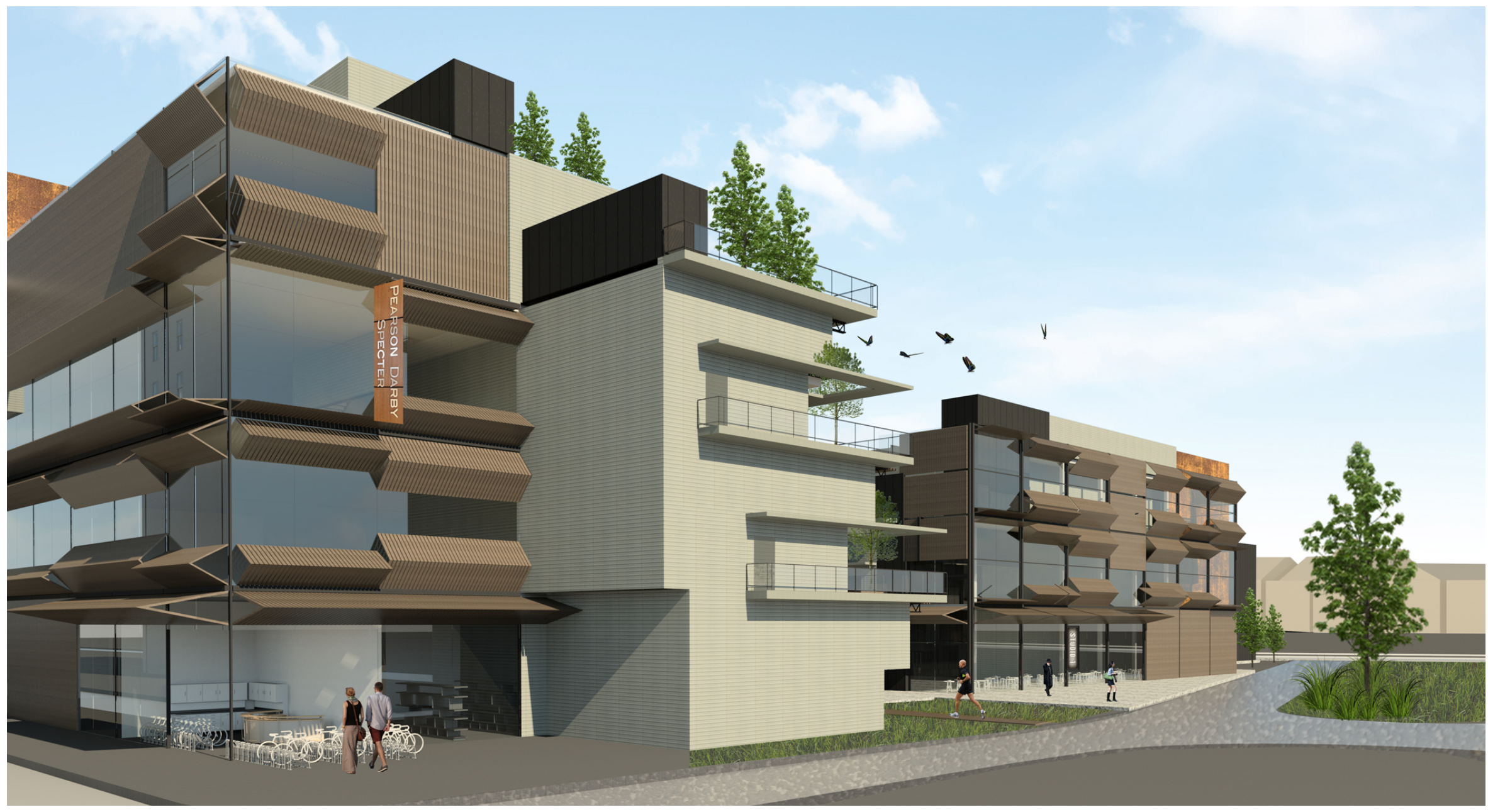

Fig. 98: North view

Multi-use spaces with ground floor commercial units also wrap around the northern and eastern facades, providing an inviting face to welcome in the community arriving from Bloor Street . Commercial and offices uses are well suited to northern light conditions especially when there is plenty of glazing for consistent lighting conditions that are more conducive to the activities inside. Figure 92 illustrates some of the configurations this facade can take, and figure 93 illustrates a typical section taken between the cascading residential units and the multi-use spaces in behind. Although the depth and height of the multi-use spaces varies depending on the height of the residential, the general configuration remains the same. The illustration also shows a shared mechanical shaft in between that can provide services to uses on both sides. 

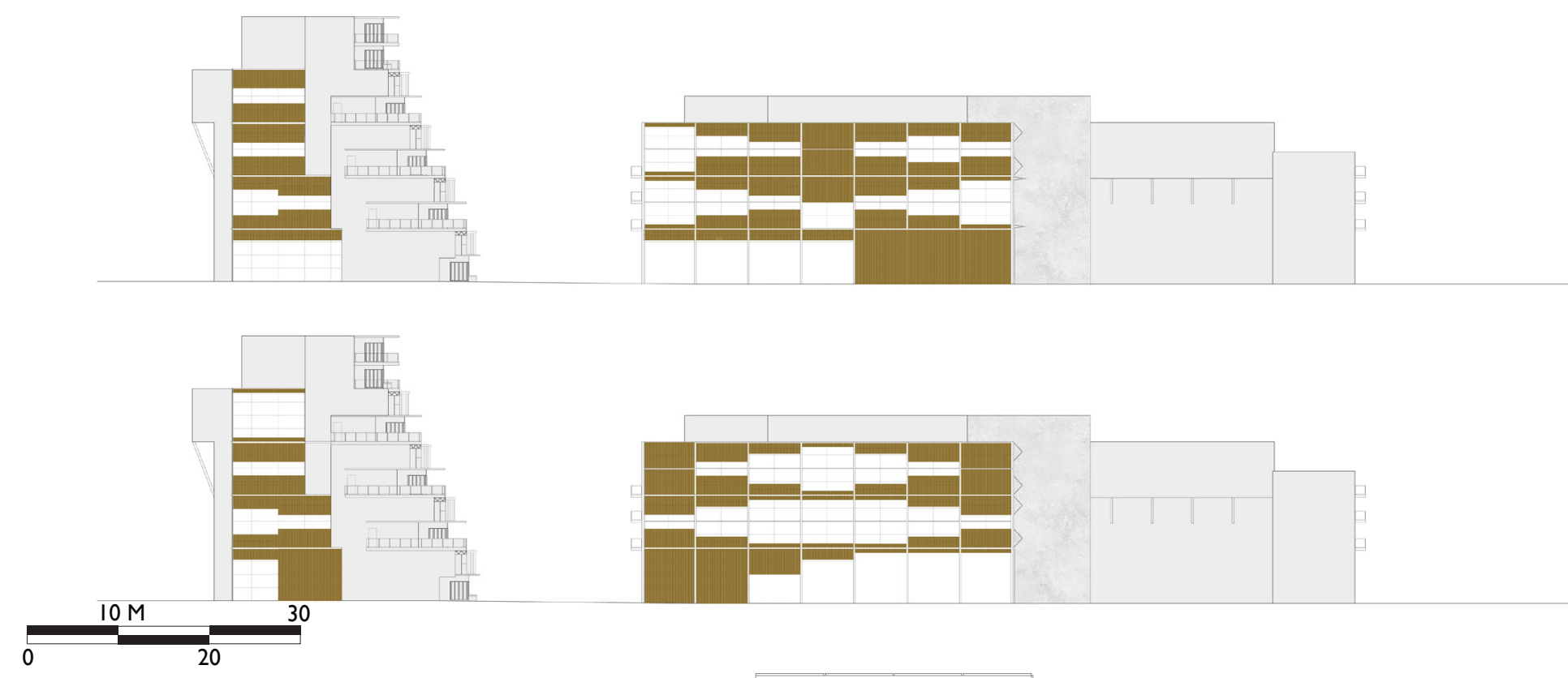

Fig.99: Variation of facade configurations

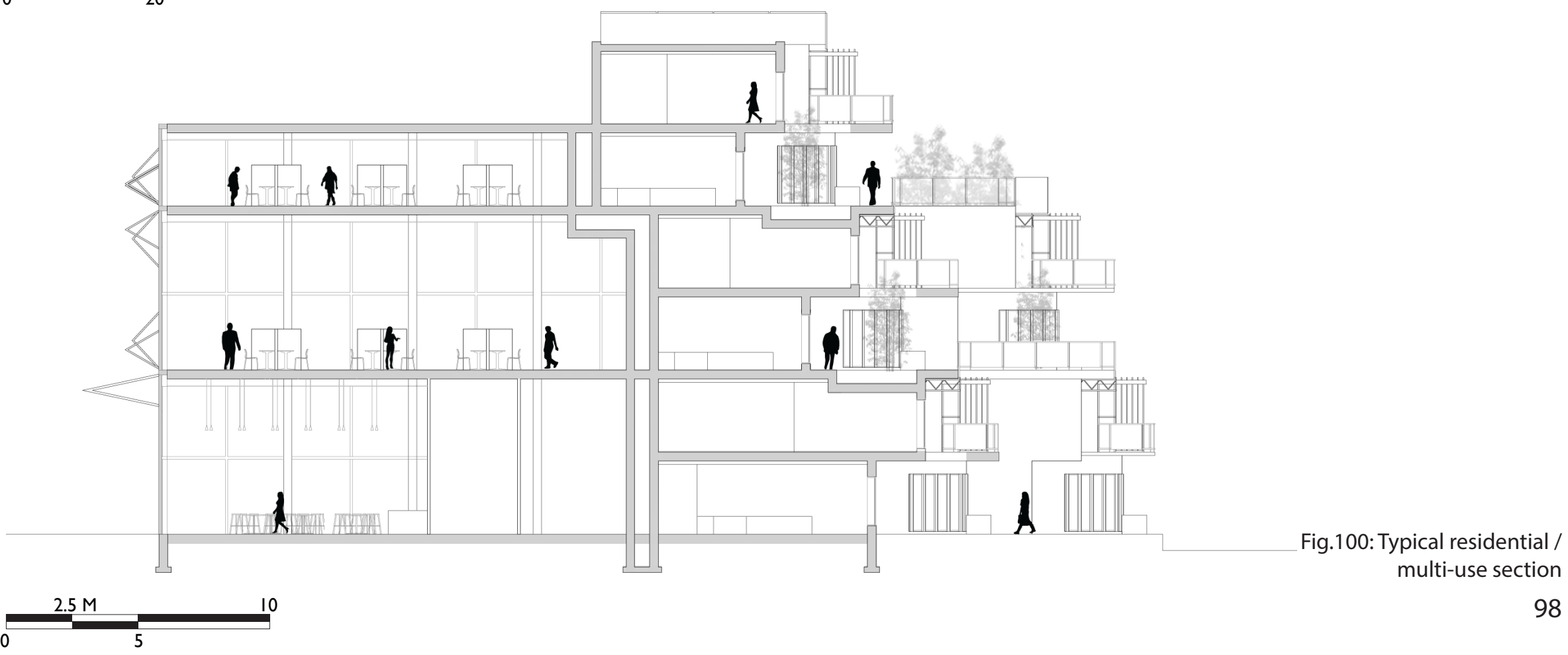


Fig. 101: Dry landscape plan / early development

\section{LEGEND}

I. LOWEST LEVEL GRADE- PEBBLE 2. MID LEVEL GRADE - ROCKS

3. UPPER LEVEL GRADE - PLANTS

4. PHYTOREMEDIATION PODS

5. PROTECTIVE FENCES

6. MAIN PATHWAY

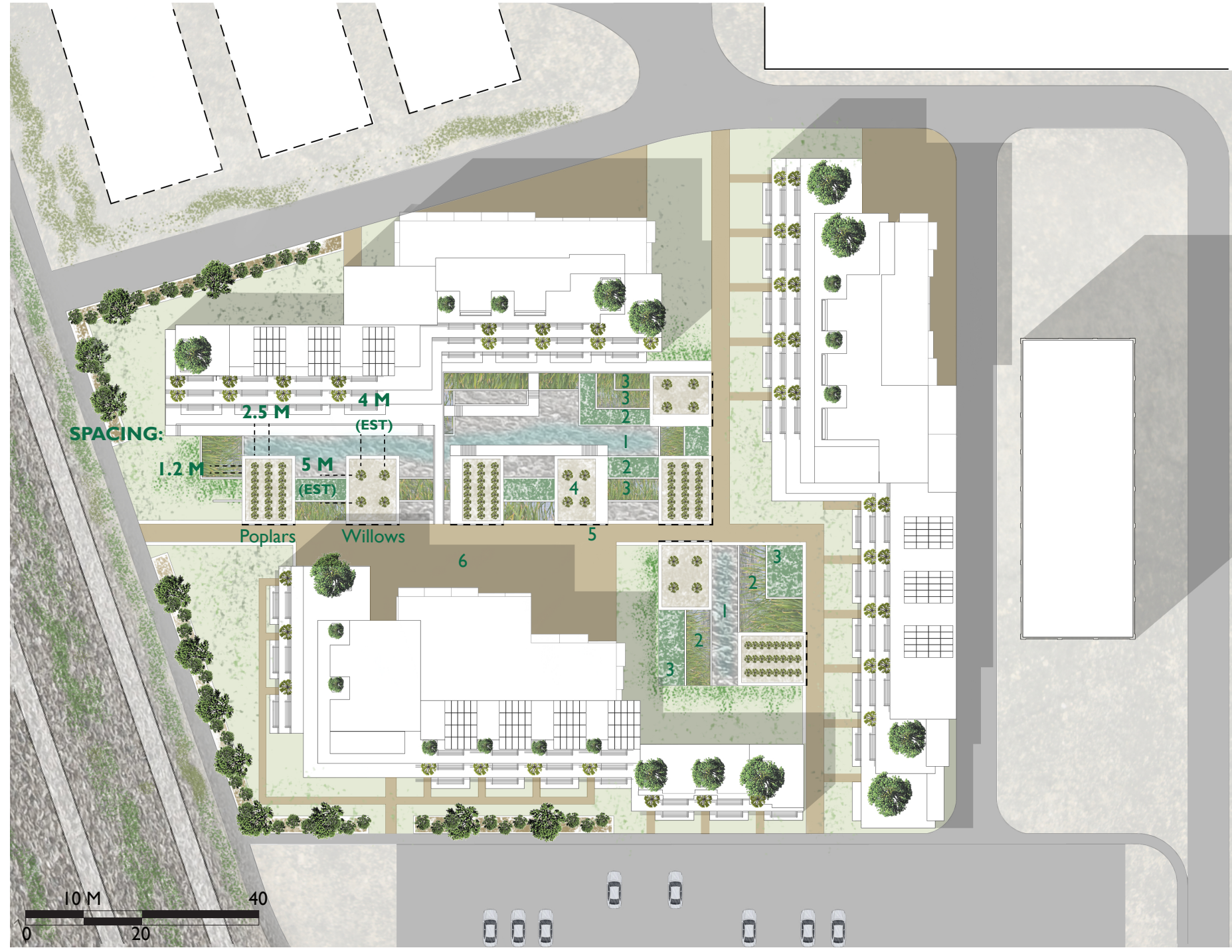

The landscape is designed to accommodate rainwater fluctuations that may occur on site throughout various seasons or years, as well as the phytoremediation growth process. These two which are paired together for the examples may or may not occur in tandum with one another (eg. a dry landscape could also occur in the future, or a wet landscape early on). Change is accomodated through the various levels created within the excavated area, ranging the ground cover palette from a pebble cover on the lowest level 
to more planted areas up above. The landscape will reveal these various areas if a dry season occurs, or will hide them under water if rainfall builds up on site after a storm, creating a dynamic interplay between the areas designed, and the way nature will take them over. Since a large portion of the surrounding industrial landscape is paved, the development could serve as an excess water reserve for other areas if runoff is channeled underground, for example from the parking lot to the south. In addition, the phytoremediation
Fig. 102: Dry landscape render / early development

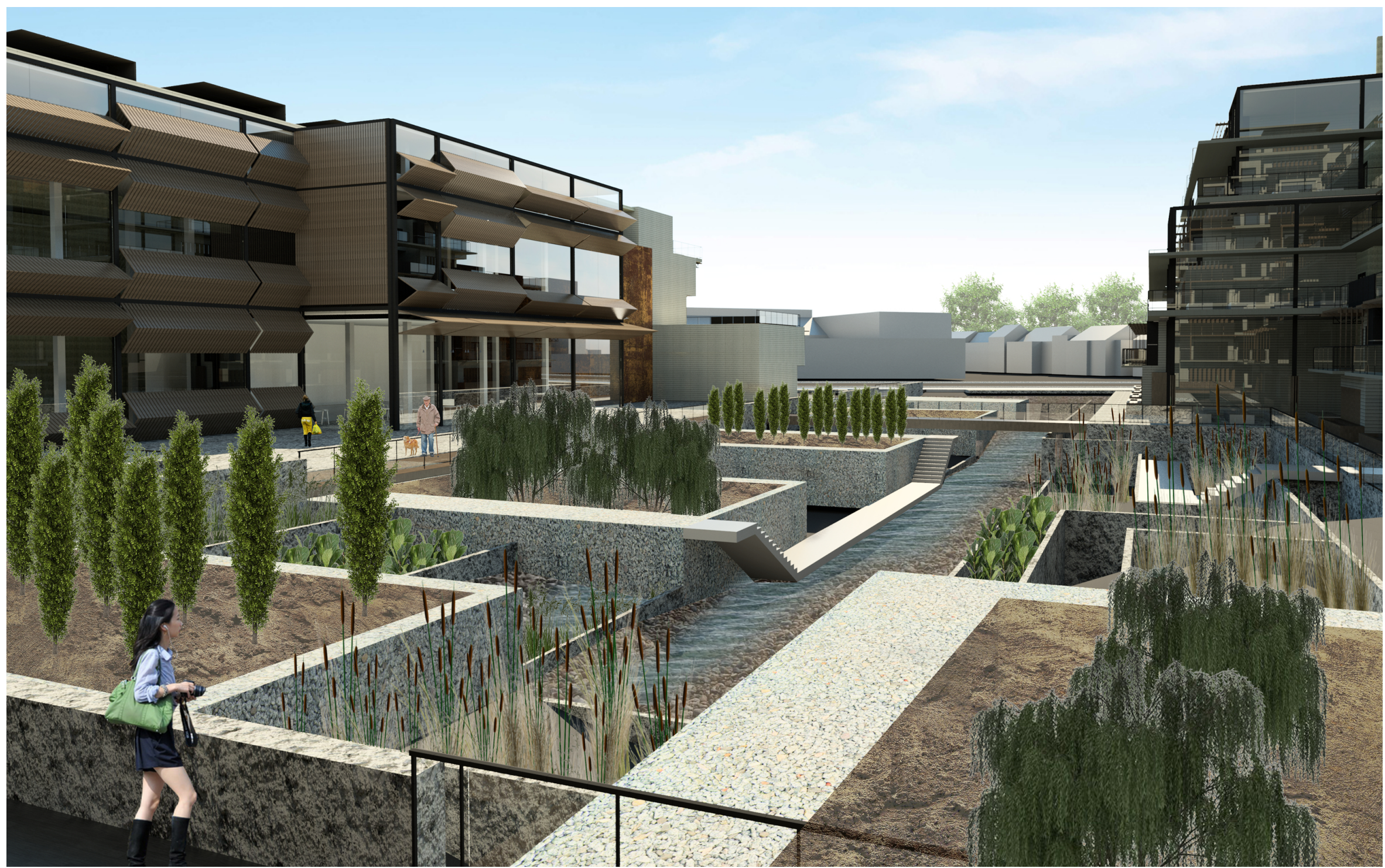


Fig. 103:Wet landscape plan / late development

\section{LEGEND}

I. LOWEST LEVEL GRADE- PEBBLE 2. MID LEVEL GRADE - ROCKS

3. UPPER LEVEL GRADE - PLANTS

4. PHYTOREMEDIATION PODS

5. RAILINGS

6. MAIN PATHWAY

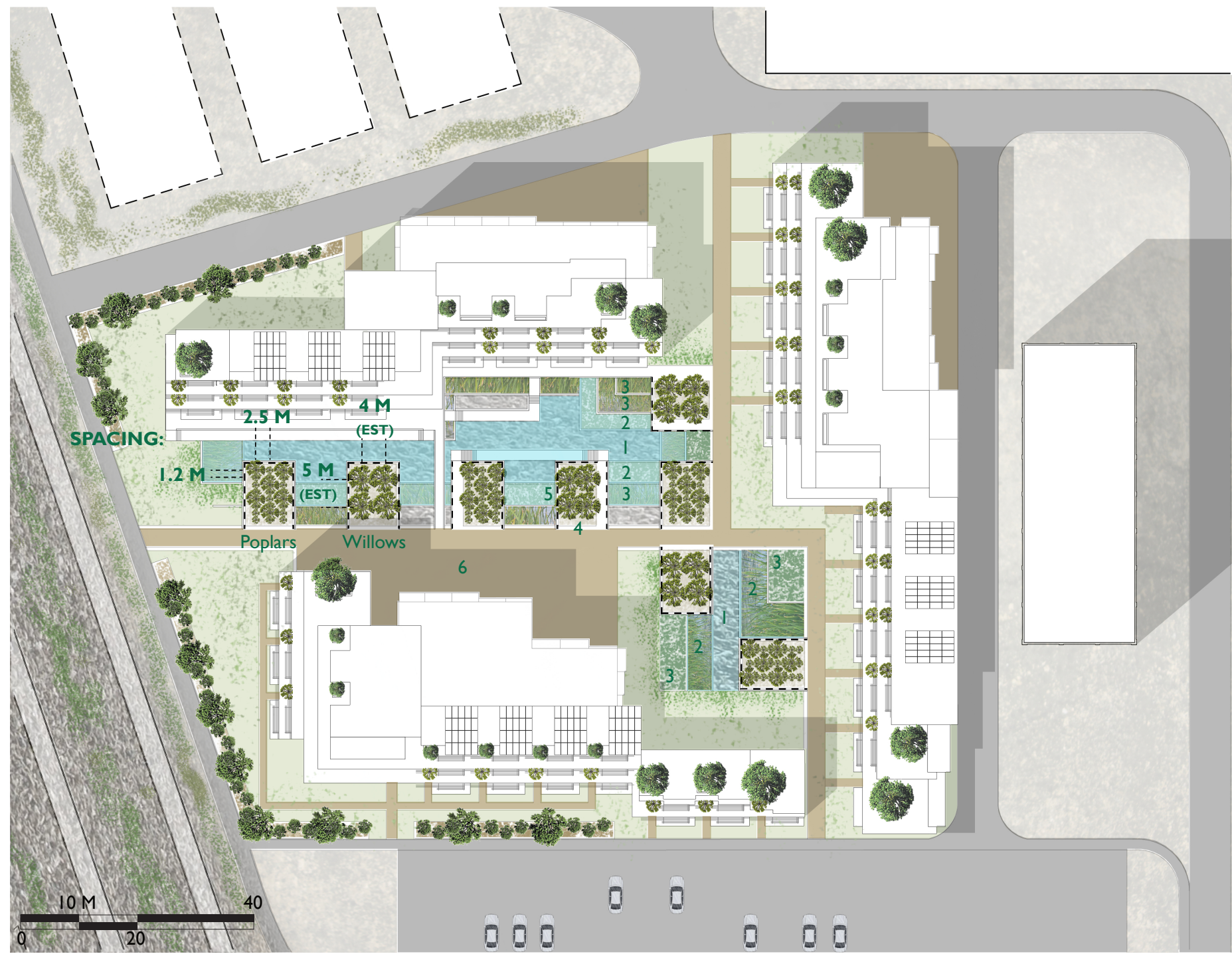

pods will need to be fenced off at the beginning of the process to ensure the soil is not tampered with. Once the process is completed, the railings can be moved to the inner side of the pods facing the water.

Depending on tests done by a soil engineer, trees may have to be removed every few years, or may be safe enough to stay in place. Once the pods are accessible, additional walkways can also be accessed that allow residents to spend time in the lower levels, experiencing whatever plants or marsh flora may 
emerge and the animals it may attract. Again, some of the time these lower levels could be accessible, and other times they may not depending on water fluctuation levels. It resists the false ability to control every part of nature, and gives in to whatever outcome may emerge. Overall the landscape idea plays with accommodating an undetermined future, by creating an enticing experience that has unpredictability built into its infrastructure.
Fig. 104:Wet landscape render / late development

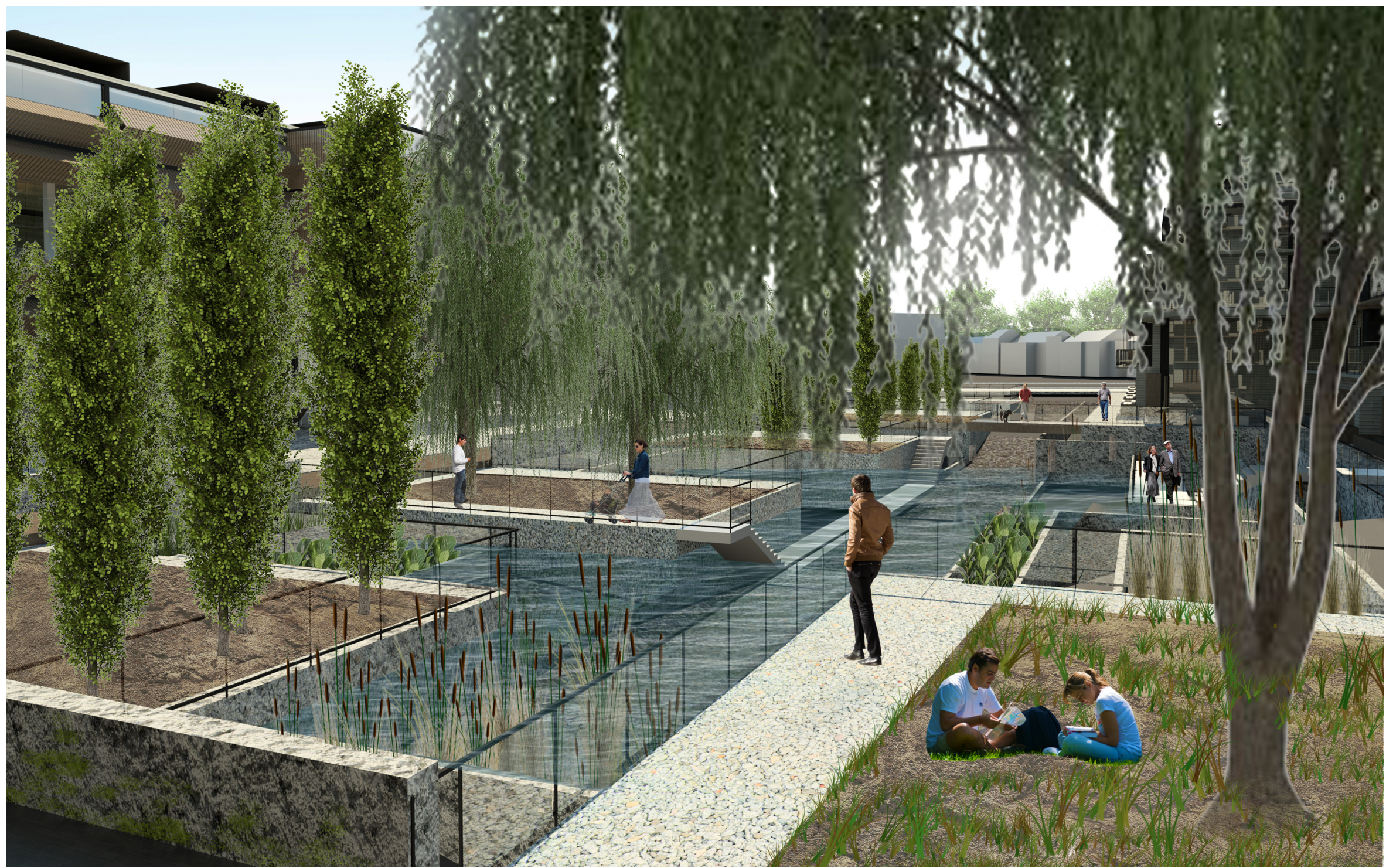




\subsection{Yearly Time and Beyond}

Conceptualizing the building through yearly time and beyond has the greatest impacts on site, materials, and program. The first way yearly time is considered is through the site massing, which anticipates future development. In the view from the train below, the site appears as a start contrast to the barren landscape. This is because future development

Fig. 105:View from train building stands high enough in anticipation that it won't be overshadowed by a new development. Similarily, the automotive building that is designated as a historical landmark is anticipated to stay, and was therefore highly considered in terms of its presence and views toward it that are created from the railway line and railpath.

Approaching the building along the railway path on the south side, it currently sits adjacent to a parking lot and low rise industrial building,

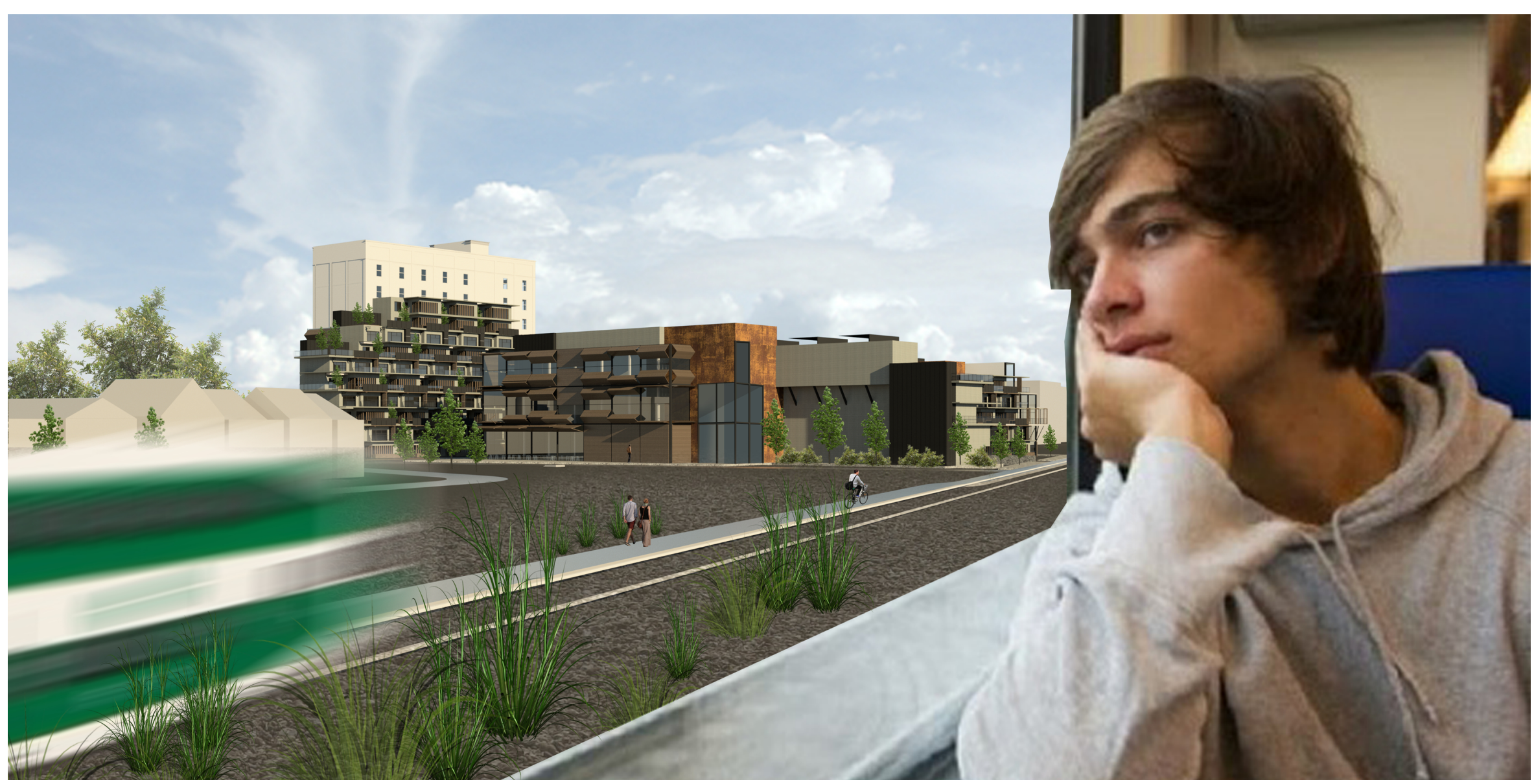




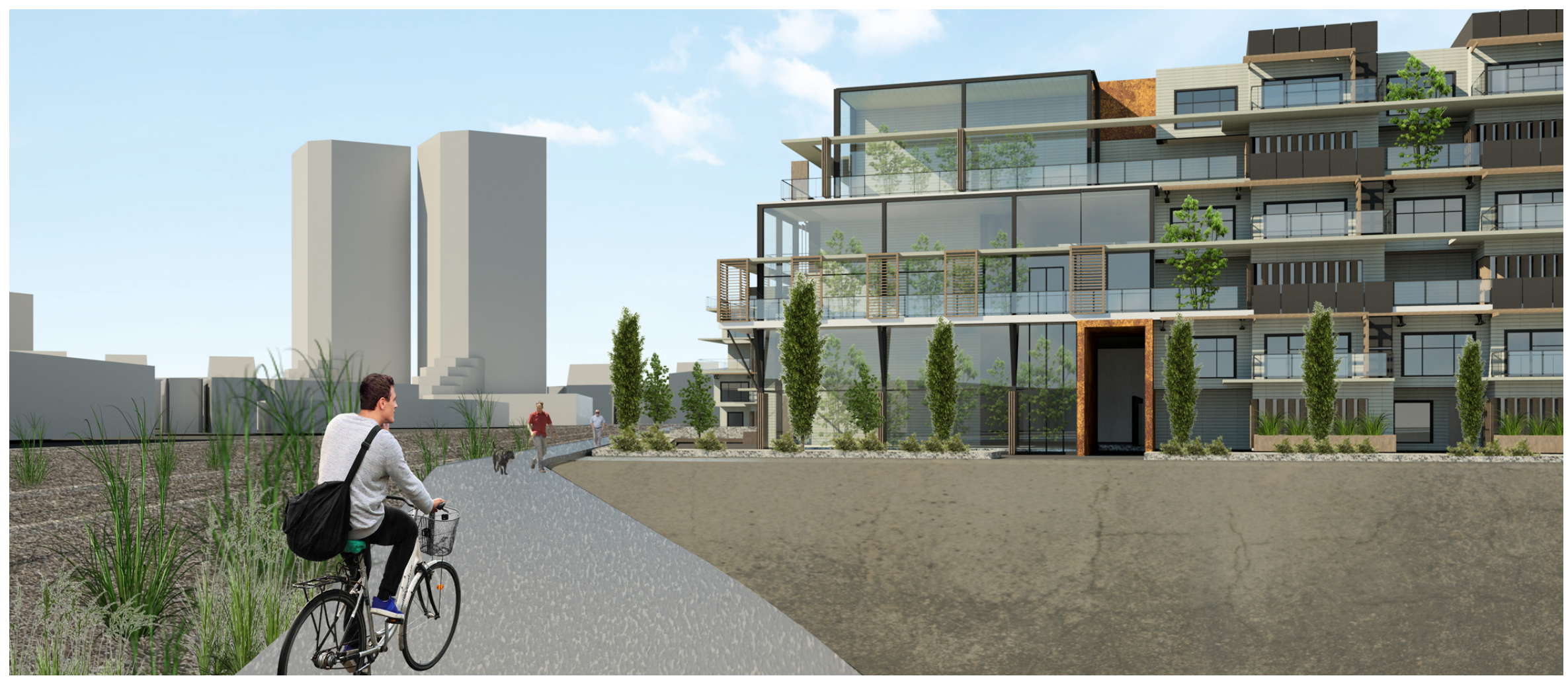

with no current plans for future development. The building is at its lowest height at this location, in an effort to merge into the lower heights of the small scale industries. Although a view towards a parking lot is not ideal, this adjacent space ensures that southern light will not be cut off from the building, and maximum light exposure and heat gain can be attained.

The sectional perspectives illustrate changes through time across the entirety of the site, representing all of the strategies as they work in tandem with one another. The materials would experience the most visible change throughout the years and beyond. Structural cores are clad in a copper facade that will exhibit the most dramatic external change, going from a deep gold to an eventual light blue. The movable wood facade panels would transform from a vivid brown to a desaturated one, and further throughout the years, will begin to disintegrate with the continual exposure to rain, deepening their internal grain patterns and exposing layers of various textures. The natural infrastructure on the site and intertwined into the facade will grow into the nooks and crannies of the building, densifying its branches and shading capabilities, merging with the permanent form of the building.
Fig. 106:View southern pathway 
As illustrated earlier, the landscape accommodates change through its various levels anticipating fluctuation, and the commercial spaces change through their internal configuration, personalization of facade throughout the seasons, and personalization of the facade through the transition of building occupants.

The tradition of architecture's permanence coupled with a mechanistic relationship with nature governed by stimulus and response is

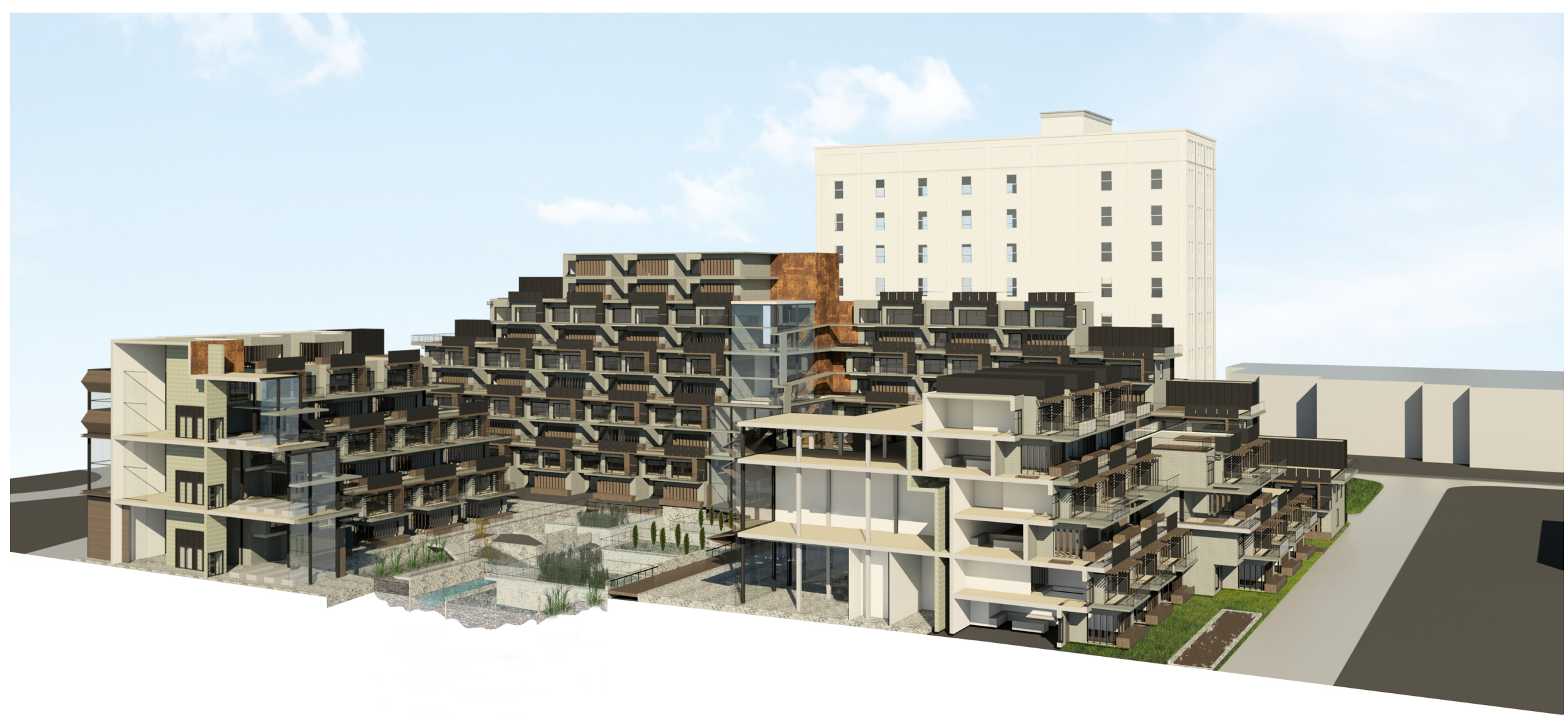

Fig.107: Sectional perspective, early built phase 
reconceptualized to become a receptacle for creative unfolding, to accept and emphasize the changes that time will bring.

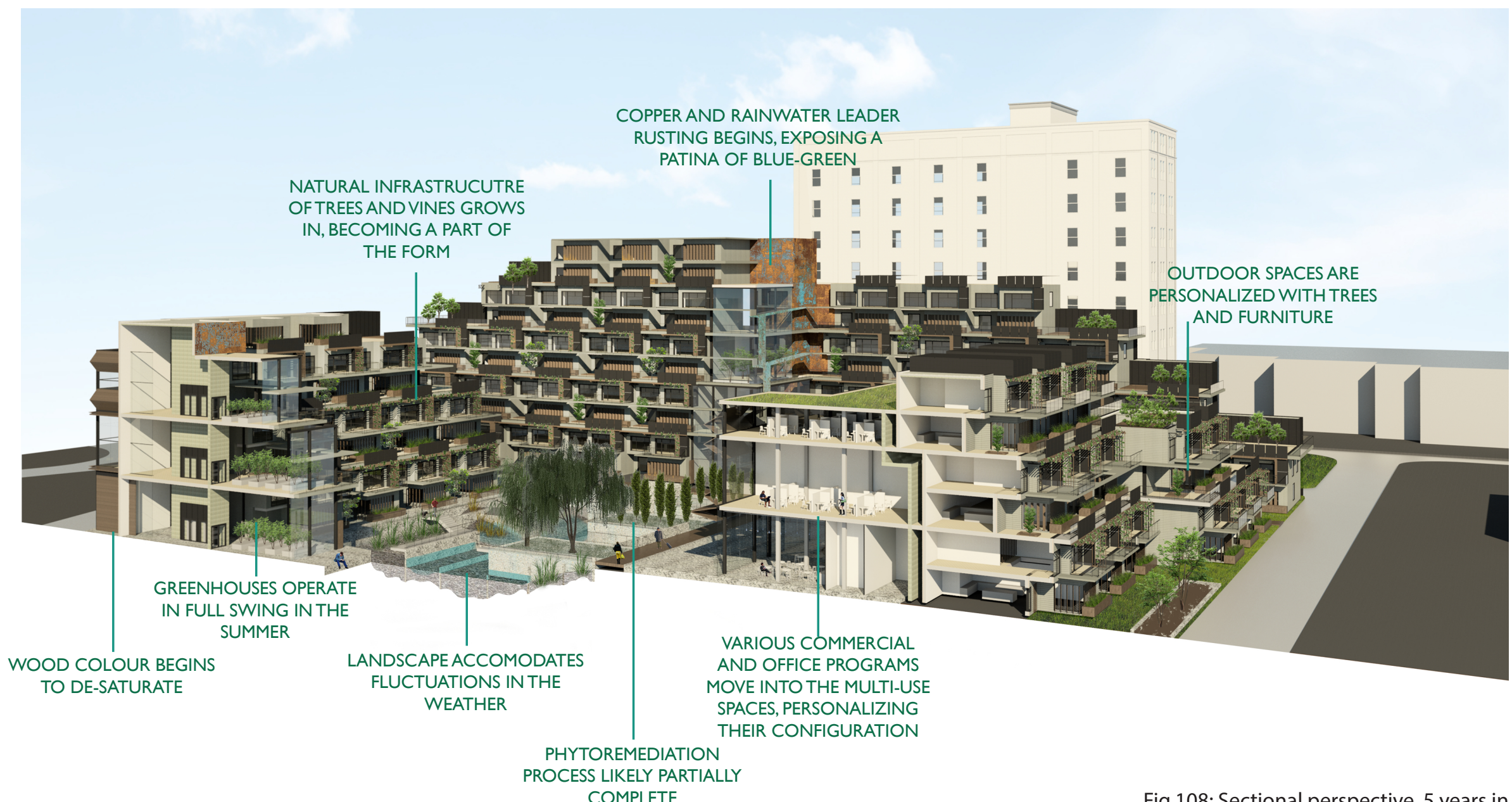

$$
\text { COMPLETE }
$$

Fig.108: Sectional perspective, 5 years in 


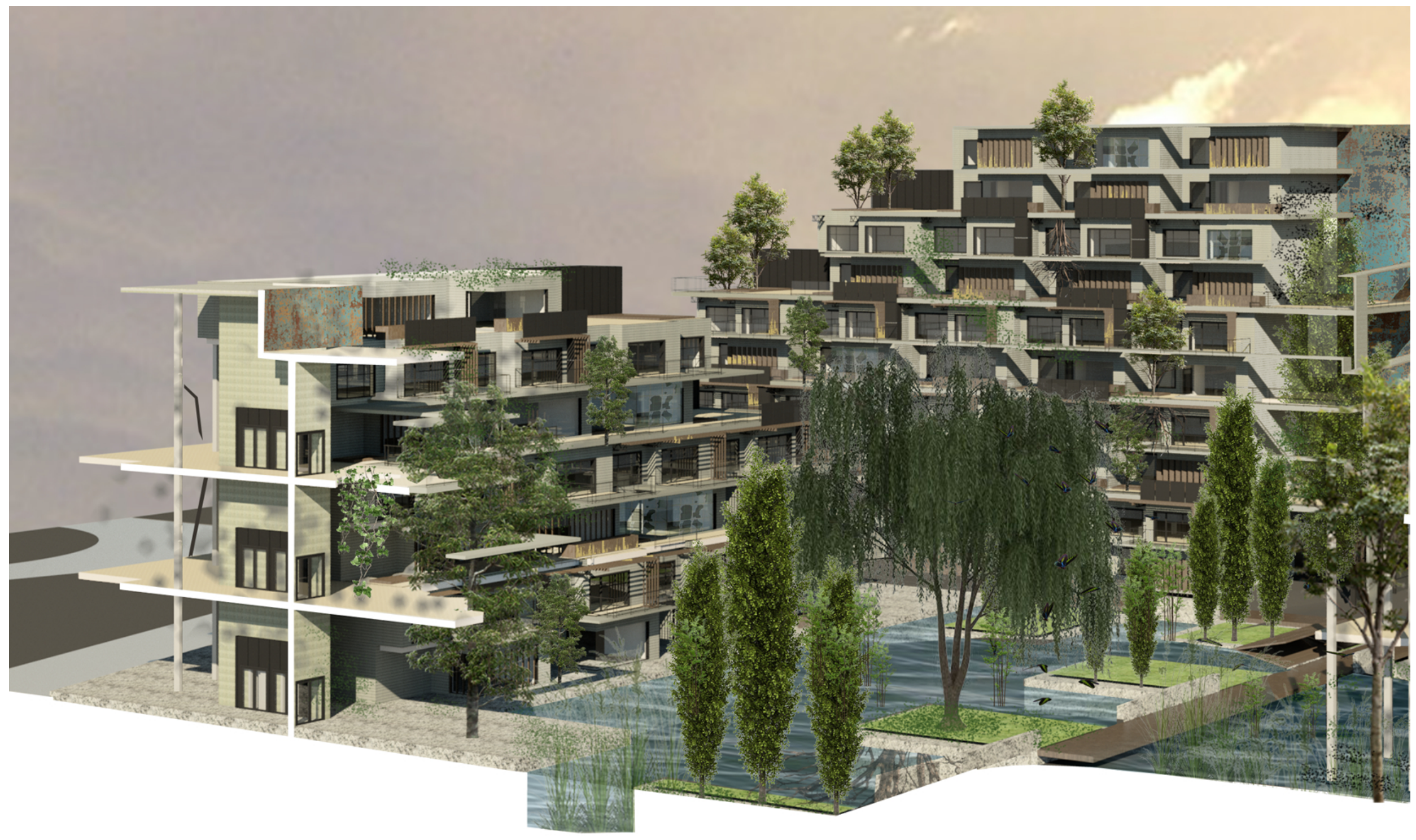

As a conclusion to the theoretical side of the exploration, an extreme scenario was imagined of a post-apocalyptic world where nature takes over, envisioning ways that the building would deteriorate and eventually collapse; a complete rejection of the anthropocentric direction. Although this isn't where we want our architecture to end up, it reminds us of our ties to the ecological realm, and that when we
Fig.109: Sectional perspective, post-apocalypse 107 


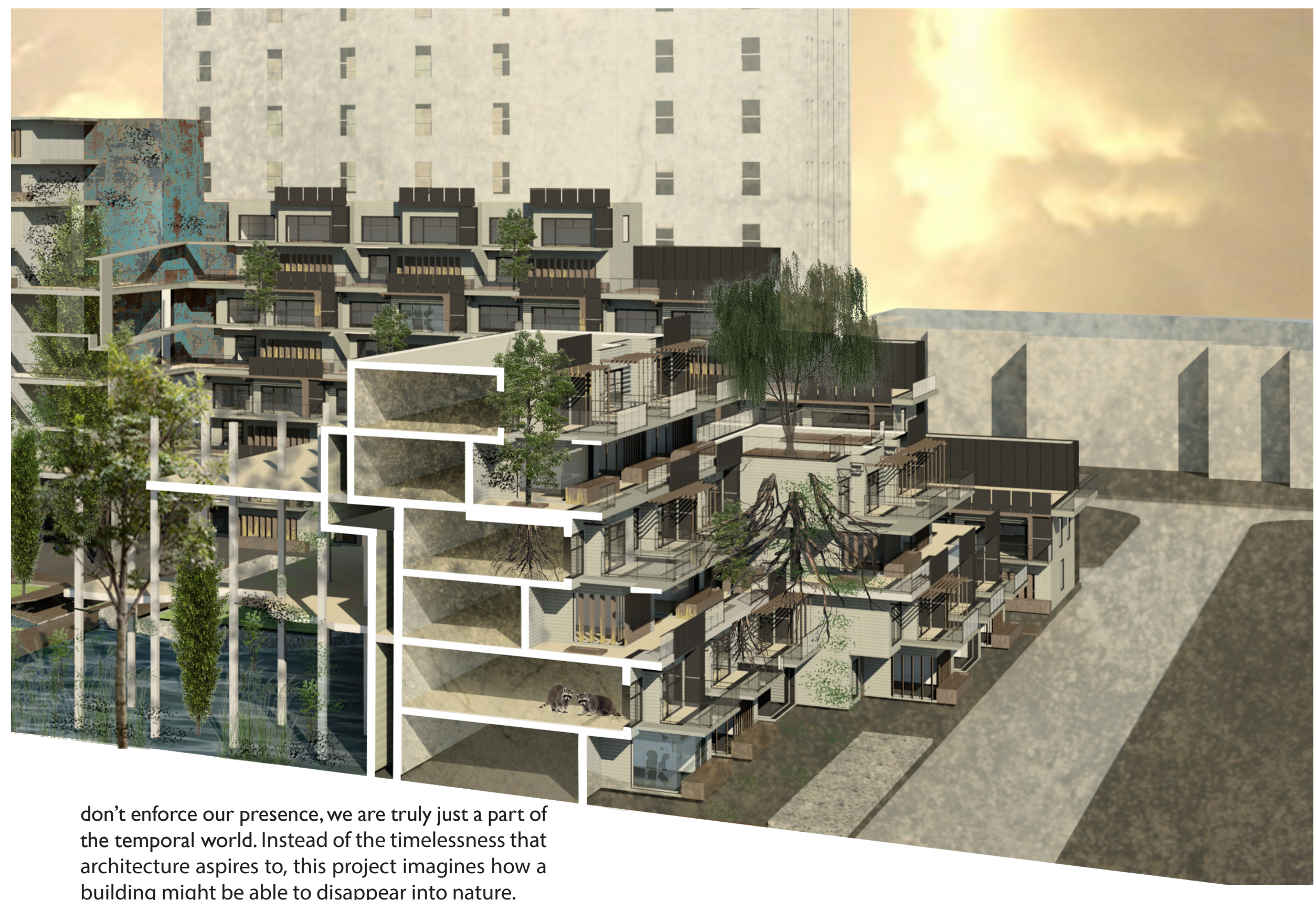




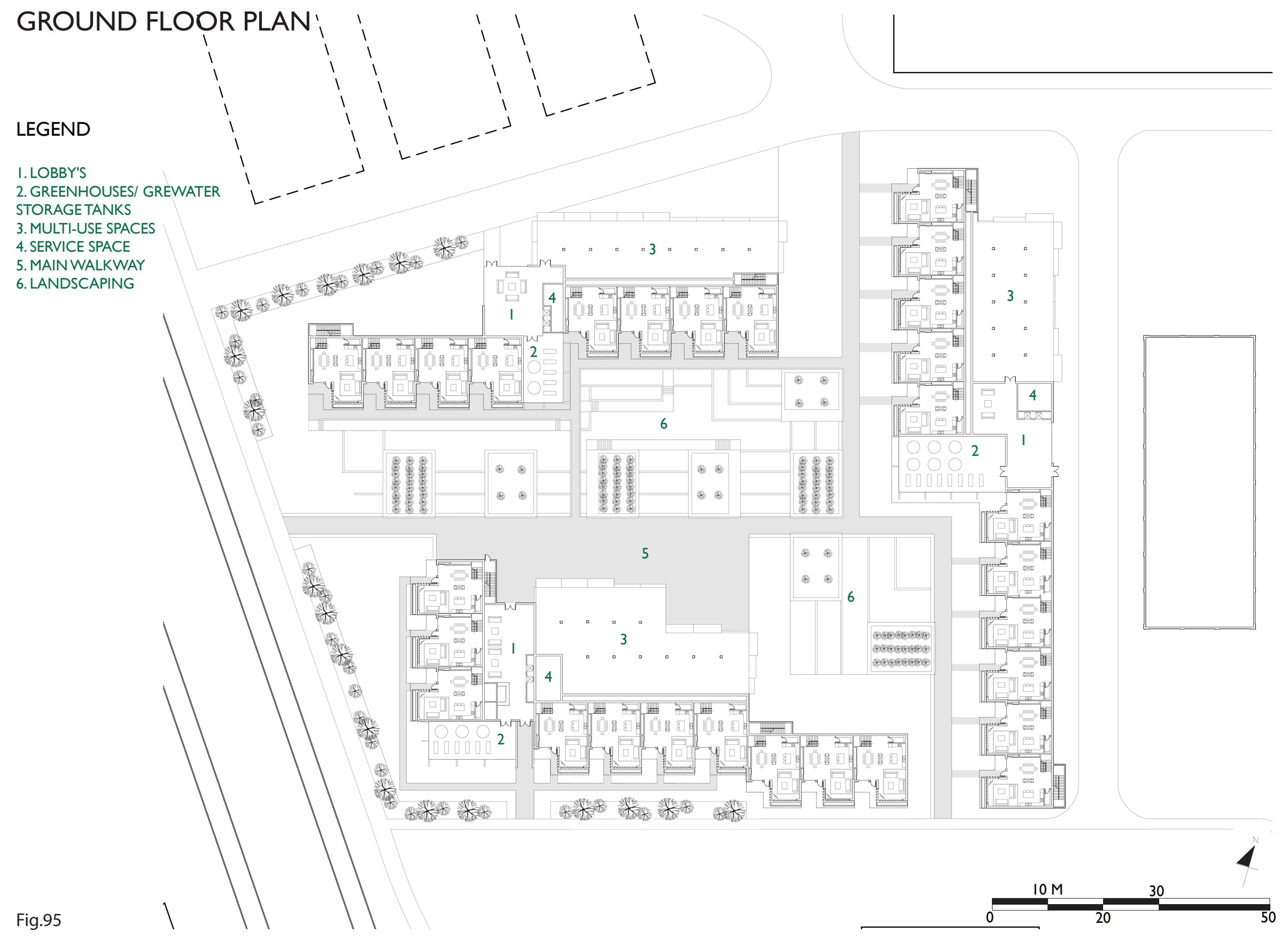




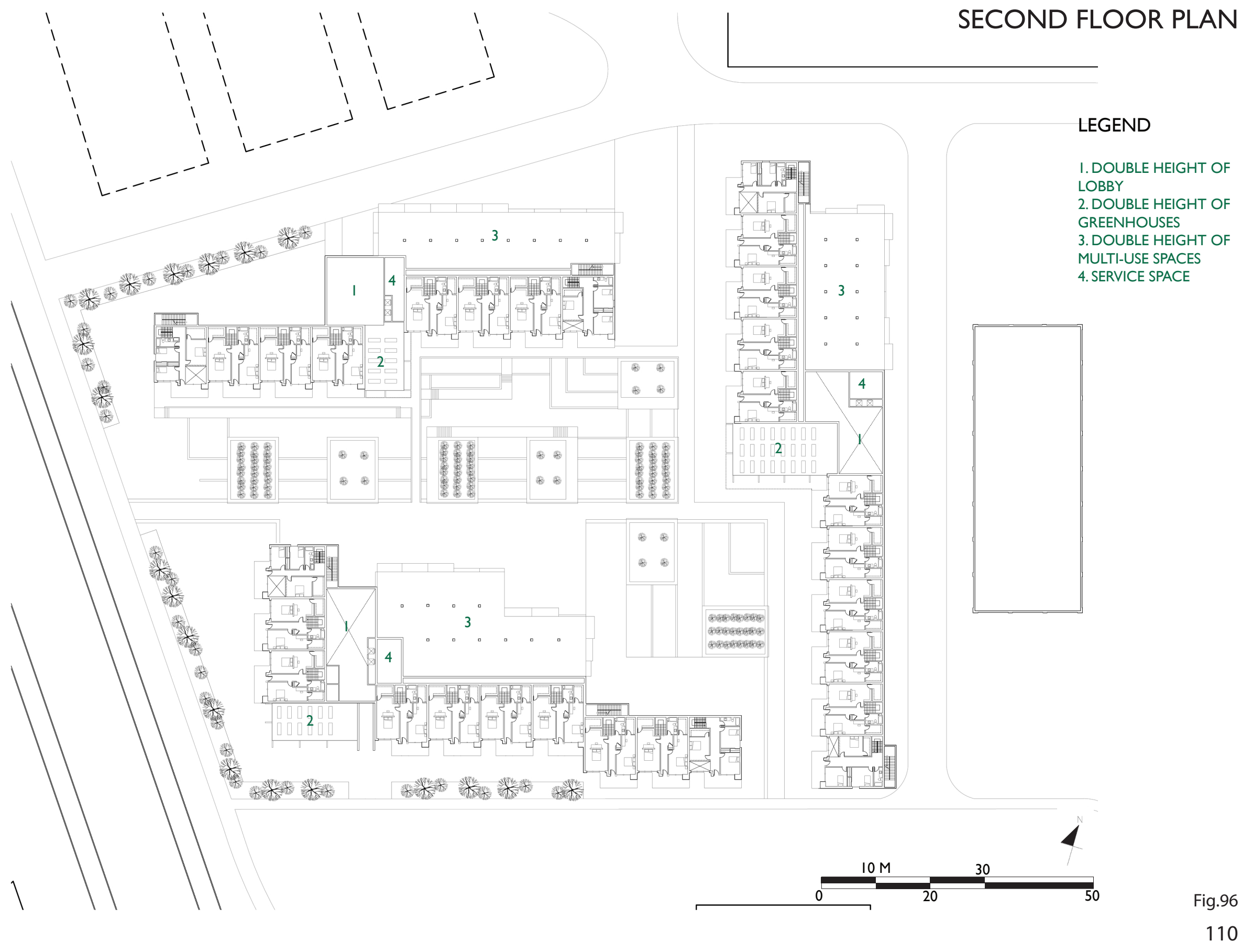




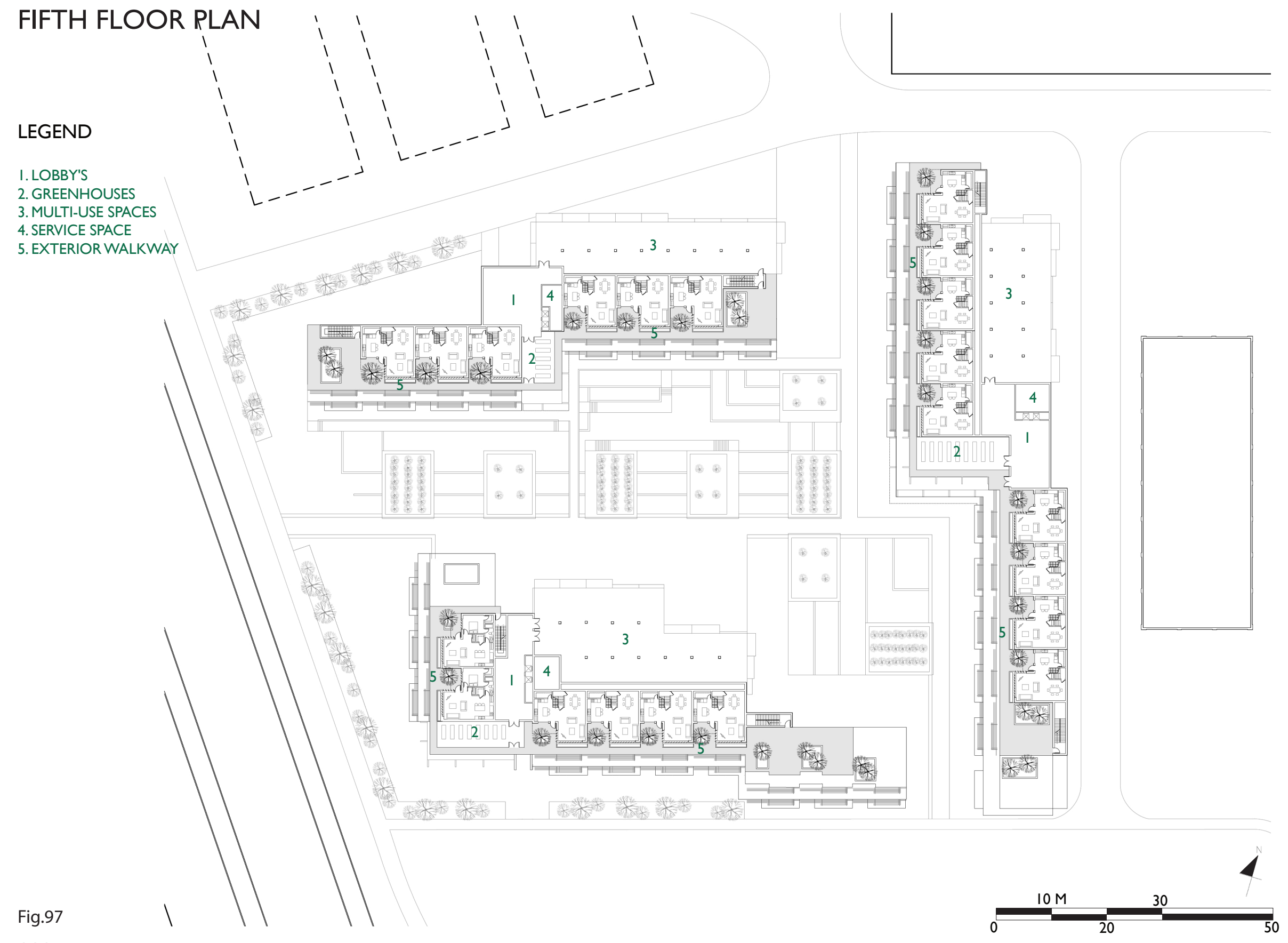




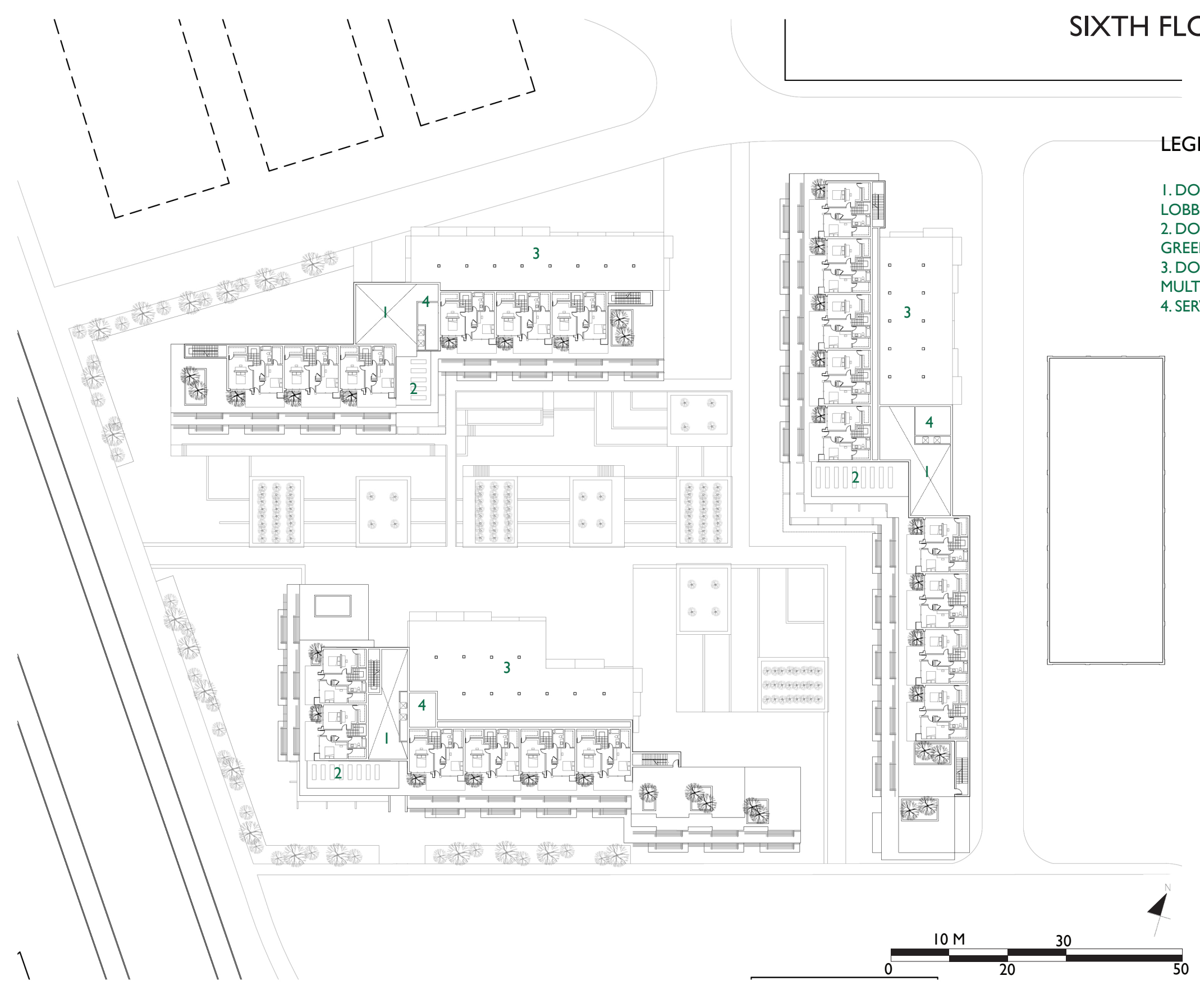

\section{LEGEND}

DOUBLE HEIGHT OF

DOUBL HEIGHT OF

REENHOUSES

3. DOUBLE HEIGHT OF

MULTI-USE SPACES

4. SERVICE SPACE 


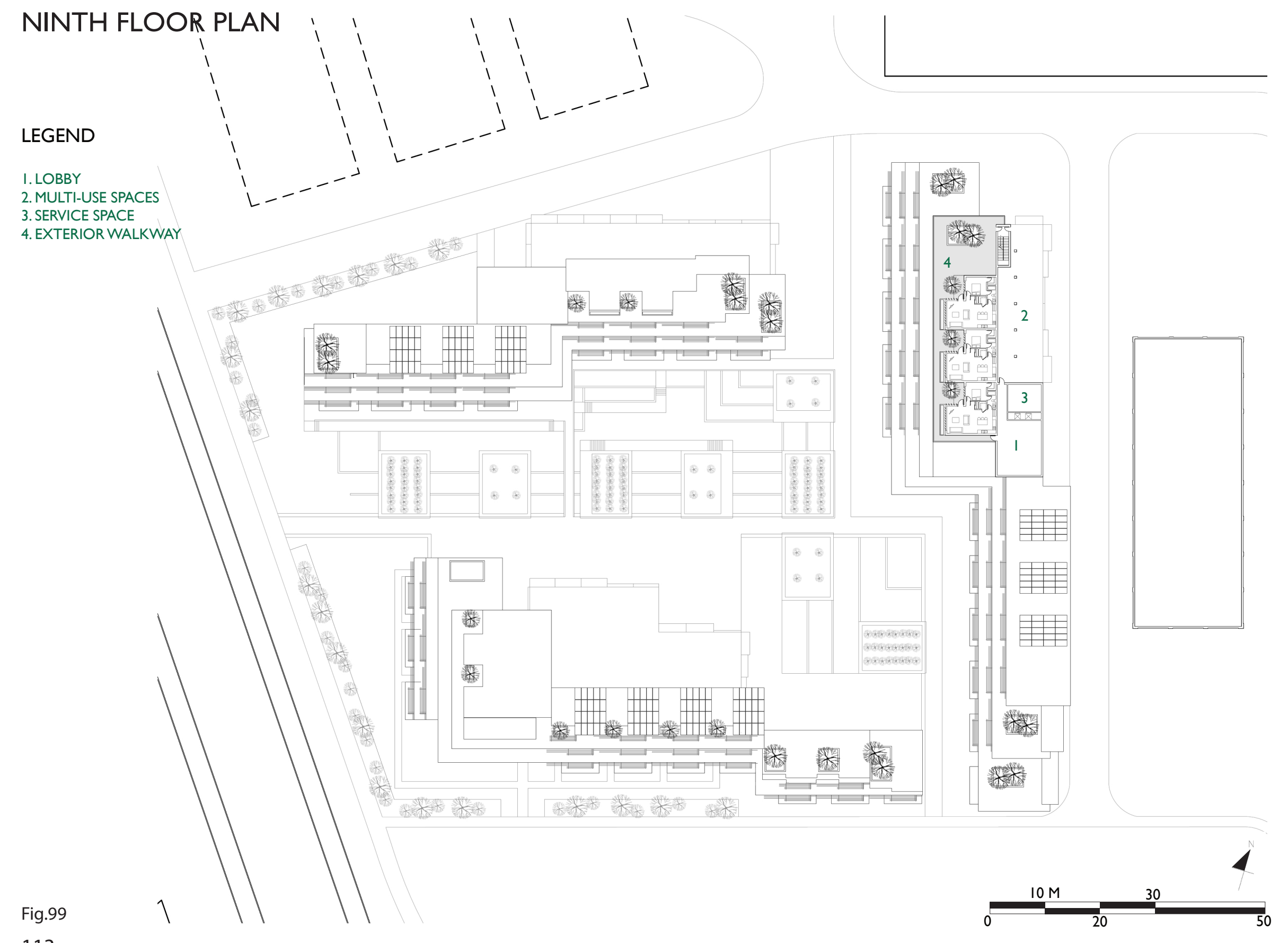




\subsection{Conclusion}

Throughout this process, the idea of what "nature" really is to this thesis has come into clarity. Nature is a spectrum where on one end, the most "natural" parts of our universe are the forms, substances, or processes that have been untouched by the control or by-products of human conciousness. At the other end, the most unnatural or artificial forms, substances, or processes are those that have been the most manipulated by human conciousness. This position has a moral underlining that we, as concious beings, are in fact extraneous to the earth's ecological processes, that we are somehow alien to this earth. It is clear that we operate beyond ecological boundaries, even though we are physically bounded within them. Our conciousness has given us power, but also the illusion of separation.

This thesis has formulated an approach that binds us closer to the way ecological processes operate in order to counter the destructive and permanent way we see progress that is leading us into the anthropocentric age. This thesis positioned the theory, specifically the 3 spatial ideologies as a way of "seeing", and the design principles as a way of "thinking".

"Seeing" through the 3 spatial concepts can be a way of ensuring that we are balancing our relationship with nature between protecting it and experiencing it. A world where we are surrounded by the artificial would dull the human experience, meanwhile, it is important to continually check in with our resource ratios and intensify our independence as the human population continues to grow. The three spatial ideologies are an over-simplified way of assessing our relationship with nature and should only be used as a way of checking in, rather than formulating a way of thought. The relationship between man and nature is far more complex than 3 spatial relationships, and the spectrum simply serves as a framework that was important to the ideas being pushed in this thesis, which are relevant to the issues we are facing today.

"Thinking" through ecological principles can be a very effective design tool to learn from the way things emerge and operate in nature. The six principles were chosen to reflect how architecture can respond to a post-industrial area, but they are not necessarily applicable to all types of typologies and locations, and may have to be narrowed or expanded to suit different needs. There always needs to be an iterative process between whether to follow the ecological principle to its fullest potential, with a consideration of how the rest of the design will play out. One example of this tension was the strong focus on facing the residential units towards the sun, which was always creating an undesirable condition on the north side. This could have potentially been better resolved if facing the sun was given less of a strict priority. Similarily, the principle of succession was focused on the site development early on, but needed a long and inconvenient development phasing plan. Put in simple terms, using ecological principles needs to be done in caution as to not create any repercussions, and only when they help formulate a desirable outcome.

A re-thinking of the ecological principles through the idea of time and emergence can help 
with planning an undetermined future, a part of our environment that humans are always trying to control. A "giving-in" to this lack of control can be a way of saving time and energy into directing the future, instead allowing flexibility for opportunities to emerge, and creating resilience in our built infrastructure. Placing a greater focus on time in the way we design can help with directing where growth, emergence, and deterioration may occur, instead of relying on a false perception of permanence.

The resurgence of a sense of place in the ecosocial realm is where the project is the most successful. Our world is continually rejecting our physical surroundings and prioritizing the virtual and mind driven dimension of our environment. The project serves as a reminder of our place within reality, within daily, seasonal, and generational experience, within the process of emergence, life, and death, within our existence as a single body, a member of the community, an extension of the city, and of course our place in the ecological spectrum. This thesis could be described as a discovery of what designing with nature can really encompass. It explored traditional parameters of "green" design that included access to greenery for our well-being and resource efficient design. It then went on to understand the larger spectrum of resource conservation within embodied concepts of energy, explored through choice of materiality and the evolving resources a site could provide. Lastly it explored the idea that "nature" is a product of time, and that engaging in the process of time is to truly give in to the most basic parameter of how nature operates. Throughout the entire development, it also engaged with the idea that a greater connection to nature is a greater connection to one another. It analyzed a wide spectrum of the idea from its technical to its poetic facets.

\subsection{Design Critiques}

In more practical terms, to counter the idea of the permanent destruction that the Anthropocentric age has created by designing for impermanence that is reflective of the greater ecological sphere of life brings up the obvious dilemma of durability. To design for things to deteriorate would be putting a greater strain on resources to have to re-design and retrofit things sooner. The idea of reflecting time within architecture may be best compartmentalized into its aesthetic, poetic components, and not within important functional spaces. The radicalization of this concept of time is insightful in a theoretical regard, but lacks many pragmatic implications. However, the dynamic change that is accommodated within the programmatic spaces of the design, as well as within the opportunity for growth through the sites evolution satisfies the objectives of rejecting the idea that njature has certainty and order, and should be designed with a creative unfolding in mind.

The idea of re-creating the community structure of the condominium may be too far of a push into some people's comfort zone. Some find the anonymity, low maintenance, and complete cut-off from nature that comes with living in a condominium to be a comfortable, clean way to live. This development would require a certain type of tenant with a strong political will to reject the modern mindset. The operation of the building itself 
might be more conductive to tighter knit community management systems such as co-operatives, cohousing structures, or eco-village style organizations. These management structures function around the adherence to actively participating in running the community, which would ensure that aspects like the community greenhouse would stay in operation. Otherwise, the idea that community members would all be actively engaged in the operation and maintenance of their spaces may be a fantasy.

\subsection{The Future of Architecture}

The ideas presented in this thesis are unlikely to manifest to their fullest potential within our current economic and capitalist society, where decisions inevitably will be continued to be made based on efficiency and economics. To shape our buildings to be more in line with longer term ecological objectives does not fit into the profit structure of capitalist organizations, nor the short term objectives of political timelines. With the pressure we will continue to see for urban development to accommodate the growing population, it appears that we may be leaning too far into the deception of total separation, that we will be able to intensify our resource and compact our developments enough to sustain the growing population forever. Sustainable building technologies are slow to realize economic gain especially in multi-storey residential buildings, and the idea of our biophilic need to connect with nature may continue to be compartmentalized into small parts of the city, unfortunately a concept that's considered luxury over necessity. It is the hope that this thesis can inspire designers and policy makers to push this way of thinking into the economical and political structures we are bound by, in order to make room to think in terms of the greater ecological picture. 
Appendix 


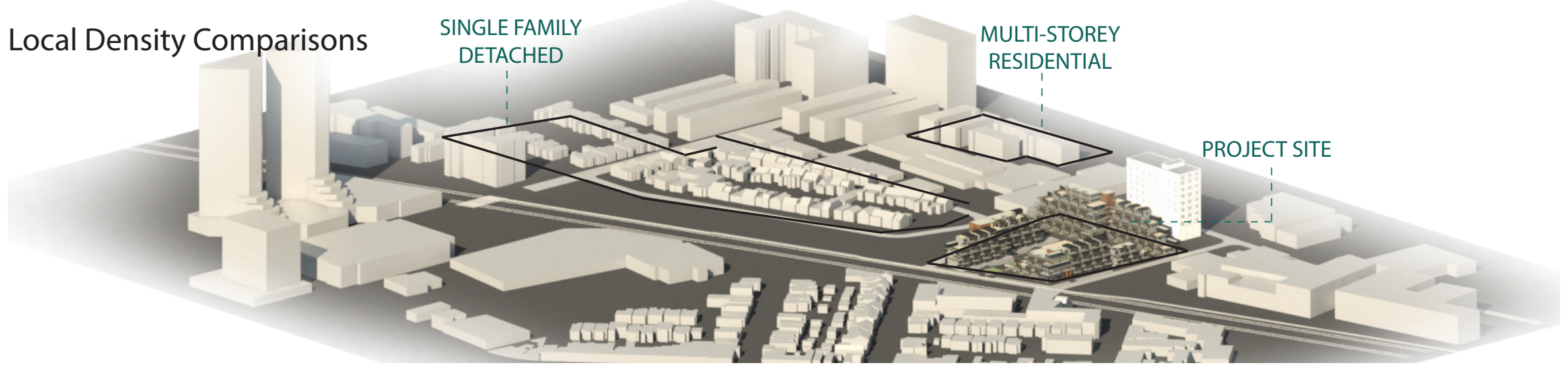

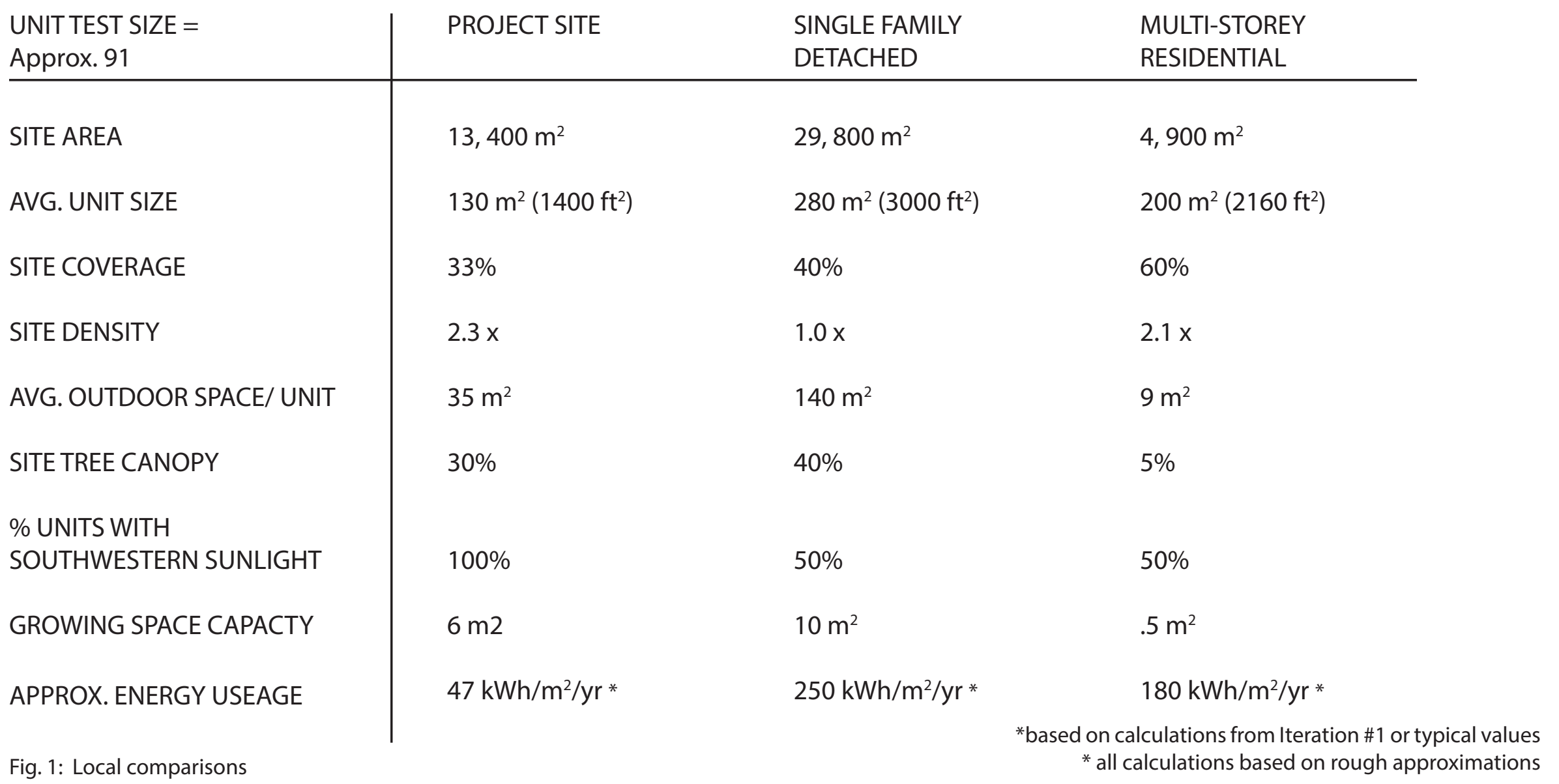



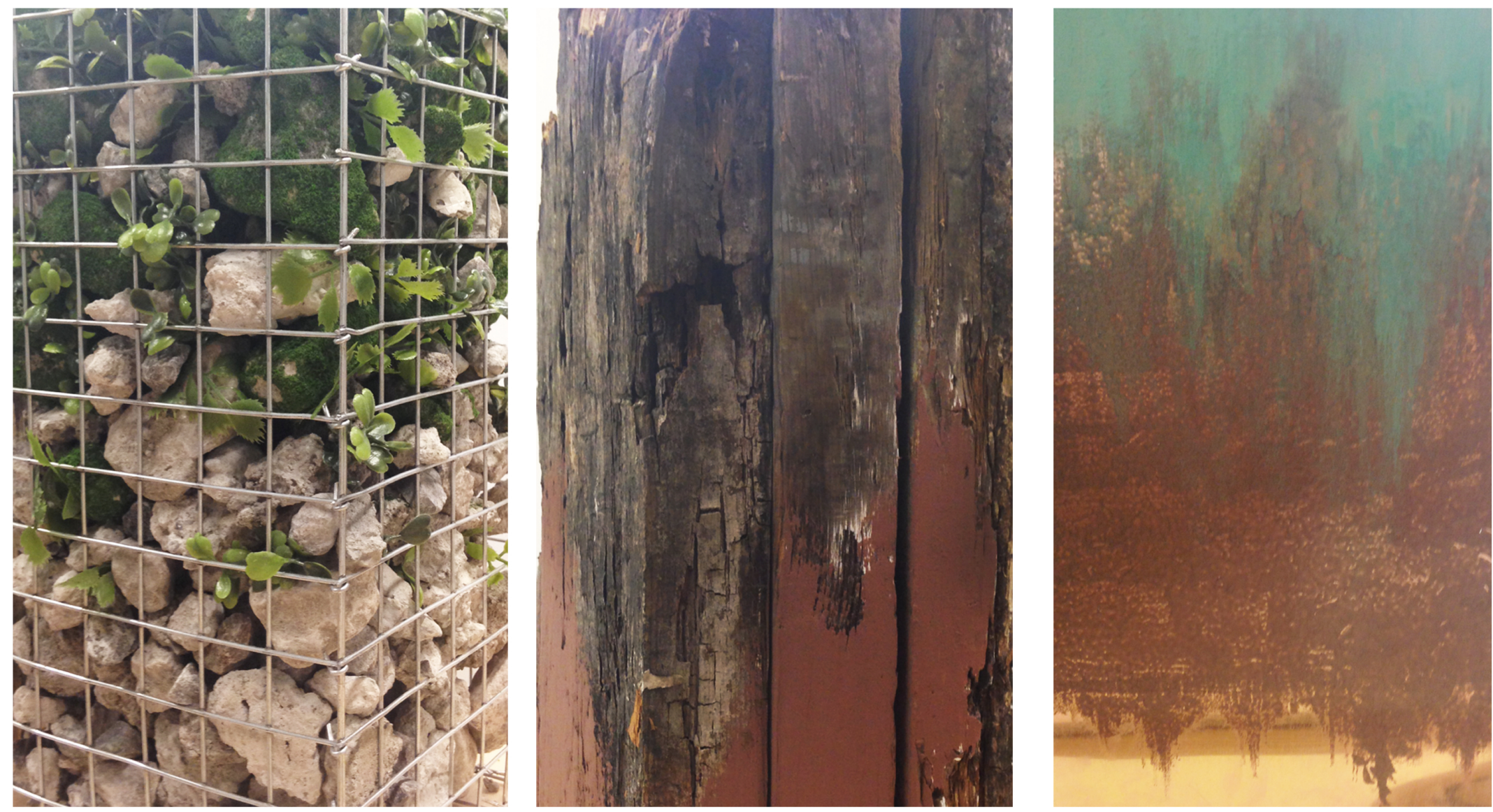

In the material model, time is conceptually represented in the vertical direction going up, showcasing how materials evolve, deteriorate, and grow. These models are important illustrations of the idea of emergence even at the material scale. The site model to the right is a massing representation of the levels of permanence embedded into the form. The most opaque materials, the cores, repesent the most permanence, and the most transparent, the glass for greenhouses and multi-use spaces, represents
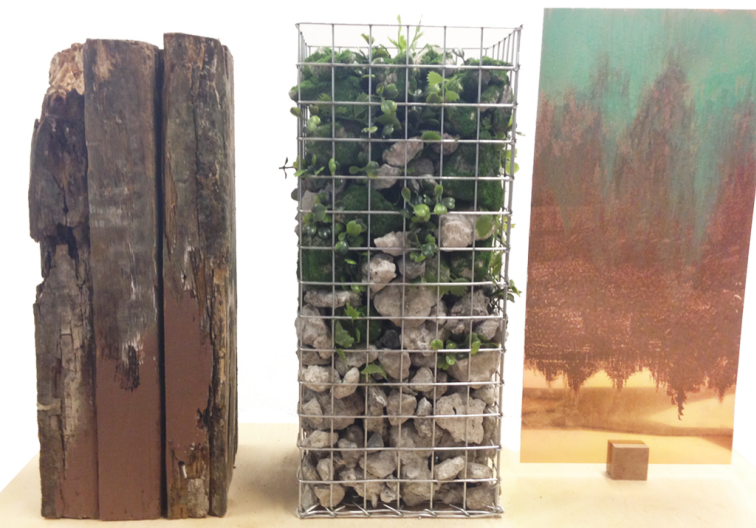

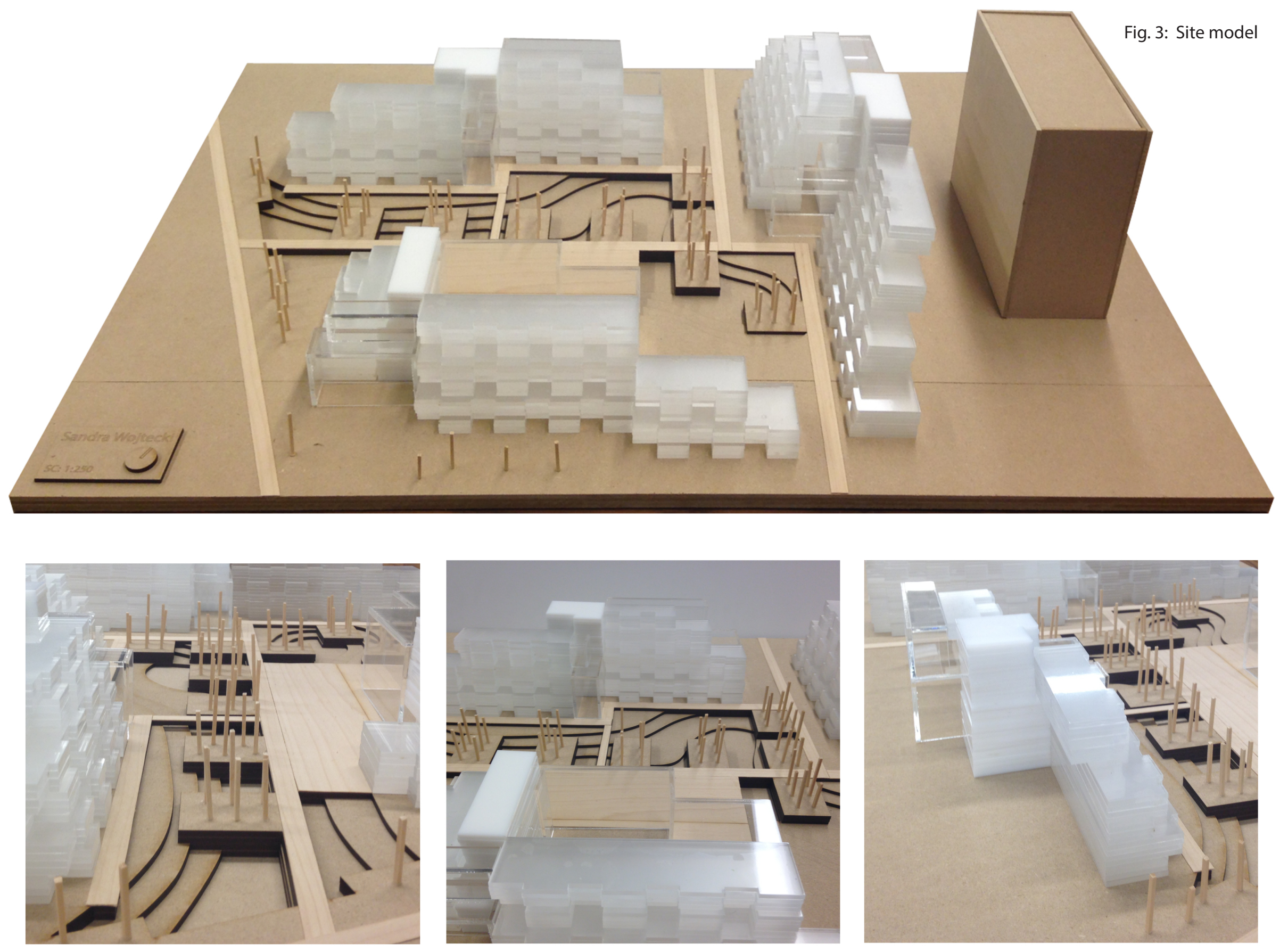


\section{Research Exploration}

\section{Concept}

The initial conceptual framework for the
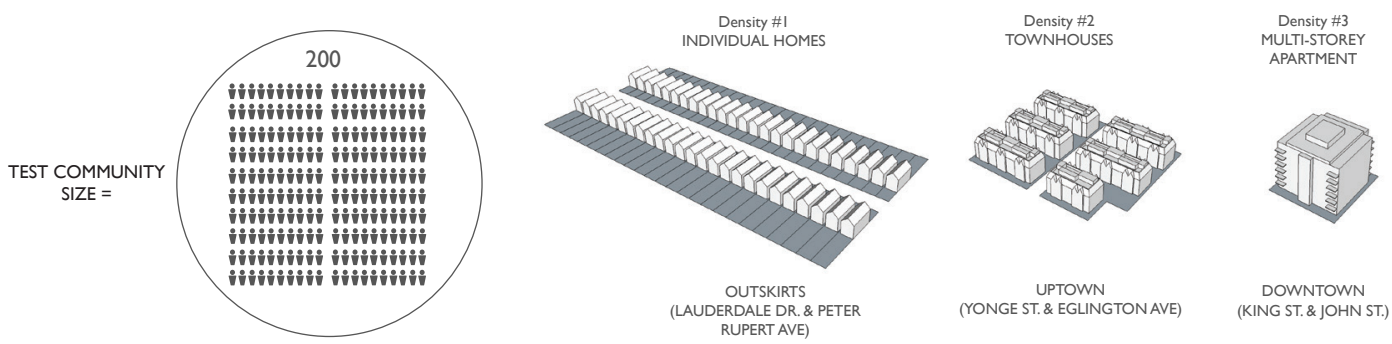

Fig. 4: Community test size configurations

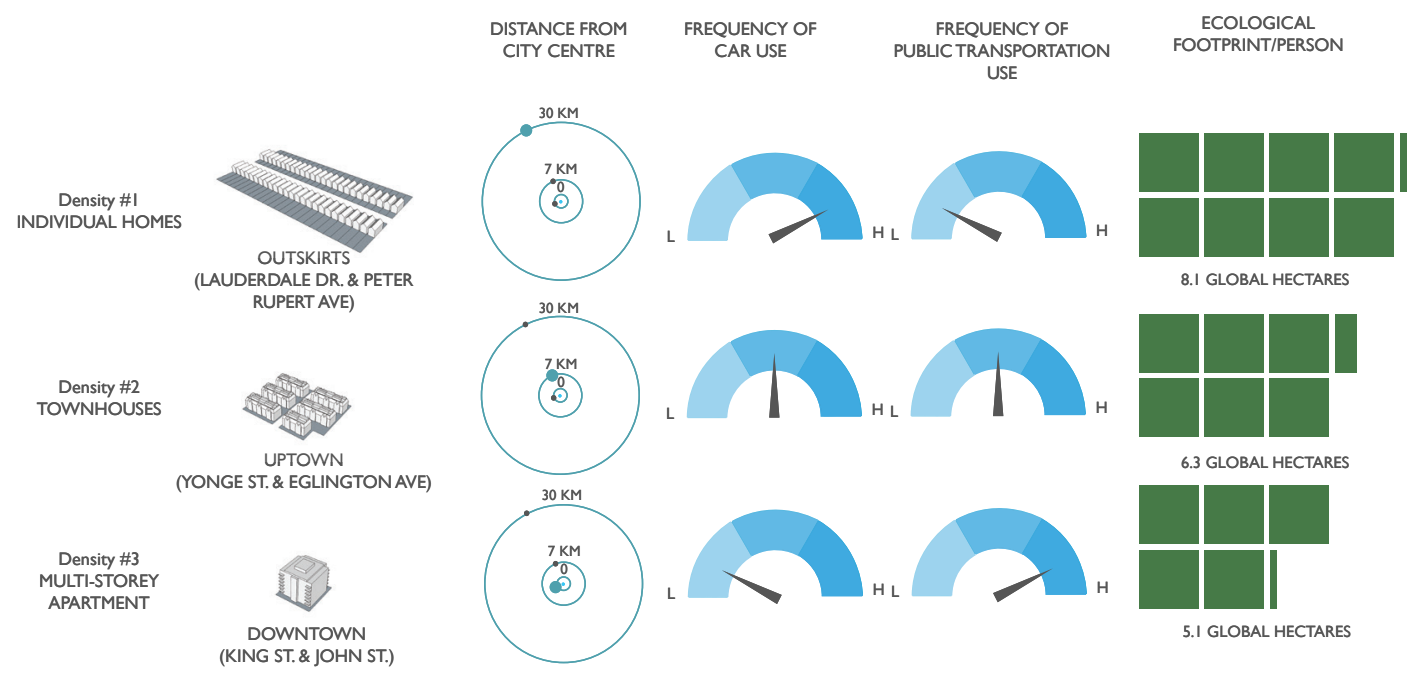

Fig.5: Community ecological footprint estimations by commuting distance direction of this thesis was concerned with being "ecologically minimal". The idea was to find if there was a building size, type, or configuration that was most conductive to a minimal lifestyle. Initially, the idea of a minimal lifestyle would be one that satisfied a set of environmental, agricultural, and social objectives. The underlying idea was to explore if there was a building type more conductive to promoting an environmentally friendly lifestyle, with a healthy level of social connectivity, and had possibilities for gardening and agricultural production. A series of experiments were done in exploration of various locations and housing types. Three typical housing communities of a test population of 200 people were studied and given a hypothetical location in the city, as well as a lifestyle of daily commuting downtown.

First environmental impacts were investigated by calculating typical ecological footprints for each scenario. It was found that one of the primary drivers for a high footprint was level of carbon emissions, which implied that the most environmentally conscious location would hypothetically be in the city, as the availability of public transportation was higher. 
Density \#I INDIVIDUAL HOMES

TOWNHOUSES

Density \#3

MULTI-STOREY

APARTMENT

$$
\begin{array}{cc}
\text { AVERAGE } & \text { TOTAL SITE AREA } \\
\text { PEOPLE/UNIT } & \text { (HECTARES) }
\end{array}
$$

iiii

OUTSKIRTS

(LAUDERDALE DR. \& PETER

RUPERT AVE)

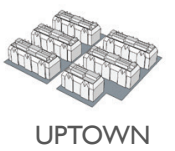

(YONGE ST. \& EGLINGTON AVE)

iii

0.51

1.94

ii
SITE AREA
IPERSON (SQ. M)
$:=100$ SQ.M

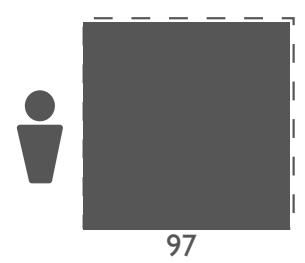

97

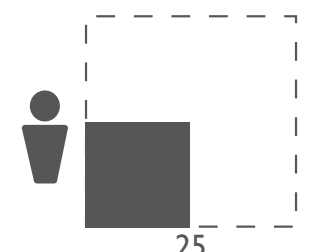

TOTAL BUILDING AREA

(SQ. M)

TOTAL BUILDING AREA /PERSON (SQ. M)

$i=100$ SQ.M

255

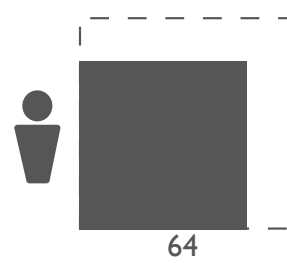

64

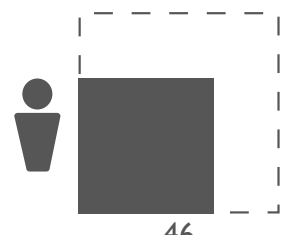

46
0.14

DOWNTOWN (KING ST. \& JOHN ST.)
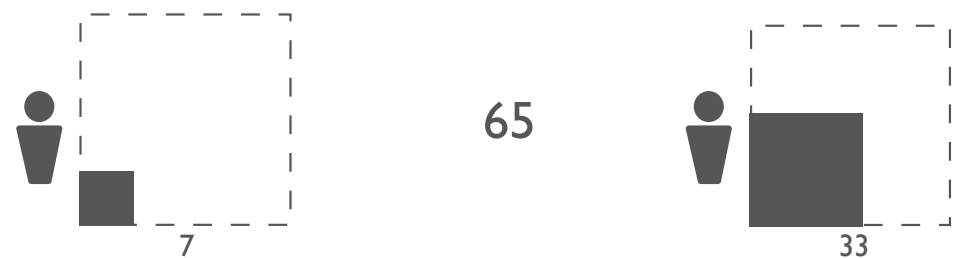

Fig. 6: Space taken up per person 


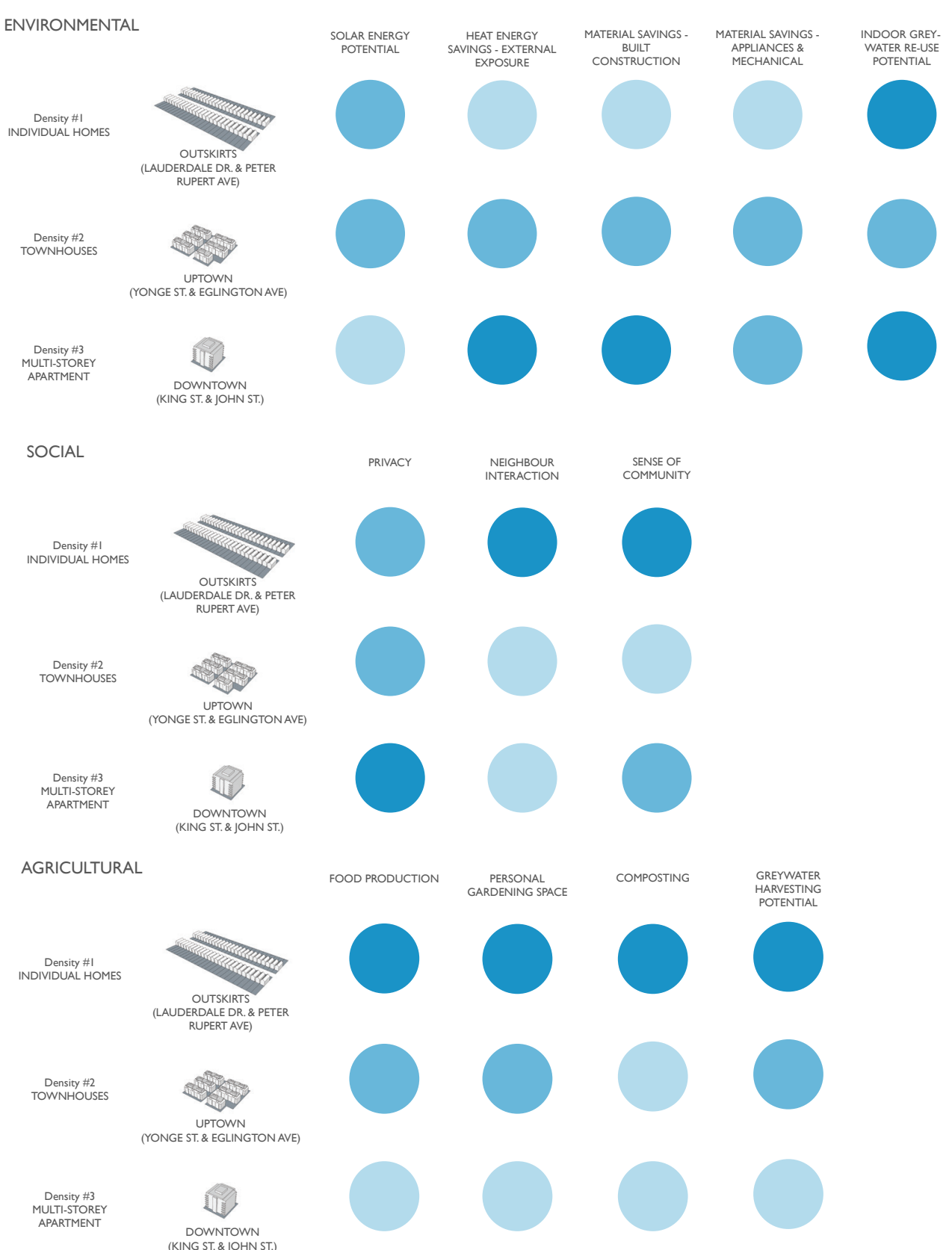

Fig. 7: Chart of high and low potential for each community type
In tandem, urban sprawl was found to be an expediting factor, as the amount of space taken up by single family housing was pushing people further away from one another and increasing the need for private transportation. Housing typologies were a key factor as single family homes were taking up as much as 10x more space then condominium dwellings. Beyond ecological footprints, the typologies provided different levels of possibilities in achieving other environmental, social, and agricultural objectives. High, medium, and low levels of potential were explored and intended to serve as a chart that could be used to gather information about whether a building type could be able to merge these factors together.

\section{Critique:}

One critique was the vagueness and ambiguity that was assigned to some of the classifications for the building types, such as "privacy". Privacy was analyzed under the notion of how often people would be seen, but things such as noise were not considered. A bigger problem was the idea that architecture alone is responsible for these elements, such as a "sense of community". These things are often dependent on the type of community and management system inside the building, for instance renting versus privately owned units, which would create much different senses of community regardless of the architecture. Though extreme conditions were identified for the sake of comparison, such as suburban houses outside the city and apartment buildings within the city, it was fruitless to consider these as typical, as different 
building types and lifestyles are present in locations all around the city. Beyond the oversimplification of each category, the idea that a classification system could be used to weave together a design approach that took the best of each category was too loose of a concept.

As a conclusion to the research, three initial site locations were proposed for the thesis intervention as being "ideally minimal", which were within the city and close to public transportation. The sites were all underutilized pieces of land with existing vegetation, that looked as if they would naturally soon be targeted for development. The critique was that it would be more valuable to choose a site that did not have any ecological features, which the proposal could then add value to, such as an industrial or brownfield site. Overall, there was a push to dig deeper into a more specific issue, rather then trying to determine how different features could work well together to create "minimal" impact.

\section{Development :}

There will never be an ideal building type or location, there are simply only better suited building types for their location. For instance, a selfsustaining eco-home outside the city may be very environmentally friendly, and so could a high rise building that utilizes renewable energy and provides walking distance amenities for all its occupants. The idea of how how to build better in these places should be focused on, rather then trying to identify an ideal type or location.

$$
\text { The idea of minimalizing negative }
$$

environmental impacts as a concept was in fact counter intuitive to the problem set out by the thesis, which was to find a way to be ecologically balanced by finding an appropriate equilibrium with nature. By looking at it through the lens of minimizing, it was falling into the trap of quantifying environmental impacts to make them less bad, instead of more good. The conceptual framework should instead come out of implementing ecologically centered design that maximizes its positive impact on the environment.

The lessons learned from the ineffectiveness this study eventually lead to a re-conceptualizing of how to frame the research, which became the ideas of interrelation, integration, and separation. To use the lens of investigating building types in different locations was not leading to the core of the research question, which was what kind of relationship with nature should our architecture aspire to. In turn, different types of "relationships with nature" became the focus, which could spread accross many different locations and typologies. 


\section{Pre-Design Proposal}

\section{Concept:}

The pre-design proposal was the first idea to emerge from the chosen site. The first attempt at a design that would satisfy the thesis questions played with the idea of re-prioritizing the human and natural environment over the industrial. By covering the railway with a platform, the space taken up by the railway could be given back to the fabric of the human experience of the urban environment. This move reconnected the two neighbourhoods that had previously been separated and created an easy walkable network to move from one side to the other. Further, it eliminated the discomfort and noise that the railway had by creating a visual and acoustic barrier. Where the intervention was close to human contact such as adjacent to a residential area, a full cover was used to eliminate the visual presence and noise. In addition, the bridge structure was intended to be fitted with vibration buffers between the structure and the foundation, making an even more comfortable environment on top of the platform. In areas where it was less important or was further away from the human realm, a less infrastructure intensive canopy was used. This was intended to be a structure grafted with a network of vines that provided some psychological relief of being close to a railway. From the residential streets that used to look onto the industrial wasteland, the intervention appeared more as a natural hill covered in vegetation, or a continuation of the streetscape moving up along a hill on the west side of the railway. On the east side, the proposed building covered the railway entirely.

The opportunity for a residential intervention was explored in greater detail. The change in grade level between the railway platform and the ground posed an interesting problem of how to seamlessly integrate a new design that felt natural and gradual. It was decided that the parking for the new residential building could be put on the ground level and the building on top could gently slope over and connect to the above railway platform. The intervention began playing with the idea of hydrology as an initial design priority by creating surfaces that sloped inwards toward a bed of planters, eliminating the strain put on existing sewage and drainage systems during a heavy rainfall. The infrastructure of the road network that is typical of most residential plans was hidden away from the human realm, covering another layer of the industrial with the natural. Although it wasn't a complete elimination of the car, the residence built above centered around a park as oppose to a street, in an effort of re-prioritizing nature. In order to maintain a visual and physical connection to the outdoors, the building's units are designed not to be isolated boxes in the sky like a typical condominium, but as walkable places that could always be accessed directly from outside like a suburban neighbourhood. This was done primarily by gentle ramps that connected to the front entry of every unit, or in some cases stairs. Privacy was maintained by every unit being a double storey, thereby only letting the living spaces be in direct access to the front doorway. Any of the units could therefore be accessed directly from the outside, from the inside by stairs or elevators, or through the underground parking. Generally it had the benefit 
of providing the energy savings of the compactness of a condominium, but the direct access and connection to the outdoors of a single family home. The clusters of units also sloped gently towards the south, allowing every block to have the maximum amount of solar heat gain for atleast one facade of each unit. This, along with the adjacent high rise building, created a visual transition sloped towards one side, also providing a gradual visual transition for the adjacent residential neighbourhoods.

Another design parameter was the maintenance of the existing walking and biking infrastructure next to the railway that currently runs along the line and provides a throughway for many pedestrians and cyclists. This railpath was maintained by a gradual ramp that went up to the level of the railway platform and back down again, cutting through the residential building.

\section{Critique \& Development:}

This initial design proposal turned out to be an exercise that filtered out many unavailing interpretations of the thesis concept, and began to shed light on where the design could move forward. At this point in time, the idea of what "nature" really was in the context of this thesis was underdeveloped, and resulted in a generalized idea that nature as a form of landscape that should be re-prioritized in our urban environments. Using the railway corridor itself as one of the places that creates neglected urban surroundings prioritized by industry, the proposal was an attempt at reviving an underutilized and polluted area.
Some of the right intentions existed in the proposal but in the wrong locations. One major critique was that the proposal was just too large in scale, but more importantly, the moves that were made were too large to justify their benefits. The amount of infrastructure needed to create a railway cover was not enough to justify the small amount of residential development that would be placed on top, while many areas were left underutilized. More important were the post-industrial landscapes surrounding the railway, as oppose to the railway itself. In addition, the discovery that many of these post-industrial areas were contaminated from their previous industrial uses lead to realization that these spaces made more sense to focus on.

To suggest that a greater presence of greenery and trees would classify as a natural environment was a very preliminary interpretation. The design of the residential spaces began to speak to how there was much more to move forward with, with moves such as facing all of the units south, creating high rise units that were walkable, or incorporating the hydrologic cycle into the design. These moves began to work with nature instead of against it, or fostered a greater connection between people and their surroundings. This lead to the development of the concept of the six "principles of emergence" that began to look at how nature operated as a guide for how to design, as oppose to just increasing its presence as greenery. 
The site was explored based on ideas that would reflect the wholistic and interconnected view of a healthly environment, with the initial idea that symbiotic relationships between human activities, machines, and traditionally defined facets of nature could be supportive.

The railway cover opened up space for new development, re-connecting neighbourhoods, reducing the presence of noise and danger for the surrounding residents, mending industrial space back into the local useable fabric, and would be isolated with vibration buffers from the ground surface.

Currently, energy from the breaking train is lost in the form of heat, but it is available to be harvested with a technology that captures kinetic energy and converts it into battery power to be used for electricity. The idea proposed that this energy could be harvested as each breaking train could create $2 \mathrm{KWH}$ of energy, meaning approx. $150 \mathrm{KWH} /$ day.
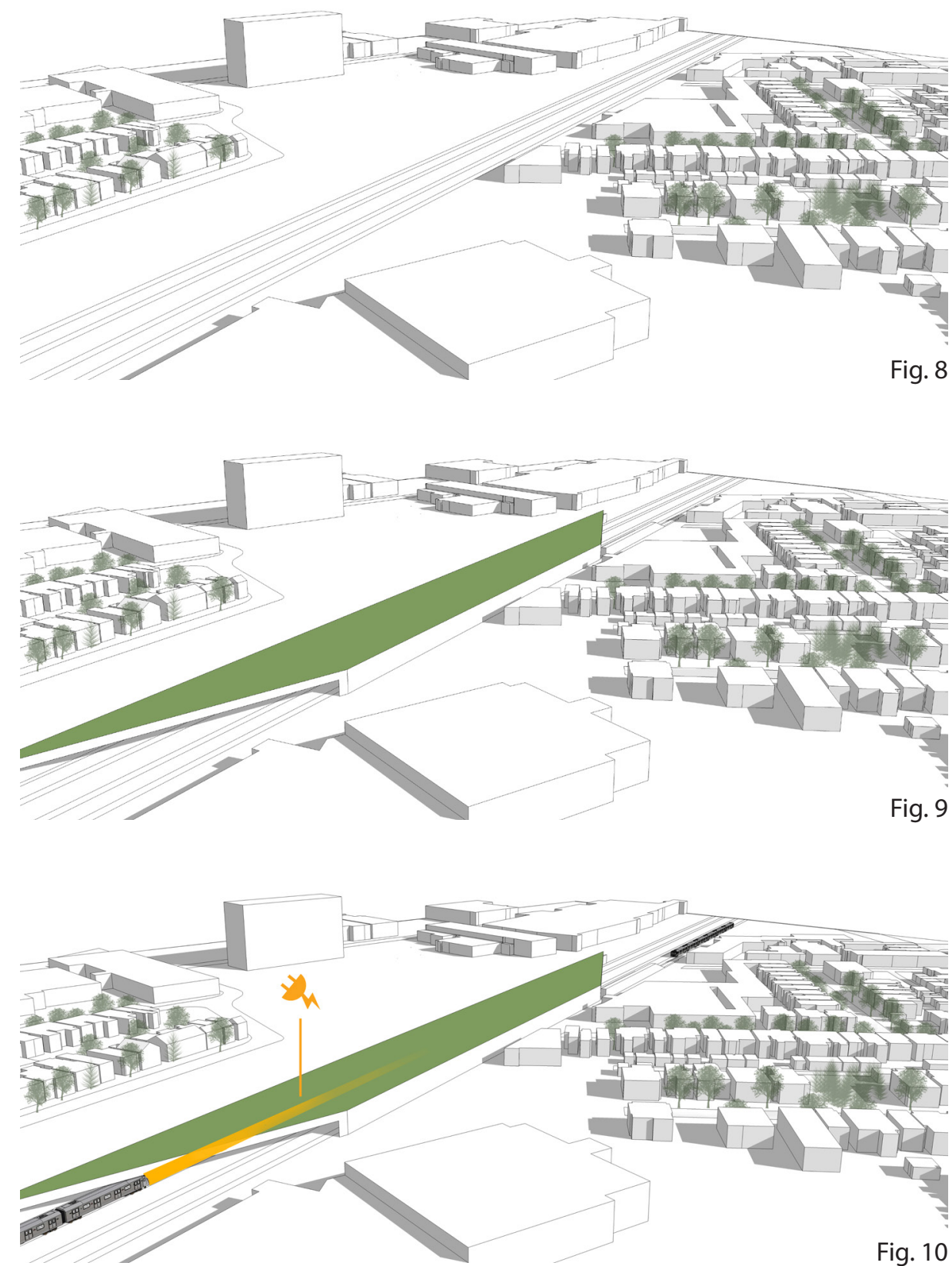

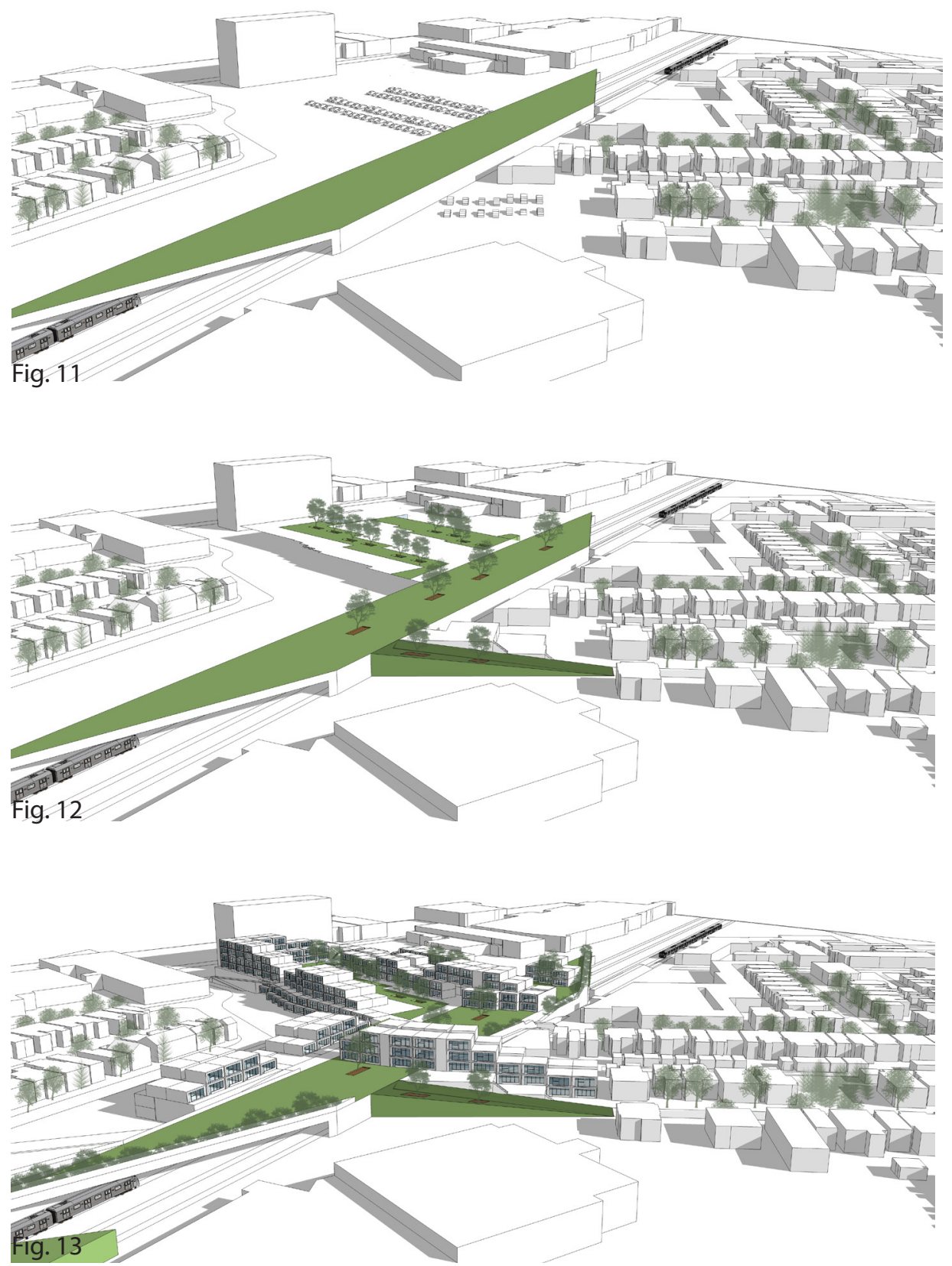

In de-prioritizing the presence of industry, there was also a de-prioritization of the car, where parking was placed underneath the development so that the neighbourhood could be re-centered around human activities, rather then the road.

The repressed polluted air could exhaust through intersecting the surface via carbon storing trees such as the yellow poplar, adding an element of responsibility for what we've put on the earth.

Above, an entirely walkable neighbourhood with access from the outside from each individual unit became centred around these areas, as oppose to the centering of the road in typical neighbourhoods, or the centering of circulation in elevator cores in other high density buildings. 
Permeable ground and roof surfaces that also drained into roof gardens, minimized the pressure placed on the cities drainage system, supporting local food growth in personal roof gardens, and mitigating the urban heat island effect that is most present in paved, industrial areas.

Vines are particularly well known to proliferate with elevated levels of carbon. Here, they were utilized as a natural cleansing infrastructure that cleaned the air while providing a cheap alternative to a visual and sound barrier in areas that didn't have buildings on top, as well as protected the train.

In a view facing north, the blocks all had access to southern light through a gradual slope towards the south, and rose up to match the adjacent building height on the east.
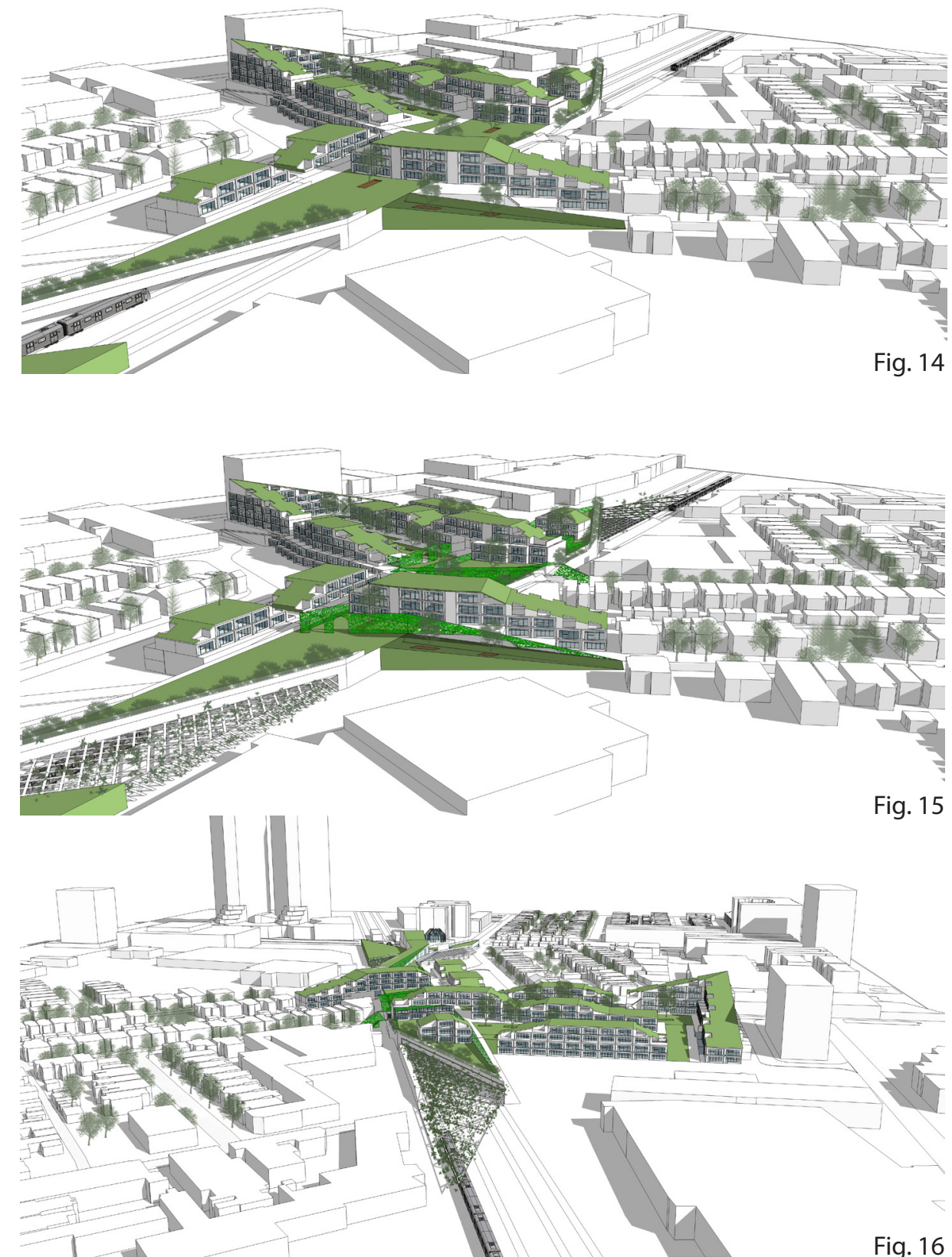

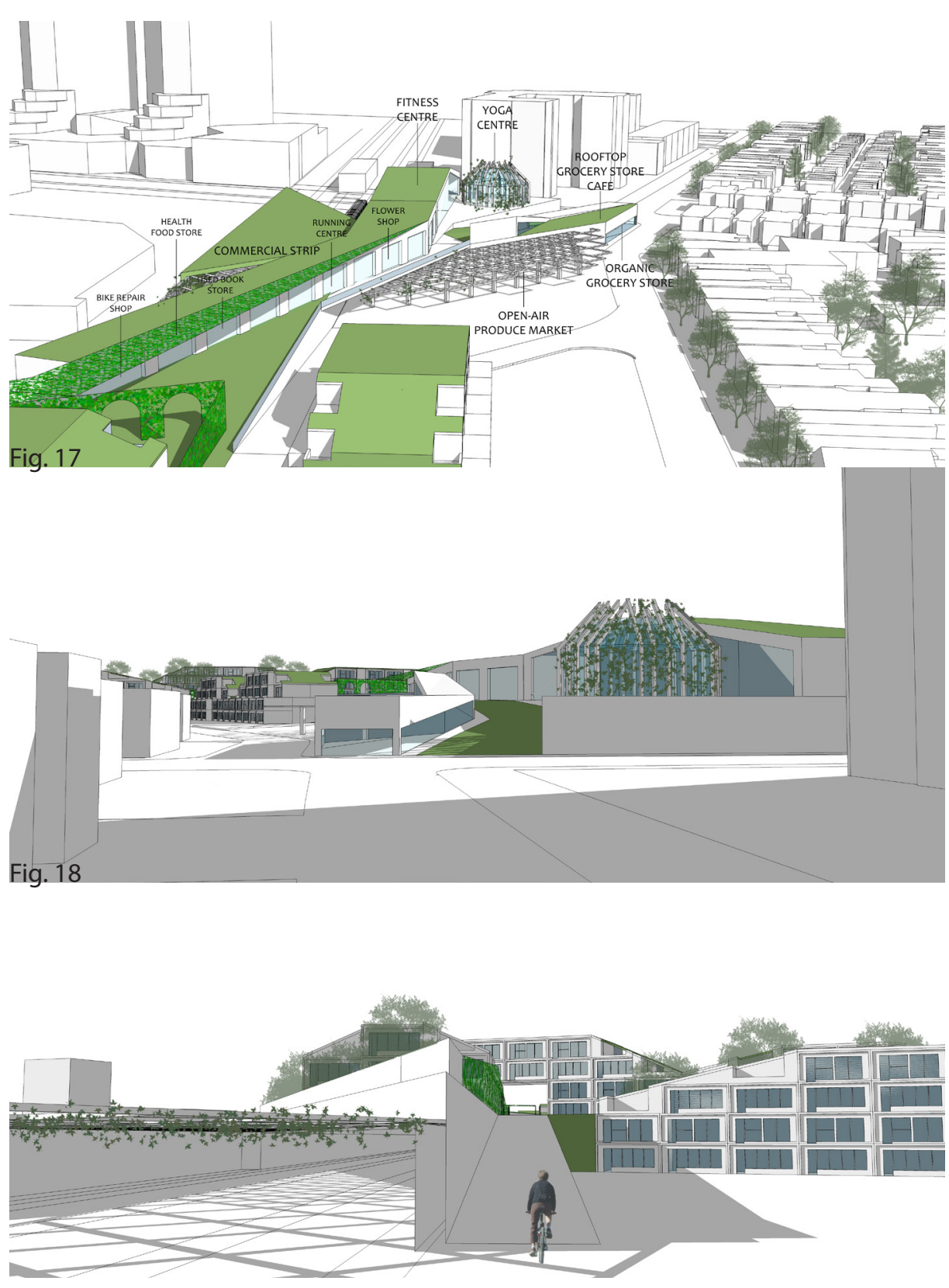

At the Bloor Street end of the site commercial amenities were laid out to bring people in and support the residents, through programs that furthered the idea of a holistically healthy relationship to the environment through cultural support. These could include a fitness centre, yoga centre, and an open air market for local produce, as well as a commercial strip that bridged across the site.

It also aimed to create a welcoming entrance, that through some architectural significance, could introduce the site and the beginning of the West Toronto Railway Path.

The integrity of the path was kept throughout the site by having it intersect the development, adding another cultural dimension by supporting car-free transportation.

Fig. 19 
Connections to the site would also be created through an extension of the development into streets that currently have a dead end looking onto the railway.
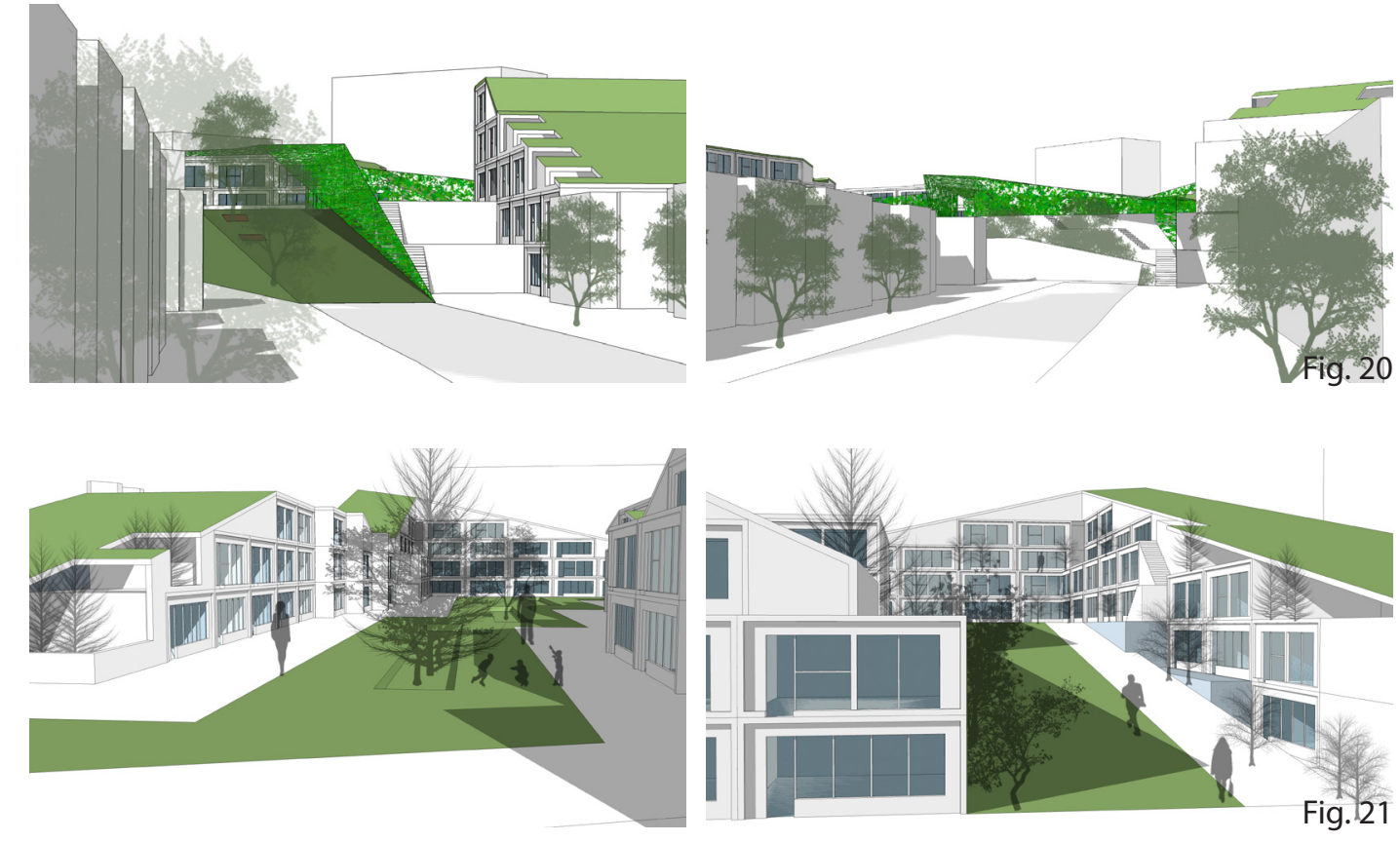


\subsection{Bibliography}

60 Richmond Housing Cooperative / Teeple Architects. (2010) ArchDaily. Retrieved from http://www.archdaily.com/85762/60-richmond-housing-cooperative-teeple-architects

Asafu Adjaye, John, et. al. (2015) An Ecomodernist Manifesto. Retrieved from http://www.ecomodernism. org/

Bergdoll, B. \& Martin, R. (2012). Foreclosed : rehousing the American dream. New York, N.Y: Museum of Modern Art.

Bioregional Development Group. (n.d.) BedZED 7 years on. Bioregional Development Group. Retrieved from http://www.bioregional.com/wp-content/uploads/2014/10/BedZED_seven_years_on.pdf

Botkin, D. (1990). Discordant harmonies : a new ecology for the twenty-first century. New York: Oxford University Press.

Buchanan, Peter. (2014) Synchronizing with Nature. Daylight \& Architecture Magazine.

Carson, R. (1962). Silent spring. Boston: Houghton Mifflin.

Chivian, E., \& Bernstein, A. S. (2004). Embedded in nature: Human health and biodiversity. Environmental Health Perspectives, 112(1), A12-3. Retrieved from http://ezproxy.lib.ryerson.ca/login?url=http://search. proquest.com/docview/222653350?accountid=13631

Desai, P. (2010). One planet communities : a real-life guide to sustainable living. Chichester: Wiley.

Devall, B. \& Sessions, G. (1985). Deep ecology. Salt Lake City, Utah: G.M. Smith.

Evernden, L. (1992). The social creation of nature. Baltimore: Johns Hopkins University Press.

Farr, D. (2008). Sustainable urbanism : urban design with nature. Hoboken, N.J: Wiley.

Fracalossi, Igor. (2013). AD Classics: The Dymaxion House / Buckminster Fuller. ArchDaily. Retrieved from 
http://www.archdaily.com/401528/ad-classics-the-dymaxion-house-buckminster-fuller

Francis, R. \& Chadwick, M. (2013). Urban ecosystems : understanding the human environment. New York: Routledge.

Gedrick, Vis. (2012). Notes from March 232012 Sterling/Tower/Castlepoint Meeting. Retrieved from http:// www.junctiontriangle.ca/node/556

Gore, A. (2006). Earth in the balance : ecology and the human spirit. New York: Rodale.

Hart, S. \& Littlefield, D. (2011). Ecoarchitecture : the work of Ken Yeang. Chichester England: Wiley.

Hosey, L. (2012). The shape of green aesthetics, ecology, and design. Washington, DC: Island Press.

Hough, M. (2004). Cities and natural process : a basis for sustainability. London New York: Routledge.

Kellert, S., Heerwagen, J. \& Mador, M. (2008). Biophilic design : the theory, science, and practice of bringing buildings to life. Hoboken, N.J: Wiley.

Kestler D'Amours, Jillian. (2015, Dec 02) Is Earth just 2 degrees from disaster? Toronto Star. Retrieved from http://www.thestar.com/news/world/2015/12/02/is-earth-just-2-degrees-from-disaster.html

Kuo, M. (2015). How might contact with nature promote human health? Promising mechanisms and a possible central pathway. Frontiers in Psychology, 6, 1093. http://doi.org/10.3389/fpsyg.2015.01093

McDonough, W. \& Braungart, M. (2002). Cradle to cradle : remaking the way we make things. New York: North Point Press.

McDonough, W. \& Braungart, M. (2013). The upcycle. New York: North Point Press, a division of Farrar, Straus and Giroux.

McCutcheon, S. \& Schnoor, J. (2003). Phytoremediation : transformation and control of contaminants. Hoboken, N.J: Wiley-Interscience. 
Pathak, H., \& Sharma, S. (2014). Basic Techniques of Phytoremediation. International Journal of Scientific \& Engineering Research, Volume 5, Issue 4. Retrieved from http://www.ijser.org/.

Pawlyn, M. (2011). Biomimicry in architecture. London, UK: Riba Publishing.

Powell, R. (1989). Ken Yeang : rethinking the environmental filter. Singapore: Landmark Books.

Reed, C. \& Lister. (2014). Projective ecologies. Cambridge, Massachusetts New York, New York: Harvard University Graduate School of Design Actar Publishers.

Richards, I. (2001). T.R. Hamzah \& Yeang : ecology of the sky. Mulgrave, Vic. Woodbridge: Images Antique Collectors' Club (distributor.

Ryn, S. \& Cowan, S. (2007). Ecological design. Washington, DC: Island Press.

Spretnak, C. (1999). The resurgence of the real : body, nature, and place in a hypermodern world. New York: Routledge.

Steemers, Koen. (2000) "The paradox of the compact city". Architects Journal. Retrieved from http://www. architectsjournal.co.uk/home/the-paradox-of-the-compact-city/193989.article

Steiner, F. (2002). Human ecology : following nature's lead. Washington, DC: Island Press.

Suzuki, D., Mason, A. \& McConnell, A. (2007). The sacred balance rediscovering our place in nature, updated \& expanded. Vancouver B.C: Greystone Books.

Tully, Krystyn. (2014, July 07) Toronto has a sewage bypass problem - the argument for a sewage alert protocol in Toronto. Lake Ontario Waterkeeper. Retreived from http://www.waterkeeper.ca/blog/2014/7/7/ toronto-has-a-sewage-bypass-problem-the-argument-for-a-sewage-alert-protocol-in-toronto

United Nations. (2014). World urbanization prospects : the 2014 revision : highlights. Retrieved from https://esa.un.org/unpd/wup/Publications/Files/WUP2014-Highlights.pdf

Wilson, E. (1984). Biophilia. Cambridge, Mass: Harvard University Press. 
World Population Clock. (n.d.). Retrieved August 08, 2016, from http://www.worldometers.info/world-population/

World Urbanization Prospects. (2014). United Nations. Retrieved from http://esa.un.org/unpd/wup/highlights/wup2014-highlights.pdf

Yeang, K. (1995). Designing with nature: The ecological basis for architectural design. New York: McGrawHill.

Yeang, K. (2009). Ecomasterplanning. Chichester: Wiley.

Yeang, K., \& Bullivant, L. (2011). Eco skyscrapers. Mulgrave, Vic.: Images Pub. 
